\title{
Die Entstehung der koreanischen Chaebol
}

\author{
Eine soziologische Analyse \\ des ökonomischen Handelns \\ in einem konfuzianisch geprägten Land
}

\begin{abstract}
Dissertation
zur Erlangung des

sozialwissenschaftlichen Doktorgrades

des Fachbereichs Sozialwissenschaften

der Universität Göttingen
\end{abstract}

\author{
vorgelegt von \\ In-Ah Rhee \\ aus Pusan (Südkorea)
}

Göttingen 1999 
Berichterstatter:

Prof Dr. Horst Kern

Mitberichterstatterin:

Prof. Dr. Ilona Ostner 


\section{Inhaltsverzeichnis}

Seite

I. Einleitung

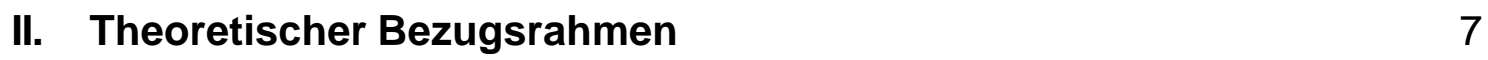

II.1 Was versteht man unter einem koreanischen "Chaebol"? 7

II.2 Forschungsstand zur Entstehungsgeschichte der Cheabol 9

$\begin{array}{ll}\text { II.3 Forschungsziel } & 23\end{array}$

II.4 Das soziologische Verständnis des ökonomischen Handelns 26

II.5 Der Unternehmer als Akteur des ökonomischen Handelns:

ein zu wenig beachteter Aspekt der soziologischen Forschung 31

II.6 Über den Nutzen der Biographie-Analyse $\quad 47$

II.7 Zur Methode 52

III. Das Verständnis des ökonomischen Handelns- historische Genese 57

III.1 Eine soziologische Herangehensweise an das koreaspezifische Verständnis des ökonomischen Handelns

III.2 Konfuzianisierung der Gesellschaft und fehlende Geldwirtschaft die institutione lle Entwicklung der Yi-Dynastie $\quad 58$

III.3 Die traditionelle Wahrnehmung des ökonomischen Handelns 64

III.4 Freies Handelssystem und Nationalismus - die abrupte Abkehr von der konfuzianischen Gesellschaftsordnung nach 1876

III.5 Gesellschaftlich-institutionelle Veränderungen während der japanischen Kolonialzeit 82

III.6 Die Entwicklung der koreanischen Unternehmen bis 1945

III.7 Resümee 101

IV. Die Bedeutung des familiär-sozialen Beziehungsgeflechts für das unternehmerische Handeln - eine Analyse am

Beispiel der drei erfolgreichsten Chaebolgründer 104

IV.1 Der biographische Hintergrund 104

IV.2 Unternehmerische Anfänge bis 1945

IV.3 "Familie" im Verständnis des koreanischen Unternehmers 127 
IV.4 Die ökonomische Entwicklung Koreas zwischen 1945 und 1960

IV.5 "Kapital Familie" - der unternehmerische Aufstieg

V. Verflechtung zwischen Staat und Chaebol

V.1 Eine soziologische Betrachtung der Beziehungslogik zwischen Staat und Unternehmen in Korea

V.2 Der Staat als "Patron" - staatliche Wirtschaftslenkung nach dem Militärputsch von 1961

V.3 Die Unternehmer als "Klientel" 180

V.4 "Oligarchisierung" der Wirtschaft in den 70er Jahren 197

V.5 Resümee

V. Das Management in den Chaebol - die Führungsstruktur in den koreanischen Massenproduktionsunternehmen

VI.1 Das koreanische Verständnis von Management 206

VI.2 Die Entstehungsbedingungen des Managements in Korea 208

VI.3 Rekrutierung und innerbetrieblicher Aufstieg der Manager 220

VI.4 Die Doppelbödigkeit der koreanischen Managementkultur 231

VI.5 Resümee

VII. Schlußfolgerung

VII.1 Zusammenfassung der Ergebnisse

VII.2 Diskussion über den Veränderungsbedarf bei den koreanischen Chaebol 


\section{Einleitung}

Meine Dissertation zielt darauf ab, die These zu belegen, daß der länderspezifische Charakter der unternehmerischen Entwicklung weniger durch die Frage, über welche gesellschaftlichen Ressourcen der jeweilige ökonomische Akteur verfügt bzw. welche strukturellen Merkmale die koreanische Gesellschaft auszeichnen, als vielmehr durch die Frage, von welchem Verständnis des ökonomischen Handelns dieser Akteur (vor allem der Unternehmer) ausgeht, herausgearbeitet werden kann. Dementsprechend ist meine Dissertation ein Versuch, die Eigentümlichkeit der koreanischen Chaebol, die mit westlichen Begriffen wie Konzern, Großunternehmen oder Familienunternehmen nur unzureichend charakterisiert sind, durch eine soziologische Analyse des unternehmerischen Handelns neu zu beleuchten.

Dafür beschäftige ich mich in einem ersten theoretischen Teil zunächst mit der Frage, warum die Analyse der koreanischen Chaebol einen neuen soziologischen Zugriff verlangt. Dabei werden nicht nur die Forschungslücken der koreanischen Chaebol-Forschung erörtert, sondern auch gezeigt, warum die bisherigen westlichen soziologischen Begriffe und Forschungsansätze für die Erklärung der Entstehung der Chaebol ergänzungsbedürftig sind.

Da eine soziologische Analyse des unternehmerischen Handelns ohne historische Analyse des koreanischen Normenwandlungsprozesses, versuche ich anschließend in einem historischen Teil, der von der Zeit der Yi-Dynastie über die von Japan erzwungene Öffnung Koreas 1876 bis zur japanischen Kolonialzeit (1910-1945) reicht, die Bedeutung der konfuzianischen Norm für die Herausbildung des koreanischen Unternehmertums zu analysieren. In diesem Zusammenhang möchte ich betonen, daß mein Interesse an der historischen Verlaufsform des Konfuzianismus bzw. des gesellschaftlich-strukturellen Wandlungsprozesses der Yi-Dynastie keineswegs als geschichtswissenschaftliches Interesse zu bezeichnen ist. Selbst wenn die Darstellungsform meiner historischen Analyse der Yi-Dynastie und der japanischen Kolonialzeit streckenweise sehr stark an eine geschichtswissenschaftliche Arbeit erinnert, muß klar gesagt werden, daß es sich hier um eine soziologische Rekonstruktion der historischen Materialien handelt. Das heißt, daß ich nur die Form einer historischen Analyse wähle, um dadurch meine genuin soziologische Frage nach der Kulturbedeu- 
tung des menschlichen bzw. unternehmerischen Handelns in Korea zu verdeutlichen.

Es reicht jedoch nicht aus, die Eigentümlichkeit des unternehmerischen Handelns in Korea allein im Rückgriff auf den Konfuzianismus erklären zu wollen. Man braucht hier eine zweite Analyseebene, nämlich die Untersuchung der Frage, wie diese Normen vom einzelnen unternehmerischen Akteur wahrgenommen und interpretiert werden. Daraus ergibt sich der biographische Teil meiner Arbeit, in dem ich mich mit der Art und Weise auseinandersetze, in der die drei erfolgreichsten koreanischen Chaebolgründer, nämlich In-Hoe Ku (Lucky-Goldstar), Byong-Chul Lee (Samsung) und Joo-Young Cheong (Hyundai), die keineswegs starre, sondern überaus wandlungsfähige traditionelle Kultur zur Grundlage ihres unternehmerischen Handelns machten. Dies geschieht in zwei Schritten: Zunächst widme ich mich der Frage, in welcher Form die traditionelle Logik der familiären Beziehungen in das unternehmerische Handeln in Korea eingebettet ist. Hier werden vor allem die Kindheit und Jugend der drei Gründerväter der koreanischen Chaebol analysiert. Anschließend setze ich mit der Frage auseinander, inwiefern das ökonomische Handeln durch eine über die engere Familie hinausgehende soziale Beziehungslogik beeinflußt wird. Um diese Frage zu beantworten, analysiere ich vor allem den unternehmerischen Werdegang der drei Gründerväter der koreanischen Chaebol, die nach der Befreiung von der japanischen Kolonialzeit in kurzer Zeit von Außenseitern zu gesellschaftlich-ökonomischen Aufsteigern wurden. Dabei gilt für diese biographische Analyse ähnliches wie für den historischen Teil meiner Arbeit: Sie ist nicht Selbstzweck, sondern dient nur als Anschauungsmaterial für eine soziologische Analyse, die den Lebensweg der drei Gründerväter der koreanischen Chaebol nicht schon per se als repräsentativ für unternehmerisches Handeln in Korea behauptet, sondern vor aller Erklärung, sich zunächst darum bemüht zu verstehen, welche Auffassung vom ökonomischen Handeln sich aus den (Auto-)Biographien dieser koreanischen Unternehmer herauskristallisieren läßt.

Ergänzt wird die biographische Analyse durch die wichtige Frage nach der Rolle, die der Staat unter Präsident Park für die Herausbildung des unternehmerischen Verständnisses in Korea spielt. Hier möchte ich zeigen, durch we Ichen gesellschaftlichen Wirkungsmechanismus die koreanische Beziehung 
zwischen Staat und Unternehmen bzw. Staat und Chaebol geprägt ist. Dabei wird die spezifisch koreanische Beziehung zwischen Staat und Chaebol als koreaspezifische Variante des starken Staates, der wesentlich zur Entstehung der Chaebol beitrug, im konkreten historischen Kontext rekonstruiert. Außerdem möchte ich zeigen, worin die Rolle des koreanischen Staates für die Entwicklung der Chaebol bestand und wie dieser koreaspezifische Wirkungsmechanismus die Aktivitäten der koreanischen Unternehmer und ihr Verständnis des ökonomischen Handelns beeinflußte.

Im letzten Teil meiner Arbeit setze ich mich schließlich mit der Frage auseinander, wie sich das ökonomische Handeln innerhalb der unternehmerischen Organisation der koreanischen Chaebol ausdrückt. Hier richtet sich mein Augenmerk hauptsächlich auf die koreanische "Managementkultur", deren Hauptmerkmale ohne eine genaue Analyse des koreaspezifischen Verständnisses von Management nicht zu erklären sind. Meine Hervorhebung der Managementproblematik aus koreanischer Sicht hängt nicht zuletzt mit meiner soziologischen Grundannahme zusammen, daß Manager nicht nur an den ökonomischen Erfolg ihres Unternehmens denken, sondern daß sie sich als handelnde Subjekte bei der Lösung von unternehmerischen Problemen nicht von koreanischen kulturellen Denkmustern lösen können.

Zusammenfassend will ich abschließend das hinter der Entwicklung der Chaebol stehende koreaspezifische Verständnis des unternehmerischen Handelns, wie es sich aus den vorherigen Kapiteln ergeben hat, rekonstruieren und die soziologische Bedeutung meiner Analyse im Zusammenhang mit der koreanischen Debatte über die Reformbewegung der Chaebol kurz erörtern. 


\section{II.Theoretischer Bezugsrahmen}

\section{II.1 Was versteht man unter einem koreanischen "Chaebol"?}

In Korea werden Unternehmen, die hierzulande als koreanische Hersteller höherwertiger Massenproduktionsgüter wie Autos, Unterhaltungselektronik und Schiffsbau bekannt sind, Chaebol genannt. ${ }^{1}$ In den westlichen Länder werden Unternehmen, die solche Produkte herstellen, als "Großuntemehmen" oder "Konzerne" bezeichnet. In der Regel charakterisiert man ein westliches Großunternehmen dadurch, daß das unternehmerische Tätigkeitsfeld auf eine Industriebranche konzentriert ist und das Eigentumsrecht dieses Unter-nehmens auf viele Investoren verteilt ist. Gleichzeitig fällt auf, daß die Mehrheit dieser Unternehmen nicht vom Unternehmer als Eigentümer, sondern von einem angestellten Berufsmanager geleitet wird. Obwohl man vermuten könnte, daß die koreanischen Massenproduktionshersteller wie Samsung, Lucky-Goldstar, Hyundal, Daewoo etc, die in Korea Chaebol genannt werden, die gleichen Merkmale aufweisen, handelt es sich bei den koreanischen Chaebol um eine Ansammlung von Unternehmen, die aus einer Vielzahl von Unternehmen bestehen und einem einzigen Eigentümer oder dessen Familie gehören.

Zur Zeit beträgt die Zahl der Unternehmen bei Samsung und Hyundai über 60 und bei Lucky-Goldstar 53. ${ }^{2}$ In diesem Imperium findet man nicht nur ein Unternehmen, das sich auf die Massenproduktion von Haushaltselektronik und Autos spezialisiert hat, sondern auch Unternehmen für Schiff- und Flugzeug-

\footnotetext{
${ }^{1}$ Wörtlich übersetzt bedeutet "Chae" reich und "beol" Sippe oder Clan, womit sowohl auf den hohen Anteil von Familienmitgliedern in allen Chaebol verwiesen wird als auch darauf, daß es sich um große Unternehmen handelt, deren Anteil an der gesamtwirtschaftlichen Entwicklung des Landes sehr hoch ist. "Beol" bedeutete im alten Korea der Yi-Dynastie aber auch "einflußreiches Haus", womit auch die enorme Bedeutung, die die Chaebol im politisch-wirtschaftlichen Lebens Koreas spielen, angedeutet wird. Im übrigen aber ist schwer abzugrenzen, welches Unternehmen in Korea als Chaebol bezeichnet wird und welches nicht. Dong-Sung Cho, Hanguk-Chaebol, Seoul 1997, S. 17, läßt nur die nach ihrem Gesamtumsatz zu den 30 größten Unter-nehmen Koreas als Chaebol gelten, doch wird die Bezeichnung Chaebol in der Regel nicht nach solchen strengen Regeln vergeben.

${ }^{2}$ Frankfurter Allgemeine Zeitung, 8. Dezember 1998, Nr. 285, S. 25.
} 
bau, Lebensmittel- und Textilherstellung, Hotels etc. Wenn man alle Produkte von Samsung aufzählen würde, sähe das Unternehmen wie ein großes Kaufhaus aus, in dem man von Lebensmitteln bis zu hochwertigen Produktionsanlagen alles kaufen kann. Das gleiche Bild zeigt sich bei Hyundai, Lucky-Goldstar und Daewoo. Wenn man das Alltagsleben in Korea betrachtet, fällt auf, daß es kaum einen Lebensbereich gibt, in dem man mit den Produkten der Chaebol nichts zu tun hat. So lebt die Mehrheit des koreanischen Mittelstandes in Hochhäusern, die von einer Baufirma dieser Chaebol erbaut wurden; man kocht den Reis im elektronischen Reiskocher, der von einem der Chaebol hergestellt worden ist; man benutzt Kosmetik, die ebenfalls von diesen Chaebol hergestellt worden ist; man kleidet sich mit ihren Anzügen und fährt zur Firma mit einem von diesen Chaebol produzierten Auto; man arbeitet in einer Firma, die zu einem der Chaebol gehört; dort telefoniert man mit dem Gerät, das wiederum von innen produziert worden ist; man ißt im Restaurant, das zu den Chaebol gehört, und nach Feierabend sieht man in einen von ihnen hergestellten Fernseher. Zusammengefaßt: Die Chaebol gestalten einen Großteil des Alltagslebens in Korea.

Obwohl die Produktionspalette der Chaebol so groß und verschiedenartig ist, werden die verschiedenen, in einem Chaebol zusammengefaßten Unternehmen von einer Person bzw. einem Eigentümer-Unternehmer geleitet. Während bei Samsung und Lucky-Goldstar nach dem Tod der Gründerväter die Macht über das gesamte Unternehmensimperium an die Söhne weitergeleitet wurde, wird Hyundai weiterhin vom Gründervater Joo-Young Cheong beherrscht. ${ }^{3}$ Weil dieser Eigentums-Unternehmer nicht als Symbolfigur, sondern als aktiver Topmanager agiert, drängt sich die Frage auf, wie es für eine Person möglich ist, so verschiedenartig zusammengesetzte Unternehmen zu managen. Nirgendwo sonst in der Welt gibt es Topmanager wie in den Chaebol in Korea, die für alle Branchen zuständig sind.

Als das koreanische Auto von Hyundai und elektronische Geräte von Samsung und Lucky-Goldstar auf den nordamerikanischen Markt kamen, begannen sich westliche Beobachter zu fragen: Was ist ein "Chaebol"? Wer steckt dahinter? Für

\footnotetext{
${ }^{3}$ Offiziell gab auch Cheong seinen Präsidentenposten im Unternehmen an seinen ältesten Sohn Mong-Ku Cheong ab. Aber wenn es sich um wichtige unternehmerische Angelegenheiten (z.B. Investitionen in Nordkorea oder den Ankauf des Unternehmens von Kia) handelte, dann intervenierte Joo-Young Cheong regelmäßig.
} 
sie war bald klar, daß die Chaebol Hauptakteure des viel bestaunten ökonomischen Wachstumswunders in Korea waren. Seitdem genoß das Wort "Chaebol" einen hohen Stellenwert bei den Koreaforschern. ${ }^{4}$ Die Chaebol galten als die wichtigste Triebkraft für das schnell fortschreitende koreanische Wirtschaftswachstum. ${ }^{5}$ Aber dieses positive Bild geriet ins Wanken, als die Topmanager der Chaebol wegen ihrer zahlreichen an Politiker und ehemalige Regierungsbeamte gezahlten Bestechungsgelder vor Gericht gestellt wurden. Das geschah zwischen 1994 und 1996, als die beiden ehemaligen koreanischen Präsidenten wegen Amtsmißbrauchs angeklagt wurden. Von da ab zählten die Chaebol nicht mehr zum erfolgreichen Typus eines Unternehmens, dessen genauere wissenschaftlichen Analyse sich lohnte, sondern waren vielmehr eine plötzlich enttarnte geheime "Quelle der gesamten koreanischen Korruption",, die für die gegenwärtige Fnanzkrise in Korea verantwortlich gemacht wurde. Kann man sich ein derartig radikal gewandeltes Bild bei westlichen Großunternehmen oder Konzernen vorstellen? So stellt sich noch einmal die Frage: Was ist das wahre Bild der Chaebol in Korea?

\section{II.2 Forschungsstand zur Entstehungsgeschichte der Chaebol}

Obwohl es nicht üblich ist, beim Überblick über den Forschungsstand journalistische Beiträge zu berücksichtigen, bin ich doch der Auffassung, daß die koreanische Forschungsgeschichte zu den Chaebol ohne die besondere Rolle der koreanischen Journalisten nicht zu verstehen ist. Dies hängt nicht allein damit zusammen, daß das koreanische Wort "Chaebol" in den 60er Jahren (und vereinzelt wohl auch schon in den 50er Jahren) zuerst von Journalisten

\footnotetext{
${ }^{4}$ Richard M. Steers, The Chaebol, Seoul 1990, S. $18 \mathrm{f}$.

${ }^{5}$ Hanguk Sanup Chojik Hakhoe (Arbeitskreis für koreanische industrielle Organisation, Hrsg.), Hanguk Keonjeeui Jinrowa Daekiop-Gibdan (Die Zukunft der koreanischen Ökonomie und die Gruppe der Großunternehmen), Seoul 1996, S. 5.

${ }^{6}$ Dong-Sung Cho, Hanguk Chaebol (Die Organisation der Chaebol), Seoul 1997, S. 2.
} 
gebraucht wurde, sondern vor allem damit, daß deren Charakterisierung der Chaebol für manche Koreaforscher eine große methodologische Herausforderung darstellte.

Im großen und ganzen begann das journalistische Interesse an der Entwicklung der koreanischen Chaebol mit Beginn der 60er Jahre, als einige führende koreanische Unternehmer von der neuen Militärregierung unter Präsident Park als "illegale Kapitalakkumulatoren" angeklagt wurden. Aber es dauerte nicht lange, dann mußten die Journalisten mit ansehen, daß die neue Regierung bereitwillig mit diesen angeklagten Unternehmern zusammenarbeitete. Daher trugen die journalistischen Beiträge über die Entwicklung der Chaebol stark den Charakter von Enthüllungsreportagen. Zunächst konzentrierten sich die Journalisten auf die Frage, wie schnell sich die koreanischen Chaebol mit Hilfe der zahlreichen staatlichen Förderungsmaßnahmen bereichert hatten. Dann stellten sie anhand vieler konkreter Fälle dar, mit welchen Methoden die Unternehmer bzw. die Gründerväter der Chaebol ihr Kapital akkumuliert und wie sie ihr Unternehmen ausgebaut hatten. Für die koreanischen Journalisten, die in der Regel an westlich orientieren Eliteuniversitäten studiert hatten und daher die westliche gesellschaftliche Entwicklung als Folie für die eigene Gesellschaftskritik benutzten, war die Entwicklung der Chaebol eine Skandalgeschichte des koreanischen Modernisierungsprozesses, deren Hintergrund von innen nun ans Licht gebracht werden mußte. Dabei stand die Aufdeckung über die Methoden der rapiden Kapitalakkumulation der koreanischen Chaebol im Mittelpunkt ihrer Recherchen. So versuchten sie nachzuweisen, daß der große ökonomische Erfolg der koreanischen Chaebol nicht auf technologischer Innovation oder unternehmerischer Risikobereitschaft im schumpeterischen Sinne $^{7}$ beruhte, sondern sich vielmehr den zahlreichen ökonomischen Privilegien verdankte, die vor allem von der Regierung unter Präsident CheongHee Park (Amtszeit 1961 bis 1979) gewährt wurden. ${ }^{8}$ Diese Sichtweise der koreanischen Journalisten hängt natürlich damit zusammen, daß sie als Reporter oft unmittelbare Zeugen der ökonomischen Verflechtung zwischen einzelnen Unter-

\footnotetext{
${ }^{7}$ Joseph Schumpeter, Theorie der wirtschaftlichen Entwicklung, München/Leipzig 1926.

${ }^{8}$ Sung-Du Kim, Gudulyi Hanguk Koengje rul Chaijiuju hago issunga (Die Chaebol, die die koreanische Wirtschaft beherrschen), in: Wolgan-Chosun, Heft 9 (1980), S. 224234.
} 
nehmern und Regierungstechnokraten waren. So nutzten die Unternehmer, die selbst Zeitungsfirmen oder Rundfunkanstalten besaßen, ihren Kontakt zu den Medien intensiv aus, wenn sie staatliche Förderungsmaßnahmen für ihre unternehmerischen Pläne benötigten.

Als Ende der 60er Jahre die Regierung Park die Entwicklung der Massenproduktion zu ihrem ökonomischen Ziel erklärte, wurden die Journalisten zum Hauptkritiker dieser Regierungspolitik. Wozu braucht ein Land eine Massenproduktionsstrategie - so fragten sie -, wenn sich die Mehrheit der Bevölkerung die höherwertigen Massenproduktionsgüter wie Autos und Haushaltselektronik aufgrund ihres niedrigen Einkommens gar nicht leisten kann? Dabei äußerten sie den Verdacht, daß diese staatliche Förderung der Massenproduktion nur dazu diene, die rapide Expansion der Chaebol, die als Hersteller von Massenproduktionsgütern vorgesehen waren, zu ermöglichen. ${ }^{9}$

Doch seit dem Ende der 70er Jahre meldete sich eine Gruppe von Wissenschaftlern zu Wort, die sich mit dem bisherigen, von Journalisten bestimmten, negativen Bild der Chaebol nicht zufriedengeben wollte. Sie drückten ihr Unbehagen an der bisherigen journalistischen Herangehensweise an die Chaebol aus und kritisierten, daß trotz des häufigen Gebrauchs dieses Wortes immer noch keine brauchbare wissenschaftliche Definition für "Chaebol" vorläge. Zu diesen Wissenschaftlern gehörten nicht nur volkswirtschaftlich orientierte Ökonomen, sondern auch Betriebswirte und Soziologen. Sie waren sich darin einig, daß man die koreanische Entwicklung der Chaebol nicht mehr nur negativ bewerten könne. Der Grund für diesen Perspektivwechsel ist vor allem darin zu suchen, daß koreanische Unternehmen wie Samsung, Lucky-Goldstar und Hyundai, die in der Presse einseitig als nicht-innovative Unternehmen charakterisiert worden waren, inzwischen so erfolgreich waren, daß dieser Erfolg nach einer Erklärung verlangte, die über die bisher von journalistischer Seite vorgelegten Ansätze hinausging.

Ökonomische Erklärungsansätze: Es ist unbestreitbar, daß die internationale Aufmerksamkeit für die Eigentümlichkeit der koreanischen Chaebol zuerst durch

\footnotetext{
${ }^{9}$ Gab-Seop Lee, Hwansa euro guchil Sobi-Heokmeong (Massenkonsum als Illusion), in: Sintonga, Heft 1 (1967), S. 104-113.
} 
das 1980 erschienene, von dem amerikanischen Wirtschaftswissenschaftler Jones gemeinsam mit seinem koreanischen Kollegen Sakong ver-faßte Buch "Government, Business, and Entrepreneurship in Economic Development: The Korean Case" geweckt wurde. ${ }^{10}$ Doch ist ihre Sichtweise auf die koreanischen Chaebol durch einen traditionell ökonomie-theoretischen Blickwinkel bestimmt. Dabei gilt inr Hauptanliegen weniger der Frage, wie die Chaebol in Korea entstehen konnten, als vielmehr der Frage, ob die staatliche Wirtschaftspolitik unter Präsident Park aus der Sicht der bisherigen ökonomischen Entwicklungstheorie eine richtige Option war oder nicht. Zwar wird auf die koreanische Eigentümlichkeit der Chaebol aufmerksam gemacht, aber nur, um auf diese Weise zu erklären, daß die koreanische Entwicklung der Chaebol aus ökonomischer Sicht unausweichlich war.

In Anlehnung an das Modell des klassischen westlichen Großunternehmens, das im Vergleich zu Klein- oder mittleren Unternehmen über bessere Wettbewerbsfähigkeit auf dem Markt verfügt, argumentieren Jones und Sakong, daß die koreanische Volkswirtschaft die angestrebte enorme Wachstumsrate nur mit Hilfe gezielter staatlicher Unterstützung bei der Herausbildung der Großunternehmen bzw. Chaebol erreichen konnte. Folgt man diesem Argument, so stand hinter der Entstehung der Chaebol nichts anderes als die reine Logik ökonomischer Unausweichlichkeit. ${ }^{11}$

Ein ähnliches Argument wie bei Jones und Sakong findet sich auch in dem Buch von Alice Amsden "Asia's Next Giant: South Korea and Late Industrialization", das im Jahr in New York 1989 veröffentlicht (und noch im gleichen Jahr ins Koreanische übersetzt) wurde. Alice Amsden gehört zu jenen ameri-

\footnotetext{
${ }^{10}$ Leroy P. Jones/ll Sakong, Government, Business, and Entrepeneurshikp in Economic Development: The Korean Case, Cambridge u. a. 1980.

${ }^{11} \mathrm{Im}$ Gegensatz dazu schloß allerdings Sakong, der koreanische Koautor des genannten Buches, in einem anderen Aufsatz die Möglichkeit nicht aus, daß die koreanische Entwicklung der Chaebol nicht möglich gewesen wäre, wenn die Regierung Park ihr politisches Ziel nicht im rapiden ökonomischen Aufschwung, sondern in der Demokratie gesehen hätte. Siehe II Sakong, Keongie Seongjang kwa Chaebol (Ökonomisches Wachstum und die Chaebol), in: Wolgan Chosun, Heft 9 (1980), S. 245-257.
} 
kanischen Ökonomen, die von der Annahme ausgehen, daß Korea das beste Beispiel für die These vom starken Staat sei. Doch während sich Jones und Sakong zwischen der These vom starken Staat und der schumpeterischen Auffassung von der Rolle des Unternehmers nicht klar entscheiden können, beharrt Amsden darauf, daß die Herausbildung der Chaebol eindeutig eine Folge des "lernfähigen starken Staates" in Korea sei. ${ }^{12}$ Zwar beschäftigt sich Amsden auch mit den ökonomischen Aktivitäten der koreanischen Chaebol, aber ihr Erkenntnisinteresse zielt in erster Linie darauf, zu zeigen, wie sehr die Entwicklung der Chaebol an die Entwicklung des Großunternehmens in den westlichen Ländern erinnert und wie diese Nachahmung des Spätentwicklers Korea durch geschickte staatliche Interventionen beschleunigt wurde.

Im Gegensatz zu den Darstellungen der Chaebol in der Presse, in denen die enge Beziehung zwischen Staat und Chaebol als ökonomische Katastrophe gewertet wurde, vertreten die genannten Bücher also die These, daß die koreanische Entwicklung der Chaebol aus Sicht der ökonomischen Theorie keineswegs so irrational war, wie die koreanischen Journalisten immer behaupteten. Mit Blick auf die westlichen Erfahrungen mit Großunternehmen wird die koreanische Entwicklung der Chaebol im großen und ganzen als ein positives Phänomen dargestellt, da die rapide ökonomische Wachstumsrate in Korea ohne ihren Beitrag nicht zu erklären sei. Doch das führte keineswegs dazu, daß sich das Bild von den Chaebol in der koreanischen Öffentlichkeit seit der Veröffentlichung dieser beiden Bücher zum Positiven veränderte. Eher ist es so, daß diese beiden Sichtweisen der koreanischen Chaebol in einem sich gegenseitig ausschließenden Konkurrenzverhältnis stehen. Denn: So elaboriert der neue ökonomische Erklärungsansatz der koreanischen Entwicklung der Chaebol auch erscheinen mag, er betrifft nur die Makroebene der ökonomischen Entwicklung, nicht die Mikroebene des ökonomischen Handelns, das von koreanischen Journalisten unmittelbar beobachtet und kritisiert wurde.

\footnotetext{
${ }^{12}$ Alice Amsden, Asia's Next Giant: South Korea and Late Industrialization New York/Oxford 1989, S. $91 \mathrm{f}$.
} 
Betriebswirtschaftliche Erklärungsansätze: Das 1990 erschienene Buch "The Chaebol: Korea's New Industrial Might" ist die erste englischsprachige Monographie, die die koreanische Entwicklung der Chaebol aus der Sicht der Betriebswirtschaft beleuchtet. Die Verfasser - Steers, Shin und Ungson - sindzwei amerikanische und ein koreanischer Betriebswirt(e). Selbst wenn ihr Hauptinteresse darin bestand, zu zeigen, mit welchem Managementkonzept die koreanischen Chaebol ihre ökonomischen Ziele erreichten, ist unverkennbar, daß es sich hier um einen Perspektivwechsel in der bisherigen koreanischen Chaebol-Forschung handelt. Während der bisherige ökonomische Erklärungsansatz dazu neigte, die ökonomische Effizienz der staatlichen Wirtschaftspolitik hervorzuheben, zeichnet sich die betriebswirtschaftliche Auffassung dadurch aus, daß für sie die Ursache des koreanischen Wirtschaftserfolges ohne genauere Analyse der unternehmerischen Organisationsstrukturen der koreanischen Chaebol nicht zu erklären ist. ${ }^{13}$ Kurz gesagt: Die Autoren halten es für undenkbar, daß hinter der Entwicklung der koreanischen Chaebol keine ökonomische Rationalität bzw. Effizienz steht, wie es bereits auch von den Ökonomen als Möglichkeit angedeutet wurde.

Um eine wissenschaftliche Begründung für die ökonomische Effizienz der koreanischen Chaebol bemühten sich jedoch ausschließlich koreanische Betriebswirte. Dies hängt damit zusammen, daß sich die unternehmerische Praxis anders als die staatliche Wirtschaftspolitik ohne sprachliche und kulturelle Vorkenntnisse der koreanischen Gesellschaft nicht nachvollziehen läßt. Dabei lassen sich zwei Herangehensweisen erkennen:

Die erste Herangehensweise findet sich in den Arbeiten von Dong-Sung Cho, der gegenwärtig als Professor an der Seoul-National-Universität tätig ist. In seiner 1991 und nur leicht verändert auch 1997 erschienen Monographie beschäftigt er sich nicht nur mit der Definition der koreanischen Chaebol, sondern vor allem mit der Frage, warum die Entstehung der koreanischen Chaebol als ein normaler Vorgang des allgemeinen Kapitalismus anzusehen ist. Nach seiner Auffassung lassen sich als Chaebol nur diejenigen Großunternehmen bezeichnen, die erstens nach ihrem Gesamtumsatz zu den 30 größten Unter-

\footnotetext{
${ }^{13}$ Richard M. Steers/Yoo-Keun Shin/Gerardo R. Ungson, The Chaebol: Korea's New industrial Might, New York 1989, wiedergegeben nach der koreanischen Übersetzung Se-
} 
nehmen des Landes gehören und zweitens von der Unternehmerfamilie selbst geführt werden. ${ }^{14}$ Ich bin der Auffassung, daß Dong-Sung Cho der konsequenteste koreanische Anhänger der traditionellen westlichen Unternehmenslehre ist, nach der die weltweite Verbreitung des westlichen Großunternehmens nicht Zufall, sondern ein Beweis für dessen ökonomische Überlegenheit ist. Dabei bezieht sich Cho vor allem auf die Erklärungsansätze für die Entstehung des Großunternehmens, die von R. H. Coase und Oliver E. Williamson vertreten wurden. ${ }^{15}$ Ich finde es allerdings fraglich, ob Dong-Sung Cho mit seiner vor allem für eine statistische Untersuchung geeigneten Charakterisierung den koreanischen Chaebol gerecht wird.

Konzentriert man sich auf das Skelett des Arguments von Cho, dann kann man seine Sichtweise der koreanischen Chaebol wie folgt zusammenfassen: Die oben genannten beiden westlichen Erklärungsansätze für die Entstehung von Großunternehmen hält er ohne weiteres für auf die koreanische Entwicklung der Chaebol übertragbar. Die Chaebol in Korea seien nicht nur die reichsten Unternehmen im Lande, sondern auch die Träger der ökonomischen Wettbewerbsfähigkeit, die auf dem Weltmarkt die Konkurrenzfähigkeit mit den westlichen Großunternehmen garantierten. Insofern ist es konsequent, wenn er der koreanischen Öffentlichkeit gegenüber die positive Seite der koreanischen Entwicklung der Chaebol herausstreicht und die negativen Aspekte relativiert. Das negative Bild, das in der Öffentlichkeit vorherrsche, so Cho, sollten die einzelnen Unternehmer durch eine "bescheidenere Haltung" korrigieren und sich hauptsächlich darauf konzentrieren, die vorhandene Wettbewerbsfähigkeit der Chaebol zu verbessern. ${ }^{16}$

Die zweite betriebswirtschaftliche Herangehensweise an die koreanische Entwicklung der Chaebol findet sich bei Yu-Kun Shin, der Koautor der oben

oul 1990, S. 16.

${ }^{14}$ Dong-Sung Cho, Hanguk-Chaebol, Seoul 1997, S. 13-17.

${ }^{15}$ Dabei verweist Cho auf den Aufsatz von R. H. Coase, The Nature of the Firm, in: Economica, Vol. IV, No. 16 (1937), S. 386-405, und auf den Aufsatz von Oliver E. Williamson, The Modern Corporation: Origins, Evolution, Attributes, in: Journal of Economic Literature, Vol. XIX (December 1981). S. 1537-1568.

${ }^{16}$ Dong-Sung Cho, Hanguk Chaebol (Die Organisation der Chaebol), Seoul 1997, S. 310. 
genannten englischsprachigen Monographie über die Chaebol und ebenfalls Professor an der Seoul-National-Universität ist. Obwohl er sein umfangreiches Buch nicht "Chaebol", sondern allgemeiner "Das Management in Korea" betitelt hat, ist unverkennbar, daß das Buch auch von der koreanischen Entwicklung der Chaebol handelt. ${ }^{17}$ Solange die Chaebol auf dem Weltmarkt als unbekannte Hersteller aus Dritte-Welt-Land fungierten, war es für die koreanischen Betriebswirte in Korea kaum denkbar, daß man sich mit der Frage nach dem nationalspezifischen Charakter der Managementlehre beschäftigen könnte. Lange galt es für sie als Selbstverständlichkeit, daß die Unternehmen in den Entwicklungsländern nur durch den Transfer der westlichen Managementlehre ihre ökonomische Rationalität erweisen konnten. Als die westlichen Betriebswirte damit anfingen, vom japanischem $\mathrm{Ma}$ nagement zu lernen, begann man sich jedoch auch in Korea zu fragen, ob es eine koreanische Managementlehre gebe. Shin gehört zu jenem Typus der koreanischen Betriebswirte, die in Anlehnung an die koreanische Entwicklung der Chaebol versuchten, zu zeigen, worin die koreanische Eigentümlichkeit des Managements besteht. ${ }^{18}$

In seinem Buch "Das Management in Korea" trägt Shin umfangreiche und ausführliche Informationen über die koreanische Managementpraxis zusammen, die sich vor allem an den Chaebol beobachten lassen. Er nennt drei charakteristische Merkmale für die koreanische Managementstruktur: 1. die familiäre Dominanz in der Unternehmensstruktur, 2. der patriarchalische Führungsstil, 3. die repressive Arbeitspolitik. Weil diese Merkmale ohne Rückgriff auf die konfuzianische Kultur in Korea nicht zu erklären seien, hält er die bisherige konvergenztheoretische Annahme, daß die Chaebol als Nachahmung des westlichen Großunternehmens aufzufassen seien, für unwahrscheinlich. Insofern lehnt er es ab, die Chaebol in Korea eo ipso für ökonomisch effizient zu erklären. Deswegen ist es nicht erstaunlich, daß er sich bei seiner Analyse des koreanischen Managements nicht sonderlich für die positive oder negative Seite der koreanischen Chaebol interessierte. Wahrscheinlich hoffte Shin sogar, die bisherige polarisierte Debatte über die Rolle der koreanischen Chaebol mit seiner betriebswirtschaftlich untermauerten Analyse

\footnotetext{
${ }^{17}$ Yu-Kun Shin, Hanguk eui Keong-Yeong (Das Management in Korea), Seoul 1993.

${ }^{18}$ Ebenda, S. $32 \mathrm{f}$.
} 
des Managements überwinden zu können. Kurz gesagt: Er wünschte sich, daß sich die Chaebol in Korea ungeachtet ihrer problematischen Entwicklungsgeschichte an einem ökonomisch erfolgreichen koreanischen Managementmodell orientierten.

Zusammenfassend läßt sich sagen, daß es verständlich ist, daß die koreanischen Betriebswirte angesichts der zunehmenden ökonomischen Bedeutung der Chaebol unter einem gewissen Rechtfertigungsdruck standen. Sie fühlten sich dazu verpflichtet, die koreanische Entwicklung der Chaebol aufgrund ihres Beitrags zum rapiden Industrialisierungsprozeß des Landes zu legitimieren und darüber hinaus sogar als Unternehmensexperten Einfluß auf die Entwicklungsrichtung der koreanischen Chaebol zu nehmen. Ich bin jedoch der Auffassung, daß sich hinter diesen Bemühungen die Neigung der Betriebswirte verbirgt, Unternehmen nicht als sich notwendig ständig gesellschaftlich wandelnde Institutionen zu betrachten, sondern davon auszugehen, daß diese eine perfekte und damit dann auch unveränderbare ökonomische Organisationsform entwickeln sollten.

Soziologische Erklärungsansätze: Das soziologische Interesse an den Chaebol, auf die, wie oben dargestellt, zuerst einheimische und ausländische Ökonomen und Betriebswirte aufmerksam gemacht hatten, speist sich aus zwei unterschiedlichen Quellen: Zum einen bezog die koreanische Soziologie ihr Forschungsinteresse an den Chaebol aus einer allgemeinen Kapitalismuskritik, die mit Kritik an den Chaebol gleichgesetzt wurde. Zu den Vertretern dieser klassentheoretischen Richtung gehören die Soziologen Duk-Yul Hong, Jae-Jin Suh und Je-Uk Kong. Zum anderen kam das Interesse von Seiten der Vertreter der amerikanischen Organisationssoziologie, die sich bemühten, die länderspezifische Entwicklung ökonomischer Organisationen zu erklären. Zu den Anhängern dieser Forschungsrichtung gehören Garry G. Hamilton, Nicole Woolsey Biggart und Eun-Mee Kim. Um zu zeigen, wie unterschiedlich die Soziologie das Phänomen der koreanischen Chaebol wahrgenommen und analysiert hat, werde ich hier einen kurzen Abriß ihrer Forschungsmethode geben:

a) Klassentheoretische Herangehensweise: $\mathrm{Da}$ sich unter den Erforschern der koreanischen Chaebol nur selten ein koreanischer Soziologe oder eine ko- 
reanische Soziologin finden läßt, halte ich nicht für besonders verwunderlich. Meines Erachtens hängt dieses Phänomens mit der koreanischen Entwicklung der Soziologie zusammen, die sich bis Ende der 70er Jahre hauptsächlich darauf konzentrierte, den gesellschaftlichen Wandlungsprozeß in Korea mit Hilfe der amerikanischen struktur-funktionalistischen Modernisierungslehre zu erklären. Es gab zwar einige Soziologen, die die realgesellschaftliche Entwicklung in Korea mit Hilfe der quantitativen Methode der empirischen Sozialforschung untersuchten. Doch sie gaben sich hauptsächlich damit zufrieden, zu zeigen, inwiefern der Industrialisierungsprozeß in Korea durch die traditionelle Einstellung der verschiedenen Berufsgruppen beeinträchtigt wurde. ${ }^{19}$ Gleichzeitig war es für die Soziologen in Korea, die zumeist in den USA ausgebildet worden waren, bezeichnend, daß sie vor dem Hintergrund des herrschenden staatlichen gegen Nordkorea gerichteten Antikommunismus auf jegliche Rezeption des marxistischen Forschungsansatzes verzichteten. In der Regel wurde die fehlende Rezeption der marxistischen Lehre damit begründet, daß sie von einem Ökonomie-Determinismus ausgehe und daß ihre Analyse der koreanischen Gesellschaft zu einseitig sei. So erklärt sich, daß die soziologische Analyse des ökonomischen Handelns bzw. Entwicklungsprozesses keine nennenswerten Erkenntnisse vorzuweisen hatte. ${ }^{20}$

Doch mit Beginn der 80er Jahre fing die jüngere Generation der koreanischen Soziologen an, sich für die ökonomische Entwicklung in Korea zu interessieren. Dabei gingen sie von der Annahme aus, daß fehlende Kenntnisse über die gesellschaftliche Bedeutung der Ökonomie durch die verspätete Rezeption der marxistischen Soziologie zu überwinden seien. Besonders die Soziologiestudenten wollten sich mit der herkömmlichen Rezeption der westlichen Klassiker der Soziologie (Max Weber, Emile Durkheim und Talcott Parsons) nicht mehr zufriedengeben und wandten sich trotz staatlicher Verfolgung immer häufiger der Lehre der marxisti-

\footnotetext{
${ }^{19}$ Der Soziologe Keong-Dong Kim gilt als Repräsentant solcher Forschungspraxis. Ein Beleg dafür ist sein Buch "Hanguk in eui Gachikwn kwa Sahoe Euisik" (Koreanische Wertvorstellungen und Gesellschaftsbewußtsein), Seoul 1993 (erstmals 1967).

${ }^{20}$ Trotz dieser antimarxistischen Tradition der koreanischen Soziologie verhinderte der Staat die Etablierung der Soziologie als eigenständiges Fach an der Universität. Grund war die Befürchtung, daß die zunehmende Zahl der Soziologiestudenten erneut zu Studentenunruhen in Korea führen könnte. Denn als die Studenten der Eliteuniversität Anfang der 70er Jahre gegen die Einführung des diktatorischen Verfassungssystems de-
} 
schen Soziologie zu, die die gesellschaftliche Bedeutung der Ökonomie vor allem an der Klassenstruktur der kapitalistischen Gesellschaft festmachte. Die begriffliche Differenzierung für die verschiedenen Stufen des Kapitalismus (wie z. B. der halbfeudale Kapitalismus oder Staatsmonopolkapitalismus), die die marxistische Theorie bereitstellt, versuchten sie auf die spezifische Entwicklung des koreanischen Kapitalismus anzuwenden und so zu einer soziologischen Charakterisierung der koreanischen Wirtschafts- und Gesellschaftsstruktur zu gelangen.

Solange die soziologische Diskussion der koreanischen Entwicklung des Kapitalismus auf der allgemein-marxistisch-theoretischen Ebene geführt wurde, interessierte sich niemand sonderlich für die Entwicklung der Chaebol. Nachdem jedoch die Kritik an der unspezifischen Allgemeinheit des marxistischen Ansatzes innerhalb dieser jüngeren Generation von Soziologen immer lauter geworden war, begannen die oben bereits genannten drei jungen Soziologen - Duk-Yul Hong, Jae-Jin Suh und Je-Uk Kong - auf die Entwicklung der koreanischen Chaebol aufmerksam zu machen. ${ }^{21}$ Für sie waren die Chaebol in Korea die Verkörperung des koreanischen Kapitalismus. Da sie ihre Analyse der Chaebol mit den Methoden der marxistischen Klassenanalyse betrieben, konzentrierte sich ihr Erkenntnisinteresse auf Fragestellungen, die ursprünglich auch in der westlichen marxistischen soziologischen Diskussion eine große Rolle gespielt hatten. Zum Beispiel: Aus welcher gesellschaftlichen Schicht stammen die koreanischen Kapitalisten bzw. die Gründerväter der Chaebol? - oder - Welche Rolle spielt der Staat bei der Kapitalakkumulation?

Ergebnis ihrer Forschungen ist zusammengefaßt die These, daß die Chaebol in Korea nicht durch ihre ökonomischen Leistungen, sondern durch "staatliche Mobilisierung" ermöglicht wurden. ${ }^{22}$ Sie gingen dabei von der Annahme aus, daß diese einseitige staatliche Förderung der koreanischen Chaebol aus der Perspektive

monstriert hatten, stellte sich später sich heraus, daß die Demonstrationen mehrheitlich von Soziologiestudenten organisiert worden waren.

${ }^{21}$ Duk-Yul Hong, Hanguk Daechabonga eui Chojikhwa wa Kaegup Silcheone daehan Yeongu (Eine Abhandlung über die Organisation der koreanischen Großkapitalisten und ihr Klassenverhalten), Seoul National-University Press 1993; Jae-Jin, Suh, Han-guk Chabonga Kaegup (Die koreanische Kapitalistenklasse), Seoul 1991; Je-Uk Kong, Hanguk Chabonga Kaegup eui Seongjang kwa Gukga (Die Herausbildung der koreanischen Kapitalistenklasse und der Staat), Seoul 1994. 
der gesamtgesellschaftlichen Entwicklung viele strukturelle Widersprüche des koreanischen Kapitalismus (wie beispielsweise die durch die enge Beziehung zwischen Staat und Unternehmern bedingte Korruption und die fehlende soziale Fürsorge für die Arbeiter) noch verstärkt hat. ${ }^{23}$ Insofern ist es nicht verwunderlich, daß diese Soziologen nicht nur die Chaebol kritisierten, sondern sogar für die Auflösung der Chaebol in Korea als größte Aufgabe eines demokratischen Regierungssystems plädierten.

b) Organisationssoziologische Herangehensweise: Obwohl Hamilton und Biggart in ihrem gemeinsamen Aufsatz "Market, Culture, and Authority: A Comparative Analysis of Management and Organization in the Far East" (1988) nur einen kurzen Abriß der koreanischen Entwicklung der Chaebol gaben, stellt dieser die erste ernsthafte soziologische Analyse der Chaebol dar. Während die klassentheoretische Herangehensweise der koreanischen Soziologie sich nur auf die Kritik an der "illegalen Kapitalakkumulation" der Chaebol beschränkte, setzen sich Hamilton und Biggart in ihrem Aufsatz mit der Frage auseinander, wodurch sich die koreanische Eigentümlichkeit der unternehmerischen Entwicklung erklären läßt. ${ }^{24}$

Im großen und ganzen stimmen sie ihren koreanischen Kollegen zu, daß diese Entwicklungsform in Korea ohne die Rolle des starken Staates nicht zu erklären ist, aber sie geben sich nicht damit zufrieden, sondern fragen weiter: Wieso hat sich ausgerechnet in Korea eine Form des Großunternehmens entwickelt, das eine so enge bzw. sogar eine untergeordnete Beziehung zum Staat hat? Nach einer sorgfältigen Analyse der Sekundärliteratur über die historische Entwicklung der koreanischen Gesellschaft sowie über die ökonomischen Aktivitäten des koreanischen Staates stellen Hamilton und Biggart fest, daß sich die Organisationsstruktur der koreanischen führenden Unternehmen auf die enge Beziehung zum Staat zurückführen läßt und dies wiederum hängt mit der traditionellen konfuzianischen

\footnotetext{
${ }^{22}$ Jae-Jin Suh, Hanguk Chaebonga Kaegup (Die koreanische Kapitalistenklasse), Seoul 1991, S. 19.

${ }^{23}$ Duk-Yul Hong, Hanguk Chabonjeui wa Chaebol (Der koreanische Kapitalismus und die Chaebol), in: Reoksa wa Bipeong, (Sommer 1998), S. 93.

${ }^{24}$ Garry G Hamilton/Nicole Wolsey Biggart, Market, Culture, and Authority: A Comparative Analysis of Management and Organization in the Far East, in: American Journal of Sociology, Vol. 94 (Supplement 1988), S. 52-94.
} 
Vorstellung vom "starken Staat" zusammen, die seit Beginn der Yi-Dynastie (1392-1910) als Herrschaftsideologie fungierte. Sie gehen dabei von der Annahme aus, daß die organisatorische Entwicklung eines Unternehmen ungeachtet seiner ökonomischen Zielvorstellung insofern ein länderspezifisches gesellschaftliches Phänomen ist, als sich die Akteure des ökonomischen Unternehmens bewußt oder unbewußt an den vor-existierenden traditionellen Vorstellungen von Autoritätsbeziehungen orientieren, um sich zu legitimieren.

Während Hamilton und Biggart aufgrund des unterschiedlichen unternehmerischen Entwicklungsprozesses in Japan und Korea die koreanische Entwicklung der Chaebol nicht als Nachahmung der japanischen Zaibatsu ${ }^{25}$ ansehen, stellt die koreanische, in den USA tätige Soziologin Eun-Mee Kim in ihrem Aufsatz "The Industrial Organization and Growth of the Korean Chaebol: Integrating Development and Organizational Theories" fest, daß die Koreaner seit der Öffnung des Landes im Jahr 1876 mit dem japanischen Beispiel der Zaibatsu konfrontiert waren und sich daran orientierten. Als die Koreaner von der japanischen Kolonialherrschaft befreit wurden und ihre eigene ökonomische Entwicklungslaufbahn einschlugen, ahmten sie, so Kim, aus Unsicherheit das vertraute japanische Modell nach, und diese Anpassung wurde im Laufe des rasanten Industrialisierungschubes unter Präsident Park nur beschleunigt. ${ }^{26}$ Kim relativiert also das herkömmliche ökonomische Argument, daß für die Entwicklung der Chaebol maßgeblich die Rolle des starken Staates verantwortlich macht, und weist auf die historische Bedingtheit des durch Nachahmung entstandenen Organisationsmodells „Chaebol“ hin.

\footnotetext{
${ }^{25}$ Die Zaibatsu waren große japanische Unternehmen, die seit Ende des 19 Jahrhunderts durch staatliche Förderungsmaßnahmen sehr schnell expandierten. Bezeichnenderweise waren manche Zaibatsu aus traditionellen Familienunternehmen in Japan entstanden und behielten trotz ihrer unternehmerischen Expansion in der Schwerindustriebranche ihren alten familiären Charakter. Nach Beendigung des Zweiten Weltkrieges wurden die japanischen Zaibatsu zur Auflösung gezwungen, weil sie während der Kriegsjahre an der Herstellung von Kriegswaffen beteiligt gewesen waren. Die Alliierten ordneten an, daß die von den Unternehmerfamilien gehaltenen Aktien der Zaibatsu zunächst vom Staat übernommen wurden. Danach wurden diese Aktien nur den nicht zu den Eigentümerfamilien gehörenden Bevölkerungsgruppen zum Kauf angeboten. Die ehemaligen Unternehmerfamilien der Zaibatsus schafften es danach niemals wieder, die Mehrheitsanteile an ihren Unternehmen zurückzugewinnen, was die Auflösung des japanischen Zaibatsusystems bedeutete.

${ }^{26}$ Eun-Mee Kim, The Industrial Organisation and Growth of the Korean Chaebol: Integrating Development and Organizational Theories, in: Gary G. Hamiliton (Ed.), Asian Business Networks, Berlin/New York 1996, S. 231-251.
} 
Es steht außer Frage, daß die drei genannten Fachdisziplinen einen wichtigen Beitrag zur Erweckung der wissenschaftlichen Neugier an der koreanischen Entwicklung der Chaebol geleistet haben. Doch wie sehr die einzelnen Vertreter dieser Disziplinen auch von der Plausibilität ihrer Argumente überzeugt sein mögen, bin ich doch der Auffassung, daß die bisherige Herangehensweise an die Chaebol zu sehr von der unkritischen Übernahme des westlichen Entwicklungsmodells des Kapitalismus beeinflußt worden ist. Mit anderen Worten: Ich habe den Eindruck, daß die Forscher, seien es Ökonomen, Betriebswirte oder Soziologen, ungeachtet ihres unterschiedlichen Fachhintergrundes von der Annahme ausgehen, daß die koreanische Entwicklung der Chaebol im Rahmen der bisherigen westlichen ökonomischen Theorien und Begriffe ausreichend zu erklären ist. Ich bestreite nicht, daß die westlichen Theorien und Begriffe auf einer sehr elaborierten Forschungsmethode beruhen und deswegen einen weiten Gültigkeitsbereich beanspruchen können. Doch bedeutet dies nicht, daß ihre Anwendung auf andere Gesellschaften unproblematisch ist.

Die Gefahr der unkritischen Anwendung westlicher Theorien oder Begriffe bei der Charakterisierung der koreanischen Chaebol besteht vor allem darin, daß die wissenschaftliche Analyse des einheimischen Forschungsgegenstandes nicht über das Niveau von normativen Aussagen hinausgelangt. Konkreter gesagt: Man kann die koreanische Entwicklung der Chaebol in Anlehnung an die westlichen Begriffe wie "Großunternehmen" oder "Klasse" oder an den japanischen Begriff des "Zaibatsu" positiv oder negativ beurteilen und dementsprechend entweder für die Förderung oder für die Verhinderung dieser ökonomischen Institution sprechen. Aber damit ist nicht geklärt, was meine grundsätzliche Frage an die bisherige Forschungspraxis ist, nämlich: Beruht die bisherige wissenschaftliche Analyse der koreanischen Chaebol überhaupt auf einer realitätsadäquaten Erkenntnis des Untersuchungsgegenstandes? Wo muß man als Forscher anfangen, wenn man sich mit den Chaebol als Forschungsgegenstand ohne gedankliche Voreingenommenheit und ohne eine feste, auf der spezifischen westlichen Entwicklungsform des Kapitalismus beruhenden Vorstellung beschäftigen will? Meines Erachtens hängt dieses methodologische Dilemma der bisherigen Forschung zu den 
koreanischen Chaebol eng damit zusammen, daß nicht klar ist, welche Ziele eine wissenschaftliche Auseinandersetzung mit den Chaebol überhaupt verfolgt.

\section{II.3 Forschungsziel}

Wie entstanden die Chaebol in Korea? Diese für meine Dissertation zentrale Frage könnte fälschlicherweise den Eindruck erwecken, als ob hier eine historisch-genealogische Untersuchung geplant sei. Doch, auch wenn der historische Entwicklungsprozeß der koreanischen Unternehmen in der hier vorliegenden Arbeit einen vergleichsweise großen Raum einnimmt, handelt es sich dennoch um einen genuin soziologischen Versuch, der darauf abzielt, den landesspezifischen Charakter der ökonomischen Institutionen aus der spezifisch koreanischen Egentümlichkeit des ökonomischen Handelns abzuleiten. Die Darstellung der Entwicklungsgeschichte der koreanischen Chaebol dient also dazu, die Eigentümlichkeit der koreanischen Chaebol im Zusammenhang mit der gesellschaftlichen Bedingtheit des ökonomischen Handelns zu verdeutlichen. Auf diese Weise läßt sich die Erfolgsgeschichte der koreanischen Chaebol nicht durch den ökonomischen Output (z. B. die Wachstumsrate), sondern in ihrer gesamtgesellschaftlichen Bedeutung neu beleuchten.

Um den Hintergrund dieser soziologischen Herangehensweise an die koreanische Entwicklungsgeschichte der Chaebol verständlich zu machen, möchte ich hier kurz meine bisherigen Eindrücke bei der Lektüre der entsprechenden Koreaforschungen wiedergeben:

Mein erster Eindruck ist, daß es manchem westlichen Wissenschaftler nicht bekannt ist, daß die Gründerväter der koreanischen Chaebol trotz ihrer Bewunderung für deren ökonomischen Erfolge ein sehr distanziertes Verhältnis zu den westlichen Wissenschaftlern (vor allem zu den Ökonomen) hatten. So leitet Joo-Young Cheong, der Gründervater von Hyundai, seine koreanisch geschriebenen Autobiographie nicht ohne Grund mit der Behauptung ein, daß sein ökonomischer Erfolg in der Automobilbranche, im Schiffsbau etc. in Korea nicht denkbar gewesen wäre, wenn er die damalige Ansicht zeitgenössischer Wirtschaftswissenschaftler 
geteilt hätte. In seinen Worten gesagt: "Aus der Sicht der orthodoxen ökonomischen Lehre gesehen, gab es in der koreanischen Ökonomie gar nichts, was man noch tun könnte. Alles war insofern von vorneherein zum Mißerfolg verurteilt, als das Land nicht nur Mangel an Ressourcen, sondern vor allem an Kapital sowie an Technologie zu leiden hatte." ${ }^{27}$

Obwohl es unbestreitbar ist, daß Cheong durch diese herablassende Bemerkung über die zeitgenössische Wirtschaftswissenschaft bei seinen koreanischen Lesern einen besseren Eindruck von seiner eigenen unternehmerischen Leistung erwecken wollte, bin ich doch der Auffassung, daß er durch seine Zweifel an der traditionellen ökonomischen Lehre unbewußt eine zentrale Schwachstelle der bisherigen Chaebol-Forschung getroffen hat. Denn Cheong, der offenbar ein anderes Verständnis des ökonomischen Handelns hatte als die Wirtschaftswissenschaftler, hatte trotz der Warnung vieler Ökonomen und anderer rational denkender zeitgenössischer Intellektueller (vor allem der Journalisten) großen Erfolg, und angesichts dieses Erfolgs, muß man sich fragen, wieso sich das ökonomische Handeln Cheongs in den Denkfiguren der Wirtschaftswissenschaftler nicht wiederfinden läßt. Ich vermute, daß sich dies dadurch erklären läßt, daß die Wirtschaftswissenschaft sich mit einem abstrakt bzw. idealtypischen Verständnis des ökonomischen Handelns befaßt, während der reale Unternehmer von einem durch die verschiedenen und vielschichtigen gesellschaftlichen Faktoren bedingten, komplexen Verständnis des ökonomischen Handelns ausgeht.

Mein zweiter Eindruck betrifft zwei unterschiedliche Annahmen zur Genese der koreanischen Chaebol. Bei der ersten handelt es sich um die sogenannte Nachahmungsthese, die besonders von Historikern und Soziologen vertreten wird. ${ }^{28}$

${ }^{27}$ Joo-Young Cheong, Sireonen Issedo Silpae nun Eopda (Es gibt zwar Schwierigkeiten, aber keinen Mißerfolg), Seoul 1991, S. 4.

${ }^{28} \mathrm{Zu}$ den Befürwortern dieser Nachahmungsthese gehören zum einen viele Soziologen, zum anderen viele ausländische, vor allem die japanischen Historiker, während die meisten koreanischen Historiker diese Sichtweise ablehnen, weil sie die These vertreten, daß die koreanische Ökonomie während der japanischen Kolonialzeit nur von Japanern und für Japaner bestimmt gewesen sei. Die Koreaner hätten gar nicht die Möglichkeit gehabt, die komplexe Organisationsstruktur und den Funktionsmechanismus der Zaibatsu zu durchschauen und dann nachzuahmen. Diese These wird jedoch bestritten von: Dennis L. McNamara, The Colonial Origins of Korean Enterprise 19101945, New York 1990; und ebenso von: Carter J. Eckert, Offspring of Empire: The Kochang Kims and the Colonial Origins of Korean Capitalism 1876-1945, Seattle/London 1991. 
Sie beruht auf der Annahme, daß die ökonomische Organisationsform in sogenannten spätentwickelten Ländern immer durch Nachahmung des Organisationsmodells der entwickelten Industrieländer entsteht. Ein charakteristisches Beispiel dafür ist die Vorstellung, daß die Koreaner aufgrund der langjährigen japanischen Kolonialherrschaft über die besten Möglichkeiten zur Nachahmung der japanischen unternehmerischen Organisationsform verfügten. Bei der zweiten Annahme handelt es sich um den Versuch, die Chaebol in Korea in Anlehnung an die westliche Entwicklung des Unternehmens zu verstehen, wobei die Chaebol als Familienunternehmen als mehr oder weniger historisch unvermeidbare Vorstufe des modernen Großunternehmens aufgefaßt werden. ${ }^{29}$ Diese Annahme findet sich am häufigsten bei Ökonomen und Betriebswirten, weil sie mit dem Vorbild des westlichen Unternehmens vor Augen genau sagen können, in welche Richtung sich die Organisationsstruktur der koreanischen Chaebol entwickeln sollte. ${ }^{30}$

Doch wie plausibel und sinnvoll diese beiden Annahmen über die koreanischen Chaebol auch erscheinen mögen, mein Unbehagen daran rührt daher, daß es sich hier um eine soziologisch unreflektierte Voreingenommenheit von der ökonomischen Organisation bzw. vom Unternehmen handelt. Ich bestreite nicht, daß sich jeder Unternehmer bewußt und oder unbewußt bemüht, seinen unternehmerischen Erfolg durch geschickte Organisation der vorhandenen ökonomischen Ressourcen zu optimieren, aber ich halte es für unwahrscheinlich, daß allein diese Motivation die Entscheidungen des Unternehmers für eine bestimmte ökonomische Organisationsform bestimmt. Zugespitzt formuliert: Es ist eine Illusion des rational denkenden Wissenschaftlers zu glauben, daß Unternehmer am besten von der ökonomischen Entwicklung der frühindustrialisierten Länder lernen, wie man eine unternehmerische Organisation entwickelt.

\footnotetext{
${ }^{29}$ Mit der Veröffentlichung der Studie von Michael Piore und Charles F. Sabel, Das Ende der Massenproduktion, Berlin 1985, änderte sich das Bild des Familienunternehmens als traditioneller Unternehmenstyp radikal. Denn die beiden Verfasser konnten durch eine soziologische Analyse der realen Verlaufsform der Weltwirtschaft zeigen, daß Familienunternehmen sich trotz der herrschenden Massenproduktionsstrategie in Marktnischen erfolgreich halten konnten. Dabei galt das Familienunternehmen als Symbol für Flexibilität und Spezialisierung.

${ }^{30}$ Dong-Sung Cho, Hanguk Chaebol (Die Organisation der Chaebol), Seoul 1997, S. 273-276; Yu-Kun Shin, Hanguk eui Keong-Yeong (Das Management in Korea), Seoul 1993, S. 770 f.; Jeong-Pyo Choi, Sunjinhwa rul wihan Chaebol eui Seontak (Die Modernisierungsstrategie der koreanischen Chaebol), Seoul 1996, S. $178 \mathrm{ff}$.
} 
Meines Erachtens besteht die Komplexität der wirtschaftlichen Organisation bzw. des Unternehmens darin, daß sie je nach dem länderspezifischen Verständnis des ökonomischen Handelns sehr unterschiedlich ausgelegt und umgesetzt werden kann. Selbst wenn manche koreanische Sozialwissenschaftler erfolgreiches ökonomisches Handeln immer im Rückgriff auf die westliche Unternehmensgeschichte zu definieren versuchen, bin ich der Auffassung, daß das koreanische Verständnis des ökonomischen Handelns aufgrund der unterschiedlichen gesellschaftlichen Entwicklungslogik keineswegs mit dem der westlichen Länder identisch ist.

Aus den verschiedenen genannten Gründen halte ich eine kulturkritische Analyse der koreaspezifischen Auffassung vom ökonomischen Handeln für eine realitätsadäquate Charakterisierung der koreanischen Chaebol für unerläßlich. Dementsprechend handelt es sich bei meiner Dissertation um den Versuch, das herkömmliche Bild der koreanischen Chaebol aufgrund einer soziologischen Analyse der Entstehungsgeschichte der Chaebol zu modifizieren und auf diese Weise zu einem besseren Verständnis für die gesellschaftlichen Zusammenhänge bei der Entwicklung der koreanischen Chaebol zu kommen.

\section{II.4 Das soziologische Verständnis des ökonomischen Handelns}

Bei dem japanischen Zaibatsu und dem koreanischen Chaebol handelt es sich um den gleichen Unternehmenstyp, wobei die unternehmerische Organisationsstruktur trotz des hohen Anteils an der gesamtwirtschaftlichen Entwicklung nicht über das Niveau eines kleinen Familienunternehmens hinauszugehen scheint. Doch im Unterschied zu Japan, das auf eine lange Zaibatsu-Tradition zurückblicken kann (die auch durch die Zerschlagung der Zaibatsus durch die amerikanische Besatzungsmacht nicht vollständig zum Erliegen kam, da die neu entstandenen Unternehmensgruppen trotz des fehlenden Familien-Eigentümers auf der horizontalen Ebene sehr eng zusammenarbeiten ${ }^{31}$ ), tauchte in Korea das Wort

\footnotetext{
${ }^{31}$ Näheres über die japanischen Zaibatsu findet man in: Johanne Hirschmeier, The Origins of Entrepreneurship in Meiji Japan, Cambridge u. a. 1964. Vgl. auch Anm. 25.
} 
„Chaebol“ erst seit Mitte der 60er Jahre auf. Bis zu diesem Zeitpunkt hatte sich in Korea kein Unternehmen entwickelt, das man mit dem japanischen Zaibatsu vergleichen könnte. Zwar gab es Unternehmen, die sich an einem kleinen einheimischen Markt orientierten, aber die stellten hauptsächlich Lebensmittel wie Zucker, Mehl, Zahnpasta und chemische Düngemittel her, wobei die Rohstoffe aus dem Ausland importiert werden mußten. Als sich Mitte der 60er Jahre das Regime unter Präsident Park zu einer rapiden ökonomischen Modernisierung bzw. staatlich geleiteten Industrialisierung entschloß, wurden die neuen industriekapitalistischen Unternehmen immer häufiger als Chaebol bezeichnet. Die neuen Industriekapitalisten, in die sich die ehemaligen Kleinunternehmer plötzlich verwandelt hatten, unterschieden sich vom früheren Typus des Unternehmers dadurch, daß ihr Betätigungsfeld von der herkömmlichen kleinen binnenmarktorientierten Importsubstitutionsindustrie auf exportorientierte Massenproduktionsbereiche wie Autos und Elektronik verlegt worden war. Aber diese Verlegung bedeutete keineswegs eine Trennung von alten unternehmerischen Tätigkeiten, sondern führte nur zu einer Expansion der Unternehmen.

Angesichts dieser Tatsache könnte man durchaus meinen, daß die Ursprünge der koreanischen Chaebol erst Mitte der 60er Jahre zu finden sind. Ich gehe jedoch von der Annahme aus, daß eine soziologische Analyse der Entstehungsgeschichte der Chaebol viel früher ansetzen muß. Der Grund dafür hängt eng mit meiner soziologischen Auffassung von der Wechselwirkung zwischen institutioneller Entwicklung und menschlichem Handeln zusammen, wobei das logische Verhältnis dieser beiden Faktoren nicht monokausal zu sehen ist. Um diese Überlegung zu verdeutlichen, setze ich mich im folgenden mit den berühmten religionssoziologischen Studien von Max Weber auseinander:

Max Weber hat in seiner berühmten Arbeit „Die protestantische Ethik und der "Geist" des Kapitalismus" und in seinen religionssoziologischen Abhandlungen versucht, den Zusammenhang zwischen den verschiedenen Weltkulturen bzw. religiösen Weltanschauungen und der Entwicklung des Kapitalismus aufzuzeigen. ${ }^{32}$ Er gelangte zu der Schlußfolgerung, daß die kapitalistische Entwicklung insofern 
kein rein ökonomisches Phänomen sei, als der für die Entwicklung des Kapitalismus konstitutive, an reiner "Zweck-Rationalität" orientierte ökonomische Handlungstypus nur in bestimmten kulturellen Räumen (vor allem in protestantischen Regionen) zu finden sei. Die konfuzianische Weltanschauung hielt er dagegen für die Entwicklung des Kapitalismus für eher hinderlich, was angesichts der rapiden ökonomische Entwicklung der letzten Jahrzehnte in den sogenannten ostasiatischen Ländern zumindest hinterfragt werden muß. ${ }^{33}$

Zwar ist es sicher richtig, daß die erste Generation der westlichen Unternehmer neben den allgemein günstigen gesellschaftlichen Entwicklungen (z.B. die Herausbildung des Rechtsstaates sowie der naturwissenschaftliche Fortschritt etc.) über besondere subjektive „Eigenschaften“ verfügte, die als "protestantische Ethik" dem kapitalistischen ökonomischen Handeln besonders förderlich waren. Aber man kann hieraus nicht eo ipso ableiten, daß ökonomisches Handeln in der kapitalistischen Gesellschaftsordnung außerhalb dieser Motivlage nicht existieren kann. Kurz gesagt: Es ist zumindest voreilig, aus der westlichen Besonderheit des ökonomischen Handelns ein allgemeingültiges Bild des kapitalistischen ökonomischen Handelns ableiten zu wollen. Mir scheint es dagegen unerläßlich zu sein, die kulturbedingte Andersartigkeit des menschlichen Handelns in den asiatischen Ländern für die soziologische Analyse des ökonomischen Handelns angemessen zu berücksichtigen und in diesem Punkt auch über die Weberschen Ergebnisse hinauszugehen, um die realgesellschaftlichen Zusammenhänge bei der Herausbildung des Kapitalismus in diesen Ländern adäquat beschreiben zu können.

Die Webersche Analyse des ökonomischen Handelns ist aber ungeachtet seines Verdikts gegen den Konfuzianismus insofern auch für die hier vorliegende Ar-

\footnotetext{
${ }^{32}$ Max Weber, Die protestantische Ethik und der "Geist" des Kapitalismus, in: Archiv für Sozialwissenschaft und Sozialpolitik, Bd. 20, Tübingen 1905; Ders., Gesammelte Aufsätze zur Religionssoziologie, 3 Bde, Tübingen 1920/21.

${ }^{33}$ Der amerikanische Soziologe Mark Granovetter gehört zu den westlichen Soziologen, die die gegenwärtige ökonomische Entwicklung in den ostasiatischen Ländern nicht als einen Widerspruch zur Weberschen Auffassung des ökonomischen Handelns verstehen, sondern versuchen, diese Entwicklung zur Grundlage einer Erweiterung der Weberschen Auffassung vom ökonomischen Handeln zu machen. In diesem Zusammenhang kritisiert er die amerikanische Rezeption Webers, die durch Talcott Parsons stark beeinflußt wurde. Vgl. dazu Mark Granovetter, Entrepreneurship, Development and the Emergence of Firms, Discussion Paper, Wissenschaftszentrum Berlin für Sozialforschung 1990.
} 
beit konstitutiv, als er das ökonomische Handeln aus der Perspektive des subjektiv handelnden Akteurs verstanden und erklärt hat. Dadurch unterscheidet er sich von Wirtschaftswissenschaftlern, die ökonomisches Handeln ausschließlich oder doch in erster Linie im Rückgriff auf die Logik des Marktes oder bestimmte gesellschaftliche institutionelle Rahmenbedingungen (vor allem die Rolle des starken Staates) verstehen. Meines Erachtens erweist sich die Nützlichkeit der Weberschen Perspektive vor allem darin, daß der Wirkungszusammenhang des ökonomischen Handelns durch den von inm gesetzten Fokus auf dessen subjektive Bedingungsfaktoren, die durch länderspezifische kulturelle und historische Erfahrung bestimmt sind, genauer und vor allem konkreter erfaßt werden kann als dies durch eine rein ökonomische Sichtweise möglich wäre. Mit anderen Worten: Es handelt sich um eine wesentliche, meines Erachtens sogar unabdingbare, Horizonterweiterung, wenn man wie Weber auch die scheinbar nicht ökonomisch relevanten, für das länderspezifische Verständnis des ökonomischen Handelns aber zentral wichtigen gesellschaftlichen Faktoren in die Analyse mit einbezieht.

Dennoch kann man nicht außer acht lassen, daß die Anwendung der soziologischen Einsichten von Weber für die Analyse von nicht-westlichen Gesellschaften keineswegs so problemlos ist wie für westliche Gesellschaften, da in den nichtwestlichen Ländern ein korrespondierendes Verhältnis von ökonomischer Motivation und realer ökonomischer Handlungsweise sehr schwer nachzuweisen ist. Wie Mark Granovetter richtig beobachtet hat, fällt auf, daß das ökonomische Handeln in den südostasiatischen Ländern weniger von der unmittelbaren ökonomischen Zielsetzung als vielmehr von der Logik der sozialen Beziehungen geprägt ist. ${ }^{34}$ Während die bisherige an Modernisierungstheorien orientierte Analyse des ökonomischen Handelns solche Merkmale des ökonomischen Handelns in der Regel als "Culture-Gap" oder "Übergangsphänomene" von der traditionellen Gesellschaft zur modernen interpretiert, neige ich eher zu der Auffassung, dieses Phänomen nicht so linear oder evolutionistisch aufzufassen. Dabei gehe ich von der Grundannahme aus, daß es sich hier um einen sehr komplexen gesellschaftlichen Wandlungsprozeß handelt, wozu sich kein Äquivalent in der bisherigen Geschichte der westlichen Gesellschaften finden läßt. Während sich das westliche Verständnis

\footnotetext{
${ }^{34}$ Ebenda.
} 
vom ökonomischen Handeln historisch mehr oder weniger als ein stetiger, langsam voranschreitender Prozeß entwickelte, stand am Beginn des kapitalistischen Zeitalters in Korea ein sehr komplexer, aber sich sehr rasch vollziehender Umbruch, wobei die koreanische Bevölkerung angesichts der plötzlichen Öffnung des Landes die gesellschaftliche Bedeutung von ökonomischen Handeln völlig "neu" definieren mußte.

Diese Definition bzw. Neukonzipierung dessen, was ökonomisches Handeln künftig sein sollte, ist ohne die Auseinandersetzung mit der vorhandenen traditionellen Kultur und der bestehenden institutionellen Ordnung der Yi-Dynastie nicht denkbar. Daher halte ich es für unwahrscheinlich, daß das neue Verständnis des ökonomischen Handelns, das später die Institutionalisierung der Chaebol als koreaspezifische Form der Unternehmensorganisation hervorbrachte, aus dem „Nichts“ oder als blinde Nachahmung des westlich geprägten Typus des ökonomischen Handelns entstehen konnte. Es ist eher zu vermuten, daß der Prozeß der Aneignung einer neuen Auffassung vom ökonomischen Handeln durch das handelnde Subjekt, den Unternehmer, in einer engen Wechselbeziehung zu dem strukturellen und kulturellen Wandlungsprozeß der koreanischen Gesellschaft insgesamt steht. Deshalb bin ich der Auffassung, daß es eine wichtige Ergänzung zu den bisherigen soziologischen Analysen des ökonomischen Handels ist, das sich neu herausbildende Verständnis des ökonomischen Handelns in Korea im Kontext des gesamtgesellschaftlichen Transformationsprozesses zu beleuchten. 


\section{II.5 Der Unternehmer als Akteur des ökonomischen Handelns: ein zu wenig beachteter Aspekt der soziologischen Forschung}

In ihrem 1994 erschienenen Aufsatz "The Sociological Perspective on the Economy", der eine sehr gute Einführung in die Wirtschaftssoziologie darstellt, ${ }^{35}$ versuchen die beiden Autoren N. J. Smelser und R. Swedberg, der Auseinandersetzung zwischen Ökonomen und Soziologen über den Wandlungsprozeß der ökonomischen Institutionen bzw. Unternehmen die Spitze zu nehmen:

"The 'imperialistic' mode, whether in its sociological form or in its economic form, seems unpromising as a way of dealing with either economic behaviour or economic institutions (or for that matter, behaviour and institutions general). The complexity of determinants bearing on every kind of behaviour suggests the greater scientific utility of approaches that are less monolithic. It is true that 'imperialistic' works have greatly stimulated this debate around economy and society. Eventually, however, this approach becomes counterproductive scientifically, tending to excite territorial battles rather than dispassionate inquiry." (Smelser/Swedberg, 1994, S. 20)

Vereinfacht und typisierend gesagt, vertreten Ökonomen und Soziologen zwei unterschiedliche Auffassungen vom ökonomisch Handelnden: Während Ökonomen dazu neigen, den Akteur als eine "frei" und "rational" entscheidende Person zu verstehen, ist es aus soziologischer Sicht undenkbar, daß dieser Akteur als Mitglied der Gesellschaft ungeachtet der verschiedenen gesellschaftlichen Zwänge "frei" und "rational" entscheiden kann. Ökonomen plädieren also eher für einen "methodischen Individualismus", in dem der ökonomische Kontext aus der Perspektive des einzelnen Individuums erklärt wird, während Soziologen ökonomisches Handeln nur unter Berücksichtigung der nicht individuell steuerbaren verschiedenen gesellschaftlichen Kräfte für realitätsadäquat beschreibbar halten, sie betonten also gegenüber den Ökonomen sehr viel stärker den gesellschaftlichen Zwang. Smelser und Swedberg fordern nun dazu auf, die Differenz zwischen den beiden wissenschaftlichen Disziplinen nicht zuzuspitzen, sondern zu synthetisieren, wie dies beispielsweise die Klassiker der Soziologie Max Weber und Talcott Parsons getan haben.

${ }^{35}$ Der Aufsatz findet sich in: The Handbook of Economic Sociology (ed. by N. J. Smelser/R. Swedberg), Princeton/New York 1994, S. 3-26. 
Wenn man bedenkt, daß keine Prämisse in beiden Wissenschaften in empirischer Hinsicht sich eindeutig als wahr oder falsch erweisen läßt, dann erscheint eine solche Forderung nach wissenschaftlicher Synthetisierung sehr angebracht. Mir persönlich kommt es vor allem darauf an, die von ökonomischer Seite in die Diskussion eingebrachte wichtige Perspektive, nach der dem Akteur Wahlmöglichkeiten bei der Definition bzw. Auslegung der gegebenen Handlungssituation zugesprochen werden, auch in die soziologische Analyse mit einzubringen. Ich halte diese Fragestellung deswegen für wichtig, weil sich speziell für die Erklärung des ökonomischen Entwicklungsprozesses in den sogenannten nicht-westlichen Gesellschaften wie Korea der "gesellschaftliche Zwang" als nicht sehr tragfähig erweist. Meine These, die ich in Anlehnung an die westliche soziologische Lehre begründen will, lautet wie folgt: Es ist nur ein halber soziologischer Beitrag, wenn das ökonomische Handeln nur im Rückgriff auf das gesellschaftliche Umfeld erklärt wird. Dieses Erklärungsmodell kann nicht begreiflich machen, warum Menschen trotz gleicher gesellschaftlicher Rahmenbedingungen unterschiedliche Peaktionen bzw. Handlungsstrategien entwickeln.

Nun kann man fragen, ob sich die Vertreter der westlichen Soziologie tatsächlich nicht für die Erforschung der subjektiven Seite des menschlichen Handelns interessiert haben, wie dies Smelser und Swedberg implizit behaupten. ${ }^{36}$ Obwohl es auffällig ist, daß sich die Soziologie nicht nur in Deutschland kaum mit dem unternehmerischen Handeln beschäftigt hat, bin ich doch der Auffassung, daß sich aus den Texten der westlichen Soziologen wichtige Anregungen für eine Analyse des Unternehmers gewinnen lassen. Zwar ist nicht von der Hand zu weisen, daß die dort zu findenden Definitionen und Betrachtungsweisen stark durch die westliche Erfahrung des Kapitalismus geprägt sind, aber dennoch erwies sich die Art und Weise, wie dort der Begriff des Unternehmers konstituiert wird, für meine Erörterung des länderspezifischen Charakters des koreanischen Unternehmers bzw. des Unternehmertums als sehr nützlich, auch wenn ihre Übertragbarkeit auf die ko-

\footnotetext{
${ }^{36}$ Speziell über Max Weber schreiben Smelser und Swedberg jedoch differenzierend: "Sociology lacks one dominating tradition. Various sociological approaches and schools differ form and compete with one another, and this circumstance has affected economic sociology. For example, Weber was skeptical about the notion of a social "system," whether applied to economy or society, while Parsons viewed society as a system and economy as one of its subsystems." (Smelser/Swedberg, 1994, S. 4).
} 
reanischen Verhältnisse im einzelnen zu prüfen sein wird. Im folgenden werde ich mich mit den Positionen von Max Weber, Joseph Schumpeter, Mark Granovetter und Johannes Berger auseinandersetzen, die alle für die hier vorliegende Arbeit von Bedeutung sind:

Max Weber: Wenn Max Weber vom ökonomischen Akteur des Kapitalismus spricht, dann meint er damit nicht nur Unternehmer, sondern auch Arbeiter. Entsprechend verwandte Weber für die Charakterisierung des ökonomischen Akteurs eher die Bezeichnung des "Berufsmenschen" als die des „Unternehmers" oder "Arbeiters“. Dennoch findet sich auch bei inm eine Definition des Unternehmers als einem aus Profitinteresse sowohl um asketische Lebensführung als auch um Rationalisierung des ökonomischen Prozesses bemühten „Berufsmenschen“:

"Der 'Idealtypus' des kapitalistischen Unternehmers scheut [...] den unnötigen Aufwand ebenso wie den bewußten Genuß seiner Macht und die inm eher unbequeme Entgegennahmen von äußeren Zeichen der gesellschaftlichen Achtung, die er genießt. Seine Lebensführung trägt $\mathrm{m}$. a. W. oft [...] einen gewissen asketischen Zug an sich. [...] Er 'hat nichts' vor seinem Reichtum für seine Person, - außer: der irrationalen Empfindung guter 'Berufserfüllung'." (Weber, 1905, S. 31)

Die Frage, die Weber leitete, war bekanntlich, herauszufinden, wodurch sich der Unternehmer einen solchen asketischen und rationalen Habitus oder auch "kapitalistischen Geist" aneignen konnte. Für inn lag die Antwort in der protestantischen Religion, deren „Ethik“ in säkularisierter Form weitreichende gesellschaftliche Auswirkungen hatte. Der oben zitierte Unternehmertypus ist dementsprechend als das Resultat eines tiefgreifenden religiösen Wandlungsprozesses in den europäischen Ländern zu betrachten. Fragt man danach, worin die Webersche genuin soziologische Analyse des Unternehmers zu sehen sei, dann lautet die Antwort: Weber hat versucht, den ökonomischen Habitus des Unternehmers nicht aus seiner unmittelbaren ökonomischen Motivation wie beispielsweise Profitinteresse, sondern als Ergebnis eines nicht-öko-nomischen, gesellschaftlichen Wandlungsprozesses zu erklären. 
Joseph Schumpeter: 1911 veröffentlichte der österreichische Ökonom Schumpeter seine "Theorie der wirtschaftlichen Entwicklung", in der er sich auch mit der Charakterisierung des Unternehmers beschäftigte. Nach Schumpeter zeichnet einen Unternehmer nicht so sehr das Profitinteresse aus, sondern die Fähigkeit, vorhandene gesellschaftliche Ressourcen neu zu kombinieren und diese neue Kombination in der Produktion durchzusetzen. ${ }^{37}$ Seine Hervorhebung der Fähigkeit zur neuen Kombination als genuin unternehmerische Funktion verdeutlichte vor allem die fortschrittsorientierte Triebkraft des Kapitalismus. Obwohl bekannt ist, daß Schumpeter von Max Weber intellektuell stark beeinflußt wurde, bin ich der Auffassung, daß sich das Schumpetersche Konzept von der Rolle des Unternehmers von der Webersche Auffassung deutlich unterscheidet.

Zunächst fältt auf, daß Schumpeter unter „Unternehmer“ jemanden versteht, der sich nicht mit der gewohnten traditionellen ökonomischen Handlungsweise begnügt, sondern einen neuen Typus des ökonomischen Handelns schafft. Schumpeter kritisiert daher, daß die Bezeichnung "Unternehmer" willkürlicherweise auf alle Typen von ökonomischen Akteuren angewendet wird, wie dies Max Weber getan hatte. Zwar erwähnt Schumpeter Max Weber nicht ausdrücklich, aber er schreibt wie folgt:

"Unter unseren Begriff [des Unternehmers - I.R.] fallen nicht alle selbständigen, für eigene Rechnung handelnden Wirtschaftssubjekte, wie das üblich ist. Eigentum am Betrieb - oder überhaupt irgendwelches "Vermögen" - ist für uns kein wesentliches Merkmal: aber auch abgesehen davon schließt Selbständigkeit in diesem Sinne nicht schon von selbst die Erfüllung der für unseren Begriff konstitutiven Funktion ein. Nicht nur Bauern, Handwerker, Angehörige freier Berufe - die man mitunter einschließt -, sondern auch "Fabrikherren" oder "Industrielle", oder "Kaufleute" - die man immer einschließt - brauchen nicht notwendig "Unternehmer" zu sein." (Schumpeter, 1926, S. 111 f.)

Im Gegensatz dazu spielt bei Max Weber das Kriterium des Kapitals bzw. Vermögens für die Definition des Unternehmers insofern eine zentrale Rolle, als die Sammlung des Kapitals durch das asketische Lebensführungsprinzip ermöglicht wird.

${ }^{37}$ Joseph Schumpeter, Theorie der wirtschaftlichen Entwicklung, München/Leipzig 1926, S. 110. 
Obwohl Schumpeter von der Weberschen Forderung nach einer "Synthetisierung von Wirtschaftswissenschaft und Soziologie" beeindruckt gewesen mag, kann man sagen, daß seine Theorie des "Unternehmers" bzw. "Unternehmertums" auf einem ökonomiespezifischen Menschenbild beruhte. ${ }^{38} \mathrm{Er}$ lehnte nämlich die soziologische Annahme strikt ab, daß der Mensch als Gefangener des gesellschaftlichen Systems anzusehen ist und sich allein aus Interesse an Profit für das ökonomische Handeln interessiert. Denn der Unternehmer ist nach Schumpeter imstande, im Gegensatz zu der traditionell lebenden Mehrheit der Bevölkerung von den gegebenen gesellschaftlichen Denkgewohnheiten abzuweichen und die gesellschaftlichen ökonomischen Ressourcen "neu" zu kombinieren. Der Unternehmer handelt also nicht durch Anpassung an die gesellschaftliche Norm, sondern auf eigene Initiative auch gegen diese Norm oder diese überschreitend. Damit ist nach Schumpeter für den geradezu "heldenhaft" charakterisierten Unternehmer eine gewisse gesellschaftliche Isolation wegen seines von der Tradition abweichenden Verhalten und auch Angst wegen der ungewissen Folgen seiner innovativen ökonomischen Handlungsweise verbunden. ${ }^{39}$

Durch die einseitige Betonung der subjektiven "Fähigkeiten" und des "Blicks" des einzelnen Akteurs klingt die Schumpetersche Auffassung vom Unternehmer sehr asoziologisch. Sein methodologisches Dilemma beginnt damit, daß seine Charakterisierung des "innovativen" unternehmerischen Handelns nur in bezug auf die Mobilisierung des Produktionsmittels eingeschränkt wird. Konkreter gesagt: Seine berühmte Typologisierung des innovativen unternehmerischen Handelns beruht nicht auf der tatsächlichen Analyse der Art und Weise, wie der Unternehmer sich mit der traditionellen Lebenswelt auseinandersetzt bzw. deren Elemente "neu" kombiniert, sondern auf leicht schematisierbaren konkreten ökonomischen Vorgängen wie der Einführung neuer Produkte, neuer Produktionsmethoden, der Erschließung neuer Märkte, der Gewinnung neuer Lieferanten und letztlich der neuen Monopolisierungsmethode. ${ }^{40}$ Dies bedeutet, daß Schumpeter nur die Resultate des innovativen unternehmerischen Handelns, nicht aber deren Zustandekommen

\footnotetext{
${ }^{38}$ Vgl. Richard Swedberg, Schumpeter: A Biography, Princeton/New York 1911, S. 2.

${ }^{39}$ Joseph Schumpeter, Theorie der wirtschaftlichen Entwicklung, München/Leipzig 1926, S. 124.

${ }^{40}$ Vgl. Richard Swedberg, Schumpeter: A Biography, Princeton/New York 1911, S. 34.
} 
beschreibt. Insofern läßt Schumpeter trotz seines wichtigen Hinweises auf die unternehmergenuine Rolle im ökonomischen Handeln die Frage völlig im Dunkeln, woher und auf welcher Weise der Unternehmer aus der traditionellen Lebensform oder ökonomischen Denkweise heraustritt. Mit anderen Worten: Bei Schumpeter fehlt der Versuch, seine genuin soziologische Einsicht über die Person des Unternehmers als wichtigen Bestandteil des ökonomischen Entwicklungsprozesses am konkreten biographischen Beispiel des einzelnen Unternehmers zu belegen.

Swedberg weist allerdings darauf hin, daß Schumpeter in seinem späteren Leben die Bedeutung der biographischen Analyse des Unternehmers durchaus erkannt hat. Swedberg schreibt dazu:

"Economic historians, he specified, could for one thing help the economist better to understand the institutional forms of entrepreneurship. With the help of economic history one could also get a better view of entrepreneurship in the different fields of the economy, such as finance, commerce and industry. Historical data could be useful in mapping out the different types of entrepreneurs. Finally, Schumpeter was very enthusiastic about the potential use of industrial monographs and biographies of industrial leaders in research on entrepreneurship. This type of study was invaluable to the economic theorist, he said, especially if it had been carried out according to some general plan." (Swedberg, 1991, S. 175)

Mark Granovetter: Unter den zeitgenössischen Soziologen ist Mark Granovetter nicht nur ein Repräsentant der sogenannten "EmbeddednessTheorie", sondern auch der einzige, der sich mit der Rolle des Unternehmers bei der Herausbildung des Unternehmens bzw. der "Firmen" auseinandergesetzt hat. 1985 veröffentlichte er einen Aufsatz "Economic Action and Social Structure: The Problem of Embeddedness" im American Journal of Sociology, in dem er versuchte, die "Transaktionskosten-Theorie" der "New Institutional Economics" mit Hilfe einer genuin soziologischen Sichtweise des ökonomischen Handelns zu entkräften. ${ }^{41}$ In Anlehnung an verschiedene soziologische und anthropologische Forschungsarbeiten wirft er Williamson vor, daß dieser die Einbettung der nicht-ökonomischen Institutionen in das ökonomische Handeln zu sehr durch die Logik der Effizienz erklären

\footnotetext{
${ }^{41}$ Mark Granovetter, Economic Action and Social Structure - The Problem of Embeddedness, in: American Journal of Sociology, Nr. 2 (1985), S. 481-510.
} 
wolle, also nicht durch die Logik der "social structure". Granovetter erklärt die Neigung des Ökonomen, das ökonomische Handeln im Rückgriff auf die Logik der ökonomischen Effizienz erklären zu wollen, dadurch, daß Wirtschaftswissenschaftler in der Regel von einem "undersocialized" Menschenbild ausgehen. So schreibt er an einer Stelle:

"In the undersocialized account, atomization results from narrow utilitarian pursuit of self-interset." (Granovetter, 1985, S. 485)

Und weiter unten:

"The undersocialized account is found mainly in the new institutional economics a loosely defined confederation of economists with an interest in explaining social institutions from a neoclassical viewpoint. [...] The general story told by members of this school is that social institutions and arrangements previously thought to be the adventitious result of legal, historical, social or political forces are better viewed as the efficient solution to certain economic problems." (Ebenda, S. 488.)

Granovetter stellt daher die Forderung auf, das Augenmerk des Ökonomen vom abstrakten Modell der Effizienz weg auf die Dimension der sozialen Netzwerke, in denen das ökonomische Handeln eingebettet ist, zu richten.

Der Vortrag "Entrepreneurship, Development and the Emergence of Firms", den Granovetter im Rahmen einer Konferenz im Wissenschaftszentrum Berlin für Sozialforschung 1990 hielt, stellte den Versuch dar, seine These von der Bedeutung der sozialen Netzwerke für die Analyse des Unternehmers zu verdeutlichen. ${ }^{42}$ In der Einleitung führte Granovetter aus:

"I have argued elsewhere that the mediating of economic activity by personal relations is extremely common and that this substantially impacts the movement of prices as well as the texture and moral tone of community life. In the present paper, I want to broaden the discussion to inquire how social structure helps determine the scope of economic activity. One of the obvious facts of economic life is that some individuals not only have a clientele with whom they regularly do business, but also

\footnotetext{
${ }^{42}$ Mark Granovetter, Entrepreneurship, Development and the Emergence of Firms. Discussion Paper FS I 90-2, Wissenschaftszentrum Berlin für Sozialforschung 1990.
} 
assemble some of these relationships into relatively organized combinations of activity that we call 'firms'." (Granovetter, 1990, S. 3)

Granovetter stützt sich dabei nicht auf eigene empirische Untersuchungen über die Unternehmer, sondern auf bereits vorliegende anthropologische Forschungsergebnisse wie die von D. Szanton und C. Geertz. Für Granovetter waren die Arbeiten von Anthropologen insofern ein wichtiger Beleg für seine soziologische These, als diese sich mit der jeweils unterschiedlichen kulturbedingten Logik der sozialen Netzwerke beschäftigten. Durch Auswertung dieser Arbeiten stellte Granovetter fest, daß Unternehmer weniger nach der Logik der ökonomischen Effizienz als nach der kulturspezifischen Logik von sozialen Netzwerken handeln.

Damit hat Granovetter einen wichtigen Beitrag zur Erforschung des unternehmerischen Handelns geleistet. Sein Verdienst liegt vor allem darin, daß er sehr plausibel verdeutlicht hat, daß sich unternehmerisches Handeln nicht allein aus der Logik der ökonomischen Effizienz erklären läßt, wie dies häufig von den Ökonomen behauptet wird. Gleichzeitig lehnt er auch die durch Parsons geprägte modernisierungstheoretische Annahme ab, nach der das unternehmerische Handeln aufgrund von ökonomischen Zwängen immer stärker von Rationalität geprägt wird, während gleichzeitig die nicht-ökonomischen Lebensbereiche wie soziale Netzwerke immer weiter an Bedeutung verlieren. Besonders wenn man in diesem Zusammenhang an die unternehmerische Entwicklung in den nicht-westlichen Ländern denkt, in denen eine Koexistenz zwischen dem reinen ökonomischen Interesse und der keinesfalls geringer werdenden Bedeutung von Familien und Freundschaftsbeziehungen herrscht, kann man nur betonen, wie wichtig die Granovettersche Auffassung vom unternehmerischen Handeln für die Analyse dieser Länder sein kann. Es ist meines Erachtens daher auch nicht verwunderlich, daß Granovetter für sein Argument sehr viele Beispiele ausgerechnet in den nicht-westlichen Gesellschaften gefunden hat.

Doch ist kritisch anzumerken, daß Granovetter durch seine aufwendige Kritik an Williamson nur etwas bestätigt, was Durkheim schon vor hundert Jahren behauptet hat: nämlich, daß die soziale Struktur entscheidet, wie ein Mensch handelt. So glaubt Granovetter fest, daß man voraussagen könne, wie sich der länderspezifische Institutionalisierungsprozeß entwickelt, wenn man die soziale Struktur der 
untersuchten Gesellschaft kenne. Damit aber postuliert er genau den sozialen Determinismus, den ich oben an soziologischen Ansätze kritisiert habe, und genau daher rührt mein Unbehagen an der Granovetterschen Argumentation. Indem er sich wieder nur auf eine Variable, nämlich die der sozialen Netzwerke oder der social structure beschränkt, vernachlässigt er die individuellen Freiheitsgrade, die jedes unternehmerische Handeln meines Erachtens immer auch enthält und die schon bei der Art der Wahrnehmung der traditionellen sozialen Struktur eine wichtige Rolle spielen können. Daher bin ich der Auffassung, daß eine realitätsadäquate Analyse des unternehmerischen Handelns ohne eine genaue Analyse auch der Wahrnehmung und Interpretation des sozialen Umfelds durch die handelnden Akteure (einschließlich der nicht ökonomischen Partner wie Politiker), also durch Einbeziehung des situativ bedingten Verhaltens, erfolgen muß.

Während Granovetter von der Annahme ausgeht, daß die Beziehung zwischen den ökonomischen und politischen Akteuren in den nicht-westlichen Gesellschaften immer entlang der vertikalen sozialen Struktur verläuft, die von den traditionellen Gesellschaften weiter tradiert wurde, halte ich es für unwahrscheinlich, daß es sich hier bloß um die gesellschaftliche Reproduktion einer vorgegebenen sozialen Struktur handelt. Meine Einbeziehung von "situativen Faktoren" beim unternehmerischen Rückgriff auf die Logik der sozialen Struktur berücksichtigt dagegen, daß der Unternehmer und seine politischen Partner nicht nur aus gesellschaftlichmoralischem Zwang, sondern auch aus einem individuell überlegenden Kalkül die jeweilige politische und ökonomischen Situation betreffend entscheiden. Mit anderen Worten: Ich gehe davon aus, daß der unternehmerische Akteur nicht auf eine der beiden genannten Betrachtungsweisen festgelegt ist, sondern beide gleichzeitig berücksichtigt, wobei im realen, immer sehr komplexen Handlungszusammenhang auch inkonsistente oder widersprüchliche Entscheidungsstrukturen denkbar sind.

Johannes Berger: In der gegenwärtigen wirtschaftssoziologischen Debatte spielen die deutschen Soziologen verglichen mit den Amerikanern eher eine marginale Rolle. Dies hängt wohl mit der spezifischen Entwicklung der Soziologie in Deutschland zusammen, in der wirtschaftssoziologische Fragen lange hauptsächlich aus dem Blickwinkel der traditionellen bzw. marxistisch orientierten Industrie- 
soziologie betrachtet wurden. Obwohl das deutsche Interesse an der amerikanischen wirtschaftssoziologischen Debatte in der Regel nicht über das Niveau einer abstrakten theoretischen Auseinandersetzung hinauszugehen scheint, bin ich der Meinung, daß der Aufsatz von Johannes Berger "Warum arbeiten die Arbeiter?" als ein neuer Beitrag zur Unternehmerforschung anzusehen ist. ${ }^{43}$ Diese Auffassung scheint auf den ersten Blick erstaunlich, da der Titel des Aufsatzes in keiner Weise mit Unternehmern zusammenzuhängen scheint. Doch in der Einleitung begründet Berger diese Betitelung damit, daß diese Fragestellung zu einem blinden Fleck in der bisherigen neoinstitutionalistischen und neomarxistischen Organisationstheorie gehört, da diese sehr wohl zentral in eine Analyse des Unternehmertums gehört. Seine Kritik ist an diesen Theorien die folgende: Neomarxisten und Neoinstitutionalisten verkennen das Grundproblem des Unternehmers völlig, ndem sie (vor allem der Neomarxismus) dazu neigen, die unternehmerische Abhängigkeit von Arbeitnehmern bzw. von deren Bereitschaft zur Arbeit völlig außer acht lassen. Konkreter gesagt: Es darf nicht übersehen werden, daß die Aktivität des Unternehmers nicht mit der Einstellung der Arbeitskräfte aufhört, sondern daß die eigentliche Arbeit darin besteht, die Arbeiter in das Unternehmen zu integrieren. So schreibt Berger:

"Was der Unternehmer von den Arbeitern kauft, ist ein Versprechen: die Bereitschaft, sich für bestimmte Zeitperioden in das Kommando des Unternehmers zu fügen. Dieses Versprechen gehen die Beschäftigten ein, weil sie bezüglich ihrer Existenzsicherung keine andere Wahl haben. Auf einem ganzen anderen Blatt steht aber, ob es der Unternehmung gelingt, dieses Versprechen zu aktualisieren und die Leistungsbereitschaft in wirkliche Leistung umzusetzen." (Berger, 1995, S. 413).

Die Bergersche Auffassung der Unternehmung bzw. des Unternehmers unterscheidet sich von der der Neomarxisten und Neoinstitutionalisten also dadurch, daß diese die Entwicklung des Unternehmens in erster Linie vom Interesse des Kapitals bestimmt sehen, während Berger auf die wichtige Rolle hinweist, die das Verständnis vom Management bzw. die für die Integration der Arbeiter getroffenen organisatorischen Maßnahmen spielen. Auf diese Weise erklärt Berger auch, daß die Entwicklung der japanischen Unternehmen von ihrer Grundlogik her ganz an-

$\overline{{ }^{43} J o h a n n e s ~ B e r g e r, ~ W a r u m ~}$ arbeiten die Arbeiter? Neomarxistische und neodurk- 
ders als die der westlichen Unternehmen verlief. Für die japanischen Unternehmen sei es bezeichnend, daß sie durch den hohen Integrationsgrad der Arbeiterschaft bzw. die starke Bindung des einzelnen Arbeiters an das Unternehmen das Grundproblem der Unternehmung, nämlich das Dilemma zwischen dem unternehmerischen und dem persönlichen Interesse, ohne große innerliche Konflikte auf Arbeitnehmerseite lösen konnten. Seine Einsicht von der gegenseitigen Abhängigkeit von Unternehmer und Arbeitnehmer verdankt Berger vor allem dem französischen Klassiker der Soziologie, E. Durkheim, der die menschliche Neigung zur Identifikation mit einem Unternehmen, dem man sich zugehörig fühlt, und deren Bedeutung für die Unternehmen bzw. Unternehmer schon sehr früh erkannte. ${ }^{44}$

Es kommt mir hier darauf an, zu verdeutlichen, wie stark die Entwicklung des Unternehmens vom länderspezifischen unternehmerischen Verständnis vom $\mathrm{Ma}$ nagement abhängt. Ich bin der Auffassung, daß Berger mit diesem Aufsatz, selbst wenn er sich nicht explizit dafür interessiert hat, überzeugend die Bedeutung des Unternehmers für die länderspezifische Entwicklung des Unternehmens verdeutlicht hat. Im Gegensatz zu Neomarxisten und Neoinstitutionalisten sieht er die Person des Unternehmers nicht auf die Position dessen festgelegt, der sich nur für die Gewinnmaximierung oder die Ausbeutung der Arbeiter interessiert, sondern erkennt den häufig verkannten Handlungsspielraum, den jeder Unternehmer zweifellos hat. Dennoch hält er den unternehmerischen Handlungsspielraum nicht, wie sich dies Unternehmer immer wünschen, für willkürlich erweiterbar, sondern ist der Ansicht, daß sich der Unternehmer dem Zwang des gesamtgesellschaftlichen Wandlungsprozesses nicht völlig entziehen könne.

Meine Auseinandersetzung mit den oben genannten Soziologen und Ökonomen und die aus deren Arbeiten gewonnenen wichtigen Hinweise auf die Bedeutung des Unternehmers hat ergeben, daß es nicht genügt, sich bei der Analyse des ökonomischen Handelns nur auf die gesellschaftliche Seite von menschlichen Handlungsmechanismen zu beschränken. Anthony Giddens hat in seinem erstmals 1979 erschienenen Buch "Central Problems in Social Theory" zu Recht bemerkt, heimsche Erklärungen, in: Zeitschrift für Soziologie, Jg. 4. Heft 6 (1995), S. 407-421. 
daß der westlichen Soziologie eine "theory of action" fehlt. ${ }^{45}$ Dieses Defizit kann man auf die ökonomische Soziologie wie folgt übertragen: Es fehlt eine genaue soziologische Analyse des Unternehmers als handelndes Subjekt und seines Entscheidungsspielraumes innerhalb der ökonomischen Handlungssituation. In diesem Zusammenhang muß man danach fragen, welche Faktoren den Handlungsspielraum des ökonomischen Akteurs einschränken bzw. - eventuell auch trotz ungünstiger gesellschaftlicher Rahmenbedingungen - erweitern.

Gleichzeitig ist es aber für eine realitätsadäquate Analyse der koreanischen Chaebol, die als "Familienunternehmen" ebenso unzulänglich charakterisiertsind wie als "Großunternehmen" im westlichen Sinne, auch unerläßlich, die gesellschaftliche Bedingtheit des ökonomischen Akteurs nicht aus den Augen zu verlieren. Konkreter gesagt: Wenn die Soziologen imstande sind zu klären, wie der einzelne ökonomische Akteur sein soziales und ökonomisches Umfeld interpretiert und auf welche Weise er auf die jeweilige Handlungssituation reagiert, dann gewinnt man einen wichtigen Einblick in einen bis jetzt wenig erforschten menschlichen Handlungsbereich. Insofern zielt diese Frage nicht nur darauf ab, den ökonomischen Wandlungsprozeß aus der Perspektive des Akteurs zu betrachten, sondern vor allem darauf, zu klären, in welcher Art und Weise der menschliche Rückkoppelungsprozeß auf die gesellschaftlichen Faktoren erfolgt. Dadurch kann man letztlich erfahren, worin das länderspezifische Innovationspotential bei der Umsetzung des ökonomischen Handelns zu sehen ist und in welcher Richtung die gesellschaftliche Reformpolitik entwickelt werden sollte. Die bisherige soziologische Forschung hat auf die Person des Unternehmers zu wenig geachtet und hat damit einen wichtigen Aspekt der Forschung außer acht gelassen.

Ich bin der Auffassung, daß diese Problemstellung nur dann sinnvoll bewältigt werden kann, wenn der Begriff des unternehmerischen Handelns jenseits der bisherigen soziologischen und ökonomischen Debatte "neu" definiert wird. Dabei ist das Wort "neu" in dem Sinne zu verstehen, daß sich der Forscher bemüht, die

\footnotetext{
${ }^{44}$ Vor diesem Hintergrund bezeichnet er seine theoretischen Annahmen über die Entwicklung des Unternehmens als "neodurkheimschen Ansatz".

${ }^{45}$ Anthony Giddens, Central Problems in Social Theory: Action, Structure and Contradiction in Social Analysis, London u. a. 1979. Giddens geht davon aus, daß die fehlende soziologische Theorie des "Handelns" in Anlehnung an philosophische Traditionen wie Phänomenologie und Hermeneutik zu gewinnen ist.
} 
Reichweite der bisherigen Definition im Kontext des länderspezifischen gesellschaftlichen Zusammenhanges zu modifizieren bzw. zu erweitern. Insofern wäre es falsch anzunehmen, daß mein Anspruch auf Erweiterung der Definition des ökonomischen Verständnisses des Unternehmers im Sinne eines neuen Allgemeinheitsanspruchs verstanden wird, der gleichzeitig den Geltungsanspruch des bisherigen Verständnisses des ökonomischen Handelns grundsätzlich in Frage stellen würde.

Vier Aspekte halte ich zur Charakterisierung des ökonomischen bzw. unternehmerischen Handelns für wesentlich:

Erstens: Das ökonomische Handeln des Unternehmers läßt sich insofern als ein komplexer gesellschaftlicher Vorgang bezeichnen, als dessen konstitutive Merkmale sich nicht durch einen einzigen gesellschaftlichen Faktor (z. B. Staat, Markt oder Kultur) erklären lassen. Wie die berühmte soziologische Studie von Max Weber "Die protestantische Ethik und der 'Geist' des Kapitalismus" gezeigt hat, setzt ein bestimmter Typus des unternehmerischen Handelns einen gewissen sozio-kulturellen Wandlungsprozeß der jeweiligen Gesellschaft voraus. Weber ztfolge geht das Berufsethos des westlichen Unternehmertums schon auf die Peformationszeit zurück, in der Luther und Calvin "Berufung" als Amt und Beruf interpretieren und damit ein neues (protestantisches) Arbeitsethos "schufen". Doch Weber führte die Entstehung des okzidentalen Kapitalis- 
mus nicht allein auf diesen kulturellen bzw. religiösen Wandlungsprozeß zurück. Friedhelm Guttandin hat in seiner "Einführung in die 'protestantische Ethik' Max Webers"46 richtigerweise darauf hingewiesen, daß nach Weber immer mitzubedenken ist,

"daß der moderne, weil rationale, Kapitalismus nur entstehen konnte, weil er mit all den anderen sich rational entwickelnden Sphären zusammentraf und sich verzahnen konnte. Es ist das Spezifische des modernen Kapitalismus, daß er jene anderen rationalen Prozesse sich dienstbar machte und deren Weiterentwicklung im Sinne seines eigenen Progresses durch ökonomische Prämien vorantrieb." (Guttandin, 1998, S. 25)

Weber faßte das unternehmerische Handeln niemals als Angelegenheit des atomisierten bzw. gesellschaftlich isolierten Individuums auf, sondern bettete es in dessen historischen und kulturell-religiösen Kontext ein. Den Unternehmer sah er wie andere Mitglieder der Gesellschaft als ein historisches Individuum, das sich nicht von den Einflüssen der traditionellen Gesellschaft lösen kann. Insofern war sein Versuch, die Wurzeln des unternehmerischen Handelns durch eine geschichtliche Analyse aufzudecken, nur folgerichtig.

Im Hinblick auf Korea muß man dementsprechend folgende Frage stellen: Welcher sozial-historische Wandlungsprozeß verbirgt sich hinter der koreanischen Entwicklung des Unternehmertums? Diese Frage zielt keineswegs darauf ab, die Eigentümlichkeit des koreanischen Unternehmertums ausschließlich im Rückgriff auf die traditionelle Kultur, speziell den Konfuzianismus, erklären zu wollen. Sie dient vielmehr dazu zu klären, welcher sozio-historische Wandlungsprozeß der koreanischen Gesellschaft dazu geführt hat, daß sich das koreanische unternehmerische Handeln trotz fehlender protestantischer Ethik und ohne eine der europäischen entsprechenden kaufmännischen Tradition entwickeln konnte.

Zweitens: Obwohl das ökonomische Wahrnehmungsmuster des Unternehmers maßgeblich durch die herrschende gesellschaftliche Norm beeinflußt wird, hat dies nicht zu bedeuten, daß sich das unternehmerische Handeln allein durch die herrschenden gesellschaftlichen Normen erklären läßt. Schumpeter hat gezeigt, daß "Unternehmer" nicht ein Synonym für "Profitmensch" ist, denn indem der Unter-

\footnotetext{
${ }^{46}$ Friedhelm Guttandin, Einführung in die 'protestantische Ethik' Max Webers, Opladen
} 
nehmer die vorgefundenen traditionellen Elemente "neu kombiniert", ist er ein wichtiger Träger des gesellschaftlichen Wandlungsprozesses. Wenn man diese Schumpeterische Sichtweise des Unternehmers akzeptiert, ist es nicht schwer zu erkennen, daß der Unternehmer seinen Handlungsspielraum durch seine Auseinandersetzung mit der Tradition nicht einengt, sondern erweitert. Wie der Unternehmer seinen Handlungsspielraum erweitert, hängt dabei nicht allein von seinen ökonomischen Ressourcen (z. B. Kapital, Technologie und Markt) ab, sondern auch mit der Art und Weise zusammen, in der er die traditionelle Lebensform innovativ gestaltet.

Im Hinblick auf die koreanische Entwicklung des unternehmerischen Handelns ist die Schumpeterische Sichtweise insofern nützlich, als die erste Generation der koreanischen Unternehmer (vor allem die Gründerväter der Chaebol) im Vergleich zu den westlichen Unternehmern weder über großes Eigenkapital noch über technologisches Know-how verfügten. Damit blieb für sie kein anderer Ausweg, als ihren unternehmerischen Handlungsspielraum durch Mobilisierung der nichtökonomischen Ressourcen zu erweitern. Wie dies geschieht, läßt sich beispielsweise durch eine genaue soziologische Analyse von Unternehmerbiographien erforschen, da diese den gesellschaftlichen Wirkungsmechanismus zwischen dem unternehmerischen Handlungsspielraum und landesspezifischen traditionellen Lebensformen (wie sich in der Familie, Freundschaft oder auch im herkunftsorientiertem Regionalismus manifestieren) aufdecken kann.

Drittens: Das unternehmerische Handeln hängt nicht allein von der Verfügbarkeit der gesellschaftlichen bzw. institutionellen Ressourcen ab, sondern auch von "situativen Faktoren" (beispielsweise politischen Gegebenheiten), mit denen der Unternehmer direkt oder indirekt konfrontiert ist. Dabei ist zu berücksichtigen, worauf insbesondere Berger hingewiesen hat, daß der Unternehmer nicht isoliert oder autonom handelt, sondern immer in Kooperation mit anderen gesellschaftlichen Akteuren (wie Arbeitern, Politikern oder den Vertretern anderen Interessensgruppen). Die Komplexität des unternehmerischen Handelns besteht daher vor allem darin, daß sich der Unternehmer nicht nur an seinen ökonomischen Interessen, sondern auch am Interesse anderer gesellschaftlicher Gruppen orientieren muß.

u. a. 1998. 
Granovetters Hinweis auf außer-ökonomische Motive im unternehmerischen Handeln, mit dem er das Primat der ökonomischen Effizienz für unternehmerische Entscheidungen durch die Bedeutung sozialer Netzwerke in Frage stellte, ist daher in diesem Sinne zu erweitern. Ich bin der Auffassung, daß sich das unternehmerische Handeln in Korea, das in der hier vorliegenden Arbeit am Beispiel von drei Gründervätern der koreanischen Chaebol dargestellt werden soll, ohne Analyse der situationsbedingten Kooperationsform zwischen diesen Unternehmern und dem Regime unter Präsident Park nicht nachvollziehen läßt.

Viertens: Der länderspezifische Charakter des Managements kann nicht nur dazu beitragen, einen bestimmten Typus des ökonomischen Handelns innerhalb des Unternehmens zu reproduzieren, sondern er kann auch dazu führen, daß der institutionelle Wandlungsprozeß der Gesellschaft von der Logik des Managements bestimmt wird. Das heißt: Die gesellschaftliche Rolle des Managements beschränkt sich nicht darauf, einen möglichst effizienten Produktionsvorgang zu gestalten, sondern einzelne oder eine Gruppe von Unternehmern versuchen den gesamten gesellschaftlichen Wandlungsprozeß zu ihren Gunsten zu regulieren und zu beeinflussen. Diesen Einfluß zu untersuchen, würde bedeuten, den Bergerschen Hinweis auf die wechselseitige Abhängigkeit zwischen Unternehmern bzw. Managern und Arbeitnehmern und seine daraus abgeleitete Auffassung vom Management auf die gesamtgesellschaftliche Perspektive zu übertragen. Um ein Beispiel aus Korea zu nennen: Aufgrund der Bevorzugung von Absolventen der Eliteuniversitäten bei der Einstellung in den Unternehmen, herrscht in der koreanischen Gesellschaft seit langem ein "Bildungsfieber", das eine große, jeden einzelnen treffende Belastung für die gesamte koreanische Gesellschaft darstellt. Das gleiche kann auf andere gesellschaftliche Bereiche (z. B. die Verstärkung des Regionalismus oder Nepotismus in allen Verwaltungsbereichen) übertragen werden. Ohne genauere Analyse der Wechselwirkung zwischen Management und dem gesellschaftlichen Wandlungsprozeß ist nicht nachvollziehbar, warum die koreanische Eigentümlichkeit des unternehmerischen Handelns, die durch die Chaebol geprägt ist, ein gesamtgesellschaftliches Problem ist, mit dem sich die gesamte koreanische Bevölkerung auseinandersetzen muß. 


\section{II.6 Über den Nutzen der Biographie-Analyse}

Der Hauptteil meiner Dissertation beschäftigt sich mit der Analyse der Biographien von drei Gründervätern der koreanischen Chaebol: In-Hoe Ku (1907 - 1969), Byong-Chul Lee (1910 - 1987) und Joo-Young Cheong (geb. 1915). ${ }^{47}$

Diese Biographien sind aus verschiedenen Anlässen entstanden und dementsprechend unterschiedlich: Bei der Lebensbeschreibung Kus handelt es sich um eine Biographie, die aus Anlaß seines zehnjährigen Todestages im Namen seiner Firma Lucky-Goldstar geschrieben wurde. Das erstmals 1979 erschienene und 1993 dann noch einmal nachgedruckte Buch war nur für die Mitarbeiter seines Unternehmens bestimmt und nicht verkäuflich. Wie bei firmeneigenen Publikationen häufig, wird leider kein Verfasser genannt. Das Buch, das den Titel "Wenn du anfängst, jemandem einmal zu glauben, dann sollst du bereit sein, ihm alles anvertrauen zu können" trägt, stellt nicht nur den genaueren familiären Hintergrund Kus, sondern auch sehr detailliert seinen unternehmerischen Werdegang dar. ${ }^{48}$

Bei Lee handelt es sich um eine Autobiographie, die er 1985 im Alter von 75 Jahren über sein unternehmerisches Leben schrieb. Er nannte das Buch "Hoams Autobiographie", nach seinem zweiten Namen Hoam, den er sich nach alter kon-

\footnotetext{
${ }^{47}$ Soweit ich weiß, gibt es bisher überhaupt keine Forschungsarbeiten, die sich mit der Biographie, Sozialisation und Entwicklung der Gründerväter der koreanischen Chae-bol beschäftigen, weder auf der Basis von (Auto-)Biographien noch auf der Grundlage auf andere Weise erhobener soziologischer Daten. Lediglich Leroy P Jones und II Sa-kong, Government, Business, and Entrepreneurship in Economic Development: The Korean Case, Cambridge u. a. 1980, behandeln die allgemeine Frage, ob eine be-stimmte regionale Herkunft oder aber die Religion bei der Herausbildung der koreani-schen Chaebol eine besondere Rolle gespielt haben. Dabei untersuchten sie stati-stisch, ob es eine zahlenmäßige Dominanz bestimmter Herkunftsregionen bei den koreanischen Unternehmern gibt. Ergebnis ihrer Untersuchungen ist die relativ nichts-sagende Aussage, daß weniger die regionale Herkunft als vielmehr der persönliche Charakter für den unternehmerischen Werdegang entscheidend ist (S. 221). Im Hin-blick auf die Rolle der Religion schließen sie, "religion plays an extremely minor role in differentiating the entrepreneurial elite from the population as a whole" (S. 223).

${ }^{48}$ Lucky-Goldstar (Hrsg.), Hanbeon Midemyeon Modu Matkeora (Wenn du anfängst, jemandem einmal zu glauben, dann sollst du bereit sein, ihm alles anvertrauen zu können), Seoul 1979/ 1993. Möglich wäre, daß die Familie den Verfasser deshalb nicht genannt haben wollte, weil sie befürchtete, daß dessen Insiderwissen von Journalisten für Enthüllungsgeschichten genutzt werden könnte, oder aber der Ver-fasser selbst wollte nicht genannt werden, weil er oder sie nicht mit der Biographie eines Unternehmers in Verbindung gebracht werden wollte.
} 
fuzianischer Gelehrtentradition selbst gegeben hatte und der nur unter engen Freunden gebräuchlich war. Lee beschäftigte sich in seiner Autobiographie nicht nur mit seinem familiären Hintergrund, sondern auch mit verschiedenen gesellschaftlichen Ereignissen, die seine unternehmerische Laufbahn stark beeinflußten. In erster Linie wollte er mit dieser autobiographischen Darstellung die koreanischen Leser überzeugen, daß sein unternehmerisches Handeln nichts mit Gewinnsucht, sondern nur mit seiner nationalen Gesinnung zu tun hatte. Aber der Autobiographie seines ältesten Sohnes Maeng-Hee Lee, der ursprünglich Nachfolger seines Vaters war, dann aber die Firma verlassen mußte, kann man entnehmen, daß Byong-Chul Lee wohl dazu neigte, seine Lebensgeschichte in seinem Interesse zu schönen. ${ }^{49}$ Nach seinem Tode erschien ein zweites biographisches Buch über Byong-Chul Lee, das von Mitarbeitern seiner Firma Samsung mit dem erklärten Ziel verfaßt wurde, zur Stärkung der Unternehmenskultur beizutragen. In diesem Buch ist hauptsächlich Lees Managementphilosophie dargestellt, illustriert durch Anekdoten aus seinem unternehmerischen Leben. ${ }^{50}$

Über Cheong existieren zwei biographische Essaysammlungen. Die eine stammt aus dem Jahr 1991, in dem er Präsidentschaftskandidat war, und trug den Titel "Es gibt manche Schwierigkeiten, aber keinen Mißerfolg". Das zweite Buch erschien 1998 und hieß "Geboren in diesem Lande"..$^{51}$ Der Einleitung zu beiden Büchern kann man entnehmen, daß seine Geschichte von der koreanischen Schriftstellerin Su-Heon Kim aufgeschrieben wurde. Auch er erzählt wie die beiden anderen Unternehmer zunächst von seinem einfachen bäuerlichen Familienhintergrund, aber beschränkt sich in seinem ersten Buch ansonsten nur auf die Darstellung der Erfolge in seiner unternehmerischen Laufbahn, so daß man anders als bei Ku oder Lee sehr schwer nachvollziehen kann, worauf sein unternehmerischer Erfolg eigentlich zurückzuführen ist. Im zweiten Buch, dessen Hauptteil im Grunde eine Wiederaufnahme des ersten Buches ist, erzählt er darüber hinaus jedoch eini-

\footnotetext{
${ }^{49}$ Byong-Chul Lee, Hoam Chacheon (Hoams Autobiographie), Seoul 1985; Maeng-Hee Lee, Mudedun Yiyagi (Die unbekannte Geschichte), Seoul 1993.

${ }^{50}$ Samsung Keongje Yeonguso (Verfassergruppe), Hoameui Keongyeong Chulhak (Hoams Managementphilosophie), Seoul 1988.

${ }^{51}$ Joo-Young Cheong [verfaßt von Su-Heon Kim], Sireonun Issedo Silpae nun Eopda (Es gibt zwar Schwierigkeiten, aber keinen Mißerfolg), Seoul 1991; Ders. [verfaßt von Su-Heon Kim], I Tange Taenaseo (Geboren in diesem Lande), Seoul 1998.
} 
ge Geschichten, die er wohl 1991 noch nicht wagte, öffentlich zu machen. So schildert er hier nun sogar Fehler, der er bei unternehmerischen Entscheidungen gemacht hat, sowie seine Strategie, eine enge Verbindung zu dem früheren Präsidenten Park aufzubauen. Außerdem kritisierte er die Regierung von Präsident Young-Sam Kim (1992 - 1998), der sein Gegner bei der Präsidentschaftswahl 1992 gewesen war, und vertrat die Meinung, sein Unternehmen habe durch politische Verfolgung sehr viel gelitten. Es fällt jedoch auf, daß Cheong auch mit diesem zweiten Buch keine gründliche Analyse seiner unternehmerischen Laufbahn vorlegt.

In den bisherigen Forschungen zu den Chaebol sieht man keinerlei Anzeichen dafür, daß (Auto-)Biographien als ernstzunehmende Quelle wissenschaftlicher Analyse betrachtet werden. Lediglich Jae-Jin Suh betont in seinem Buch "Hanguk Chabonga Kaegup (Die koreanische Kapitalistenklasse) den Nutzen der Biographie-Analyse. Aber seine Analyse beschränkt sich hauptsächlich darauf, den realen ökonomischen Status der Herkunftsfamilien der koreanischen Gründerväter der Chaebol zu ermitteln. ${ }^{52}$ Das Desinteresse an der Analyse von Biographien hängt meines Erachtens mit zwei Faktoren zusammen: Zunächst spiegelt sich darin die allgemeine Meinung, daß Biographien grundsätzlich nur der Verherrlichung und Heroisierung des Porträtierten dienten und deshalb wenig wahrheitsgetreu und nur von einem geringen Zuverlässigkeitsgrad seien. Zum zweiten aber hängt dieses Desinteresse damit zusammen, daß die koreanischen Sozialwissenschaftler kaum qualitativ arbeiten. Weil sie während ihrer Studienzeit, sei es in Korea oder in USA, nur mit der quantitativen Forschungsmethode vertraut gemacht wurden, mißtrauen sie der wissenschaftlichen Aussagefähigkeit qualitativer Forschungsmethoden generell. Daß Biographien insofern als wissenschaftlich bedeutsame Quellen zu betrachten sind, als sie ein anschauliches Bild des gesell-

\footnotetext{
${ }^{52}$ So kritisiert er, daß die wenigen Soziologen, die mit der Befragungsmethode versucht hätten, den ökonomischen Hintergrund der Chaebolgründer zu durchleuchten, dazu neigen, das ökonomische Potential der untersuchten Familien zu überschätzen, da man beispielsweise aus der Angabe, daß der Unternehmer aus einer Grundbesitzerfamilie stamme, nicht ohne weiteres schließen könne, daß die Familie genügend Kapital zur Gründung eines Industrieunternehmens zur Verfügung gehabt habe. Jae-Jin Suh, Hanguk Chabonga Kaegup (Die koreanische Kapitalistenklasse), Seoul 1991, S. 54.
} 
schaftlichen Wandlungsprozesses sowie der subjektiven Wahrnehmung des handelnden Akteurs geben, ist innen schlicht unbekannt. Aber man muß natürlich hinzufügen, daß dieser potentielle wissenschaftliche Gehalt der Biographien nur mit einem hohen Grad von soziologischer Sensibilität zu erschließen ist, wobei der Soziologe als Forscher die Fähigkeit haben muß, sich nicht nur in die Rolle des handelnden Akteurs hineinzuversetzen, sondern auch aus der Distanz heraus dessen Handlungslogik kritisch zu überprüfen.

In diesem Zusammenhang muß darauf hingewiesen werden, daß es ein Irrtum ist zu glauben, die Aufgabe des Soziologen bestünde darin, einzelne Aussagen in den Biographien im Sinne des Verfassers zu rekonstruieren. Meines Erachtens ist es notwendig, sie als "offene Daten" zu verstehen, wobei sich der Forscher ausdrücklich darum bemühen muß, das einzelne individuelle Handeln und die entsprechenden Denkmuster im Kontext der allgemein gesellschaftlichen Entwicklung zu bewerten. Um das zu ermöglichen, ist es unentbehrlich, die Biographie-Analyse immer mit "objektiven" Daten zu konfrontieren. ${ }^{53}$ Ich habe dieses Problem dadurch gelöst, daß ich mich bemüht habe, den Wahrheitsgehalt der einzelnen Aussagen in den von mir analysierten Biographien im Rückgriff auf andere zeitgenössische Zeugenaussagen sowie durch eine soziostrukturelle Analyse des gesellschaftlichen Wandlungsprozesses in Korea gründlich zu überprüfen. ${ }^{54}$ Danach versuchte ich, herauszufinden, inwiefern das koreanische Verständnis des ökonomischen Handelns durch gesellschaftliche und kulturelle Faktoren beeinflußt bzw. auf toreaspezifische Weise geprägt wurde. Dies habe ich am Beispiel der koreanischen Anfänge des Unternehmertums im Kontext des gesellschaftlichen Umbruchprozesses um das Jahr 1876 darzustellen versucht. Damals wurde das Wort "Fir-

\footnotetext{
${ }^{53}$ Horst Kern, Empirische Sozialforschung: Ursprünge, Ansätze, Entwicklungslinien, München 1982, S. 105.

${ }^{54}$ Hierbei beziehe ich mich nicht nur auf die Biographien von ehemaligen Wirtschaftstechnokraten und Politikern, sondern auch auf einige journalistische Artikel, die unterschiedliche Akteursperspektiven über die koreanische Entwicklung des Kapitalismus enthalten. Eine besondere Rolle spielt dabei die 1931 zur "Förderung der koreanischen Kultur und des koreanischen Nationalbewußtseins gegründete, 1936 von den Japanern verbotene und 1964 wiederbelebte Zeitschrift Sintonga, in der bis Ende der 1970er Jahre alle wichtigen sozialwissenschaftlichen Aufsätze in Korea veröffentlicht wurden. Außerdem berücksichtige ich einige andernorts erschienene sozialgeschichtliche Aufsätze oder Monographien zu den Chaebol.
} 
ma" zum ersten Mal ins Koreanische übersetzt, und es gründeten sich erste Unternehmen.

Ich bin der Auffassung, daß eine so geartete soziologische Analyse der oben genannten drei Biographien eine wichtige Erkenntnislücke der bisherigen Forschungen zur Entwicklung der koreanischen Chaebol schließen kann. Worauf es ankommt, ist, die bisherige strukturalistische Sichtweise des ökonomischen Handelns aus der Perspektive des handelnden Akteurs neu zu beleuchten. Weil die Biographien in erzählerischer Form geschrieben wurden, enthalten sie viele Details über konkrete Handlungszusammenhänge. Selbst wenn deren Rekonstruktion von einem späteren Zeitpunkt aus erfolgte und deswegen durchaus je nach Erinnerungsvermögen und Intention des Verfassers bzw. (bei nicht-autobiographischen Darstellungen) des Informationen vermittelnden Erzählers manipuliert sein kann, ist es unbestreitbar, daß der Verfasser oder Erzähler sich mit seiner oder der inm übermittelten subjektiven gesellschaftlichen Realität (einschließlich der traditionellen kulturellen Vorstellungen) auseinandersetzen muß. Das heißt: In der (Auto)Biographie werden die subjektive Wahrnehmung und die Verarbeitung des gesellschaftlichen Wandlungsprozesses zum Ausdruck gebracht, die für die hier vorliegende Arbeit von zentraler Bedeutung sind.

In der bisherigen Chaebol-Forschung wird der enge Zusammenhang zwischen den Familien und der unternehmerischen Organisationsstruktur nur an der hohen Zahl der Manager, die aus dem familiären Umkreis stammten, festgemacht. Die Frage, wie sich eigentlich diese hohe Affinität zwischen den beiden Faktoren erklärt und woran sie sich festmacht, wird meistens gar nicht oder bestenfalls damit beantwortet, daß man sie als ein bloßes Übergangsphänomen von der traditionellen zur modernen Gesellschaft wertet. Ich dagegen bin der Auffassung, daß man sich dieser Frage mit Hilfe der Biographie-Analyse zumindest nähern kann. Denn in jeder Biographie wird die Beziehung zwischen dem jeweiligen Unternehmer und anderen Familienmitgliedern ausführlich dargestellt, so daß leicht nachzuvollziehen ist, wie sich der Übergang von der traditionellen konfuzianischen Lebensform zur modernen unternehmerischen Laufbahn vollzog und welche Konflikte dabei auftraten. Das gleiche gilt für die enge Beziehung zwischen Staat und 
Chaebol, die in den herkömmlichen Forschungen immer als eine einseitige Beziehung vom Staat zum Chaebol dargestellt wird.

Kurz gesagt: Die Biographie-Analyse ist eine unentbehrliche soziologische Forschungsmethode, die die den Industrialisierungsprozeß in Korea bestimmenden Wechselwirkungen zwischen den verschiedenen Institutionen und dem einzelnen handelnden Subjekt auf eine neue Weise erschließen und verständlich machen kann.

Abschließend noch eine kurze Bemerkung zur zeitlichen Eingrenzung der Analyse: Da die drei Biographien in einem großen zeitlichen Abstand (zwischen 1979 und 1991) geschrieben wurden und die in ihnen enthaltenen Rückblicke auch sehr unterschiedliche Zeiträume umfassen, ist es notwendig, meine Auseinandersetzung mit der Entstehungsgeschichte der koreanischen Chaebol mit der Etablierung der sogenannten koreanischen Managementstruktur, deren Entwicklungshöhepunkt Mitte der 80er Jahre erreicht wurde, abzuschließen. Dies bedeutet, daß die neue Entwicklungsdynamik, der die koreanischen Chaebol mit der politischen Demokratisierung nach der Streikwelle im Sommer 1987 unterworfen waren, nicht mehr behandelt wird. ${ }^{55}$

\section{II.7 Zur Methode}

In der Regel hängt die gewählte Methode in der soziologischen Forschung von der Frage ab, was der Forscher eigentlich untersuchen will. Mein soziologisches Erkenntnisziel besteht darin, die länderspezifischen Merkmale des unternehmerischen Handelns bezogen auf die koreanischen Chaebol von einer "einheimischen" Perspektive aus zu verstehen und zu beleuchten. Dabei werde ich vornehmlich "induktiv" vorgehen, was allgemein in der Soziologie mehr oder weniger

\footnotetext{
${ }^{55}$ Mit der Streikwelle im Sommer 1987 mußten die Chaebol in Korea die Löhne erhöhen, die Arbeitszeiten verkürzen und ihren autoritären Managementstil verändern. Dies bedeutet, daß niedrige Löhne und lange Arbeitszeiten nicht mehr zu den komparativen Vorteile von koreanischen Produkten gezählt werden können.
} 
als Vorstufe zur "deduktiven" Methode aufgefaßt wird. Aussage- und Erklärungswert beider Methoden werden deshalb hier kurz erörtert:

Die deduktive Methode folgt einer Forschungsstrategie, in der der Forscher sein Forschungsmaterial mithilfe einer theoretischen Folie oder bestimmten theoretischen, bereits erprobten Erklärungsansätzen ordnet und daraus neue soziologische Zusammenhänge ableitet. Diese Methode, die seit Auguste Comte in der westlichen Soziologie praktiziert wird, zeichnet sich dadurch aus, daß der Forscher aus einzelnen besonderen gesellschaftlichen Phänomenen verallgemeinerbare Gesetzmäßigkeiten über gesellschaftliche Vorgänge abstrahiert. ${ }^{56}$ Folgt man dieser Denklogik, ist die induktive Methode ein Bestandteil des Forschungsprozesses, der letztlich die deduktive Vorgehensweise bzw. verallgemeinerbare theoretische Aussagen ermöglicht. Diese soziologische Forschungstradition hat durch Verfeinerung des begrifflichen Apparats sowie durch die Betonung der dialektischen Beziehung zwischen Theorie und Empirie in den letzten Jahrzehnten große methodische Fortschritte erzielt. Bei aller methodischen Verfeinerung hat sich jedoch die Neigung, aus der Besonderheit das Allgemeine abzuleiten, grundsätzlich kaum geändert, wobei die trotz aller unterschiedlichen Ansätze ebenfalls unveränderte soziologische Grundprämisse, daß sich nämlich das menschliche Handeln im Rückgriff auf die soziale Struktur oder die Eigentümlichkeit der Gesellschaft erklären läßt, die Grundlage der gesamten deduktiven Tradition ist.

Trotz aller unbestrittenen Vorteile und Erfolge dieser Methode, wie sie sich vor allem in den Ergebnissen der empirischen Sozialforschung niedergeschlagen haben, mußte ich mich der Frage stellen, ob die deduktive Forschungsmethode für die Erforschung der Besonderheit der unternehmerischen Entwicklung in Korea sinnvoll ist. Um Mißverständnisse zu vermeiden, möchte ich hier betonen, daß ich unter "Besonderheit" nicht in erster Linie den Charakter eines einzelnen Phänomens, das auf der Ebene der Allgemeinheit noch einmal rekonstruiert werden muß, sondern vor allem die verschiedenen bzw. länderspezifischen Sichtweisen eines gesellschaftlichen Phänomens verstehe. Ich halte es für einen methodologi-

\footnotetext{
${ }^{56}$ Siehe dazu durchaus mit kritischer Stoßrichtung, aber ohne den "Wert, den Generalaussagen in der Soziologie besitzen", grundsätzlich zu bestreiten: Horst Kern, Über die Gefahr, das Allgemeine im Besonderen zu sehr zu verallgemeinern", in: Soziale Welt Heft 1/2 (1989), S. 259-268 (Zitat, S. 259).
} 
schen Mangel der bisherigen westlich geprägten soziologischen Forschung, daß sie bei ihren Analysen von gesellschaftlichen Entwicklungen die Besonderheit des länderspezifischen Verständnisses des menschlichen Handelns nicht genügend berücksichtigt hat. Bestätigt sehe ich meine Annahme vor allem dadurch, daß sich immer häufiger Soziologen vom herkömmlichen strukturalistischen Entwicklungsansatz distanzieren und die Bedeutung der Kultur für das menschliche Handeln betonen. $^{57}$

Mein soziologisches Anliegen bei der Erfassung der Besonderheit des koreanischen unternehmerischen Handelns besteht nicht darin, die Ähnlichkeit bzw. Differenz zu westlichem unternehmerischen Handeln zu überprüfen. Ich beabsichtige vielmehr, die Besonderheit des koreanischen unternehmerischen Handelns nicht aus einer westlichen soziologischen theoretischen, sondern aus der einheimischen Perspektive zu erschließen. Aus diesem Grunde ist es unausweichlich, daß ich in der vorliegenden Arbeit nicht deduktiv, sondern induktiv vorgehe. Dabei verstehe ich unter induktiver Methode jedoch keinesfalls eine bloße Materialsammlung, die sich mit "Oberflächen-Phänomenen" zufrieden gibt und sich vom "Wust des Konkreten" erdrücken läßt, sondern ich bin im Gegenteil der Meinung, daß ohne soziologische Vorkenntnisse über die Zusammenhänge zwischen Handeln und Gesellschaft Erkenntnisse über das länderspezifische Verständnis menschlichen Handelns nicht zu gewinnen sind. Das heißt: Meine induktive Methode setzt voraus, daß man das Material nach den Kriterien soziologischer Erkenntnisse ordnet - dies aber sehr bewußt ohne "vorschnelle Verallgemeinerung, die wir zu Theorien sublimieren, welche dann unsere eigene Wahrnehmung selektiv steuern und sich auf diese Weise ihre eigenen Bestätigung schaffen" - und dann daraus die Besonderheit des länderspezifischen Charakters menschlichen Handelns ableitet. ${ }^{58}$

\footnotetext{
${ }^{57}$ Vgl. z.B. Phillipe d'Irbarne, Nationale Formen gesellschaftlicher Bindung und unternehmerische Funktionsprinzipien, in: Heidenreich, Martin/Schmidt, Gert (Hrsg.), International vergleichende Organisationsforschung, Opladen, 1991, S. 106-116.; Geert Hofstede, Culture's Consequences, Beverly Hills/London 1980; Matthes Joachim, Zwischen den Kulturen? Die Sozialwissenschaften vor dem Problem des Kulturvergleichs, Sonderband 8 (Soziale Welt), Göttingen 1992.

${ }^{58}$ Zitate in diesem Abschnitt aus: Horst Kern, Über die Gefahr, das Allgemeine im Besonderen zu sehr zu verallgemeinern", 1989, S. 259.
} 
Mit den "Kriterien soziologischer Erkenntnis" ist dabei kein bestimmtes theoretisches Modell, das sich etwa mit den Namen der Klassiker der Soziologie wie Max Weber, Karl Marx, Emil Durkheim oder Talcott Parsons verbinden läßt, gemeint, sondern eher eine metatheoretische Überlegung, die verschiedene soziologischen Forschungsansätze umfaßt. Dazu gehören die folgenden Fragestellungen:

- Welche Rolle spielt die Kultur für das menschliche Handeln?

- Wie hat sich die Bedeutung der Kultur im Laufe des länderspezifischen historischen Wandlungsprozesses geändert?

- Warum wurde die Kultur je nach gesellschaftlicher Schicht unterschiedlich wahrgenommen?

- Welche Rolle spielen situationsspezifische Gegebenheiten (z. B. politische Situation) für die Wahrnehmung der Kultur?

- Wie äußerte sich die Bedeutung der Kultur im unternehmerischen Handeln?

Ich bin der Meinung, daß die Antworten auf diese Fragen noch nicht so erschöpfend sind, daß die Soziologen darüber verallgemeinerbare Aussagen machen könnten. Außerdem bin ich der Auffassung, daß solche metatheoretischen Überlegungen für die schöpferische Umsetzung der induktiven Methode sehr nützlich sind. Denn dadurch kann man vermeiden, die verschiedenen gesellschaftlichen Materialien immer nur auf die Ebene des einzelnen Phänomens festzulegen und so ihre soziologische Bedeutung zu verdecken.

Vor diesem Hintergrund möchte ich meine induktive Methode als "offene" Soziologie bezeichnen, weil sich die Antwort auf meine soziologische Fragestellung nicht direkt aus der Fülle der unmittelbaren Forschungsmaterialien, sondern aus dem soziologisch vorgedacht und neu rekonstruierten Material ableiten läßt. So gesehen bin ich keine konsequente Anhängerin der induktiven Methode, die mit den Fakten sehr streng umgeht und keine theoretische Interpretation der Fakten zuläßt. Es wäre außerdem ein großes Mißverständnis, wenn mein Versuch, das koreanische Material neu zu interpretieren, in dem Sinne verstanden würde, daß ich aus der koreanischen Besonderheit eine neue Allgemeinheit bzw. einen Paradigmenwechsel ableiten wollte. Der Sinn meiner induktiven Methode besteht $b$ diglich darin, mit Hilfe von genuin soziologischen Überlegungen die Besonderheit 
des koreanischen Verständnisses des unternehmerischen Handelns von der Perspektive des einheimischen Akteurs aus neu zu beleuchten und zu verstehen. Um daraus eine neue allgemeingültige Aussage ableiten zu können, benötigte man eine international vergleichende Analyse. Das könnte zwar eine neue und weitreichende und sehr erfolgversprechende Forschungsperspektive sein, ist aber in der hier vorliegenden Arbeit nicht zu leisten. 


\section{Das Verständnis des ökonomischen Handelns - historische Genese}

\section{III.1 Eine soziologische Herangehensweise an das koreaspezifische}

\section{Verständnis des ökonomischen Handelns}

Eines der wichtigsten Ziele dieses Kapitels wird es sein, zu zeigen, warum die Nachahmungsthese als Erklärungsansatz für die Entwicklung der koreanischen Chaebol zu kurz greift. Diese These geht von der Annahme aus, daß das ökonomische Handeln überall in der Welt gleich motiviert ist, nämlich durch das Interesse an der Maximierung des Gewinns. Aufgrund dieser Profitorientierung, so wird zugleich unterstellt, neigt jeder ökonomische Akteur ungeachtet seiner kulturellen und historischen Hintergründe dazu, immer das ökonomische Mittel zu wählen, das sich bereits als das beste erwiesen hat, also die ökonomische Erfolgsstrategie anderer in ihrer ökonomischen Entwicklung historisch vorangegangener Länder nachzuahmen. ${ }^{1}$ Meines Erachtens handelt es sich hierbei um eine nichthinterfragte Übertragung des westlich geprägten Verständnisses des ökonomischen Handelns auf die Analyse historisch-kulturell ganz anders geprägter Gesellschaften, die zudem von einem neoklassizistischen Menschenbild bzw. Verständnis des ökonomischen Handelns ausgeht, nach dem der Mensch ausschließlich rational handelt. Doch meiner Meinung nach läßt sich ökonomisches Handeln nicht ungeachtet der länderspezifischen gesellschaftlichen Entwicklungszusammenhänge eo ipso als gewinnorientiertes Handeln definieren. Insbesondere halte ich es für unwahrscheinlich, daß das koreanische Verständnis des ökonomischen Handelns unabhängig von den koreaspezifischen gesellschaftlich-kulturellen, durch den Konfuzianismus bestimmten Traditionen erklärt und als der gleichen ökonomi-

\footnotetext{
${ }^{1}$ D. Eleanor Westny, Imitation and Innovation: The Transfer of Western Organizational Pattern to Meiji Japan, Cambridge u. a. 1987, z. B. bezieht sich zwar nicht auf die Entwicklung der koreanischen Chaebol, aber sie behauptet, daß der ökonomische Erfolg in Japan nur durch die erfolgreiche Nachahmung westlicher Organisationsformen ermöglicht wurde. Dabei legt sie den Begriff der Nachahmung allerdings insofern etwas weiter aus, als ihrer Meinung nach eine erfolgreiche Nachahmung ohne Innovation nicht stattfinden kann.
} 
schen Motivation bzw. Norm wie in den westlichen Ländern verhaftet gesehen werden kann. ${ }^{2}$

Ich werde mich daher im folgenden zunächst darum bemühen, zu zeigen, worin die Eigentümlichkeit des traditionellen koreanischen Verständnisses des ökonomischen Handelns in der Hochzeit des Konfuzianismus in Korea während der YiDynastie bestand. Obwohl die konfuzianische Norm im wesentlichen eine Norm der herrschenden Elite war, ist es wichtig, die Analyse nicht auf die Ebene des herrschenden Standes "Yangban" einzuschränken. Denn ich bin der Auffassung, daß das ökonomische Handeln als länderspezifisches historisches Resultat eines gesellschaftlichen Diskurses zu verstehen ist, an dem nicht nur die herrschende Schicht bzw. der herrschende Stand, sondern auch die beherrschten Schichten/Stände der Bauern, Handarbeiter und Händler beteiligt waren.

\section{III.2 Konfuzianisierung der Gesellschaft und fehlende Geldwirtschaft - die institutionelle Entwicklung der Yi-Dynastie}

Sung-Gae Yi, der Namensgeber der Yi-Dynastie, der sich 1392 selbst zum Begründer einer neuen Dynastie erklärte hatte, galt als Prototyp des Aufsteigers, der mit der damals herrschenden, buddhistisch geprägten Gesellschaftsordnung der vorausgegangenen Wang-Dynastie brach. Das größte gesellschaftliche Problem der Wang-Dynastie war die Landkonzentration in den Händen weniger aristokratischer Familien und der buddhistischen Klöster, worunter vor allem die Kleinbauern, die die Mehrheit der Bevölkerung stellten, litten. Yi machte nun die jungen, meistens aus kleinbürgerlichen ländlichen Familien stammenden konfuzianischen

\footnotetext{
${ }^{2}$ Der amerikanische Soziologe, James V. Spickard, Ethnocentrism, Social Theory and Non-Western Sociologies of Religion: Toward a Confucian Alternative, 1998, S. 188, vertritt die These, daß sich die Eigentümlichkeit des Konfuzianismus mit den herkömmlichen westlichen religionssoziologischen Erklärungsansätzen nicht erklären läßt. Dabei begründet er dies mit dem Argument, daß das Menschenbild des Konfuzianismus nicht identisch mit dem Menschenbild in den westlichen Kulturkreisen sei, wo der Mensch mehr oder weniger als ein isoliertes Individuum vor Gott aufgefaßt werde. Im Gegensatz dazu seien die Menschen in den konfuzianischen Kulturkreisen gewohnt, ihre Identität
} 
Gelehrten, die in der Wang-Dynastie kaum Aufstiegsmöglichkeiten gehabt hatten und deswegen zu ihren schärfsten Kritikern zählten, zu den Trägern seiner neuen Herrschaft, die er mit dem Idealbild des konfuzianischen Staates zu legitimieren versuchte.

Die Grundidee des Konfuzianismus geht davon aus, daß eine erfolgreiche Herrschaft des Königs bzw. des Staates ohne eine Vertrauensbeziehung zwischen Herrschenden und Beherrschten nicht denkbar ist. Diese Maßgabe wird für wichtiger gehalten als ökonomisches und militärisches Wachstum. ${ }^{3}$ Um dieses Vertrauen in den König bzw. in die herrschenden Organe des Staates gewährleisten zu können, plädierten die Klassiker der konfuzianischen Lehre für eine Herrschaft durch die konfuzianischen Gelehrten. Dabei galt die konfuzianische Lehre vom tugendhaften menschlichen Verhalten als wichtigste Qualifikation für das Beamtentum. Der König sowie die herrschende Beamtenschicht waren aufgefordert, als Vorbild für das einfache Volk zu dienen. Wichtig waren hier vor allem drei Verhaltensmerkmale: Gehorsamkeit gegenüber und Ehrfurcht vor den eigenen Eltern sowie dem König, die Liebe zur asketischen Lebensform und die Verachtung jeglichen durch Gewinnsucht geprägten ökonomischen Handelns. ${ }^{4}$

Ein charakteristisches Merkmal der konfuzianischen Gesellschaftsordnung läßt sich an der Institution der staatlichen Beamtenprüfung festmachen, deren erfolgreiche Absolvierung die Voraussetzung für eine höhere Beamtenlaufbahn war. Bei dieser staatlichen Beamtenprüfung wurde nicht nach verwaltungsspezifischen Kenntnissen, sondern vielmehr nach den allgemeinen Grundsätzen der konfuzianischen Lehre gefragt. ${ }^{5}$ Für die Verwaltungsbereiche, in denen spezifische Kenntnisse für die Ausübung des Amts (z. B. im Wetterdienst, bei der Übersetzung ausländischer Bücher, für die ärztliche Behandlung der königlichen Familie) benö-

immer in bezug auf ihre Position innerhalb der verschiedenen sozialen Beziehungen aufzufassen. Deshalb plädiert Spickard für eine "Confucian sociology of religion".

${ }^{3}$ Hanguk Chongsin Munhwa Yonguwon, Hanguk Minjok Munhwa Taepaekwa Sajon (Enzyklopädie der koreanischen Kultur), Bd. 16 unter dem Stichwort "Yukyo" (Konfuzianismus), Seoul 1991, S. 881 f.

${ }^{4}$ Sang-Eun Lee, Hanguke isseosseui Yukyoeui Kongbiron (Vorteile und Nachteile des Konfuzianismus in Korea), in: Il-Chul Shin (Hrsg.), Hangukineui Sasang (Das Denken in Korea), Seoul 1984, S. 322 f.

${ }^{5}$ Ki-Baik Lee, Hanguksa Sinron (Die neuere koreanische Geschichte), Seoul 1976, S. 210. 
tigt wurden, konnten sich nur Angehörige der gesellschaftlichen Schicht bewerben, die in Korea "Chungin" (Mittelstand) genannt wurde. Obwohl auch diese über gewisse Kenntnisse der konfuzianischen Lehre verfügen mußten, dienten sie meistens nur als Sekretäre der höheren konfuzianisch ausgebildeten Beamten und mußten daher nicht ausdrücklich in der konfuzianischen Herrschaftslehre ausgebildet sein. Während in der vorhergehenden Wang-Dynastie die Zugehörigkeit zum herrschenden Stand durch die Abstammung aus einer aristokratischen Familie gegeben war, wurde in der Yi-Dynastie das konfuzianische Prüfungssystem die wichtigste institutionelle Instanz für die gesellschaftliche Reproduktion der herrschenden Schicht. Das koreanische Wort "Yangban", das in vielen koreanischen Büchern als Synonym für den herrschenden Stand gebraucht wird, stammt aus dieser Beamtentradition. Denn "Yang" bedeutet "zwei" und "ban" die "Hälfte", was sich darauf bezieht, daß den erfolgreichen Prüfungskandidaten zwei unterschiedliche Laufbahnen offen standen, entweder bei der Verwaltung der politischen und wissenschaftlichen Angelegenheiten oder in der Armee. ${ }^{6}$ Für letztere wurden nicht nur die konfuzianischen Kenntnisse, sondern auch militärische Fähigkeiten (z. B. Bogenschießen und Reiten) geprüft.

Außer dem Beamtenberuf hatten die Prüfungskandidaten keine anderen beruflichen Möglichkeiten. Denn der berufliche Einstieg konfuzianischer Gelehrter, in deren Lehre ja jedes gewinnorientierte Verhalten abgelehnt wurde, in Handel und Handwerk war streng untersagt. Vor diesem Hintergrund erließ der Staat der YiDynastie ein Gesetz, das den konfuzianischen Gelehrten verschiedene Privilegien zusicherte. Die wichtigsten waren die Befreiung von der Wehrpflicht sowie von steuerlichen Abgaben.

Die ökonomisch und politisch privilegierte Beamtenlaufbahn verschaffte nicht nur dem Amtsinhaber, sondern auch den anderen Mitgliedern seiner Familie ein hohes gesellschaftliches Ansehen. Die Zahl der Prüfungskandidaten, die für eine erfolgreiche Prüfung gezwungen waren, ihre ganze Zeit und Energie für die Prü-

\footnotetext{
${ }^{6}$ Anfangs wurde die Bezeichnung "Yangban" nur für den aktuellen oder ehemaligen $\mathrm{h}$ haber der Beamtenstelle gebraucht. Wenn dieser gestorben war, durften seine Kinder seinen Titel nicht weiterführen. Dies ließ sich aber nicht durchhalten und Yangban be-
} 
fungsvorbereitung zu verwenden, stieg deshalb schneller an als die Zahl der Beamtenstellen. Daher mußten die Absolventen trotz erfolgreicher Absolvierung der Prüfung lange Wartezeiten in Kauf nehmen, die durch das staatliche Verbot jeglicher Erwerbstätigkeit außerhalb der Beamtenlaufbahn noch verlängert wurden. Daher war es keine Seltenheit, daß sich der gegenwärtige Amtsinhaber bei der Besetzung einer freiwerdenden Stelle darum bemühte, möglichst seine eigenen Familienmitglieder und Freunde zu begünstigen. Brauchte er für die Beförderung der eigenen Familienmitglieder ein politisches Argument, dann versuchte er die konkurrierenden Bewerber dadurch aus dem Feld zu schlagen, daß er deren Auslegung der konfuzianischen Lehre bei bestimmten wichtigen Regierungszeremonien (z. B. bei der Beerdigung des Königs) als falsch bezeichnete. Daraus entwickelten sich zunehmende politische Fraktionskämpfe, so daß die Grundidee des Konfuzianismus immer häufiger auf triviale und formalistische Sittlichkeitsfragen reduziert wurde, ${ }^{7}$ so daß das Vertrauen des Volkes in die politischen Fähigkeiten der Yangban immer weiter schwand. ${ }^{8}$

Mit Beginn der Yi-Dynastie war erklärt worden, daß Grund und Boden von nun an dem König gehören sollten, damit abgesehen vom König niemand eine ökonomische Grundlage für den Ausbau einer Machtposition erwerben konnte. ${ }^{9}$ Um potentielle Widerstände gegen den Zentralstaat im Keim zu ersticken, gab der König zwar einigen verdienstvollen Angehörigen der konfuzianischen Beamtenschaft als Belohnung für ihre Loyalität einen Teil des Landes, aber dieses Land lag ausschließlich in der Nähe der Hauptstadt Hanyang, in der Region Keongi Chibang. Denn der König befürchtete, daß Leute aus fernerliegenden Provinzen, der staatlichen Kontrolle schwerer zugänglich, als Feudalherren auftreten könnten. Im

zeichnete bald ganz allgemein den aristokratischen Stand in Korea. Vgl. auch Carter J. Eckert, Korea Old and New - A History, Cambridge u. a. 1990, S. 107-131.

${ }^{7}$ Beispielsweise wurde darüber gestritten, wie lange die konfuzianische Trauerfeier für einen König genau dauern sollte.

${ }^{8}$ Taek-Hwi Lee, Chosuncho Cheongchi Jedo wa Cheongchi Heongtae (Politische Institution und Handeln in der Chosun-Epoche), in: Chang-Soo Cheong, Hanguk Sahoeron (Studie über die koreanische Gesellschaft), Seoul 1995, S. 75.

${ }^{9}$ Martina Deuchler, The Confucian Transformation of Korea: A Study of Society and Ideology, Cambridge u. a.1992, S. 205. 
Prinzip war angeordnet worden, daß dieses Land nach dem Tod des betreffenden Beamten dem König zurückgegeben werden sollte. ${ }^{10}$ In der Regel wurde diese Anordnung jedoch nicht eingehalten, so daß das ursprünglich königliche Land bald in die Hände der mächtigen Angehörigen des Yangban-Standes geriet. ${ }^{11}$ Der Rest des gesamten Bodens wurde an die Kleinbauern, die nach der klassischen konfuzianischen Lehre als Grundlage der konfuzianischen Herrschaftsform galten, verteilt. Dafür wurde innen die Abgabe einer Nutzungsgebühr als ein Teil der staatlichen Steuern auferlegt. ${ }^{12}$ Diese Abgabe wurde in Form von Reis, Leinen und anderen regionalen Produkten erhoben und sowohl für den königlichen Haushalt als auch für die Bezahlung der höheren Beamten verbraucht.

Der erste Versuch der Yi-Dynastie, das Geldsystem im Lande einzuführen, stammt aus dem Jahr 1401. Man bediente sich des chinesischen Geldsystems. Das erste Geld, das Cheohwa genannt wurde, wurde aus Papier hergestellt. ${ }^{13}$ Obwohl sich die Beamten der Yi-Dynastie bemühten, den Gebrauch des Geldes als Tauschmittel zu fördern, um damit die Transportschwierigkeiten bei der Steuer reduzieren zu können, bevorzugte die Bevölkerung weiter den gewohnten Tausch mit Naturalien wie Reis und Tuch. Bei der einfachen Bevölkerung, die unter dauernder Mangelwirtschaft litt, erweckte das Papiergeld kein Vertrauen, und so scheiterte dieser erste Versuch, in Korea Geld einzuführen. ${ }^{14}$

Der zweite Versuch wurde im Jahr 1423 unternommen. Diesmal produzierte man kein Papiergeld, sondern Münzen, die den vorwiegend aus Kupfer herstellten

\footnotetext{
${ }^{10}$ Es gab auch Ausnahmen: Wenn die Familie des verstorbenen Beamten nur aus einer Witwe und den Kindern bestand, dann durfte das Land weiter vererbt werden.

${ }^{11}$ Ki-Baik Lee, Hanguksa Sinron (Die neuere koreanische Geschichte), Seoul 1976, S. 220.

${ }^{12}$ Es gab noch zwei andere Arten der Steuer: Die eine war der Beitrag für die staatliche Aufrechterhaltung der Armee und die andere war eine Art der staatlichen Versicherung, in die der Bauer Reis für Notzeiten einzahlen mußte, durch den dann später in Not geratenen Bauern geholfen wurde.

${ }^{13}$ In den westlichen Ländern entwickelte sich zunächst die Münze und danach das Papiergeld. Doch während der Yi-Dynastie war in Korea die Bergbautechnologie noch kaum entwickelt. Denn die konfuzianischen Bürokraten interessierten sich nicht für die Entwicklung des Bergbaus, da sie befürchteten, daß daraus nur eine Vergrößerung der koreanischen Abgaben an die chinesische Regierung erwachsen würde. Gleichzeitig glaubten sie daran, daß der Gebrauch von Münzen nur das Konsumverhalten in der Bevölkerung verstärken würde.
} 
chinesischen Münzen nachgebildet waren. ${ }^{15}$ Obwohl die Beamten der Yi-Dynastie wieder versuchten, die Steuereintreibung mit Münzen durchzusetzen, setzte sich auch der Gebrauch dieser Münze nicht durch. Der Grund dafür lag zum einen an den zu geringen staatlichen finanziellen Mitteln und zum anderen an der nach wie vor fehlenden Bereitschaft der Bevölkerung, ihre Lebensmittel gegen den abstrakten Wert von Geld zu tauschen. ${ }^{16}$

Im Jahr 1678 versuchte die Regierung der Yi-Dynastie dann zum dritten Mal Münzen als Tauschmittel einzuführen. ${ }^{17}$ Obwohl der Gebrauch dieser Münzen bei den Händlern, deren Zahl erst seit dem 17. Jahrhundert rapide zugenommen hatte, anstieg, hatte das nicht zu bedeuten, daß das Geldsystem als wichtige institutionelle Instanz des koreanischen ökonomischen Handelns hatte Fuß fassen können. Die wohlhabenden Grundbesitzer bereicherten sich ebenso wie die mächtigen konfuzianischen Beamten weiterhin in erster Linie durch die Vergrößerung ihres Bodenbesitzes, nicht aber durch die Akkumulation von Geld, dem sie nach wie vor elementar mißtrauten. I $\mathrm{hr}$ Interesse am Geld beschränkte sich auf das eines Sammlers. So war es keine Seltenheit, daß Geld fehlte, weil die wohlhabenden Angehörigen des Yangban-Standes und die Händler ihr Geld in ihren Schatztruhen aufbewahrten, statt es zu benutzen.

Im Jahr 1866 gab es dann einen letzten Versuch, Münzen als Tauschmittel zu verbreiten. ${ }^{18}$ Aber diesmal scheiterte die königliche Regierung bei der Verbreitung der neuen Münzen vor allem an ihrer falschen Geldpolitik, weil der reale Wert der Münze unter dem nominellen lag. Obwohl der König mit dieser nominellen Werterhöhung der Münze die staatliche Finanzlage hatte verbessern wollen, führte die Einführung der neuen, überbewerteten Münze nur dazu, daß der Preis der Waren auf dem Markt sehr schnell in die Höhe getrieben wurde. Zwei Jahre später verbot die Regierung, diese Münze als Tauschmittel zu benutzten. Damit endete

\footnotetext{
${ }^{14}$ Suk-Ryun Lee, Urinara Hwape Kumyungsa (Die Geschichte der koreanischen Währung und Banken), Seoul 1994, S. 44.

${ }^{15}$ Dieses Kupfer wurde aus Japan importiert. Die Koreaner verfügten nicht über die Möglichkeit zur Gewinnung von Kupfer.

${ }^{16}$ Suk-Ryun Lee, Urinara Hwape Kumyungsa (Die Geschichte der koreanischen Währung und Banken), Seoul 1994, S. 44.

${ }^{17}$ Ebenda, S. 90.

${ }^{18}$ Ebenda, S. 147.
} 
der letzte Versuch der Einführung des Geldes als Tauschmittel in der Yi-Dynastie erfolglos.

Festzuhalten ist, daß in Korea bis in das 19. Jahrhundert hinein das ökonomische Handeln nicht wie in den westlichen Ländern durch den gesellschaftlichen Vermittlungseffekt des Geldes beeinflußt wurde. Um zu zeigen, welche gesellschaftlichen Faktoren abgesehen von der fehlenden Existenz des Geldes das ökonomische Handeln in Korea beeinflußten, möchte ich nun versuchen, die traditionelle Auffassung vom ökonomischen Handelns abhängig vom gesellschaftlichen Stand des Akteurs zu analysieren.

\section{III.3 Die traditionelle Wahrnehmung des ökonomischen Handelns}

Während der Yi-Dynastie gab es in Korea vier, nach ihren gesellschaftlichen Aufgaben differenzierte soziale Stände, die dem Prinzip der Arbeitsteilung in einer typischen Agrargesellschaft entsprachen: Ganz oben in der gesellschaftlichen Hierarchie standen die in der königlichen Verwaltung tätigen Nachfahren der konfuzianischen Gelehrtenfamilien, die Yangban oder auch $\mathrm{Sa},{ }^{19}$ die durch die kleinbäuerliche Mehrheit der Bevölkerung, die Nong, ernährt wurden. Außerdem entwickelten sich mit Billigung der königlichen Regierung der Stand der Kong, die Handwerker waren, und der Stand der Händler, die Sang genannt wurden.

Die Sa bzw. Yangban: Die Yangban waren die Nachfahren ehemaliger Regierungsmitglieder, die - wenn sie erfolgreich waren - ihren vom König als Belohnung für ihre Dienste erhaltenen Landbesitz im Laufe der Jahrzehnte und Jahrhunderte ständig vergrößert hatten. Da das Land unter den Familienmitgliedern, zu denen allerdings nur die männlichen Nachkommen zählten, aufgeteilt werden mußte, war diese Expansion nur dadurch möglich, daß der durch Tod freiwerdende Beamten-

\footnotetext{
${ }^{19}$ Ursprünglich bezeichnete "Sa" nur allgemein einen Menschen, der nach konfuzianischen Regeln lebt, doch veränderte sich im Laufe der Zeit die Konnotation dieses Begriffes so, daß man inn als Synonym für die Angehörigen des Yangban-Standes gebrauchte.
} 
posten wieder mit einem Mitglied der Familie besetzt wurde, was zumindest am Anfang der Yi-Dynastie absolut üblich war. ${ }^{20}$

Es gelang jedoch nicht allen Angehörigen des Yangban-Standes sich über die Generationen hinweg eine ökonomisch gesicherte Lebenslage zu erhalten. Für die Familien, deren Nachfahren den harten Wettkampf um die Bewerbung der höheren Beamtenposten nicht durchgestanden hatten, war ein langsamer Verarmungsprozeß vorprogrammiert. Außerdem war es keine Seltenheit, daß männliche Nachfahren in der Hoffnung, daß sie irgendwann die staatliche Beamtenprüfung bestehen und vom Gehalt eines höheren Beamten leben könnten, ein Leben lang ohne andere Erwerbsmöglichkeit blieben und sich nur mit dem Erlernen des richtigen konfuzianischen Lebens beschäftigten. Dies entsprach zwar der konfuzianischen Lehre, bedeutete jedoch, daß sie von den Erträgen ihres durch Erbteilung immer kleiner werdenden Landes leben mußten, so daß sich ihr Leben kaum von dem der armen Kleinbauern unterschied.

Doch auch die objektive Verschlechterung ihrer Lage weckte bei den verarmten Angehörigen des Yangban-Standes kein ökonomisches Interesse und hatte nicht die Auflösung des alten ständischen Charakters der Berufskultur ${ }^{21}$ oder die Aufgabe der konfuzianischen Lebensform zur Folge. ${ }^{22}$

Auffällig ist jedoch folgendes: Solange die jungen Männer Hoffnung auf die erfolgreiche Absolvierung der Beamtenprüfung und den damit verbundenen Posten hatten, investierten sie ihre ganze Zeit und Energie in die langwierige konfuzianische Ausbildung (während ihre Ehefrauen und Verwandten die Verantwortung für den familiären Familienunterhalt übernahmen). Sobald sie aber im Amt waren, neigten die Beamten, ungeachtet der konfuzianischen Befürwortung eines be-

\footnotetext{
${ }^{20}$ Das stete Anwachsen der Familienmitglieder führte dazu, daß alle männlichen Mitglieder in einem Abstammungsbuch sorgfältig registriert wurden. Im Krieg mit Japan im Jahre 1592 waren jedoch viele dieser Familienbücher verbrannt, was zur Folge hatte, daß in Korea die Zahl der Yangban enorm anstieg.

${ }^{21}$ Der Begriff "Beruf" wird hier nur in seinem zeitgenössischen koreanischen Sinne verwandt, in dem dieser ein Merkmal eines bestimmten gesellschaftlichen Standes war.

${ }^{22} \mathrm{Im}$ 17. und 18. Jahrhundert gab es einmal eine konfuzianische Gelehrtengruppe, die erfolglos - für die Abschaffung der herkömmlichen Einschränkungen der beruflichen Betätigung der Yangban plädierte.
} 
scheidenen Lebens, sehr schnell dazu, Bestechungsgelder anzunehmen. ${ }^{23}$ Die auf diese Weise gesammelten Gelder nutzten viele Beamten später als eine Art von Lebensversicherung für die Zeit nach ihrem Rücktritt vom Amt.

Obwohl manche koreanische Historiker und Soziologen die Ursache des fehlenden ökonomischen Interesses der verarmten Angehörigen des YangbanStandes auf die konfuzianische Lehre zurückführen, ${ }^{24}$ bin ich der Meinung, daß die starke Ablehnung jeglichen ökonomischen Handelns weniger kulturelle Gründe hat als vielmehr durch die fehlenden gesellschaftlichen Möglichkeiten für ökonomisches Handeln bedingt war. Denn für einen Yangban bestand die einzige Lebensperspektive in einer freiwerdenden Beamtenstelle. Abgesehen davon gab es keinerlei gesellschaftlichen Anreiz, der Interesse an einem erwerbsorientierten ökonomischen Handeln hätte hervorrufen können. Da das Verständnis des ökonomischen Handelns unter den Angehörigen des Yangban-Standes, wie sich an der Institution der Bestechungsgelder zeigt, doch zumindest als sehr ambivalent zu bezeichnen ist, halte ist es daher für möglich, daß unter veränderten gesellschaftlichen Rahmenbedingung sehr rasch ein Bruch mit der traditionellen konfuzianischen Lehre erfolgt wäre.

Die Nong: Der Großteil der Bevölkerung gehörte zum Stand der Nong, den Kleinbauern, die an zweiter Stelle in der Ständehierarchie der Yi-Dynastie standen, da sie nach der klassischen Lehre das ökonomische Rückgrat der konfuzianischen Herrschaftsform bildeten. Da die Arbeit der Nong den Lebensunterhalt der Sa erwirtschaftete, brachte man innen innerhalb des Konfuzianismus einen gewissen Respekt entgegen, auch wenn der Statusunterschied zwischen den herrschenden Sa und den beherrschten Nong natürlich beträchtlich war.

\footnotetext{
${ }^{23}$ Eine beliebte Methode dafür war es, eine unschuldige Person zu verdächtigen. Aus Angst vor der Folter, zu der der Beamte berechtigt war, bot der Angeschuldigte diesem dann sein Vermögen an.

${ }^{24}$ Ein Repräsentant dieser Annahme ist der koreanische Historiker Sang-Yun Heon, dessen Buch "Chosun Yuhaksa" (Die Geschichte des koreanischen Konfuzianismus), Seoul 1949, als die erste sozialwissenschaftliche Analyse über die Bedeutung des Konfuzianismus in der koreanischen gesellschaftlichen Entwicklung gilt. Heon führt die ökonomische Stagnation in Korea auf die Lehre des Konfuzianismus zurück.
} 
Wegen dieser hohen Wertschätzung der Nong waren die Begründer der YiDynastie zunächst um die gerechte Verteilung des königlichen Landes bemüht, das nur von Kleinbauern gepachtet werden durfte. ${ }^{25}$ Mit der Ausweitung der Praxis, das Land der konfuzianischen Beamtenschicht zur Nutzung zu überlassen, und der daraus sich entwickelnden schleichenden Privatisierung, beteiligten sich - in den ihnen gesteckten engen Grenzen - auch die Kleinbauern aktiv an Kauf und Verkauf des Landes. Trotz der zunehmender Bodenkonzentration bei den Angehörigen des Yangban-Standes gab es daher auch unter den Kleinbauern einige wenige Grundbesitzer. Zwar wurde in der Yi-Dynastie die Richtlinie streng befolgt, nach der die Nachkommen nur den Beruf des Vaters wählen konnten, aber im Hinblick auf den Erwerb von Land gab es keine entsprechende ständische Einschränkung. Sogar die für die Yangban arbeitenden Sklaven konnten prinzipiell Grundbesitzer werden. ${ }^{26}$

Dennoch waren die Kleinbauern, die häufig Pächter nicht nur des Königs, sondern auch der grundbesitzenden Yangban waren, denen sie die Hälfte der Ernte abtreten mußten, in ihrer Mehrheit natürlich bettelarm. Sie trugen aber die Hauptlast der ökonomischen Versorgung des Landes. Dem auf innen lastenden Druck entzogen sie sich daher zunehmend durch Flucht, und diese Landlosen zogen dann als wandernde Händler (sog. Bobu-Sang) oder Räuber durch das Land. ${ }^{27}$

Obwohl einige führende koreanische Historiker, wie etwa Yong-Sop Kim, von einer fortschreitenden Kommerzialisierung bzw. Rationalisierung der Landwirtschaft ausgehen, ${ }^{28}$ halte ich dies angesichts der in Korea weitgehend fehlenden städtischen Märkte, auf denen die Kleinbauern einen Teil ihrer Ernte hätten verkaufen können, für unzutreffend. Denn die Entwicklung der koreanischen Städte

\footnotetext{
${ }^{25}$ Hanguk Chongsin Munhwa Yonguwon, Hanguk Minjok Munhwa Taepaekwa Sajon (Enzyklopädie der koreanischen Kultur), Bd. 5 unter dem Stichwort "Nongchon" (Land), Seoul 1991, S. 884.

${ }^{26}$ Yong-Seop Kim, Hanguk Kunheondae Nongupsa Yeongu (Studie über die neuzeitliche Agrargeschichte in Korea), Seoul 1993, S. $11 \mathrm{f}$.

${ }^{27}$ U-Kun Han, Hanguk Kaehangki eui Sangup Yeongu (Studie über den Handel während der Öffnungszeit in Korea), Seoul 1970, S. 144.

${ }^{28}$ Yong-Seop Kim, Hanguk Kunheondae Nongupsa Yeongu (Studie über die neuzeitliche Agrargeschichte in Korea), Seoul 1993, S. 13.
} 
wurde maßgeblich durch die konfuzianische Beamtenschicht vorangetrieben. ${ }^{29}$ Die meisten Beamten aber stammten vom Land und kehrten nach dem Abschied von ihrem Amt in ihre Heimatregion zurück, um dort als Grundbesitzer zu leben. Daher beschränkte sich die Nachfrage der städtischen Yangban auf Luxusgüter, wie etwa Papier oder getrocknete Meeresfrüchte, während sie sich mit Grundnahrungsmitteln selbst versorgten.

Die Verwandlung eines Kleinbauern in einen wohlhabenden Grundbesitzer (so sie denn überhaupt stattfand) war daher meiner Meinung nach nicht die Folge einer allmählichen Umstrukturierung der Landwirtschaft hin zu mehr Kommerzialisierung und Rationalisierung, sondern allein das Ergebnis von persönlichem Fleiß unterstützt durch besonders fruchtbaren Boden und gute Erntejahre. Dies aber ist ein Verhalten, das zwar durch den potentiell möglichen Kauf von Land einen Anreiz erhielt, aber nicht schon per se als profitorientiertes ökonomisches Handeln verstanden werden kann. Die auch bei den armen Kleinbauern festzustellende fehlende ökonomische Motivation hat dabei meiner Meinung nach weniger mit der Verinnerlichung konfuzianischer Werte als vielmehr mit der konfuzianischen Herrschaftsform der Yi-Dynastie zu tun, in der nicht nur - wie auch im mittelalterlichen Europa - ständisches Denken einen individuellen Aufstieg weitgehend verhinderte, sondern vor allem der fehlende städtische Markt die Entstehung einer bäuerlichen Erwerbswirtschaft verhinderte.

Die Kong: Der Ursprung von Kong liegt in der im Jahr 676 gegründeten SillaDynastie. Die Aristokraten der Silla-Dynastie pflegten ihren Bedarf an Luxusgütern wie Schmuck, Bekleidung, Porzellan und Waffen durch die Errichtung

\footnotetext{
${ }^{29} \mathrm{Ki}$-Jun Cho, Hanguk Chabonjueui Balcheonsa (Die Geschichte des koreanischen Kapitalismus), Seoul 1991, S. 143.
} 
von königlich-staatlichen Werkstätten zu decken. Diese Werkstätten wurden als "Kong-Jang" bezeichnet, die Arbeiter, die in diesen Werkstätten beschäftigt waren, als "Changin". Sie waren Sklaven des Königs, der mächtigen aristokratischen Familien oder der buddhistischen Tempelherren. Mit der Wang-Dyna-stie (9181392) bildeten sich zwei Typen von Changin heraus: zum einen die qualifizierten Arbeiter, die lebenslang ausschließlich in den königlichen Werkstätten arbeiteten, zum anderen Handwerker, die lediglich verpflichtet waren, eine bestimmte Anzahl von Tagen im Jahr Dienst in den staatlichen Werkstätten zu leisten. Letztere lebten in der übrigen Zeit an einem Ort zusammen, wo sie über gemeinsame handwerkliche Geräte verfügen konnten. Dabei lebten sie nur von ihren handwerklichen Produkten, die gegen Naturalien wie z. B. Reis getauscht wurden. Doch seit Mitte der Wang-Dynastie gerieten diese freien Werkstätten immer mehr unter die Kontrolle der königlichen Provinzverwaltungsstelle. Weil diese Kontrolle sie um ihr eigenständiges Produktionsrecht brachte, flüchteten viele Handwerker heimlich, was langfristig die Auflösung der nicht-staatlichen Werkstätten bedeutete. Mit Beginn der Yi-Dynastie im Jahr 1392 gab es dann in Korea nur noch staatliche Werkstätten. $^{30}$

Während der Yi-Dynastie waren nicht nur das gesellschaftliches Ansehen der Kong viel niedriger als das der Kleinbauern, sondern auch ihre Arbeitsbedingungen und vor allem ihre Entlohnung extrem schlecht. Ihr Lohn wurde in Naturalien ausgezahlt, wobei die innen zugeteilte Menge Reis so klein war, das man davon keine Familie ernähren konnte. ${ }^{31}$ Manchmal wurde innen selbst diese minimale Reisration vorenthalten. Weil sie nur in den staatlichen Werkstätten arbeiten durften, war es ihnen nicht möglich, ihre handwerklichen Produkte selbst auf den Markt zu bringen und damit ihren Lebensunterhalt zu verdienen. Obwohl es eine strikte Anordnung gab, daß die Söhne der Handwerker später automatisch den Beruf des Vaters übernehmen sollten, sank deshalb die Zahl der Handwerker in den staatlichen Werkstätten rapide. Viele der ehemaligen Handwerker arbeiteten als

\footnotetext{
${ }^{30}$ Hanguk Chongsin Munhwa Yonguwon, Hanguk Minjok Munhwa Taepaekwa Sajon (Enzyklopädie der koreanischen Kultur), Bd. 2 unter dem Stichwort "Kongjang" (Werkstatt), Seoul 1991, S. 837.

${ }^{31}$ Ebenda, S. 838.
} 
Sklaven von wohlhabenden Yangban. ${ }^{32}$ Denn als Sklaven brauchten sie keine steuerlichen Abgaben, weder in Naturalien noch als handwerkliche Arbeit, zu leisten. Dafür garantierte ihr Herr einen gesicherten Lebensunterhalt für ihre gesamte Familie.

Nachdem das Land durch den Krieg mit Japan im Jahr 1592 völlig verwüstet worden war und außerdem eine Vielzahl von koreanischen Keramikern als Kriegsgefangene nach Japan entführt worden waren, stieg die Nachfrage nach handwerklichen Produkten so an, daß diese von den staatlichen Werkstätten nicht mehr befriedigt werden konnte. Nicht nur der Staat, auch die Kleinbauern benötigten neue Haushaltswaren. Daher entwickelte sich außerhalb der staatlichen Werkstätten ein neuer Handwerker-Typus, der seinen Lebensunterhalt entweder durch die Herstellung von Konsumgütern für die Yangban oder durch den Verkauf an staatlich anerkannte Händler verdiente. Produziert wurden u. a. Hüte, Messingwaren und Lederschuhe. ${ }^{33}$ Diese neuen Handwerker, die zumeist in den Vororten der Hauptstadt lebten, leisteten ihre Abgaben nicht mehr in Form von Arbeit in den staatlichen Werkstätten, sondern durch eine bestimmte Menge Tuch, das sie für ihre handwerklichen Produkte von privaten Auftraggebern bekamen. Auf diese Weise entstand bald ein florierender Handel mit den von den nicht-staatlichen Handwerkern hergestellten Produkten, während es für die in den staatlichen Werkstätten, unter nach wie vor sehr schlechten Bedingungen arbeitenden Handwerker keinerlei Anreiz gab, sich um eine Erhöhung ihrer Produktivität zu bemühen.

Um der Landflucht der Kleinbauern zu begegnen, die vor allem durch das herkömmliche sich nicht nur auf Reis, sondern auch auf handwerkliche Produkte erstreckende Naturalien-Abgabesystem hervorgerufen wurde, führte die Regierung der Yi-Dynastie am Ende des 16. Jahrhunderts ein neues Abgabensystem ein, nach dem nur noch Reis abgegeben werden mußte und die staatlichen Organe selbst durch Tausch gegen Reis die benötigten handwerklichen Produkte zu beschaffen hatten. Auch diese Maßnahme steigerte die Nachfrage nach handwerkli-

\footnotetext{
${ }^{32}$ Hanguk Chongsin Munhwa Yonguwon, Hanguk Minjok Munhwa Taepaekwa Sajon (Enzyklopädie der koreanischen Kultur), Bd. 13 unter dem Stichwort "Sukongup" (Handwerk), Seoul 1991, S. 117.
} 
chen Erzeugnissen, da der Staat nun einer der größten Abnehmer dieser Produkte war. Die Folge war, daß sich die Kleinbauern in den Regionen, die für die Herstellung bestimmter handwerklicher Waren (z. B. Porzellan, Leinen und Messingwaren) berühmt waren, von nun an nur noch mit handwerklichen Tätigkeiten beschäftigten. ${ }^{34}$ Diese Gruppe der außerhalb der staatlichen Werkstätten arbeitenden Handwerker wurde "Yoibang Changin" genannt. Während die Handwerker in den staatlichen Werkstätten nur unter der Kontrolle des zuständigen Regierungsbeamten produzieren durften, war es den Yoibang Changin erlaubt, private Aufträge von wohlhabenden Yangban oder Händlern auszuführen. ${ }^{35}$ In diesen Fällen wurden die benötigten Rohstoffe von den jeweiligen Auftraggebern geliefert, und die Handwerker erhielten nur ihren Arbeitslohn, der entweder in Form von Naturalien oder Geld bezahlt wurde. Oft wurde innen dieser Lohn von den mächtigen Yangban allerdings vorenthalten. Wenn es sich um den Auftrag eines Händlers handelte, durften die Handwerker die an diesen gelieferten Produkte nicht an andere Händler oder direkt am Markt weiter verkaufen. ${ }^{36}$

Zusammengefaßt kann man sagen, daß die Lebensbedingungen der YoibangChangin aufgrund ihrer starken Abhängigkeit von privaten Auftraggebern und den Händlern nicht viel besser waren als die der Arbeiter in den staatlichen Werkstätten. Unter diesen Umständen neigten viele Handwerker dazu, die eigene handwerkliche Geschicklichkeit als den Grund für ihr "verdammtes" Leben anzusehen, so daß sie nicht einmal auf ihre handwerkliche Qualifikation stolz waren, wie dies in den europäischen Ländern der Fall war. Ich halte es daher für unwahrscheinlich, daß die Kong, die aufgrund der objektiven gesellschaftlich-staatlichen Bedingungen, unter denen sie produzieren mußten, kaum Möglichkeiten hatten, ihre Le-

\footnotetext{
${ }^{33}$ Ki-Baik Lee, Hanguksa Sinron (Die neuere koreanische Geschichte), Seoul 1976, S. 225.

${ }^{34}$ Hanguk Chongsin Munhwa Yonguwon, Hanguk Minjok Munhwa Taepaekwa Sajon (Enzyklopädie der koreanischen Kultur), Bd. 13. unter dem Stichwort "Sukongup" (Handwerk), Seoul 1991, S. 121.

${ }^{35}$ Hanguk Chongsin Munhwa Yonguwon, Hanguk Minjok Munhwa Taepaekwa Sajon (Enzyklopädie der koreanischen Kultur), Bd. 2 dem Stichwort "Kongjang" (Werkstatt), Seoul 1991, S. 839.

${ }^{36}$ Ki-Baik Lee, Hanguksa Sinron (Die neuere koreanische Geschichte), Seoul 1976, S. 276.
} 
bensbedingungen zu verbessern, ein am Gewinn orientiertes Verständnis des ökonomischen Handelns entwickeln konnten.

Die Sang: Im konfuzianischen Staat war öffentlich nur die Handelstätigkeit anerkannt, die in einem vom Staat errichteten Ladenviertel der Hauptstadt "Hanyang" (heute Seoul) betrieben wurde. Auf Koreanisch hieß dieses Handelsviertel "Sicheon", weil man dort Luxuswaren wie Seide, Papier oder pflanzliche Medikamente und außerdem regionenspezifische Produkte verkaufte. ${ }^{37}$ Für dieses Verkaufsrecht zahlte die dort tätige Händlergruppe Abgaben in Form von Waren. Während die Yangban dieses staatlich anerkannte Ladenviertel als Markt nutzte, mußte die weniger begüterte Bevölkerung sich zum Warentausch an einen anderen Ort begeben. Daraus entstand ein zweiter, nicht-staatlicher, "privater" Markt. Zunächst bemühte sich der Staat, die Aktivität dieses "privaten" Marktes möglichst zu begrenzen. Denn die Händler, die auf diesem privaten Markt tätig waren, waren - wie oben schon gesagt - meistens ehemalige Kleinbauern, die ihr Land verlassen hatten. Die Unterdrückung dieser Händler wurde durch das konfuzianische Menschenbild legitimiert, nach dem Händler gewinnsüchtig und unehrlich waren. ${ }^{38}$ Doch nachdem die königliche Regierung erkannt hatte, daß ein völliges Verbot des "privaten" Markes eine Existenzbedrohung für die verarmten Kleinbauern sowie die wandernden privaten Händler bedeutet hätte, entschloß man sich, den Markt zu bestimmten Zeiten zuzulassen: Er war nur an einigen Tagen im Monat offiziell geöffnet, so daß sich daraus kein städtisches Leben und damit eine potentielle Bedrohung für die Zentralmacht entwickeln konnte. ${ }^{39}$

Aber die Zahl der wandernden Händler, der schon erwähnten sog. Bobu-Sang, die auf dem privaten Markt verkauften, stieg dennoch stetig, so daß es zu Spannungen zwischen innen und den staatlich organisierten Händlern, den

\footnotetext{
${ }^{37}$ Carter J. Eckert u. a., Korea Old and New, Cambridge u. a. 1990, S. 120.

${ }^{38}$ Sang-Eun Lee, Hanguke isseosseui Yukyoeui Kongbiron (Vorteile und Nachteile des Konfuzianismus in Korea), in: II-Chul Shin (Hrsg.), Hangukineui Sasang (Das Denken in Korea), Seoul 1984, S. $336 \mathrm{ff}$.

${ }^{39}$ Ki-Baik Lee, Hanguksa Sinron (Die neuere koreanische Geschichte), Seoul 1976, S. 225.
} 
sog. Sicheon-Sangin, kam. Der Staat erließ deshalb ein Gesetz, das den staatlich anerkannten Händlern, die vor allem Preisdumping fürchteten, die Möglichkeit gab, die Ausdehnung des privaten Marktes in ihrem traditionellen Handelsgebiet, nämlich in den wohlhabenderen Stadtteilen der Hauptstadt, zu verhindern. Anstatt durch Innovation reagierten die anerkannten Händler also auf den wachsenden Konkurrenzdruck mit dem Ruf nach dem Eingreifen des Staates, und die konfuzianischen Machtinhaber gewährten ihnen ein Monopol, indem sie den Bobu-Sang verboten, in bestimmten Gebieten der Hauptstadt die gleichen Waren zu verkaufen wie die staatlich anerkannten Händler. ${ }^{40}$

Dennoch stieg die Zahl der Bobu-Sang weiter und in ihrem Gefolge entwickelte sich ein neuer Typ von Händlern, die "Kaekchu" genannt wurden. ${ }^{41}$ Im Unterschied zu den Bobu-Sang lebten die Kaekchu fest an dem Ort, an dem regelmäßig Markt stattfand. Sie verdienten ihren Lebensunterhalt mit der Versorgung der BobuSang, denen sie nicht nur preiswerte Unterkünfte in den von innen betriebenen Gästehäusern anboten, sondern für die sie auch als eine Art Zwischenhändler dienten, indem sie Warenlager unterhielten, aus denen die Bobu-Sang ihren Warenbestand aufstocken konnten. Sie versuchten dabei ihre Gewinnspanne zu erhöhen, indem sie Waren zurückhielten, um die Nachfrage zu steigern, was die Preise in die Höhe trieb. ${ }^{42}$

Die wohlhabenden Kaekchu betätigten sich sogar als Bankiers und die von innen ausgestellten Wechselbriefe waren bei den Händlern bald anerkannt. Mit der Zeit weitete sich die Tätigkeit der Kaekchu sogar auf den eigentlich illega-

\footnotetext{
${ }^{40}$ Hanguk Chongsin Munhwa Yonguwon, Hanguk Minjok Munhwa Taepaekwa Sajon (Enzyklopädie der koreanischen Kultur), Bd. 13 unter dem Stichwort "Sijang" (Markt), Seoul 1991, S. 550.

${ }^{41}$ Neben den Kaekchu gab es auch noch die Yeogak, die sich von ersteren nur durch die Art der Waren unterschieden, mit denen sie handelten. Da die Bezeichnung "Kaekchu" verbreiterter ist, ist im obigen Text nur von den Kaekchu die Rede. Es ist nach wie vor umstritten, ob die Kaekchu und Yeogak schon vor der Yi-Dynastie existierten. Sicher ist nur, daß sich das von ihnen repräsentierten Handelssystems erst seit dem 17. Jahrhundert durchgesetzt hat. Siehe dazu Hanguk Chongsin Munhwa Yonguwon, Hanguk Minjok Munhwa Taepaekwa Sajon (Enzyklopädie der koreanischen Kultur), Bd. 1 unter dem Stichwort "Kaekchu", Seoul 1991, S. 630.

${ }^{42}$ Hanguk Chongsin Munhwa Yonguwon, Hanguk Minjok Munhwa Taepaekwa Sajon (Enzyklopädie der koreanischen Kultur), Bd. 1 unter dem Stichwort "Kaekchu", Seoul 1991, S. 629.
} 
len Auslandshandel mit China und Japan aus. Nachdem der Ginseng zu einem der begehrtesten Produkte im Handel mit China geworden war, begannen Kaekchu den Ginsenganbau selbst zu kontrollieren. ${ }^{43}$ Dafür bekamen sie von den chinesischen Händlern kein Geld, sondern chinesische Waren, wie Seide, Schreibgeräte und Medikamente, die sich bei den wohlhabenden Yangban gut verkaufen ließen.

Die ortsansässige Tätigkeit der Kaekchu bildete einen wichtigen Eckpfeiler des damaligen Handelssystems und hat sicherlich förderlich auf das allgemeine Interesse an einem ökonomischen Handeln gewirkt. Doch auch wenn ihr Reichtum beeindruckend war, so änderte dies nichts an ihrem gesellschaftlichen Status als Angehörige des niedrigsten Standes in Korea, denen der Aufstieg in die einflußreiche Beamtenschicht grundsätzlich verwehrt war. Ihre Benachteiligung drückte sich dabei auf vielerlei Weise aus: So gab es eine strenge Bekleidungsregelung, die besagte, daß sich die Händler, wie wohlhabend sie auch sein mochten, niemals wie die herrschenden Yangban kleiden durften, und bei einer Unterhaltung mit einem Yangban durften sie sich keinesfalls herausnehmen, mit diesem von gleich zu gleich zu reden. Diese ungleiche Behandlung erzeugte Unzufriedenheit mit der gegebenen gesellschaftlichen Ordnung, die sich allerdings völlig systemkonform vor allem in der Form ausdrückte, daß sich die Kaekchu illegal in den Yangban-Stand einzukaufen versuchten. ${ }^{44}$

Auch diese neue koreanische Händlerschicht trug also nicht zur Aufweichung der starren gesellschaftlichen Strukturen in der Yi-Dynastie bei und veränderte das allgemeine, negativ besetzte, konfuzianisch geprägte Verständnis des ökonomischen Handelns nicht.

Zusammengefaßt läßt sich festhalten, daß - obwohl nicht nur Kleinbauern, Handwerker und Händler, sondern auch eine zunehmende Zahl der Yangban sehr arm waren - niemand versuchte, ökonomische Problemlösungen jenseits der herrschenden konfuzianischen Gesellschaftsordnung zu finden. Trotz der Herausbil-

\footnotetext{
${ }^{43}$ Ki-Baek Lee, Hanguksa Sinron (Die neuere Geschichte Koreas), Seoul 1976, S. 272.

${ }^{44}$ Chi-Won Park, ein Repräsentant der konfuzianischen Schule für die "praktische Wissenschaft" (Sil-Hak), verfaßte in der zweiten Hälfte des 18. Jahrhunderts den Roman "Yangbancheon" (Biographie eines Yangban), in dem diese Praxis scharf ironisiert wird.
} 
dung einer vergleichsweise erfolgreichen Händlerschicht wie der Kaekchu fehlten jene Kräfte, die gesamtgesellschaftlich die Kommerzialisierung der Landwirtschaft sowie der handwerklichen Produktion hätten vorantreiben können. Es ist daher klar, daß der Beginn der kapitalistischen Entwicklung in Korea nicht ohne Bruch mit den durch den Konfuzianismus geprägten kulturellen und institutionellen Traditionen denkbar ist. Dies aber war in Korea erst möglich, nachdem sich das Land 1876 zunächst Japan und dann auch den westlichen Ländern geöffnet hatte.

\section{III.4. Freies Handelssystem und Nationalismus - die abrupte Abkehr von der konfuzianischen Gesellschaftsordnung}

Unter militärischem Druck schloß die Yi-Dynastie im Jahre 1876 mit Japan einen sogenannten "Freundschaftsvertrag". ${ }^{45}$ Kernpunkt dieses Vertrages war die Öffnung bestimmter koreanischer Häfen für japanische Handelsniederlassungen. Daraufhin folgten weitere "Freundschaftsverträge", sprich Handelsabkommen, mit westlichen Ländern. ${ }^{46}$ Dies hatte zur Folge, daß sich die Koreaner, die auf diese Weise zum ersten Mal in ihrer Geschichte mit westlichen Unternehmen und den damit zusammenhängenden Marktmechanismen in Berührung kamen, auf breiter Front den Herausforderungen der westlichen Gesellschaft stellen mußten.

Das freie Handelssystem: Die Öffnung Koreas führte dazu, daß die wirtschaftliche Entwicklung des Landes eng an das Welthandelssystem gekoppelt wurde. Es war nunmehr nicht nur möglich, ausländische Waren ohne Einschränkung nach Korea zu importieren, sondern auch, koreanische Produkte ins Ausland (vor allem nach Japan und China) zu exportieren. Auch wenn die Mehrheit der Bevölkerung als Folge der strukturbedingten ökonomischen Unterentwicklung einem zuneh-

\footnotetext{
${ }^{45}$ Im Jahr 1875 schickte Japan seine Flotte nach Korea, die von koreanischer Seite beschossen wurde. Die Japaner interpretierten dies als Angriff auf Japan, bedrohten Korea erneut mit ihrer Kriegsflotte und erzwangen so die Unterzeichnung des "Freundschaftsvertrages."

${ }^{46}$ So kam es zu Handelsabkommen mit Nordamerika (1882), mit England und Deutschland (1883), mit Rußland und Italien (1884) sowie mit Frankreich (1886).
} 
menden Verarmungsprozeß unterworfen war, bedeutete dies nicht, daß das Land über keine Exportgüter verfügte. Insbesondere für japanische Händler waren landwirtschaftliche Produkte wie Reis, Bohnen und Rindsleder als Importgüter von groBem Interesse. ${ }^{47}$ Nachdem in Folge der beschleunigten Industrialisierung Japans die Binnennachfrage nicht mehr mit eigenen landwirtschaftlichen Produkten zu decken war, stieg das japanische Interesse an koreanischem Reis noch und trieb damit den Preis für Reis auf dem koreanischen Markt in die Höhe. ${ }^{48}$

Die großen Gewinner dieses ökonomischen Wandlungsprozesses in Korea waren in erster Linie die wohlhabenden Yangban, die sich nach Beendigung ihrer Beamtenlaufbahn als Grundbesitzer auf dem Land niedergelassen hatten. Aufgrund der spürbaren Verbesserung ihrer ökonomischen Lage änderte sich allmählich auch ihr herkömmliches konfuzianisch geprägtes Verständnis des ökonomischen Handelns. Sie erkannten, daß die hohe Gewinnspanne, die sie erzielten, nicht allein durch Fleiß, sondern vor allem durch marktkonformes ökonomisches Handeln zu erzielen war. Anzeichen für diese neue Erkenntnis war die hohe Investitionsrate beim Kauf von neuem Land. ${ }^{49}$ Das Interesse der Grundbesitzer an der Erweiterung ihres Landbesitzes war dabei natürlich an sich kein neues Phänomen. Neu war lediglich der veränderte ökonomische Handlungszusammenhang, in dem dieser Kauf gesehen werden muß. Denn die Großgrundbesitzer bzw. Yangban betrachteten nun erstmals das Land nicht mehr nur als ein Symbol für ihren Reichtum, sondern als ein wichtiges Produktionsmittel, das innen hohe Gewinne brachte.

Die traditionellen Kleinbauern, die Nong, dagegen waren nicht in der Lage, vom Exportboom beim Reis zu profitieren. ${ }^{50}$ Nicht nur durch hohe Steuern, sondern auch durch hohe Pachtgebühren stark belastet, waren viele Nong gezwungen, sich vor Beginn der Erntezeit von den Großgrundbesitzern Lebensmittel zu leihen und

\footnotetext{
${ }^{47}$ Yong-Seop Kim, Hanguk Kunheondae Nongupsa Yeongu (Studie über die neuzeitliche Agrargeschichte in Korea), Seoul 1993, S. 19.

${ }^{48}$ Ki-Baik Lee, Hanguksa Sinron (Die neuere koreanische Geschichte), Seoul 1976, S. 336.

${ }^{49}$ Yong-Seop Kim, Hanguk Kunheondae Nongupsa Yeongu (Studie über die neuzeitliche Agrargeschichte in Korea), Seoul 1993, S. 21.

${ }^{50}$ Yong-Seop Kim, Hanguk Kunheondae Nongupsa Yeongu (Studie über die neuzeitliche Agrargeschichte in Korea), Seoul 1993, S. 20. 
dafür die kommende Ernte zu verpfänden. Nach Rückzahlung des geliehenen Reises sowie der Abgeltung der Pachtgebühr hatten die meisten von innen dann einfach keinen Reis mehr, den sie auf den Markt hätten bringen können. Da die koreanischen Grundbesitzer nach wie vor darauf beharrten, daß die Pächter ihre Pachtgebühr in Form von Naturalien leisteten, gab es für die Kleinbauern außerdem keinen Grund, Reis gegen Geld einzutauschen. Von dem ökonomischen Wandlungsprozeß, der seit der Öffnung des Landes zu beobachten war, blieb die bäuerliche Mehrheit der koreanischen Bevölkerung daher ausgeschlossen.

Wohl aber kam der Reisexport zumindest anfänglich den traditionellen privaten Händlern, den Kaekchu, zugute. Denn die japanischen Händler waren insofern auf die vermittelnde Rolle der Kaekchu angewiesen, als sie aufgrund der gesetzlichen Einschränkungen ihrer Bewegungsfreiheit (außerhalb bestimmter Hafengebiete durften die japanischen Händler ursprünglich keinen Handel treiben) sowie der fehlenden sprachlichen und kulturellen Kenntnisse über Korea nicht imstande waren, selbst Reis zu kaufen. ${ }^{51}$ Doch nachdem die koreanische Regierung unter dem Druck Japans die Bewegungsfreiheit der japanischen Geschäftsleute immer mehr hatte erweitern müssen, kauften die japanischen Importeure den Reis immer häufiger direkt bei den Produzenten. Um von deren Marktkenntnissen zu profitieren, stellten die Japaner zwar nun häufig Kaekchu in ihren Handelsfirmen ein, wodurch diese zwar weiterhin ihren Lebensunterhalt mit dem Export von Reis verdienten, aber ihre Selbständigkeit verloren. ${ }^{52}$ Als Reaktion darauf versuchten einige der nicht-angestellten Kaekchu eine Nachahmung des westlichen Unternehmenssystems, so daß zwischen 1883 und 1884 insgesamt 15 koreanische Handelsfirmen neu gegründet wurden. Aufgrund des fehlenden Kapitals sowie des fehlenden unternehmerischen Know-hows war diesen Unternehmen allerdings keine lange Lebensdauer beschieden. ${ }^{53}$

\footnotetext{
${ }^{51}$ Ki-Baik Lee, Hanguksa Sinron (Die neuere koreanische Geschichte), Seoul 1976, S. 350-351; U-Kun Han, Hanguk Kaehangki eui Sangup Yeongu (Studie über den Handel während der Öffnungszeit in Korea), Seoul 1970, S. 182.

${ }^{52}$ Ebenda, S. 237.

${ }^{53}$ Ki-Jun Cho, Hanguk Chabonjueui Balcheonsa (Die Geschichte des koreanischen Kapitalismus), Seoul 1991, S. 187; Hanguk Chongsin Munhwa Yonguwon, Hanguk Minjok Munhwa Taepaekwa Sajon (Enzyklopädie der koreanischen Kultur), Bd. 1 unter dem Stichwort "Kaehwa Cheongchaek" (Öffnungspolitik), Seoul 1991, S. 627.
} 
Allgemein gilt der Artikel von Kil-Jun Yu, den dieser am 20. Oktober 1883 in der Zeitung "Hansung-Sunbo" unter dem Titel "Hoesaseol" (Eine Firmenlehre), als der Beginn der öffentlichen Rezeption des westlichen Unternehmenssystems in Korea. Yu versuchte in diesem Artikel zu definieren, was eine Firma (koreanisch "Hosea") eigentlich sei:

"Die Gründung einer Firma gehört zu einem gesellschaftlichen Phänomen, das sich nur in den wirtschaftlich wohlhabenden westlichen Ländern beobachten läßt. Während die Handelstätigkeit in den ostasiatischen Ländern nicht über das Niveau des Warentausches zwischen einzelnen Personen hinausgeht, spielt die Firma in den westlichen Ländern eine zentrale Rolle. Für Gründung und Aufbau einer Firma schließen sich mehrere Menschen zusammen und investieren gemeinsam ihr Kapital, wobei diese Kapitalinhaber dann jeweils eine spezifische Aufgabe innerhalb der Firma übernehmen. Die Tätigkeit der Firma kann nicht nur den Bereich des traditionellen Handels ("Sang"), sondern auch den Bereich der Landwirtschaft ("Nong") und des Handwerk ("Kong") umfassen. So gibt es nicht nur Firmen, die beispielsweise ausschließlich für Transportmittel wie Eisenbahn und Schiffe zuständig sind, sondern auch Firmen, die alltägliche Konsumgüter herstellen. Trotz dieser unterschiedlichen Tätigkeitsbereiche haben alle Firmen gemeinsam, daß sie durch die "Keolsa" (die Zusammenführung oder Kooperation mehrerer Interessenten) ermöglicht werden." (Zitiert nach: Ki-Jun Cho, Hanguk Chabonjueui Balcheonsa [Die Geschichte des koreanischen Kapitalismus], Seoul 1991, S. 428).

Entsprechend wurden die ersten koreanischen Firmen, vor deren Gründung übrigens erst eine offizielle Regierungsgenehmigung eingeholt werden mußte, nach westlichem Vorbild in der Rechtsform einer Gesellschaft gegründet, die -wie oben beschrieben - aus mehreren Kapitaleignern bestand und über eine hierarchische Organisationsstruktur verfügte. Faktisch waren diese ersten Firmen allerdings nichts anderes als Genossenschaften mehrerer Kaekchu, deren traditioneller Tätigkeitsbereich sich trotz ihrer Umbenennung in eine Firma ("Sanghoe", "Hoesa" und "Sangsa") nicht geändert hatte. ${ }^{54}$

\footnotetext{
${ }^{54}$ Ki-Jun Cho, Hanguk Chabonjueui Balcheonsa (Die Geschichte des koreanischen Kapitalismus), Seoul 1991, S. 22. Dennoch wertet Cho diese Zusammenschlüsse als die ersten Versuche in Korea, die westliche Unternehmensstruktur nachzuahmen und spricht deshalb auch nicht den Yangban, sondern den Kaekchu das Verdienst zu, als erste in Korea westliche Unternehmensformen eingeführt zu haben. Ebenda, S. 186.
} 
Die Kaekchu versuchten nun, diese genossenschaftlichen Firmen zur Durchsetzung ihrer Interessen gegen die ausländischen Unternehmen zu nutzen, indem sie gemeinschaftlich auftretend die Regierung dazu zu bringen versuchten, für die Wiederherstellung ihrer alten Rechte als Zwischenhändler zu sorgen: Sie verlangten ein Gesetz, das den ohne Vermittlung der Kaekchu erfolgten Handel mit ausländischen Unternehmen als illegal bezeichnete und sogar unter Strafe stellte. Damit forderten sie ein Handelsmonopol für sich auf dem koreanischen Markt, was bei den ausländischen Unternehmen und auch bei der Regierung auf so groBen Widerspruch stieß, daß diese Form des genossenschaftlichen Zusammenschlusses von Kaekchu in Firmen bald verboten wurde. ${ }^{55}$

Die wirtschaftlichen Veränderungen in der Öffnungszeit boten den traditionellen Händlern die Möglichkeit, durch ihre Erfahrungen mit den Niederlassungen ausländischer Firmen in Korea ein neues Verständnis des ökonomischen Handelns zu entwickeln. Abgesehen von dem hohen Anteil von Eigenkapital, mit dem die ausländischen Unternehmen ausgestattet waren, und der von den Kaekchu bewundernd zur Kenntnis genommenen hohen ökonomischen Aktivität, war für die Kaekchu völlig ungewohnt, daß die von westlichen Ländern eingeführten Waren nicht in Heimarbeit, sondern in einem nach rationalen Gesichtspunkten organisierten Betrieb oder einer Fabrik hergestellt wurden. ${ }^{56}$ Das in den westlichen Betrieben praktizierte Prinzip der Gewinnmaximierung durch möglichst rationale Organisation des Produktionsmittels stellte daher für die traditionellen koreanischen Händler eine völlig neue ökonomische Denk- und Verhaltensweise dar.

Der Nationalismus als Motivation des unternehmerischen Handelns: In Korea leisteten die jüngeren Angehörigen der Yangban, die 1876 in der sog. Kaehwa-Gruppe ("Kaehwa" bedeutete in diesem Zusammenhang "Lernen vom Westen") für die Öffnung des Landes plädiert hatten, dann aber ins Exil gezwungen und erst Anfang der 1890 Jahre zurückgekehrt waren, einen wesentlichen Beitrag

\footnotetext{
${ }^{55}$ U-Kun Han, Hanguk Kaehangki eui Sangup Yeongu (Studie über den Handel während der Öffnungszeit in Korea), Seoul 1970, S. 177, S. 186.

${ }^{56}$ Ebenda, S. 210; Ki-Baik Lee, Hanguksa Sinron (Die neuere koreanische Geschichte), Seoul 1976, S. 384.
} 
zur Veränderung des ökonomischen Bewußtseins und (damit verknüpft) zur Wekkung eines Nationalbewußtseins in Korea. ${ }^{57}$ Sie gründeten eine unabhängige politische Vereinigung, die "Dokriphoephoe" ("Komitee für Unabhängigkeit"), in der sich nicht nur ehemalige Yangban, sondern auch Angehörige der niedrigsten Berufsgruppen, wie z. B. Metzger, zusammenfanden. ${ }^{58}$ In ihrer Zeitung "DokripSinmun", im Jahr 1894 von dem jüngeren Kaehwa-Anhänger Jae-Pil Seo gegründet, erschien am 14. September 1895 ein Artikel, der als ein wichtiger Indikator für den Wandel des traditionellen koreanischen Verständnisses des ökonomischen Handelns gelesen werden kann. Der Titel des Artikels lautet "Über die vier verschiedenen Volksgruppen: Sa, Nong, Kong und Sang". Der unbekannte Verfasser dieses Artikels beginnt mit dem Argument, daß man eines der wichtigsten Charakteristika von Sa [=Yangban], Nong, Kong und Sang in den westlichen Ländern nicht finde, nämlich die Tatsache, daß der Sohn dieselbe Tätigkeit ausüben müsse wie der Vater. Daher sei in Korea ein flexibler bzw. einer den realen Erfordernissen entsprechender Berufswechsel zwischen den verschiedenen Berufsgruppen nicht möglich, was er als ein großes Problem für die ökonomische Entwicklung des Landes bezeichnete. Der Anonymus fordert also eine Abkehr von der traditionellen konfuzianisch geprägten Berufsvorstellung. Die Berufswahl und die berufliche Tätigkeit sollten nicht länger nur unter dem Gesichtspunkt des gesellschaftlichen Status gesehen, sondern als ein rationaler zweckorientierter, ökonomischer Vorgang aufgefaßt werden. In diesem Zusammenhang weist er $u$. a. daraufhin, daß sogar in der Landwirtschaft, wenn sie wie in den westlichen Ländern mit Hilfe wissenschaftlicher Methoden (z. B. unter Einsatz von Düngemitteln und landwirtschaftlichen Geräten) betrieben würde, eine hoher Gewinn zu erzielen sei. ${ }^{59}$ Erinnert man sich an die konfuzianische Verhaltenslehre, nach der jegliches am Gewinn orientiertes menschliches Handeln verurteilt wird, so kann man das Ausmaß des in diesem Zeitungsartikel geforderten und von einigen progressiven

\footnotetext{
${ }^{57}$ Auch der oben zitierte Verfasser der ersten koreanischen "Firmenlehre", Kil-Jun Yu, der der erste Yangban gewesen war, der sich für die Organisationsstruktur westlicher Unternehmen interessierte, gehörte zu den Kaehwa-Anhängern.

${ }^{58}$ Ki-Baik Lee, Hanguksa Sinron (Die neuere koreanische Geschichte), Seoul 1976, S. 359.
} 
Yangban auch bereits vollzogenen Wandels des ökonomischen Verständnisses ermessen.

Die Mitglieder von "Dokriphoephoe" kritisierten darüber hinaus insbesondere, daß König und Regierung ausländischen Unternehmen zahlreiche wirtschaftliche Projekte und vor allem die Ausbeutung der koreanischen Bodenschätze überlassen hatten. Insbesondere letzteres bezeichneten sie als Verrat an der Nation, da die koreanischen Rohstoffe auf diese Weise dem Land entzogen und statt dem Aufbau einer einheimischen Industrie der Entwicklung der Industrie in anderen Ländern dienten. ${ }^{60}$

Die Versuche der Kaehwa-Anhänger den Einfluß japanischer Unternehmen in Korea zurückzudrängen, blieben allerdings verglichen mit anderen politischen Aktivitäten dieser Gruppe (z. B. Reformen im Bildungsbereich) mehr oder weniger folgenlos. Denn es gab nur wenige koreanische Produzenten, die die zunehmende Nachfrage nach Alltagsgütern (wie z. B. Baumwolle und Textilien) befriedigen konnten. Doch wurden zwischen 1897 und 1907 in Korea immerhin elf Unternehmen gegründet, die sich mit der Verarbeitung von Baumwolle, Seide und Leinen beschäftigten. Unter den Unternehmern befanden sich nicht nur ein ehemaliger Beamter, der sich als Leiter einer staatlichen Manufaktur Kenntnisse über die Produktionstechnologie angeeignet hatte, sondern auch ehemalige Handwerker und Kaufleute ${ }^{61}$ - ein Zeichen dafür, daß sich die traditionelle ständische Berufsstruktur tatsächlich allmählich auflöste. Doch war dem unternehmerischen Engagement in Korea - gleich in welcher Schicht - vor allem dadurch enge Grenzen gesetzt, als jede Investition durch den Export von Reis finanziert werden mußte. ${ }^{62} \mathrm{Au}$ Berdem ist festzuhalten, daß das neue ökonomische Verständnis weit weniger durch an der Logik des Marktes orientiertes Handeln als vielmehr in erster Linie durch nationale Motive bestimmt war.

\footnotetext{
${ }^{59}$ Wiedergegeben nach: Ki-Jun Cho, Hanguk Chabonjueui Balcheonsa (Die Geschichte des koreanischen Kapitalismus), Seoul 1991, S. 432.

${ }^{60}$ Yong-Ha Shin, Hanguk Kundae Sahoesa Yeongu (Studie über die neuzeitliche Sozialgeschichte in Korea), Seoul 1987, S. 262.

${ }^{61}$ Ebenda, S. 387.

${ }^{62}$ Ebenda, S. 411.
} 
Der Bewegung, die Gründung eines Unternehmens als nationale Angelegenheit zu fördern, war allerdings keine lange Lebensdauer beschieden. Nachdem der russisch-japanische Krieg 1905 mit dem Sieg Japans geendet hatte, erkannten die westlichen Länder Japans Recht auf Korea an. Aufgrund wiederholter militärischer Drohungen Japans schloß Korea noch im gleichen Jahr ein neues Abkommen mit Japan, nach dem die koreanische Regierung ohne japanische Zustimmung keine politischen oder wirtschaftlichen Entscheidung mehr treffen durfte. Endgültig wurde Korea am 22. August 1910 von Japan annektiert. Somit endete die seit 1392 herrschende und konfuzianisch geprägte politische Herrschaftsstruktur der Yi-Dynastie im Jahre 1910.

\section{5. Gesellschaftlich-institutionelle Veränderungen während der japanischen Kolonialzeit}

Unbestritten hat der institutionelle Wandlungsprozeß während der japanischen Kolonialzeit zur Verbesserung der ökonomischen Infrastruktur in Korea beigetragen, was sich vor allem quantitativ niedergeschlagen hat. ${ }^{63}$ Doch sagt die sicherlich beeindruckende Steigerung der industriellen Produktivität noch nichts darüber aus, ob dieser Wandlungsprozeß die Herausbildung eines eigenständigen koreanischen Unternehmertums eher befördert oder behindert hat, ${ }^{64}$ und sie sagt vor

\footnotetext{
${ }^{63}$ Die städtische Bevölkerung wuchs zwischen 1910 und 1935 von drei auf sieben Prozent, und betrug 1944 sogar schon 13 Prozent. Die landwirtschaftliche Produktion wurde bis 1940 fast auf das Doppelte gesteigert, und Bergbau und Industrie wuchsen im gleichen Zeitraum um 1500 Prozent. Vgl. Dennis L McNamara., The Colonial Origins of Korean Enterprise 1910-1945, New York 1990, S. 2.

${ }^{64}$ Der amerikanische Historiker Carter J. Eckert und der englische Historiker Dennis L. McNamara sprechen eher von einer positiven Wirkung auf die Herausbildung eines koreanischen Unternehmertums, während die koreanischen Wirtschaftshistoriker darauf verweisen, daß die Mehrheit der Koreaner von der Partizipation an den wirtschaftlichinstitutionellen Errungenschaften der japanischen Kolonialzeit ausgeschlossen gewesen sei. Vgl. Carter J Eckert., Offspring of Empire: The Kochang Kims and the Colonial Origins of Korean Capitalism 1876-1945, Seattle/London 1991; Dennis L McNamara., The Colonial Origins of Korean Enterprise 1910-1945, New York 1990; Byong-Jik Ahn, Ilche eui Chosun Chibae wa Sutalkujo (Die koloniale Ausbeutung Koreas durch Japan), in: Yun-Hwan Kim u.a., Hanguk Keongje eui Cheongae Kujo (Die Entwicklung der koreanischen Ökonomie), Seoul 1981, S. 17-34.; Ki-Jun Cho, Hanguk Minjok Kiup Keonsol
} 
allem nichts über die hier interessierende Frage nach der Wahrnehmung oder Rezeption dieses Wandlungsprozesses durch die koreanischen Unternehmer im Spannungsfeld zwischen Tradition und neuen ökonomischen Erfordernissen bzw. Möglichkeiten. Dabei richtet sich meine Aufmerksamkeit nicht nur auf das ökonomische Vorgehen der koreanischen Großunternehmer, sondern auch auf die Verhaltensweise der Kleinunternehmer.

Anhand der Bodenreform, den neuen Gesetzen, die die Unternehmensgründungen kontrollierten und begrenzten, und an der Reform des Schulsystems soll im folgenden gezeigt werden, daß die Koreaner die zahlreichen institutionellen Veränderungen durch die Japaner eher als kulturelle Regression empfanden und daß eine Identifikation mit den neuen Institutionen nicht stattfand.

Die Bodenreform: Bald nach der Annexionserklärung im Jahr 1910 nahm die Kolonialregierung das Projekt in Angriff, die Besitzverhältnisse in der Wald- und Landwirtschaft in Anlehnung an die westlichen Prinzipien des privaten Eigentumsrechts neu zu regeln. ${ }^{65}$ In diesem Zusammenhang mußte jeder Koreaner, der Eigentumsansprüche geltend machen wollte, bei einer staatlichen Verwaltungsstelle vor Ort sein Land registrieren lassen. Diese Praxis war für Korea völlig neu. In der Yi-Dynastie gab es keine einheitliche Regelungen des Eigentumsrechts; sie variierten je nach Region. Obwohl das Land praktisch wie Eigentum behandelt wurde, gekauft und verkauft werden konnte, so gehörte es doch nominell nach wie vor dem König. Mit der Durchführung der Bodenreform wurde daher in Korea zum ersten Mal das Prinzip des Privateigentums offiziell durchgesetzt.

Dabei begründete die japanische Kolonialregierung die Notwendigkeit einer klaren gesetzlichen Regelung der Besitzverhältnisse mit dem großen Bauernauf-

eui Sasngjeok Baegyong (Der intellektuelle Hintergrund des nationalen Unternehmens in Korea), in: Oki Kwon (Hrsg.), Inchon Kim Sung-Su eui Aejok Sasang kwa ku Silcheon (Der Patriotismus von Sung-Su Kim in Denken und Praxis), Seoul 1982, S. 85-155; Ders., Hanguk Chabonjueui Seonripsaron (Die koreanische Entwicklung des Kapitalismus), Seoul 1973, S. 45; Sang-Chul Suh, Growth and Structural Changes in the Korean Economy 1910-1940, Cambridge u. a. 1978.

${ }^{65}$ Ki-Baik Lee, Hanguksa Sinron (Die neuere koreanische Geschichte), Seoul 1976, S. $376 \mathrm{f}$. 
stand, den es 1894 in Korea gegeben hatte und den die Japaner auf die willkürliche Ausweitung des Besitzrechts durch die Großgrundbesitzer zurückführten. ${ }^{66}$

Mit der Einführung des privaten Eigentumsrechts wurde die Beziehung zwischen Grundbesitzer und Pächter in Form eines Vertrages geregelt, der jährlich erneuert werden mußte, während die konventionelle alte Beziehung zwischen Grundbesitzer und Pächter von Generation zu Generation gegolten hatte. ${ }^{67}$ Dies bedeutete, daß mit Beginn der Kolonialzeit der Pächter plötzlich in eine Situation geraten konnte, in der er sein Land verlassen mußte, weil der Grundbesitzer den Vertrag nicht verlängerte. ${ }^{68}$ Der Bauer konnte allerdings, wenn er die Kündigung für unrechtmäßig hielt, einen Prozeß gegen den Grund-besitzer anstrengen.

1918 war das Projekt der Vermessung und Registrierung des Landes abgeschlossen. Die Kolonialregierung, die früheren Grundbesitzer der Yi-Dynastie und die von der Kolonialregierung gezielt ins Land geholten japanischen Immigranten waren die Gewinner der Landreform, während die zahlreichen koreanischen Bauern zu den Verlierern gehörten. Nicht wenige Bauern waren der Meldepflicht zur Landvermessung nicht nachgekommen, nicht nur, weil sie es nicht gewohnt waren, sich bei einer Verwaltungsstelle zu melden, sondern auch, weil sie durch einen

\footnotetext{
${ }^{66}$ Byong-Tae Kim, Nongchi Kaeheokeui Peongka wa Banseong (Auswertung und Reflexion über die Bodenreform), in: Yun-Hwan Kim u.a., Hanguk Keongje eui Cheongae Kujo (Der Entwicklungsprozeß der koreanischen Ökonomie), Seoul 1981, S. 37. In Carter J. Eckert (Hrsg.), Korea Old and New: A History, Cambridge u. a. 1990, S. 215, wird die Ursache dieser Bauernrebellion wie folgt dargestellt: "Life for the peasantry worsened under the Min oligarchy for a number of fundamental economic reasons. Special exemptions, abandoned fields, and tax evasion diminished the government's receipts, while developments subsequent to the opening of Korean ports, such as the exchange of diplomatic missions, the payment of indemnities to Japan, the acquisition of modern military weapons, and the construction of modern facilities, required new and heavy expenditures. These were paid for in part by customs receipts and foreign loans, but government activities still had to be financed primarily by tax collections from the farming villages. The burdens on the peasantry doubled or even tripled, as every pretext was used to impose fresh levies upon them, while the petty functionaries who collected the taxes resorted to increasingly harsh methods of extortion."

${ }^{67}$ Der bekannte sozialistische Schriftsteller Man-Sik Chae veröffentlichte in der Zeitung Sintonga eine Satire zu diesem Thema, deren Titel darauf anspielt, daß sich die Grundbesitzer nach der Einführung der neuen Verträge nur noch für ihre Gewinne interessierten: Man-Sik Chae, Chogmanhan Kiupga (Der kleine Unternehmer), in: Sintonga, Heft Dezember (1931), S. 106-108.

${ }^{68}$ Yong-Duk Kim, Ilche emi Keongjecheok Sutal kwa Minu:1910-1918 (Die ökonomische Ausbeutung durch Japan und das Elend des koreanischen Volkes), in: Reoksa Hakbo, Vol. 41/42 (1969), S. 6.
} 
solchen Schritt der japanischen Kolonialregierung politische Legitimität verliehen hätten. ${ }^{69}$ So geschah es häufig, daß das Land ohne Wissen des ursprünglichen Besitzers unter dem Namen eines anderen registriert wurde. Das nicht registrierte Land wurde Eigentum der Kolonialregierung. ${ }^{70}$

Obwohl sich die ökonomische Lage der privilegierten Mitglieder der ehemaligen Yangban-Schicht durch das Projekt der Landvermessung eher verbessert hatte, läßt sich nicht sagen, daß dieser ökonomische Vorteil ihre Anpassungsfähigkeit an die neuen Institutionen bzw. an einen kulturellen Wandel gefördert hätte. Im Gegenteil: In Abgrenzung von den neuen oktroyierten institutionellen Strukturen bemühten sich die koreanischen Grundbesitzer darum, ihre konfuzianisch geprägte kulturelle Identität weiterhin zu bewahren. ${ }^{71}$

Für die Pächter, deren Lage sich ständig verschlechterte, spiegelten die neuen Institutionen nur das ökonomische Interesse ihrer "Herren", seien es nun Yangban oder die japanischen Kolonialherren, wider. Ihr Widerstand gegen die von Japan ohne Rückkopplung an die einheimischen kulturelle Tradition eingeführten neuen Eigentumsregelungen, der sich in einer verstärkten kulturellen Rückwendung zur alten konfuzianisch geprägten Gesellschaftsordnung der Yi-Dynastie zeigte, war daher auch ökonomisch begründet.

Staatliche Kontrolle von Unternehmensgründungen: 1910 verabschiedete die Kolonialregierung ein Gesetz, das die Gründung eines Unternehmens in Korea nur mit Erlaubnis des Generalgouverneurs gestattete, wobei bei Zuwiderhandlung sogar Gefängnis drohte. ${ }^{72}$ Das Gesetz galt nicht nur für die koreanische Bevölkerung, sondern auch für Japaner, die in Korea ihre Filialen gründen wollten. Für die Koreaner begründete die Kolonialregierung die Notwendigkeit der staatlichen

${ }^{69}$ Ki-Baik Lee, Hanguksa Sinron (Die neuere koreanische Geschichte), Seoul 1976, S. 377.

${ }^{70}$ Yong-Duk Kim, Ilche uei Keongjecheok Sutal kwa Minu:1910-1918 (Die ökonomische Ausbeutung durch Japan und das Elend des koreanischen Volkes), in: Reoksa Hakbo, Vol. 41/42 (1969), S. 9.

${ }^{71}$ Man-Gyu Lee, Saeyangban Yirago Bulechuka? (Sollten sie neue Yangban genannt werden?), in: Sintonga, Heft Oktober (1935), S. 120. 
Kontrolle damit, daß diese noch über keine gesetzlichen Kenntnisse für unternehmerisches Handeln verfügten. Für die japanischen Unternehmen hielt sie die staatliche Kontrolle deswegen für unentbehrlich, weil sie sonst aus Unkenntnis der gesellschaftlichen Realität in Korea zu Fehlinvestitionen verleitet werden könnten. $^{73}$

Selbst wenn ein koreanischer Antragsteller in der Lage gewesen wäre, die formalen Auflagen dieses Genehmigungsverfahrens (z. B. durfte er nicht in Bereichen investieren, wo es schon einen japanischen Konkurrenten gab) zu erfüllen, scheiterte er häufig an dem strengen Kontrollverfahren der japanischen Behörden. Denn die Kolonialregierung hatte angeordnet, auch die persönlichen Verhältnisse der koreanischen Antragsteller genau zu untersuchen, vorgeblich, um potentielle Betrüger auszuschalten, faktisch aber, um die Zahl der koreanischen Unternehmensgründungen klein zu halten. Solche Maßnahmen verschärften natürlich die kulturellen Spannungen zwischen den koreanischen

\footnotetext{
${ }^{72}$ Yong-Duk Kim, Ilche uei Keongjecheok Sutal kwa Minu:1910-1918 (Die ökonomische Ausbeutung durch Japan und das Elend des koreanischen Volkes), in: Reoksa Hakbo, Vol. 41/42 (1969), S. 15.

${ }^{73}$ Ebenda, S. 14.
} 
Antragstellern und der japanischen Kolonialmacht, zumal die japanischen Behörden aus ihrer rassistischen Abneigung gegen Koreaner - wie zeitgenössische Aussagen belegen - keinen Hehl machten. Hinzu kam noch, daß die japanischen Bürokraten dazu verpflichtet waren, vor der letzten Entscheidung des Generalgouverneurs ihre Befürwortung eines koreanischen Antrages mündlich zu begründen. Um dieser Arbeitsbelastung zu entgehen, neigten viele Bürokraten dazu, entsprechende Anträge schon im Vorfeld abzulehnen. ${ }^{74}$

Kritik an den staatlichen Einschränkung bei der Gründung von Unternehmen kam in erster Linie von den japanischen Unternehmern, die ihren während des Ersten Weltkrieges erzielten Gewinn in Korea investieren wollten. ${ }^{75}$ Doch auch die Angehörigen der koreanischen Eliteschichten, die wie die ehemaligen Mitglieder der Kaehwa-Gruppe die japanischen Annexion unterstützt hatten, kritisierten zunehmend die innen auferlegten Beschränkungen. Denn sie gehörten ja zu den Yangban, die den Beruf des Unternehmers nicht mißbilligten, und sahen sich nun um ihre Hoffnung betrogen, selbst die Trägerschicht des modernen koreanischen Staates zu werden. Angesichts des zunehmenden Drucks der einheimischer Unternehmen sprach sich das japanische Parlament zwar schon 1918 für die Abschaffung des aufwendigen und restriktiven Genehmigungsverfahrens bei Unternehmensgründungen aus, doch wurden die entsprechende Gesetze erst im Jahre 1920 - nach der großen Massendemonstration für die Unabhängigkeit Koreas am 1. März 1919 - endgültig abgeschafft. ${ }^{76}$

Die Schulreform: Obwohl die japanische Kolonialregierung bei ihrer Annexionserklärung der koreanischen Bevölkerung versprochen hatte, ihre kulturelle Identiät zu respektieren, wurde 1911 ein Schulgesetz erlassen, dessen Ziel die "Japanisierung" der koreanischen Nation war. ${ }^{77}$ Das Gesetz sah vor, daß an koreanischen Schulen künftig japanische Sprache, Kultur und Geschichte unterrichtet

\footnotetext{
${ }^{74}$ Ebenda, S. $16 \mathrm{f}$.

${ }^{75}$ Ebenda, S. 18.

${ }^{76}$ Ki-Baik Lee, Hanguksa Sinron (Die neuere koreanische Geschichte), Seoul 1976, S. 411.

${ }^{77}$ Ki-Un Han, Sahak eui Balcheon kwa 3.1. Undong (Die Entwicklung privater Schulen und die Bewegung des 1. März), in: The Journal of Asiatic Studies, Vol XII (1969), S. 91.
} 
werden sollten, während zugleich der Unterricht über koreanische Geschichte und Kultur verboten wurde. Im Gegensatz zu den Verhältnissen während der YiDynastie sollten nun auch die Kinder der niedrigeren Bevölkerungsschichten in dieser modernen Schule unterrichtet werden. ${ }^{78}$

Dennoch führten diese bildungspolitischen Maßnahmen der Kolonialregierung nicht zur Abschaffung der alten konfuzianisch geprägten Schule. Zwar nutzte die Kolonialregierung sogar das Mittel polizeilicher Drohungen, um die bisher nicht beschulten koreanischen Kinder der Unterschichten in die neu errichteten staatlichen Grundschulen ("Botong-Hakgyo") zu schicken, aber sie war (zumindest in den ersten Jahren) nicht dagegen, wenn sich deren Eltern statt dessen für die traditionelle konfuzianische Schule ("Seodang") entschieden. Denn wegen des in der konfuzianischen Lehre als höchste Tugend gepriesenen Prinzips des Gehorsams bzw. der Loyalität der staatlichen Obrigkeit gegenüber erhoffte sich die japanische Kolonialregierung von den konfuzianischen Schulen die Zunahme der Anpassungsbereichtschaft an die neue koloniale Herrschaftssituation. Was die Kolonialregierung dagegen mit allen Mitteln verhindern wollte, war die Errichtung moderner koreanischer Privatschulen. ${ }^{79}$

Trotz aller Versuche, die koreanische Bevölkerung zu "japanisieren", stellte ein zeitgenössischer (japanischer) Beobachter fest, daß in Korea der Antijapanismus vor allem bei den Absolventen der höheren japanischen Schulen immer ausgeprägter wurde. ${ }^{80}$ So stammte auch die erste Initiative für die Bewegung zur Erlangung der koreanischen Unabhängigkeit, die sich auf das von dem amerikanischen Präsidenten Wilson deklarierte Prinzip der Selbstbestimmung der Völker berief und in einer großen brutal niedergeschlagenen Massendemonstration am 1. März

\footnotetext{
${ }^{78}$ In der Yi-Dynastie zielte - wie oben geschildert - die Bildungspolitik im wesentlichen auf die Reproduktion der konfuzianisch gebildeten Beamtenschicht, wobei sich fast in jedem Dorf eine konfuzianische Schule befand, die meistens von den ortsansässigen Yangban selbst getragen wurde. Als 1866 in Korea zum ersten Mal moderne Schulen nach japanischem Vorbild eingerichtet wurden, war der Zugang zu diesen Schulen auf die Kinder der privilegierten Regierungsmitglieder beschränkt.

${ }^{79} \mathrm{Ki}-$ Un Han, Sahak eui Balcheon kwa 3.1. Undong (Die Entwicklung der privaten Schulen und die Bewegung des 1. März), in: The Journal of Asiatic Studies, Vol XII (1969), S. 92.
} 
1919 gipfelte, von einer Gruppe von Studenten, die in Japan studiert hatten. ${ }^{81}$ Die von den Studenten artikulierte Kritik an der Kolonialregierung richtete sich dabei nicht nur gegen die "Japanisierung" der koreanischen Nation durch die Vernachlässigung der koreanischen Sprache und das Unterrichtsverbot für koreanische Geschichte in den Schulen, sondern auch dagegen, daß das koreanische Volk immer "ungebildeter" ("Uminhwa") werde, da es im koreanischen Schulsystem an höheren Bildungsorganisationen (insb. Universitäten) fehlte. Denn die meisten der in Korea von den Japanern neu errichteten Schulen konzentrierten sich auf die Landwirtschaft, was nach dem herkömmlichen konfuzianisch geprägten Verständnis keine klassische Bildung war. ${ }^{82}$ Für die Koreaner war diese Bildungspolitik eine Zerstörung ihrer Kultur, weil sie den traditionellen Respekt vor höherer Bildung nicht berücksichtigte. Hier zeigt sich, daß der kulturelle Wandlungsprozeß nicht unbedingt mit dem institutionellen Wandlungsprozeß einherging.

Die Massendemonstration am 1. März 1919, die zum Erschrecken der Kolonialregierung ein schichtübergreifendes Phänomen war, das insbesondere auch die Bauern erfaßte, ${ }^{83}$ zeigte den Japanern erstmals deutlich die Notwendigkeit, den institutionellen Wandlungsprozeß in Korea an die einheimische kulturelle Identität zu koppeln. Sie mußten feststellen, daß ganz gegen ihre Intention die scheinbar so erfolgreiche institutionelle Wandlung der koreanischen Gesellschaft nicht zu kultureller Assimilation, sondern vielmehr zur Stärkung der koreanischen kulturellen Identität geführt hatte.

Der Widerstand der koreanischen Elite gegen die Kolonialpolitik lag auch darin begründet, daß sie im neuen Staat nicht als Angehörige der herrschenden Schicht

${ }^{80}$ E. Patricia Tsurumi, Colonial Education in Korea and Taiwan, in: Ramon H. Myers, Mark R.Peattie (Ed.), Colonialism and Development: Korea, Taiwan, and Kwangtung, Princeton/New York 1984, S. 303.

${ }^{81}$ Ein solches Studium im Ausland war wegen der höheren Studiengebühren nur für die Kinder der ehemaligen privilegierten Yangban-Schicht möglich. Tong-Jin Kang, llche Chibaeha eui Nodong Yahak (Die Abendschule für Arbeiter in der japanischen Kolonialzeit), in: Reoksa Hakbo, Vol. 43 (1970), S. 9; vgl. auch Ki-Baik Lee, Hanguksa Sinron (Die neuere koreanische Geschichte), Seoul 1976, S. 401.

${ }^{82} \mathrm{Ki}-$ Un Han, Sahak eui Balcheon kwa 3.1. Undong (Die Entwicklung privater Schulen und die Bewegung des 1. März), in: The Journal of Asiatic Studies, Vol XII (1969), S. 109.

${ }^{83}$ Ki-Baik Lee, Hanguksa Sinron (Die neuere koreanische Geschichte), Seoul 1976, S. 403. 
gesehen wurden. Bei den Verhören durch die japanische Polizei nach der Demonstration am 1. März erklärten sie ihre Teilnahme damit, daß entgegen der japanische Annexionserklärung von 1910, die von der Gleichheit der beiden Nationen ausgegangen war, der politische, ökonomische und soziale Veränderungsprozeß der koreanischen Gesellschaft nur zugunsten der japanischen Bevölkerung stattgefunden habe. Genannt wurden in diesem Zusammenhang vor allem das Verbot moderner koreanischer Hochschulen, die fehlende höhere Beamtenschicht, die fehlende koreanische Unternehmerschaft und der Mangel an koreanischen Zeitungen, die für die kulturelle Identität der koreanischen Bevölkerung wichtig seien. ${ }^{84}$

Nach der brutalen Niederschlagung der Unabhängigkeitsbewegung gab die Kolonialregierung die endgültige Abkehr von der Phase des "military rule" bekannt, die von 1910 bis 1919 gegolten hatte. Ziel der neuen Politik war nun die kulturelle Integration der koreanischen Bevölkerung. Die Regierung versprach daher, die kulturpolitischen Forderungen der koreanischen Bevölkerung zu erfüllen. Dies bedeutete neben der Zulassung von koreanischsprachigen, nicht-zensierten Zeitungen vor allem den Fall der institutionellen Schranken, die bis dahin den Zugang vor Koreaner zur höheren (modernen) Schul- und Universitätsbildung, zur Regierungsverwaltung und zum freien Unternehmertum verhindert hatten. ${ }^{85}$

\section{III.6 Die Entwicklung der koreanischen Unternehmen bis 1945}

Im folgenden werden zunächst die Entwicklung der koreanischen Großunternehmen und anschließend die besonderen Bedingungen, unter denen sich in Korea auch Kleinunternehmen bildeten, analysiert.

\footnotetext{
${ }^{84} \mathrm{Ki}$-Un Han, Sahak eui Balcheon kwa 3.1. Undong (Die Entwicklung privater Schulen und die Bewegung des 1. März), in: The Journal of Asiatic Studies, Vol XII (1969), S. 112.

${ }^{85}$ Sun-Jae Paik, Ilche Sidae eui Gundaehwa Undong (Die Modernisierungsbewegung in der japanischen Kolonialzeit), in: Sintonga, Heft Februar (1966), S. 333; Ki-Baik Lee, Hanguksa Sinron (Die neuere koreanische Geschichte), Seoul 1976, S. 407 f.
} 
Die Großunternehmen: Unter den während der japanischen Kolonialzeit entstandenen koreanischen Unternehmen befanden sich auch einige sog. large scale enterprises, worunter man Banken, große Kaufhäuser und große Industriebetriebe versteht:

Von den koreanischen Banken, die vor 1910 gegründet wurden, mußten die meisten nach der Annexion durch Japan entweder mit japanischen Banken fusionieren oder wurden geschlossen. Nur eine koreanische Bank, die Bank "Hanil", bestand weiter. ${ }^{86}$ Sie war von dem wohlhabenden koreanischen Grundbesitzer In-Gi Paek 1906 gegründet worden, der zunächst selbst Direktor dieser Bank war. 1912 übernahm Young-lk Min, der ein politisch einflußreiches Regierungsmitglied während der Yi-Dynastie gewesen war und wegen seiner projapanischen Haltung von der Kolonialregierung sogar geadelt wurde, die Bank. Min, dessen Berufung vor allem damit zusammenhing, daß die Japaner die koreanische Elite für sich gewinnen wollten, verfügte bei Verhandlungen mit der japanischen Kolonialregierung über einen relativ großen Handlungsspielraum. ${ }^{87}$

Während sich die von den Japanern in Korea gegründete Zentralbank eher für die Förderung ihrer eigenen großen Unternehmen (den sog. Zaibatsu) als für die der einheimischen koreanischen Unternehmen interessierte, sollte Hanil nach dem Willen ihres Gründers gezielt koreanische Unternehmen fördern. ${ }^{88}$ Obwohl Hanil aufgrund ihrer finanziellen Möglichkeiten gar nicht imstande war, große unternehmerische Projekte zu finanzieren, war ihre Existenz in den 20er und 30er Jahren vor allem dadurch gesichert, daß sie als ein nationales Symbol von der japanischen Kolonialregierung, die keine Kollision mit der koreanischen Elite riskieren wollte, unterstützt wurde. Wichtig war dabei, daß die Bank trotz des zunehmenden Kapitalanteils der Kolonialregierung nach außen weiter den Eindruck erweckte, eine koreanische Bank zu sein, weshalb der Direktorenposten weiter von einem Mitglied der Min-Familie besetzt wurde. Diese interessierten sich allerdings im

\footnotetext{
${ }^{86}$ Suk-Ryun Lee, Urinara Hwape Kumyungsa (Die Geschichte der koreanischen Währung und Banken), Seoul 1994, S. 495-500.

${ }^{87}$ Dennis L. McNamara, The Colonial Origins of Korean Enterprise 1910-1945, New York 1990, S. 68, S. 73.

${ }^{8}$ Suk-Ryun Lee, Urinara Hwape Kumyungsa (Die Geschichte der koreanischen Währung und Banken), Seoul 1994, S. 499.
} 
Laufe der Jahre immer weniger für die Verwaltung ihres Unternehmens, so daß Mitarbeiter der Kolonialregierung zu Managern der Bank gemacht werden mußten. $^{89}$

Wie erfolgreich Hanil nach außen auch gewirkt haben mag, die Bank war unverkennbar von der Duldung der japanischen Kolonialregierung abhängig. Deshalb fiel dieses Unternehmen mit dem Eintritt Japans in den Zweiten Weltkrieg und der Einbindung der koreanischen Unternehmen in die japanische Kriegswirtschaft den Fusionsplänen der japanischen Kolonialregierung zum Opfer. ${ }^{90}$

Mit den japanischen Unternehmern, die sich nach der Annexion in Korea niederließen, kamen auch die kleinen und modernen Kaufhäuser nach Korea, in denen man viele Importgüter aus Japan und den westlichen Ländern kaufen konnte. Für die Mehrheit der Koreaner galten diese Kaufhäuser als Symbol des modernen und fortschrittlichen japanischen Unternehmertums. Denn vor 1919 hatten die Koreaner ihre Konsumgüter nicht in Kaufhäusern gekauft, sondern bei kleinen Händlern auf dem Markt. 1931 gründete dann der junge Unternehmer Hung-Sik Park das erste koreanische Kaufhaus "Hwashin". Bereits 1935 begann er sein Unternehmen mit insgesamt 350 Filialen landesweit auszubauen. ${ }^{91}$ Dies wurde von vielen Koreaner mit Genugtuung als ein Zeichen dafür registriert, daß koreanische Unternehmer sich nicht länger japanischen Unternehmen unterordneten. Außerdem war das Hwashin-Kaufhaus dafür bekannt, abgesehen von einem japanischen Manager, nur koreanische Mitarbeiter zu beschäftigen, was allein schon viele koreanische Konsumenten veranlaßte, in Parks Kaufhaus statt bei der japanischen Konkurrenz zu kaufen. ${ }^{92}$

Anders als Tae-Sik Min, der als der Sohn eines mächtigen und wohlhabendes ehemaligen Regierungsmitgliedes der Yi-Dynastie später Bankier geworden war, stammte Park aus armen und einfachen bäuerlichen Verhältnissen. Er hatte sich

\footnotetext{
${ }^{89}$ Dennis L. McNamara, The Colonial Origins of Korean Enterprise 1910-1945, New York 1990, S. 74, S. 76.

${ }^{90}$ Ebenda, S. 70, S. 77.

${ }^{91}$ Redaktion Sintonga, (nicht gezeichneter Artikel), Park Hung-Sik ssi Bangmunki (Ein Besuch bei Hung-Sik Park), in: Sintonga, Heft Januar (1935), S. 195.; Carter J. Eckert, Offspring of Empire: The Kochang Kims and the Colonial Origins of Korean Capitalism 1876-1945, Seattle/London 1991, S. 159.

${ }^{92}$ Ebenda, S. 93.
} 
aber - da er nach dem Tod des Vaters die Familie ernähren mußte - schon als 15jähriger im Reishandel betätigt und betrieb später in seiner Heimatprovinz eine Druckerei, bis er sich 1926 (im Alter von 23 Jahren) entschloß, das Zentrum seiner geschäftlichen Tätigkeiten nach Seoul zu verlegen. Dort errichtete er eine große Papierfabrik, die Druckmaschinen und Papier aus dem Ausland importierte, und gründete dann, noch nicht einmal 30 Jahre alt, das Hwashin-Kaufhaus. ${ }^{93}$

Da trotz seiner vorherigen unternehmerischen Aktivitäten sein Eigenkapital für das Kaufhausprojekt nicht ausreichte und er anders als Min keine finanzkräftige Familie im Hintergrund hatte, konnte er seine Finanzierungsprobleme nur aufgrund seiner geschickt eingesetzten Beziehung zum japanischen Generalgouverneur lösen. ${ }^{94}$ Der japanischen Kolonialregierung kam der gute Kontakt zu dem Emporkömmling Park insofern gelegen, als er den Typ des Koreaners repräsentierte, der erst durch die Errungenschaften der japanischen Kolonialzeit den Sprung in die Führungsschicht Koreas geschafft hatte. Unter der Herrschaft der Yi-Dynastie wäre eine solche berufliche Laufbahn nicht denkbar gewesen.

Parks Unternehmerkarriere endete 1945, da er im Zweiten Weltkrieg für die Japaner eine Waffenfabrik in Korea errichtet hatte. Park war der erste Unternehmer, der als Kollaborateur verhaftet wurde. ${ }^{95}$

Die Gründung des Baumwollunternehmens Keongseong-Bangjik durch Sung-Su Kim im Jahre 1919 stellte den Beginn der koreanischen Textilindustrie dar. Die Genehmigung für sein Unternehmen erhielt Kim von der japanischen Kolonialregierung allerdings erst, nachdem er sich damit einverstanden erklärt hatte, den ehemaligen Regierungsangehörigen Young-Hyo Park, der als führendes Mitglied der Kaehwa-Bewegung eine lange und gute Beziehung zur japanischen Kolonialregierung hatte, zum Präsidenten zu machen. Park, der nach der Annexion wie Min geadelt wurde, galt trotz seiner engen Zusammenarbeit mit der japanischen Kolo-

\footnotetext{
${ }^{93}$ Redaktion Sintonga (nicht gezeichneter Artikel), Park Hung-Sik ssi Bangmunki (Ein Besuch bei Hung-Sik Park), in: Sintonga, Heft Januar (1935), S. 156, S. 194.

${ }^{94}$ Carter J. Eckert., Offspring of Empire: The Kochang Kims and the Colonial Origins of Korean Capitalism 1876-1945, Seattle/London 1991, S. 159.

${ }^{95}$ Cheong-Jae Lee, Chaebol Yireokseo (Die Entwicklungsgeschichte der Chaebol), Seoul 1993, S. 70.
} 
nialregierung bei den Koreanern als gemäßigter Nationalist, weil er sich darum bemühte, den Anteil koreanischer Unternehmen zu erhöhen. ${ }^{96}$

Anregung und Initiative zur Gründung von Keonseong-Bangjik waren von dem ehemaligen koreanischen Techniker Kang-Hyon Lee ausgegangen, der seine Ausbildung in Japan erhalten hatte und seit seiner Rückkehr nach Seoul viele Artikel veröffentlicht hatte, in denen er die Bedeutung der Industrie für Korea betonte. Lee hielt die Entwicklung der modernen Industrie für einen "keystone for the foundation of the Nation", ${ }^{97}$ wobei für inn die Baumwollunternehmen, deren Produkte seit 1890 zu den wichtigsten koreanischen Importgütern aus Japan gehörten, der Prototyp des modernen großen Industriebetriebs war. Als 1917 der große japanische Baumwollbetrieb "Chonsun Bangjik" in Pusan gegründet worden war, ${ }^{98}$ empfanden dies mit Lee viele Koreaner als nationale Schande, da Japan damit nicht nur politisch, sondern auch wirtschaftlich seine Überlegenheit gegenüber Korea bewiesen hatte. Damals machte Lee Sung-Su Kim auf einen koreanischen Baumwollbetrieb aufmerksam, dessen Eigentümer - wohlhabende Yangban, die durch den Export von Reis nach Japan reich geworden waren, aber nichts von der Baumwollindustrie verstanden - möglichst schnell verkaufen wollten, um zumindest ihr investiertes Eingangskapital zu retten. ${ }^{99}$ An Sung-Su Kim hatte sich Lee deshalb gewandt, weil dieser als der wohlhabende Sohn eines Grundbesitzers nicht darauf angewiesen war, daß

sein Betrieb Gewinn machte, und weil Kim etwas für die Stärkung des koreanischen Nationalgefühls tun wollte und während seiner Zeit in Japan (damals hatten

\footnotetext{
${ }^{96}$ Park blieb bis 1935 Präsident bei Keongseong-Banjik. Vgl. Sung-Jae Koh, Charakteristics of the Industrial Entrepreneurship, in: Sung-Jo Park u. a., Economic Development and Social Change in Korea, Frankfurt 1980, S. 372; Carter J. Eckert, Offspring of Empire: The Kochang Kims and the Colonial Origins of Korean Capitalism 1876-1945, Seattle/London 1991, S. 97.

${ }_{97}$ Wiedergegeben nach: ebenda, S. 37.

${ }^{98}$ Ebenda, S. 42.

${ }^{99}$ Sung-Jae Koh, Charakteristics of the Industrial Entrepreneurship, in: Sung-Jo Park u. a., Economic Development and Social Change in Korea, Frankfurt 1980, S. 372. 
Kim und Lee sich kennengelernt) erkannt hatte, wie stark der industrielle Aufschwung das Nationalbewußtsein der Japaner gestärkt hatte. ${ }^{100}$

Bis zu diesem Zeitpunkt hatte sich die Familie von Kim als traditionsbewußte Yangban nicht für die Industrie oder für die Gründung von Unternehmen interessiert. Wie alle Grundbesitzer hatten sie zwar vom Reisexport nach Japan profitiert, aber ihren Gewinn hatten sie außerhalb ihres Geschäfts wie viele wohlhabende Yangban oder erfolgreiche Händler vor allem für die Förderung koreanischer Schulen verwandt. ${ }^{101}$

Nicht nur für die Familie Kim, sondern auch für die zur Gründung des neuen Unternehmens notwendigen Investoren war ein Engagement im industriellen Bereich etwas völlig Neues. Aber da die Nachfrage nach Baumwollprodukten in Korea sehr groß war, gelang es Kim und Lee vornehmlich durch Appell an die nationale Gesinnung schon bei einem ersten Investorentreffen 182 Koreaner zu mobilisieren, die insgesamt fast $63 \%$ des benötigten Kapitals aufbrachten. ${ }^{102}$

Um den nationalen Charakter des Unternehmens hervorzuheben, rekrutierte die Unternehmensleitung ihre Mitarbeiter nur aus Koreanern. Gleichzeitig bemühte sie sich, ihre Produkte möglichst für koreanische Kunden attraktiv zu gestalten. So wurden zum Beispiel bei der Bezeichnung der Produkte Namen ausgewählt, die für Koreaner nationale Bedeutung hatten. Obwohl der koreanische Markt längst von japanischen Waren dominiert war, konnten Kim und Lee vor allem im nördlichen Korea, in der sehr nationalistischen Kwanseo- und Kwanbukregion, Marktanteile erobern. ${ }^{103}$

Kim beschäftigte sich nicht nur mit unternehmerischen Angelegenheiten, sondern gründete auch eine koreanische Zeitung, Tonga ilbo, die von nun an als

\footnotetext{
${ }^{100}$ Carter J. Eckert, Offspring of Empire: The Kochang Kims and the Colonial Origins of Korean Capitalism 1876-1945, Seattle/London 1991, S. 35.

${ }^{101}$ Ebenda, S. 33. Neben den konfuzianischen Schulen hatten sich inzwischen im Zuge des neuen koreanischen Nationalismus von der Kolonialregierung geduldete, kleine modern ausgerichtete private koreanische Schulen gebildet, in denen allerdings häufig nur mäßig ausgebildete Lehrer unterrichteten.

${ }^{102}$ Ki-Jun Cho, Hanguk Chabonjueui Balcheonsa (Die Geschichte des koreanischen Kapitalismus), Seoul 1991, S. 288.

${ }^{103}$ Ebenda, S. 288 f.; Carter J. Eckert, Offspring of Empire: The Kochang Kims and the Colonial Origins of Korean Capitalism 1876-1945, Seattle/London 1991, S. 156.
} 
Sprachrohr der koreanischen Nation diente und in der er die japanische Kolonialregierung aufforderte, ihre antikoreanische Wirtschaftspolitik einzustellen. ${ }^{104}$

Aber das nationale Konzept von Keonseong-Bangjik, das auch vorsah, das Unternehmen nicht durch einen einzelnen Unternehmer, sondern mit dem Geld der Nation, also durch eine Vielzahl von Investoren zu finanzieren, stieß bald an seine Grenzen. Nach der anfänglichen Euphorie der Gründungszeit zeigte sich, daß politische Apelle nicht reichten, um neue Interessenten zu finden. Als der Preis für koreanischen Reis infolge der Rationalisierung des Bewässerungssystems durch die japanische Kolonialregierung sank, waren viele Koreaner, die früher aus nationaler Gesinnung heraus einen Teil ihres Gewinnes in Keonseong-Bangjik investiert hatten, nicht mehr bereit, weiter investiert zu bleiben oder gar ihren Anteil zu erhöhen. Damit entwickelte sich Keonseong-Bangjik immer mehr zu einem Familienunternehmen und auch die Hoffnung, daß sich ein zweites Baumwollunternehmen in Korea entwickeln würde, mußte begraben werden. ${ }^{105}$

Nachdem die Mandschurei von Japan besetzt worden war, nutzte Kim die Gelegenheit, um das Geschäftsfeld von Keonseong-Bangjik zu erweitern. Dafür benötigte Kim die Hilfe der japanischen Kolonialregierung, die inm Kredite verschaffte. Aufgrund seiner finanziellen Abhängigkeit von der Kolonialbank konnte Kim dann nicht ablehnen, als ihm die Kolonialregierung im Jahr 1939 eine japanische Konsulatsstelle anbot. Natürlich wurde damit sein nationales Image so beschädigt, daß er nach dem Krieg wie Hung-Sik Park als Verbrecher gegen die Nation verurteilt wurde. ${ }^{106}$

Diese drei Beispiele belegen, daß sich hinter der Entwicklung des koreanischen Großunternehmens eine koreaspezifische gesellschaftliche Entwicklungslogik des Unternehmertums verbirgt, die einerseits durch Abhängigkeit von der Kolonialregierung, andererseits aber auch wesentlich durch ein von nationalen Motiven beherrschtes ökonomisches Handeln charakterisiert ist, das auf traditionellen Wertvorstellungen ebenso fußt wie auf durch traditionelles ökonomisches

\footnotetext{
${ }^{104}$ Ebenda, S. 83.

${ }^{105}$ Ebenda, S. $78 \mathrm{f}$.

${ }^{106}$ Cheong-Jae Lee, Chaebol Yireokseo (Die Entwicklungsgeschichte der Chaebol),
} Seoul 1993, S. 69. 
Handeln erwirtschaftetem Kapital. In diesem Zusammenhang stellt sich die Frage, ob die beschriebenen Großunternehmen als Prototypen der koreanischen Chaebol zu bezeichnen sind. Ich bin der Meinung, daß sich die Wurzeln der koreanischen Chaebol eher bei den koreanischen Kleinunternehmern finden lassen als bei den wenigen Großunternehmern, die aufgrund ihrer guten Beziehungen zur japanischen Kolonialregierung über einen so großen unternehmerischen Spielraum verfügten, daß sie für das koreanische Unternehmertum eher als Ausnahmen angesehen werden können und damit keine (oder nur eine geringe) Vorbildfunktion für kommende Unternehmergenerationen hatten.

Die Kleinunternehmen: In den westlichen Ländern werden Kleinunternehmen gewöhnlich mit handwerklichen Betrieben gleichgesetzt, doch die Anfänge der kleinen Unternehmen in Korea beruhten nicht auf der Tradition des Handwerks, sondern hatten, wie ich im folgenden zeigen werde, ihre Wurzeln in der schlechten Arbeitsmarktlage, unter der die Mehrheit der Bevölkerung während der Kolonialzeit litt, und - damit zusammenhängend - in dem sich entwickelnden Regionalismus.

Die hohe Arbeitslosigkeit unter den Koreanern während der Kolonialzeit resultierte ganz wesentlich aus der Abschaffung der Privilegien, die den Yangban seit 1392 die höheren Beamtenposten vorbehalten hatte. Mit der damit verbundenen Aufhebung der Berufsschranken strömten nun auch die Söhne von Bauern in die Städte, um die dort gegebenen Bildungs- und Berufschancen zu nutzen. Doch die Kolonialregierung stellte in ihren Behörden bevorzugt an einer modernen Universität ausgebildeten jüngere Japaner ein, so daß - selbst als nach der Demonstration vom 1. März 1919 Koreanern der Eintritt in die Beamtenschaft erleichtert wurde - noch nicht einmal die Söhne der wohlhabenden ehemaligen Mitglieder der Yangban-Schicht ausreichend versorgt werden konnten, geschweige denn die aufstiegswilligen jungen Koreaner aus armen Bauernfamilien. Letztere aber waren vom Lande in die Städte wegen der besseren Bildungschancen (und der Hoffnung auf einen lukrativen Beamtenposten) übergesiedelt und zeigten nun, obwohl sie keine finanziellen Mittel für ein Studium hatten, wenig Interesse an den unqualifi- 
zierten Arbeitsplätzen, die ihnen in den großen japanischen Unternehmen der Schwer- oder Textilindustrie zur Verfügung standen. ${ }^{107}$ Daher versuchten sich viele von innen als Unternehmer. Da sie anders als die oben genannten Gründer der großen Unternehmen Min, Park und Kim keine staatliche finanzielle Förderung von der japanischen Kolonialregierung erwarten konnten, richtete sich ihr Interesse auf die Gründung eines kleinen Unternehmens, zumal dies das einzige Betätigungsfeld war, das einem Koreaner ohne Genehmigung der japanischen Kolonialregierung offenstand.

Während der Yi-Dynastie war die Gründung von Unternehmen hauptsächlich auf Seoul beschränkt gewesen, weil dies nur den in Seoul wohnenden wohlhabenden Regierungsmitgliedern erlaubt war. ${ }^{108}$ Nach der Annexion Koreas entwickelte sich ein völlig neues Phänomen im koreanischen Wirtschaftsleben: die Gründung von kleinen Unternehmen in den verschiedenen koreanischen Regionen.

Es begann mit der Gründung von Banken durch wohlhabende Grundbesitzer sowie ehemalige traditionelle Kaekchu, um die regionale wirtschaftliche Entwicklung zu fördern. ${ }^{109}$ Da die japanischen Unternehmer aufgrund der besseren Infrastruktur und weil es auf dem Land kaum einen Absatzmarkt für ihre Produkte gab, die Hauptstadt als Wohn- sowie als Investitionsort bevorzugten, verhinderte die japanische Kolonialregierung die Gründung dieser regionalen Banken nicht. Doch nach 1919 wuchsen mit dem Zustrom von jungen bildungswilligen Koreanern in die Städte nicht nur Seoul, sondern auch die regionalen städtischen Zentren, und es entwickelte sich dort ein Bedarf an Lebensmitteln (wie Reis, Alkohol, Sojasoße und Nudeln etc.), der vorher in den sich weitgehend selbstversorgenden ländlichen

\footnotetext{
${ }^{107}$ Vgl. Soon-Ho Hong, Social Groups and Their Dynamics, in: Sung-Jo Park u. a., Economic Development and Social Change in Korea, Frankfurt 1980, S. 342; Mark R. Peattie, Japanese Attitudes Toward Colonialism, in: Myers, Ramon H./Peattie, Mark R. (Ed.), Colonialism and Development: Korea, Taiwan, and Kwangtung, Princeton/New York 1984, S. 97; Tong-Jin Kang, Ilche Chibaeha eui Nodong Yahak (Die Abendschule für Arbeiter in der japanischen Kolonialzeit), in: Reoksa Hakbo, Vol. 43 (1970), S. 13; SangChul Suh, Growth and Structural Changes in the Korean Economy, 1910-1945, Cambridge u. a. 1978, S. 98-111.

${ }^{108}$ Ki-Jun Cho, Hanguk Chabonjueui Balcheonsa (Die Geschichte des koreanischen Kapitalismus), Seoul 1991, S. 285.

${ }^{109}$ Die Banken erhielten den Namen ihrer Region, um zu zeigen, daß sie das Wirtschaftsleben der Region repräsentierten. Vgl. Ki-Jun Cho, Hanguk Chabonjueui Balcheonsa (Die Geschichte des koreanischen Kapitalismus), Seoul 1991, S. 402.
} 
Regionen nicht existiert hatte. Um diese Nachfrage befriedigen zu können, gründeten viele jüngere Koreaner einen kleinen Betrieb, wo sie solche Lebensmittel herstellen bzw. verarbeiten konnten. ${ }^{110}$

Auch die Nachfrage nach fabrikgefertigten Socken, Schuhen und anderen Bekleidungsstücken stieg, was auf einen Wandel des koreanischen Bekleidungsstils hinweist. Dabei versuchten die jungen koreanischen Kleinunternehmer die Produkte entsprechend den koreanischen Gewohnheiten zu modifizieren. So gab es z. B. einen koreanischen Gummischuh, der an den traditionellen koreanischen Stoffschuh erinnerte. ${ }^{111}$

$\mathrm{Daß}$ diese kleinen regionalen Unternehmen überhaupt überlebensfähig waren, hängt meines Erachtens auch mit der sogenannten nationalistischen KonsumBewegung der 20er Jahre zusammen, die den Kauf eines Produktes eines koreanischen Kleinunternehmers als patriotischen Akt empfahl. Dennoch war das Aus$\mathrm{maß}$, in dem sich die Regionalisierung der koreanischen Kleinunternehmen vollzog, erstaunlich und läßt sich nicht allein durch diese nationale Bewegung erklären. Da die Gründung dieser kleinen Unternehmen meist kein großes Startkapital und wenig unternehmerisches Know-how bzw. technologisches Können erforderte, entstanden immer mehr solche Unternehmen, was einen erheblichen Konkurrenzdruck für die Unternehmer der verschiedenen Regionen bedeutete. ${ }^{112}$ Weil sich das japanische Interesse fast ausschließlich auf den industriellen Bereich beschränkte, konkurrierten etwa im Bereich der Lebensmittelherstellung nur Koreaner miteinander. Dies aber führte zum einen dazu, daß sich die Kunden nur noch die aus ihrer Region stammenden Produkte kauften, und förderte zum anderen die vorhandene Neigung der Kleinunternehmer, den Regionalismus als ihr wesentliches, ideelles Kapital einzusetzen. Man könnte dieses Phänomen als eine Art Regionalisierung des Nationalgefühls ansehen. Es wäre aber auch möglich, daß nicht

\footnotetext{
${ }^{110}$ Hanguk Chongsin Munhwa Yonguwon, Hanguk Minjok Munhwa Taepaekwa Sajon (Enzyklopädie der koreanischen Kultur), Bd. 4 unter dem Stichwort "Kiup" (Unternehmen), Seoul 1991, S. 489; Carter J. Eckert, Offspring of Empire: The Kochang Kims and the Colonial Origins of Korean Capitalism 1876-1945, Seattle/London 1991, S. 55.

${ }^{111}$ Ki-Jun Cho, Hanguk Chabonjueui Balcheonsa (Die Geschichte des koreanischen Kapitalismus), Seoul 1991, S. 290-291.

${ }^{112}$ II-Peong Mun u. a., Chosunin eui Chibangyeol Keomto (Überlegungen über den koreanischen Regionalismuswahn), in: Sintonga, Heft Januar (1934), S. 71-75.
} 
der Nationalismus, sondern der Regionalismus das ursprüngliche Motiv sowohl für die koreanischen Kleinunternehmer als auch für deren Kunden war, was bedeuten würde, daß der Nationalismus als Motiv ökonomischen Handelns sich in erster Linie bei den ehemaligen Yangban findet, während die koreanischen (ehemals bäuerlichen) Mittel- und Unterschichten regional dachten und handelten. ${ }^{113}$

Aber das Wachstum dieser koreanischen kleinen Unternehmen in der japanischen Kolonialzeit stieß Mitte der 40er Jahre an seine Grenzen. Nach dem Eintritt Japans in den Krieg, verbot die japanische Kolonialregierung Kapital und Rohstoffe für privatwirtschaftliche Zwecke einzusetzen. Am härtesten davon betroffen waren die kleinen koreanischen Lebensmittelunternehmen, die keine Waren mehr bekamen. Zusätzlich wurden viele kleine Unternehmer dazu gezwungen, mit größeren japanischen Unternehmen zu fusionieren. Das bedeutete für viele der koreanischen Kleinunternehmer die Arbeitslosigkeit. ${ }^{114}$

Trotz dieser negativen Erfahrung hatte sich durch und in den koreanischen Kleinunternehmern in Korea ein Potential an ökonomischen (Selbst-)Bewußt-sein gebildet, das nach dem Kriege die Basis für die Entstehung der Chaebol bildete, deren Gründerväter genau aus dieser Schicht von Kleinunternehmern stammten.

\section{III.6 Resümee}

Ein zentrales Problem der konfuzianischen Gesellschaft war es, daß offene ökonomische Aktivität mit sehr niedrigem Ansehen verbunden war, obwohl die ökonomische Lage der unteren Bevölkerungsschichten für ein aktives Engage-

\footnotetext{
${ }^{113}$ Es ist daher meines Erachtens fragwürdig, den Begriff "Nationalismus" - wie es der koreanische Nationalökonom Heon-Che Park tut - so zu verwenden, als ob dieses Gefühl allen Schichten der koreanischen Bevölkerung gemeinsam sei. Siehe dazu: HeonChae Park, Minjok Keonjeron eui Kicho Yiron (Die Grundlehre der Nationalökonomie), Seoul 1989, S. 240 ff. Im Jahre 1934 gab es übrigens eine Diskussion darüber, ob dieser Regionalismus ein durch den Konfuzianismus geprägtes althergebrachtes oder eine modernes gesellschaftlichen Phänomen ist. Siehe dazu: Il-Peong Mun u.a., Chosunin eui Chibangyeol Keomto (Überlegungen über den koreanischen Regionalismuswahn), in: Sintonga, Heft Januar (1934), S. 71-75.

${ }^{114}$ Ki-Jun Cho, Hanguk Chabonjueui Balcheonsa (Die Geschichte des koreanischen Kapitalismus), Seoul 1991, S. 409.
} 
ment im Wirtschaftsleben zu sprechen schien. Erst die Öffnung des Landes im Jahr 1876 brachte hier einen Wendepunkt, der sich als der Beginn eines grundlegenden Normenwandlungsprozesses erwies, dessen Ausmaß gar nicht hoch genug eingeschätzt werden kann. Zum ersten Mal in ihrer Geschichte erfuhren die Koreaner, daß eine Gesellschaft jenseits der konfuzianischen Ordnung existierte, und mußten den abrupten Übergang von der in Korea bis zu diesem Zeitpunkt noch immer vorherrschenden Naturalwirtschaft zu einem an einer ausdifferenzierten Geldwirtschaft orientierten Welthandelssystem verkraften. Dabei zeigte innen die militärische, ökonomische und naturwissenschaftliche Überlegenheit der westlichen Ländern, daß der Konfuzianismus als ideale Staatslehre versagt hatte. Obwohl viele gebildete Koreaner aus Angst vor Überfremdung weiter die kulturelle Überlegenheit des Konfuzianismus betonten, änderte dies nichts daran, daß innen die ökonomische Rückständigkeit Koreas bewußt war. Auf der institutionellen Ebene versuchten die Koreaner daher durch selektive Nachahmung der westlichen ökonomischen Institutionen diese Rückständigkeit zu überwinden. Unternehmen in ihrer westlichen Form waren eine solche gesellschaftliche Institution, die von den Koreanern übernommen wurde. Auf der Suche nach neuen Normen, die das vom Konfuzianismus abgelehnte ökonomische Handeln legitimieren sollten, definierten sie dabei die Gründung von koreanischen Unternehmen als nationale Aufgabe, um den ausländischen Einfluß im Land zurückzudrängen. Doch blieben diese ersten koreanischen Unternehmensgründungen weitgehend erfolglos, da es den koreanischen Unternehmensgründern, die zumeist aus der privilegierten Yangban-Schicht stammten, nicht nur an unternehmerischem und technologischem Know-how fehlte, sondern auch an einem wesentlichen Motiv für erfolgreiches unternehmerisches Handeln, nämlich an der Notwendigkeit, von seinen unternehmerischen Aktivitäten leben zu müssen.

Mit Beginn der japanischen Kolonialzeit trennte sich Korea endgültig von der konfuzianischen Gesellschaftsordnung. Die ständische Ordnung, in der die konfuzianischen Gelehrten alle Privilegien genossen, wurde abgeschafft. Mit der Einführung des modernen westlich geprägten Schulsystems durch die Japaner war das konfuzianische Wissen, auch wenn es zunächst parallel auch noch konfuzianische 
Schulen gab, langfristig zum Untergang verurteilt. Der Konfuzianismus verwandelte sich dementsprechend allmählich in ein schichtübergreifendes ethisches Prinzip, das sich auf die zwischenmenschlichen Beziehungen (vor allem Solidarität zwischen den Familienmitgliedern und Freunden) reduzierte. Obwohl sich die gesellschaftliche Struktur Koreas während der japanischen Kolonialherrschaft, wie oben beschrieben, grundlegend und umfassend veränderte, profitierte von diesem institutionellen und ökonomischen Wandlungsprozeß nicht die gesamte Bevölkerung in gleicher Weise. Dies zeigt sich auch bei der Entwicklung der koreanischen Unternehmen, wobei sich zwei unterschiedliche Unternehmertypen ausmachen lassen:

Zum einen gab es den nationalistischen erfolgreichen Unternehmer aus der ehemaligen Yangban-Schicht, dessen Karriere auf seinen zumeist schon in der Öffnungszeit zu den Japanern geknüpften Beziehungen beruhte, im weiteren Verlauf - wegen des Interesses der japanischen Kolonialregierung an der Befriedung der koreanischen Bevölkerung - mit japanischem Kapital gestützt wurde und (ganz wichtig) wegen seiner Verstrickung in die japanische Kriegswirtschaft nach dem Zweiten Weltkrieg endete. Das bedeutete für Korea auch das Ende der von diesen Unternehmern repräsentierten, eng an japanischem Vorbild angelehnten Unternehmensstruktur.

Zum anderen gab es den Typus des Kleinunternehmers, der aus bäuerlichem Milieu, vielfach auch aus einer verarmten ehemaligen Yangbanfamilie stammend, nach der Aufhebung der ständischen Berufsschranken zunächst noch ganz dem konfuzianischen Bildungsideal verhaftet eine städtische Beamtenkarriere angestrebt hatte, sich dann aber aus beruflicher Perspektivlosigkeit heraus für die Gründung eines kleinen Betriebes in einer der von den Japanern nicht besetzten Marktnischen entschied. Sein ökonomisches Handeln war ausschließlich regional ausgerichtet, was im ehemaligen konfuzianistischen Zentralstaat ein völlig neues Phänomen war. Obwohl aufgrund der restriktiven gesellschaftlichen Rahmenbedingungen nur auf primitiver Ebene als Unternehmer tätig, bildete dieser Unternehmertypus, wie im folgenden anhand der konkreten biographischen Analyse ge- 
zeigt werden wird, die Basis des koreanischen Unternehmertums in der Nachkriegszeit. 


\section{Die Bedeutung des familiär-sozialen Beziehungsgeflechts für das unternehmerische Handeln - eine Analyse am Beispiel der drei erfolgreichsten Chaebolgründer}

\section{IV.1 Der biographische Hintergrund}

Um den Einfluß von Biographie und Sozialisation auf die Entwicklung des koreanischen Unternehmertums und das Verständnis des ökonomischen Handelns zu verdeutlichen, habe ich die zugrundegelegten (Auto-)Biographien der Gründerväter von Lucky-Goldstar (In-Hoe Ku), Samsung (Byong-Chul Lee) und Hyundai (Joo-Young Cheong) ${ }^{1}$ vor allem unter folgenden Fragestellungen analysiert:

- Welche Motivation führte Ku, Lee und Cheong zum Unternehmertum?

- Wie wurde der Beruf eines Unternehmers wahrgenommen?

- Wie war ihre Beziehung zur traditionellen konfuzianischen Kultur?

- Wodurch unterschied sich ihr Verständnis des ökonomischen Handelns vom traditionellen Verständnis des ökonomischen Handelns in Korea?

In-Hoe Ku: In-Hoe Ku wurde 1907 als der erste Sohn einer sehr angesehenen traditionsbewußten konfuzianischen Gelehrtenfamilie in dem in einer südlichen Provinz Koreas gelegenen Dorf Sungsan geboren. ${ }^{2}$ Die Familie lebte in dem Dorf, seit ein Vorfahre Kus als Provinzgouverneur in die naheliegende Verwaltungsstadt berufen worden war, und hatte durch eine geschickte Heiratspolitik ihren Grundbesitz im Laufe der Generationen so erweitert, daß sich die Nachfahren dieses Provinzgouverneurs ohne ökonomische Sorgen auf die staatliche Beamtenprüfung vorbereiten konnten. Der letzte in der Familie, der diese Beamtenprüfung absolviert hatte, war In-Hoes Großvater, Yun-Ho Ku, der allerdings als politischer Gegner der für die Öffnung des Landes plädierenden Kaehwa-Gruppe schon 1893 seine Beamtenkarriere, in deren Verlauf er es so-

\footnotetext{
1Siehe dazu oben Abschnitt II.6 (S. 47 ff.).

2Die folgenden Angaben über Kus Leben stammen aus: Lucky-Goldstar (Hrsg.), Hanbeon Midemyeon Modu Matkeora (Wenn du anfängst, jemandem einmal zu glauben, dann sollst du bereit sein, ihm alles anvertrauen zu können), Seoul 1979/1993, S. 1955.
} 
gar bis in die angesehene Stellung eines Privatlehrers des letzten koreanischen Königs gebracht hatte, aus eigenem Entschluß beendet hatte.

In Sungsan war von den großen gesellschaftlichen Umbrüchen durch den japanischen Imperialismus kaum etwas zu spüren. Doch war 1907, als Ku geboren wurde, längst klar, daß die traditionelle konfuzianische Ausbildung keine berufliche Perspektive mehr bieten würde. Dennoch legte die Familie Kus viel Wert auf eine traditionelle Erziehung, und In-Hoe Ku besuchte zunächst eine konfuzianische Schule in seinem Dorf. Als In-Hoe Ku 14 Jahre alt war, ${ }^{3}$ ordnete der Großvater als Oberhaupt der Familie nach alter Tradition die Heirat In-Hoes mit der Tochter des größten Grundbesitzer der Region an und setzte so die erfolgreiche, grundbesitzmehrende Heiratspolitik der Familie fort. Allerdings lebten In-Hoe und seine Frau auch nach der Heirat weiter jeweils in der Obhut inrer eigenen Familie.

Zum Bruch mit diesen konfuzianischen Traditionen kam es, als sich In-Hoes Vater gegen den Willen des Großvaters entschloß, seinen inzwischen 15jährigen Sohn in die neu errichtete moderne Volksschule zu schicken. Nachdem bekannt geworden war, daß die Massendemonstration gegen die japanische Kolonialmacht am 1. März 1919 von jenen jungen Leuten organisiert wo rden war, die moderne japanische Schulen (entweder in Japan selbst oder auch in Korea) besucht hatten, veranlaßte dies einen großen Teil der koreanischen Landbevölkerung, ihre Kinder in die moderne Volksschule zu schicken. ${ }^{4}$ Mit

\footnotetext{
${ }^{3} \mathrm{Nach}$ westlicher Zählung war Ku zu diesem Zeitpunkt sogar erst 13 Jahre alt. Doch in Korea zählt die Schwangerschaft als ein eigenes Jahr, so daß ein neugeborenes Kind bereits ein Jahr alt ist. Im folgenden wird das Alter jeweils nach der koreanischen Zählung angegeben.

${ }^{4}$ Tong-Jin Kang, Ilche Chibaeha eui Nodong Yahak (Die Abendschule für die Arbeiter in der japanischen Kolonialzeit), in: Reoksa Hakbo, Vol. 43 (1970), S. 10 f. Zwar war, wie ich es oben in Kapitel III dargestellt habe, die Ursache dieser großen Demonstration die Unzufriedenheit mit der japanischen Kolonialregierung und der Wunsch nach der Unabhängigkeit Koreas, doch gab es darüber hinaus einen konkreten Anlaß, der zumindest für die Landbevölkerung von sehr viel größerer Bedeutung war: Im Januar 1919 war der letzte koreanische König gestorben und die Trauerfeiern dafür nach konzufianischem Ritus erst Monate später für den 3. März angesetzt, weshalb sich die ländliche Bevölkerung Anfang März in Seoul oder anderen Städten in Trauerzügen sammelte. Als diese von der Kolonialregierung auseinandergetrieben wurden, kam es zu den großen Auseinandersetzung zwischen der japanischen Polizei und dem koreanischen Volk. So erklärt sich, daß diese Demonstrationen nicht auf Seoul beschränkt waren, sondern sich landesweit verbreiteten und über einen Monat anhielten. Für die weitere Entwicklung wichtig war dann vor allem, daß das koreanische Volk durch den Tod des Königs eine zentrale Symbolfigur verlor, die sie bisher mit der konfuzianischen 
dem Eintritt in diese Schule schnitten sowohl In-Hoe als auch sein Vater sich ihre langen Haare ab (was nach konfuzianischer Lehre nicht erlaubt war, da diese Eigentum der Eltern waren), und gaben so ihrer Hinwendung zu einer moderneren Lebensweise auch symbolisch Ausdruck.

Nach zwei Jahren auf dieser Schule, in der die Atmosphäre wegen der rassistischen Haltung der japanischen Lehrer den koreanischen Schülern gegenüber ziemlich angespannt gewesen sein muß, wechselte In-Hoe Ku auf die von dem koreanischen Baumwollunternehmer Sung-Su Kim gegründete koreanische Highschool in Seoul "Chungang Kobo". 5

Motiviert für sein Studium in Seoul hatte In-Hoe Ku - nach eigenen Angaben sein Schwager In-Ku Hur, der bereits in Seoul studiert hatte und In-Hoe den Eindruck vermittelt hatte, daß man in Zukunft ohne moderne schulische Ausbildung die Welt nicht mehr verstehen könne. Dabei sah er den Wert dieser neuen schulischen Ausbildung - ganz im Sinne traditioneller konfuzianischer Vorstellung - nicht in einer beruflichen Qualifikation, sondern in einem der Entwicklung der Persönlichkeit dienenden allgemeinen Wissen.

Der Großvater scheint den Ausbruch In-Hoes aus den konfuzianischfamiliären Traditionen nur mit Widerwillen akzeptiert zu haben. Denn als zwei Jahre nach Studienbeginn In-Hoes Schwiegervater starb, der bisher das Studium finanziert hatte, ordnete der Großvater an, daß In-Hoe sein Studium abbrechen und nach Hause zurückkehren sollte. Das war im Jahre 1926 und In-Hoe Ku war damals 20 Jahre alt.

Obwohl sich In-Hoe während seines Studiums in Seoul hauptsächlich mit westlicher und asiatischer Literatur beschäftigt hatte, scheint er in Seoul doch auch einen neuen Blick auf die Lebensformen auf dem Land gewonnen zu haben. Denn wieder in sein Elternhaus zurückgekehrt, versuchte er als aufgeklärter junger Mensch, die traditionellen ländlichen Lebensgewohnheiten zu verändern, dazu gehörte zum Beispiel auch das frühe Aufstehen. Gleichzeitig bemühte er sich, seine durch Bücher erworbenen Kenntnisse über neue land-

Gesellschaft der Yi-Dynastie verbunden hatte, so daß die Erkenntnis von deren Ende nun auch für die bäuerliche Bevölkerung unabweisbar geworden war. Vgl. dazu Carter J. Eckert u.a., Korea Old and New - A History, Cambridge u.a. 1990, S. 277.

${ }^{5}$ Nach dem Ende der japanischen Kolonialzeit wurde diese Hochschule in KoreaUniversität" umbenannt. Zu Sung-Su Kim siehe oben die Ausführungen zur Entstehung der koreanischen Textilindustrie in Abschnitt III.6 (S. 93-96). 
wirtschaftliche Methoden praktisch anzuwenden. Die Dorfbewohner waren mehr als erstaunt, daß In-Hoe Ku sich als Sohn einer konfuzianischen YangbanFamilie mit landwirtschaftlicher Arbeit beschäftigte. Denn in der gesellschaftlichen Ordnung der Yi-Dynastie war dies die Aufgabe von abhängigen Kleinbauern und Sklaven gewesen. Insofern kann man sagen, daß sich Ku dank seines Besuches der höheren Schule in Seoul von dem alten konfuzianischen Standesbewußtsein entfernte.

Außerdem engagierte sich In-Hoe Ku nach seiner Rückkehr ehrenamtlich in dem genossenschaftlichen Kaufverein, wobei er für den Einkauf preiswerter Lebensmittel für die Dorfgemeinde zuständig war. Dieser genossenschaftliche Verein war als Konkurrenzunternehmen zu dem im Dorf ansässigen japanischen Lebensmittelladen gegründet worden, dessen Monopolstellung die Preise hochgetrieben hatte. In der Genossenschaft sammelte Ku erste kaufmännische Erfahrungen, wenn auch nur als Mitglied der dörflichen Gemeinschaft und nicht als echter Kaufmann. Denn er verkaufte die Waren, die er aus Läden in der benachbarten Stadt geholt hatte, ohne jeden Gewinn, und da die Dorfbewohner inm diese Waren wegen ihres niedrigen Preises sicher abnahmen, trug er auch kein geschäftliches Risiko.

Im engeren Sinn berufstätig war In-Hoe Ku, der inzwischen auch Vater geworden war, nach seiner Rückkehr zunächst nicht, und - obwohl sein Vater und sein Großvater wahrscheinlich davon ausgingen, daß er als der älteste Sohn eines Tage die Rolle des häuslichen Vermögensverwalters übernehme, litt InHoe Ku, der während seines Studiums den rasanten kulturellen und ökonomischen Wandel im Land beobachten konnte, zunehmend unter seiner Arbeitslosigkeit. Hinzu kam, daß die finanzielle Lage der Familie nicht mehr gesichert war, so daß für seine Brüder die teure Ausbildung nicht mehr finanzierbar war.

Entweder weil seine abgebrochene Ausbildung anderes nicht zuließ oder aber auch aufgrund seiner ersten kaufmännischen Erfahrungen in der Genossenschaft, entschloß sich In-Hoe Ku nicht wie viele andere junge Koreaner, die in dem neuen verwestlichten Bildungssystem ausgebildet worden waren, für den Beruf des Richters und Lehrers, sondern für den des Kaufmanns (der keine bestimmte Vorbildung erforderte). Auf Widerspruch stieß er dabei vor allem bei seinem Vater, der die Schande fürchtete, die diese Berufswahl für eine alte konfuzianische Familie bedeutete. Erstaunlicherweise zeigte sich diesmal der 
Großvater offener für In-Hoes Pläne, wahrscheinlich, weil inn eine besonders enge Beziehung mit seinem ältesten Enkel verband. Er erklärte seinem Sohn, In-Hoes Vater, daß sich die Welt verändert habe und daß die ständischen Berufsschranken verschwunden seien. Obwohl er persönlich dies bedauere, wolle er nicht, daß sein ältester Enkel von dieser veränderten modernen Welt ausgeschlossen werde, deshalb solle In-Hoes Vater inm das Startkapital für seine kaufmännischen Pläne schenken.

Damit war In-Hoes Berufstätigkeit nicht mehr seine private Angelegenheit, sondern eine Familiensache, da der Großvater die Ehre und den guten Ruf der Familie vom beruflichen Erfolg des Enkelsohns abhängig gemacht hatte. Als sich In-Hoe Ku von seinem Vater verabschiedete, um in der Provinzstadt ein Geschäft zu eröffnen, bat der Vater seinen Sohn, sich als Kaufmann um harmonische Geschäftsbeziehungen zu kümmern und das Vertrauen seiner Geschäftspartner nicht zu enttäuschen, um den guten Ruf der Familie nicht zu gefährden. Die Tatsache, daß In-Hoe Ku dies für so wichtig hält, um es in seiner Autobiographie zu erwähnen, kann als Beleg für den Versuch gewertet werden, die traditionellen konfuzianischen Werte in die moderne kaufmännischen Berufswelt zu übertragen.

Byong-Chul Lee: 1910 wurde Byong-Chul Lee als der jüngste Sohn einer konfuzianisch gebildeten Yangban-Familie in dem Dorf Chung-Kyori, das in derselben Provinz lag wie der Geburtsort von In-Hoe Ku, geboren. ${ }^{6}$ Anders als in Kus Familie hatte Lees Großvater jedoch, obwohl er Umgang mit vielen berühmten konfuzianischen Gelehrten pflegte, nie eine Beamtenstelle bekleidet und wohl auch nicht angestrebt, sondern kümmerte sich vor allem um die stetige Vergrößerung seines Landbesitzes, die Verwaltung seiner Güter und die Vermehrung seines Vermögens.

Mit fünf Jahren, kam Byong-Chul Lee in die von seinem Großvater errichtete private konfuzianische Schule des Dorfes, wo er sich fünf Jahre lang mit den chinesischen Schriftzeichen sowie den klassischen konfuzianischen Lehrbüchern auseinandersetzte. Obwohl er sich nicht sonderlich für die klassische

6Die Angaben im folgenden stammen aus Lees Autobiographie: Byong-Chul Lee, Hoam Chacheon (Hoams Autobiographie), Seoul 1985, S. 3-18. 
konfuzianische Lehre interessierte und als nicht besonders begabt galt, las er zumindest ein wichtiges konfuzianisches Werk, das "Lun Yü".7 Sein Sohn und Nachfolger Kun-Hee Lee erklärte später in einem Interview auf die Frage, ob er von seinem Vater etwas über Management gelernt habe, sein Vater habe inm empfohlen, das genannte Buch zu lesen. ${ }^{8}$

Wie bei In-Hoe Ku beschlossen auch Byong-Chul Lees Eltern inn nach der großen Massendemonstration vom März 1919 in die neu gegründete japanische Schule in der benachbarten Stadt Jinju schicken sollte. ${ }^{9}$ Neben japanischen Sprachkenntnissen weckte dieser Schulbesuch in Byong-Chul vor allem die Sehnsucht nach einem Leben in der Stadt und so überredete er seinen Vater, inm den Besuch der ersten von der japanischen Kolonialregierung genehmigten koreanischen Grundschule in Seoul zu erlauben. Byong-Chuls Lernbegeisterung hielt sich auch hier in Grenzen, aber seinem Vater, der den Sohn vor allem immer wieder die konfuzianischen Erziehungsideale, wie etwa den Grundsatz, daß man zu anderen Menschen eine Vertrauensbeziehung aufbauen müsse und deshalb auf keinen Fall sein Gesicht verlieren dürfe, vor Augen hielt, schien dies nicht besonders wichtig zu sein. Lee behauptete später, daß diese Lehre seines Vaters seine Geschäftsphilosophie wurde. ${ }^{10}$

\footnotetext{
${ }^{7}$ Dieser Text wurde allerdings nicht von Konfuzius selbst, sondern wahrscheinlich von einem seinem Schüler verfaßt.

8Hyo-Jin Oh, Samsung New Leader Lee Kun-Hee Hoejang (Der neue Unternehmensleiter von Samsung, Kun-Hee Lee), in: Wolgan-Chosun, Heft 12 (1989), S. 351.

${ }^{9}$ Aus diesem gemeinsamen Schulbesuch entwickelten sich später sowohl Geschäftsbeziehungen (Ku und Lee investierten gemeinsam in Radio und Fernsehen) als auch eine durch Heirat vermittele Verwandtschaftbeziehung (ein Sohn von Ku heiratete eine Tochter von Lee). Doch ging die Freundschaft in die Brüche, als Lee Ende der 60er Jahre in die Monopolstellung einbrach, die Ku bis zu diesem Zeitpunkt Ku in der Elektroindustrie besessen hatte. Maeng-Hee Lee, Mudedun Yiyagi (Die unbekannte Geschichte), Seoul 1993, S. 248.

10Die konfuzianische Lehre legt sehr viel Wert auf harmonische zwischenmenschliche Beziehungen. Dabei geht die Lehre von der Annahme aus, daß diese harmonischen zwischenmenschlichen Beziehung nur dann möglich sind, wenn kein Beteiligter vor dem anderen sein Gesicht verliert. Häufig wird der Respekt vor anderen daher nicht nur durch besondere Höflichkeit ausgedrückt, sondern auch durch das Bemühen, selbst sein Gesicht nicht zu verlieren. Deshalb verbirgt man auch möglichst seinen inneren Gefühlszustand vor dem anderen. Selbst wenn das Gegenüber z. B. einen Wunsch oder eine Erwartung beim anderen wahrnimmt, dürfte er sich das niemals anmerken lassen. Lee galt unter den koreanischen Unternehmer als jemand, der besonders viel Wert auf diesen konfuzianischen Verhaltenskodex legte.
} 
Trotz seiner Begeisterung für alles Moderne weigerte sich Byong-Chul nicht, als inm sein Vater eine traditionelle frühe Heirat mit einer Frau befahl, die er erst nach der Hochzeit zum ersten Mal sah. Damals war er 19 Jahre alt.

Noch vor dem Schulabschluß in Seoul entschloß Byong-Chul Lee sich, sein Studium in Japan fortzuführen. Diesmal reagierte der Vater wütend, weil sein Sohn offensichtlich nicht die in der konfuzianischen Lehre viel gepriesene Ausdauer besaß, stimmte aber letztendlich zu. Während seiner ersten Reise nach Japan (das war im Jahr 1930) erfuhr Byong-Chul dann zum ersten Mal, was es heißt, Angehöriger eines Kolonialvolkes zu sein, und daß ihn angesichts dieser Tatsache auch der Reichtum ${ }^{11}$ seiner Familie nichts nützte. Als er auf dem Schiff eine Erste-Klasse-Kabine buchen wollte, machte ein japanischer Offizier neben inm die Bemerkung, daß er es unmöglich fände, daß sich ein Koreaner den Luxus der ersten Klasse leiste. Lee sagte später, daß dieser Vorfall sein Nationalgefühl geweckt habe.

Anfangs war Byong-Chul Lee mit seinem Studium der Sozialwissenschaften an der renommierten japanischen Waseda-Universität in Japan sehr zufrieden, verlor aber zusehends die Motivation, nachdem er erfahren hatte, daß viele apanische Absolventen der Universität wegen der wirtschaftlichen Depression keine Arbeit fanden. Außerdem wurde er krank, so daß er sich relativ plötzlich zur Rückkehr in sein Heimatdorf entschloß. Nachdem er sich erholt hatte, ging er wiederum nach Seoul, wo er allerdings nur am gesellschaftlichen Leben teilnahm. Auch diesmal finanzierte inm sein Vater den Aufenthalt.

Nach zwei Jahren kam Lee wieder in sein heimatliches Dorf zurück, wo sein Vater inzwischen die Verwaltung seines Besitzes an Byong-Chuls ältere Brüder weitergegeben hatte. Um sich die Zeit zu vertreiben, versuchte er die während seiner Ausbildung gelernten wissenschaftlichen Methoden für die Züchtung von Gemüse in der Praxis anzuwenden und ließ sich Saatgut aus Japan schicken. Doch kam er nie über das Niveau eines Hobbygärtners hinaus. Im übrigen verbrachte er bis zum Alter von 26 Jahren seine Zeit hauptsächlich mit Glücksspielen. Dann endlich entschloß er sich, obwohl er als Sohn eines wohlhabenden Großgrundbesitzers keine finanziellen Sorgen hatte, etwas Sinnvolles zu

\footnotetext{
${ }^{11}$ Lees Eltern schickten inm monatlich 200 Yen nach Japan. Damals benötigte eine vierköpfige japanische Familie in der Großstadt 50 Yen für ihren Lebensunterhalt. Lee konnte also in Japan weiterhin sein gewohntes luxuriöses Leben führen.
} 
tun, und nachdem inm klargeworden war, daß er als junger Koreaner eigentlich nur die Wahl hatte, entweder Unabhängigkeitskämpfer oder Beamter der japanischen Kolonialregierung zu werden, entschloß er sich, Unternehmer zu werden. Denn - so Lee in seiner Autobiographie - ein Beitrag zum wirtschaftlichen Aufschwung der Nation sei genauso wichtig wie die Teilnahme an der Unabhängigkeitsbewegung. Ohne genauere Vorstellungen davon, wie und wo er seine unternehmerische Laufbahn beginnen wolle, erklärte der inzwischen 26jährige Byong-Chul seinem Vater seinen Plan, und dieser stellte ihm ohne weitere Fragen das notwendige Startkapital zur Verfügung.

Obwohl Byong-Chul Lee - wie ja auch In-Hoe Ku, wenn auch aus anderen Gründen - sein Studium abgebrochen hatte, gehörte er zweifellos zu den am besten ausgebildeten jungen Koreanern während der japanischen Kolonialzeit. Die Frage ist nun, ob sein unternehmerisches Interesse eine Folge der modernen Bildung war, die er genossen hatte, oder aber wieder nur die einzige inm offen stehende Betätigungsmöglichkeit. Hinter dieser Frage verbirgt sich die bekannte modernisierungstheoretische Auffassung, daß die aus den westlichen Ländern importierte Bildung wesentlich zur Modernisierung der traditionellen Gesellschaften beitrug, da die in der Schule erfahrene Aufklärung den jungen Männern die Überwindung der traditionellen Wertvorstellungen ermöglichte.

Ich meine, daß sich bei Byong-Chul Lee Beispiele für die direkte Wirkung der erfahrenen modernen Bildung finden lassen: Hier ist erstens Lees zwar letztlich gescheiterter Versuch mit moderner Gemüsezüchtung zu nennen, mit dem er aber doch konkret sein in der Schule erworbenes Wissen direkt auf die Praxis übertrug. Doch zeigt die Halbherzigkeit dieses Versuchs, daß Lee nicht zu den radikalen idealistischen jungen Männer gehörte, die glaubten, die Rückständigkeit auf dem Land durch die Anwendung ihres schulischen Wissens überwinden zu können. Noch wichtiger ist in diesem Zusammenhang sein (erfolgreicher) Versuch, seinen Vater zu überreden, die Sklaven der Familie frei zu lassen. Nach Lektüre der Werke Tolstois war Byong-Chul Lee zu der Ansicht gekommen, daß Sklaven für die gesellschaftliche Entwicklung eher hinderlich als förderlich seien. Obwohl die Sklavenhaltung in Korea schon 1894 noch während der Yi-Dynastie abgeschafft worden war, bestand sie auf dem Land weiter. Lee sagte später, daß dieser Schritt für ihn ohne seinen Studienaufenthalt in Japan nicht denkbar gewesen wäre. Seine Entscheidung, Unternehmer zu werden, 
scheint jedoch weniger ein überlegter bewußter Bruch mit der Tradition als vielmehr einer der für Byong-Chul Lee typischen spontanen, aus persönlicher Unzufriedenheit entstandenen Entschlüsse gewesen zu sein, dem nachträglich zusätzlich ein nationales Motiv unterlegt wurde. Die häufigen Rekurse auf seine konfuzianische Erziehung in seiner Autobiographie und das Herausstellen der Bedeutung konfuzianischer Werte für sein unternehmerisches Handeln zeugen zudem nicht nur von dem tiefen Respekt, den Lee für seinen Vater empfand, sondern auch davon, daß diese Erziehung trotz aller moderner Bildung in Lee zeitlebens lebendig blieb.

Joo-Young Cheong: Joo-Young Cheong wurde 1915 als ältester Sohn einer armen Bauernfamilie im nördlichen Korea, in Tongcheon, geboren. ${ }^{12}$ Obwohl Joo-Youngs Großvater noch als Lehrer an einer traditionellen konfuzianischen Schule unterrichtete, unterschied sich die Lebensweise des Vater, dem als ältesten Sohn die Verantwortung für den Unterhalt der gesamten Familie oblag, kaum von der eines kleinen Bauern. Bis auf die Tatsache, daß Joo-Youngs Vater praktizierender Konfuzianer war, der die vorgeschriebenen Rituale vor den Ahnen regelmäßig durchführte, erinnerte nichts mehr daran, daß die Familie ursprünglich einmal zur Yangban-Schicht gehört hatte. Angesichts der schwindenden beruflichen Möglichkeiten hatte sich die Familie Cheong schon vor Generationen wie viele andere ihres Standes auch für das bäuerliche Leben auf dem Land entschieden, und Joo-Youngs Vater hielt es daher für selbstverständlich, daß auch sein ältester Sohn Bauer werden würde.

Im Alter von sechs Jahren kam Joo-Young auf die konfuzianische Dorfschule des Großvaters und wechselt vier Jahre später auf die japanische Grundschule, die er bis zum Alter von vierzehn Jahren besuchte. Obwohl Joo-Young, der ein überdurchschnittlich guter Schüler war, schon als Kind fest in den bäuerlichen Alltag seiner Familie eingebunden war, entfernte er sich immer mehr von den traditionellen Vorstellungen seines Vaters und träumte davon, Lehrer an der Grundschule zu werden. Doch dieser Traum ließ sich nicht verwirklichen, weil inm seine Eltern die Ausbildung in der benachbarten Stadt nicht bezahlen

12Die folgenden Angaben sind entnommen: Joo-Young Cheong, Sireonun Issedo Silpae nun Eopda (Es gibt zwar Schwierigkeiten, aber keinen Mißerfolg), Seoul 1991, 
konnten. In Joo-Young wuchs der Widerstand, vor allem, weil er - wie er später schrieb - nicht verstehen konnte, daß sein Vater trotz seines unglaublichen Fleißes so arm war. In einer bereits mehrere Wochen alten Zeitung las er eines Tages eine Anzeige, in der Tagelöhner für den Ausbau der Straßen und die Errichtung großer japanischer Fabriken gesucht wurden, und von da an träumte er davon, nach Seoul durchzubrennen, sich dort seinen Lebensunterhalt als Tagelöhner zu verdienen und sich wie der Held des ersten koreanischen Romans "Erde" von Kwang-Soo Lee nebenbei weiterzubilden, um später die staatliche Prüfung als Rechtsanwalt ablegen zu können. ${ }^{13}$

Viermal lief Joo-Young von Zuhause weg, jedesmal holte der Vater inn zurück, denn er war fest davon überzeugt, daß sein Sohn als ungebildeter und mittelloser Junge vom Land in der großen, bereits von arbeitslosen jungen Koreanern überfüllten Stadt Seoul keine Chance haben würde. Doch zielstrebig und selbstbewußt gab Joo-Young nicht auf: Nach dem dritten Fluchtversuch besuchte er, bis der Vater inn zur Rückkehr zwang, sogar schon einen Kurs für Buchführung, um damit später als kaufmännischer Angestellter arbeiten zu können, und er schreckte auch nicht davor zurück, die wichtigste Geldquelle eines jeden Bauern, die Kuh seines Vaters zu verkaufen, um damit seine Flucht zu finanzieren. ${ }^{14}$

Als Joo-Young 19 Jahr alt wurde, unternahm er seinen letzten, diesmal erfolgreichen Fluchtversuch. Erst drei Jahre später meldete er sich wieder bei seinem Vater, nachdem er in Seoul eine Aushilfsstelle in einem koreanischen Reisgeschäft gefunden hatte. Da sein Gehalt schon damals über dem Einkommen seines Vaters lag, war inm klar, daß sein Vater inn nicht länger dazu zwingen würde, seine traditionelle Rolle als Bauer wahrzunehmen.

Obwohl die Beziehung von Joo-Young Cheong zu seinem Vater eher durch Rebellion als durch das bekannte konfuzianische Verhaltensmuster der "Gehorsamkeit gegenüber den eigenen Eltern" geprägt war, bedeutete das nicht, daß

S. 17-65; Ders., Joo-Young Cheong, I Tange Taenaseo (Geboren in diesem Lande), Seoul 1998, S. 15-52.

${ }^{13}$ Lee Kwang-Soo war der erste koreanische Schriftsteller, der eine Geschichte in Form des westlichen Romans geschrieben hatte. "Heulg" (Erde) erschien erstmals zwischen 1932 und 1933 in einer koreanischen Zeitung.

141997 schenkte Cheong der nordkoreanischen Regierung 500 Kühe und erklärte dabei, daß er diese Kühe noch seinem Vater schulde. 
er kein konventioneller Koreaner war. Ihm war die traditionelle konfuzianische Vorstellung von der Familie durchaus wichtig. Er nahm seine Verantwortung als ältester Sohn der Familie wahr und inm war immer bewußt, daß die Familie ökonomisch von seinem Erfolg abhängig war. In seiner neuen Biographie (1998) wies er noch einmal verstärkt darauf hin, daß die Armut seiner Familie und der deswegen zwischen seinen Eltern herrschende ständige Streit für inn eine wichtige Motivation gewesen seien, unbedingt Geld verdienen zu wollen. Der Widerspruch zwischen der traditionellen konfuzianischen Vorstellung von der harmonischen Familie und die eigene täglich erlebten harten gesellschaftlichen Wirklichkeit des Kleinbauern brachte inn dazu, sich als Unternehmer zu versuchen.

Anders als die beiden anderen Gründerväter der Chaebol verband JooYoung Cheong, der während seiner Schulzeit in der Grundschule nicht viel mehr als Koreanisch Lesen und ein wenig Japanisch gelernt hatte, Bildung nicht oder zumindest nicht ausschließlich mit traditionellen konfuzianischen $\mathbf{h}$ halten. Für Cheong diente Bildung, wie beispielsweise der von inm belegte Buchführungskurs zeigt, auch oder sogar in erster Linie der Berufsvorbereitung.

Trotz des ihm fehlenden höheren Schulwissens oder vielleicht sogar deswegen entwickelte Cheong großes unternehmerisches Selbstvertrauen. Denn als ungebildeter junger Koreaner verfügte er über keine andere Möglichkeit, als durch konkretes Tun, durch Fleiß und Disziplin seine Fähigkeiten unter Beweis zu stellen, und um vorwärtszukommen, hatte er keine andere Möglichkeit, als auch Risiken einzugehen, was beispielsweise bedeuten konnte, sich auf ein unbekanntes unternehmerisches Tätigkeitsfeld einzulassen. Genau dazu aber war Cheong in großem Maße bereit, da er schon als Kind und junger Mann darauf angewiesen gewesen war, die inm verwehrte Bildung durch Tatkraft und Risikobereitschaft auszugleichen.

Vergleicht man die familiäre Sozialisation von In-Hoe Ku, Byong-Chul Lee und Joo-Young Cheong, so fällt zunächst einmal auf, daß sie alle zu einer Generation gehörten, die erst am Beginn der japanischen Kolonialzeit geboren wurde. Ihre Kindheit war daher durch eine Mischung aus der alten herkömmlichen konfuzianischen Weltanschauung und der von Japan neu eingeführten modernen schulischen Sozialisation geprägt, wobei dies für Cheong aufgrund seiner 
geringen schulischen Bildung weniger stark zutrifft als für Ku und Lee. Seine Erziehung war sehr viel traditioneller als die der beiden anderen Chaebolgründer und sein Widerstand gegen sein Elternhaus nahm daher auch sehr viel extremere Formen an. Da er ohne jegliche familiäre Unterstützung finanziell ganz auf sich selbst gestellt war, entwickelte Cheong auch nicht, wie etwa Lee für sich geltend machte, seine unternehmerischen Pläne im Interesse einer größeren nationalen Aufgabe, sondern aus reiner ökonomischer Existenznot heraus. Hervorzuheben ist neben der unterschiedlichen wirtschaftlichen Lage der Familien der Chaebolgründer auch noch die jeweilige Stellung in der Geschwisterkonstellation: Cheong und Ku waren beide älteste Söhne, die für den Unterhalt ihrer Familie verantwortlich waren und deshalb Unternehmer wurden. Der aus einer wohlhabenden Familie stammende Lee war dagegen der jüngste Sohn, für den, nachdem seinen älteren Brüdern der Besitz übergeben worden war, keine eigene Aufgabe in der Familie übriggeblieben war. Für alle drei, selbst für Cheong, der ja schließlich auch seine erste Bildung in der konfuzianischen Schule seines Großvaters erhalten hatte und auch einmal davon geträumt hatte, Rechtsanwalt zu werden, stellte die Entscheidung für den Unternehmerberuf jedoch eher eine "Verlegenheitslösung" als eine bewußte, von einer klaren Vorstellung vom Unternehmertum (oder anders gesagt vom ökonomischen Handeln) getragene Entscheidung.

\section{IV.2 Unternehmerische Anfänge bis 1945}

In diesem Abschnitt werden die unternehmerischen Aktivitäten der drei Chaebolgründer vor dem Ende der japanischen Kolonialzeit 1945 geschildert:

In-Hoe Ku: Wie die in der "historischen Genese" beschriebenen Kleinunternehmer entschloß sich Ku das von inm geplante Textilgeschäft nicht in Seoul oder Pusan, sondern in der kleinen, benachbarten Provinzstadt Jinju zu eröff- 
nen, in der es keine japanische Konkurrenz, sondern nur kleine koreanische Unternehmer gab, die Ku zumeist persönlich kannte. ${ }^{15}$

Da das Startkapital, das Ku von seinem Vater bekommen hatte, nicht ausreichte, wandte er sich wegen einer Beteiligung an seinen jüngeren Bruder Chul-Hoe, der von einem kinderlosen Onkel adoptiert worden war und daher einmal das Vermögen dieses Onkels erben würde. Wie In-Hoe lebte auch ChulHoe ohne modernen Schulabschluß und erwerbslos auf dem Land von dem Vermögen seiner Eltern. Gemäß dem konfuzianischen Verhaltenskodex, nachdem der Jüngere dem Älteren zu gehorchen hat, sagte Chul-Hoe seine Beteiligung zu und gemeinsam brachten die Brüder ein Startkapital von etwas weniger als 4000 Yen zusammen, was damals dem durchschnittlichen Startkapital für ein kleines koreanisches Unternehmen entsprach.

Im Juli 1931 begannen die beiden Brüder mit ihren unternehmerischen Aktivitäten, indem sie in einem Mietshaus unter In-Hoes Namen einen Textilladen eröffneten. Die Kundschaft blieb jedoch aus. Erst nachdem ein koreanischer Konkurrent, der aber bereit war, In-Hoe Ku zu helfen, weil seine Frau aus dem gleichen Dorf wie Ku stammte, ${ }^{16}$ ihnen einen Laden direkt neben seinem eigenen, bereits gut eingeführten Geschäft angeboten hatte, kamen die Kunden auch zu den Brüdern Ku.

Für die danach bald mögliche Ausweitung seines Geschäfts benötigte In-Hoe Ku einen Kredit, den ihm die staatlich-japanische Grundstücksfirma "Dongyang Chuksik Hoesa"17 gegen eine Hypothek auf den Grundbesitz von Kus Familie bereit war zu geben. Als er deshalb seinen Vater nochmals um Hilfe bat, übergab dieser inm die Urkunde, in der der Familienbesitz verzeichnet war, und

\footnotetext{
15Die Angaben im folgenden stammen aus: Lucky-Goldstar (Hrsg.), Hanbeon Midemyeon Modu Matkeora (Wenn du anfängst, jemandem einmal zu glauben, dann sollst du bereit sein, inm alles anvertrauen zu können), Seoul 1979/1993, S. 45-95.

16Die gemeinsame regionale Herkunft schuf eine Beziehung zwischen den beiden Geschäftsleuten, die die Konkurrenzsituation überlagerte. Ku war durch die gemeinsame Herkunft nicht mehr nur ein geschäftlicher Konkurrent, sondern ein potentieller Freund, weil die Familie Kus zum Bekanntenkreis der Schwiegereltern von Kus Konkurrenten gehörte. Wenn Kus Konkurrent die Bitte von Ku um Hilfe abgelehnt hätte, wäre dies moralisch verwerflich gewesen, weil er einen Freund nicht angemessen behandelt hätte.

17Diese Firma wurde 1908 von der japanische Regierung gegründet, um durch den Verkauf von Gründstücken an Japaner die Immigrationspolitik der Regierung zu fördern. Seit Mitte der 20er Jahre war sie weniger mit dem Verkauf von Grundstücken als vielmehr mit der Vergabe von Krediten gegen Hypotheken betraut.
} 
legte damit das Schicksal der Familie in die Hände seines ältesten Sohnes. Dabei ermunterte ihn der Vater mit den Worten: "Selbst wenn der Anfang schwer sein sollte, muß man nicht so schnell aufgeben. Das Resultat erkennt man nicht gleich, sondern erst wenn man mindestens zehn Jahre investiert hat". 18 Dieser Ratschlag spiegelt die konfuzianischen Einstellung wider, daß man für alles im Leben lange Lehr- und Lernzeiten braucht. Das vom Vater dem Sohn gegenüber bezeugte Vertrauen trug dazu bei, daß beide Generationen, ungeachtet aller gesellschaftlichen Veränderungen, weiter in einer engen kulturellen Gemeinschaft lebten.

Obwohl sich In-Hoe Ku und sein Bruder ohne jedes kaufmännische Vorwissen auf das Geschäft mit Textilien eingelassen hatten, florierte ihr Geschäft, so daß sie schon bald ihre Schulden zurückzahlen konnten. Seine verbesserte fnanzielle Lage vergrößerte In-Hoe Kus unternehmerischen Handlungsspielraum und erlaubte ihm, sein Warenangebot zu erweitern und seine Preisgestaltung kundenfreundlicher zu gestalten, so daß sich seine Kundenzahl und damit sein Gewinn vergrößerte. Außerdem hatte er auch ein wenig Glück, da er während eines Hochwassers, das alle Geschäfte in der Stadt in Mitleidenschaft zog, zufällig einen Teil seiner Waren ausgelagert hatte. Auf diese Weise verlor er nicht nur viel weniger als seine Konkurrenten, sondern profitierte auch noch davon, daß durch das geringe Warenangebot die Preise in die Höhe getrieben wurden.

Als er durch ein zweites Hochwasser dann doch alles verlor, wandte er sich diesmal nicht an seine Familie, sondern an einen ihm bekannten koreanischen Mediziner, der durch seine Arztpraxis genügend Kapital angesammelt hatte, um Ku ohne Bürgschaft so viel Geld leihen zu können, daß dieser sein Geschäft wieder aufbauen konnte. Für Ku war dies ein Zeichen dafür, daß er in der Region inzwischen als vertrauenswürdiger Geschäftsmann anerkannt war.

Doch als nach der japanischen Kriegserklärung 1940 nur noch Uniformen hergestellt werden durften und es für den privaten Konsum keine Waren mehr gab, mußte auch Ku den Handel mit Textilien weitgehend aufgeben. Inzwischen hatte er aber genügend unternehmerisches Know-how erworben, um über Alternativen nachdenken zu können. Ihm war als Unternehmer ohne besondere

\footnotetext{
18Zitiert nach: Lucky-Goldstar (Hrsg.), Hanbeon Midemyeon Modu Matkeora (Wenn du anfängst, jemandem einmal zu glauben, dann sollst du bereit sein, inm alles anvertrauen zu können), Seoul 1979/1993, S. 59.
} 
Produktionskenntnisse und ohne großes Risikokapital klar, daß seine Chance nur in der Entdeckung einer neuen Marktnische liegen würde, und so versuchte er sich im Fischhandel, da Fische wegen ihrer kurzen Haltbarkeit vom Staat nicht kontrolliert werden konnten. Er fand einen Partner, der im Gegensatz zu ihm etwas vom Fischgeschäft verstand, und war dann innerhalb kürzester Zeit so erfolgreich, daß er drei Jahre nach Geschäftseröffnung sein Eingangskapital bereits verzehnfacht hatte.

Doch je deutlicher sich die japanische Niederlage abzeichnete, desto größer wurden Kus Befürchtungen, daß er sein Geld durch Inflation verlieren könnte. Deswegen suchte er nach sicheren Investitionsmöglichkeiten und wandte sich diesbezüglich um Rat an seinen Vater. Sein Vater, der sein Leben lang unter der Tatsache gelitten hatte, daß sich der familiäre Besitz ständig verkleinert hatte, schlug ihm vor, sein Geld in Grundbesitz zu investieren. Diesen Rat untermauerte er mit dem Argument, daß Land nicht von den Japanern zu Kriegszwecken mobilisiert werden könne. Ku folgte dem Rat seines Vaters und verhielt sich damit zu dessen Freude ausgesprochen standesgemäß. Denn so wie die Ablehnung jeder Handelstätigkeit durch den Konfuzianismus noch immer nicht aus den Köpfen der Koreaner verschwunden war, so war der Besitz von Land, der einst nur den mächtigen Yangban-Familien zugestanden hatte, noch immer ein Symbol für Macht und Ansehen. Doch obwohl In-Hoe Ku hier den konfuzianischen Wertvorstellungen seines Vaters folgte, unterschied er sich von seinem Vater doch inzwischen vor allem dadurch, daß er nicht mehr nur als ein Yangban dachte und fühlte, sondern auch ein Ethos als Unternehmer entwickelt hatte. Für ihn war sein kleines Unternehmen nicht nur ein Mittel, um die finanziellen Probleme der Familie zu lösen, sondern ein wichtiges Betätigungs- und Berufsfeld, in dem er Anerkennung und Selbstvertrauen fand.

So gab sich Ku auch nicht mit der Investition in Grundbesitz zufrieden, sondern suchte nach einer neuen Nische in der Kriegswirtschaft und gründete wieder ohne jedes branchenspezifische Vorwissen - eine Speditionsfirma für den Transport von Kriegsgütern. Doch diesmal scheiterte er. Die gebrauchten Wagen, die er gekauft hatte, bleiben ständig mit Motorschäden liegen, die kriegswichtigen Güter erreichten nicht rechtzeitig ihr Ziel, und Ku mußte deshalb Schadenersatz leisten. Als die Verluste zu groß geworden waren, gab er auf. Die ihm fehlenden Kenntnisse ließen sich in einer technisch und logistisch 
so komplizierten Branche wie dem Speditionswesen nicht durch die inm eigene große Tatkraft und Risikobereitschaft ausgleichen. Eine neue unternehmerische Chance bot sich Ku erst nach dem Ende der japanischen Kolonialzeit.

Byong-Chul Lee: Auch Byong-Chul Lee wählte für seine im März 1936 gemeinsam mit zwei ebenfalls aus Großgrundbesitzerfamilien stammenden Freunden in Masan gegründete Reisschälerei eine kleine Provinzstadt, da er sich mit seinem Startkapital der japanische Konkurrenz in den größeren Städten nicht gewachsen fühlte. ${ }^{19}$ Mit dem Anstieg des Reisexports nach Japan war der Bedarf an Reisschälereien, die sowohl von Japanern als auch von Koreanern betrieben wurden, ständig gestiegen und Masan war als Hafenstadt ein geradezu idealer Standort. ${ }^{20}$ Während die japanischen Reisschälereien von der Größe und Technologie her ziemlich modern waren, zeichnete sich die Mehrheit der koreanischen Reisschälereien durch ihre bescheidene Größe und eine veraltete Technik mit viel Handarbeit aus. Lee plante daher eine große, moderne Reisschälerei, in der Hoffnung, daß sich die koreanischen Kunden dann alle bevorzugt an seine, koreanische Reisschälerei wenden würden.

Jeder der drei Freunde investierte 10000 Yen in die neue Reisschälerei, der sie den Namen "Heop-Dong" (Kooperation) gaben. ${ }^{21}$ Doch reichte ihr Eingangskapital nicht für die neue japanische Anlage aus, die sie importieren wollten, und Lee wandte sich daher wegen eines Kredits an die Filiale einer japanischen Industriebank in Masan. Bei dem diesbezüglichen Gespräch befragte inn ein japanischer Bankangestellter nach seinen Branchenkenntnissen und

\footnotetext{
19Die Angaben im folgenden Abschnitt über den unternehmerischen Werdegang Lees stammen aus: Byong-Chul Lee, Hoam Chacheon (Hoams Autobiographie), Seoul 1985, S. 23-40.

20Hinzu kam, daß in Masan einer von Byong-Chuls älteren Brüdern wohnte. Vgl. dazu Sang-Hun Choe, Der Stellenwert der Mischkonzerne (Chaebol) im koreanischen Industrialisierungsprozeß: Dargestellt am Beispiel des Werdegangs und der Strukturmerkmale Samsungs, Hamburg 1994, S. 61.

${ }^{21}$ Dieser Name bezog sich nicht nur darauf, daß hier drei Unternehmer gemeinsam eine "Kooperation" gegründet hatten, sondern enthielt sozusagen eine höhere "nationale" Anspielung. Denn nach der Annexion Koreas durch Japan hatten viele japanische Historiker behauptet, daß diese nur eine Folge der Unfähigkeit der koreanischen Politiker gewesen sei, die sich in inneren Fraktionskämpfen zersplittert hätten, statt sich darauf zu konzentrieren, einen einigen, starken nationalen Staat zu schaffen. In diesem Zusammenhang erklärten die prokolonialistisch gesinnten japanischen Historiker die Koreaner alle und grundsätzlich als jedes Zusammenschlusses, jeder "Kooperation" für
} 
wollte u. a. von inm wissen, wovon der Reispreis auf dem japanischen Markt abhinge, was nach Meinung Lees für den Besitzer einer Reisschälerei eine völlig nebensächliche Frage war. Obwohl sich Lee durch diese Fragen des japanischen Bankangestellten, der ihm den Kredit aber dennoch bewilligte, beleidigt fühlte, schrieb er später in seiner Biographie, daß sein wirtschaftlicher Mißerfolg im ersten Geschäftsjahr vor allem auf die von inm nicht durchgeführte Analyse des Reismarktes zurückzuführen sei, und gab diesem damit indirekt recht.

Im ersten Jahr hatte Lee nämlich den Fehler gemacht, den Reis immer dann zu kaufen, wenn der Preis gerade hoch war, weil viele kauften. Später schrieb er in seiner Biographie, daß diese Haltung auf die Massenpsychologie des Menschen zurückzuführen sei. ${ }^{22}$ Erst nach massiven Verlusten kam er auf die Idee, die Ware dann zu kaufen, wenn der Preis gerade fiel. Der Stolz, mit dem er diese Sache noch im Rückblick hervorhob, zeigt zum einen ein wie naives Verständnis des unternehmerischen Handelns Lee anfänglich hatte, und zum anderen, wie primitiv der Preismechanismus in der koreanischen Wirtschaft damals war.

Um die neue japanische Maschine ohne Unterbrechung nutzen zu können, verfeinerte Lee dann seine Geschäftsmethoden weiter, in dem auch er die in der Reisschälerei sehr verbreitete Strategie übernahm, den Reis zu einem günstigen Zeitpunkt in großen Mengen zu kaufen, zu schälen und erst dann wieder zu verkaufen, wenn der Reispreis gestiegen war. Diese Praxis erinnert stark an die traditionelle Handelstätigkeit der (mit Beginn der japanischen Kolonialzeit praktisch verschwundenen) Kaekchu, die ebenfalls durch Lagerung den Preis der zu verkaufenden Güter in die Höhe getrieben hatten.

Ein Jahr nach Eröffnung der Reisschälerei erzielten Lee und seine Partner dann bereits so große Gewinne, daß sie ihr Geschäftsfeld auf den Speditionsbereich ausdehnen konnten, was insofern sehr vielversprechend war, weil damals Transportmittel für Reis Mangelware waren. Lee entschloß sich daher, eine japanische Speditionsfirma in Masan zu übernehmen und - im Gegensatz zu $\mathrm{Ku}$, der an den technischen Mängeln seinen maroden Gebrauchtwagen gescheitert war - investierte Lee als erstes in den Kauf neuer japanischer Lastwa-

unfähig. Siehe dazu Ki-Beok Cha, Hanguk eui Cheongchi Balcheon kwa Cheontong (Die Entwicklung von Politik und Tradition in Korea), Seoul 1984, S. 149.

22Byong-Chul Lee, Hoam Chacheon (Hoams Autobiographie), Seoul 1985, S. 28. 
gen und erreichte so, daß auch diese neue Firma innerhalb kürzester Zeit florierte. Aus diesen Erfahrungen entwickelte Lee dann später seine berühmt gewordene Managementphilosophie, nachdem sein Erfolg darauf beruhte, daß er immer versucht habe, der Beste in der Branche zu sein.

Seine Gewinne investierte Lee ganz traditionell in den Erwerb von Grundbesitz, wobei er dafür zusätzlich sogar noch einen großen Kredit bei einer japanischen Bank aufnahm. Damals war die Zahl der verarmten koreanischen Bauern sehr hoch und der Bodenpreis entsprechend niedrig, während die Pachtpreise mit dem ständig wachsenden Reisexport immer höher stiegen. Da außerdem die Kreditzinsen sehr niedrig waren, war der Erwerb von Land auf Kreditbasis ein lohnendes Geschäft. Denn die eingenommene Pacht überstieg die Zinszahlungen um ein Vielfaches. Je mehr Land Lee kaufte, desto mehr Kredite bekam Lee von der Bank. Er schrieb in seiner Biographie, daß er in dieser Zeit das Geld der Bank wie sein eigenes nutzen konnte.

Aber sein gewaltiger Expansionsdrang wurde gestoppt. Als Folge der japanischen Kriegserklärung an China kündigte inm die Bank den Kredit, und Lee und seine Geschäftspartner mußten, um ihre Schulden zurückzahlen zu können, nicht nur das neu erworbene Land, sondern auch die Reisschälerei und die Spedition verkaufen. Lee führte diesen unerwarteten geschäftlichen Mißerfolg später zum einen auf seine Unfähigkeit zurück, die politische Lage und deren Auswirkungen auf seine Geschäfte richtig einschätzen zu können, zum anderen auf seine, durch die Banken geförderte Naivität im Umgang mit dem Geld.23

Obwohl sich die wirtschaftliche Lage Koreas durch die japanische Kriegserklärung an China weiter verschlechterte, entschloß sich Lee, diesmal allein einen Neuanfang zu wagen. Um sich zu orientieren, machte er zunächst eine Reise in die großen Städte Koreas und der Mandschurei, die jedoch lediglich ergab, daß auch der von inm avisierte Lebensmittelhandel in den großen Städten von japanischen und chinesischen Unternehmern beherrscht wurde. Er entschied sich daher wieder für einen Standort in einer kleinen Stadt seiner heimatlichen Region, diesmal für Taegu, die für den Handel mit Lebensmitteln, wie Gemüse, Obst und getrocknete Meeresfrüchte, besser als Masan geeignet war, weil sie mitten in dem seit Beginn der japanischen Kolonialzeit durch den Bau

${ }^{23}$ Ebenda, S. 31. 
von Eisenbahnen und Straßen entstandenen Handelszentrum im mittleren Teil Koreas lag. ${ }^{24}$ Diesmal nannte Lee die von inm neu gegründete Handelsfirma "Samsung Sang-Hoe", wobei 'Sang-Hoe" einfach die erste, schon von den Kaekchu benutzte, koreanische Übersetzung für "Firma" ist, ${ }^{25}$ während "Sam" (drei) eine Glückszahl und das Wort 'Sung" (Stern) etwas Unveränderliches und Höchstes bezeichnet. "Samsung" sollte, so Lee in seiner Biographie, sofort zu erkennen geben, daß dieses Unternehmens etwas ganz Großes, etwas bisher noch nie Erreichtes anstrebe. ${ }^{26}$

Mit der Gründung dieses neuen Geschäfts wagte Lee dann tatsächlich sofort etwas ganz Neues: Er stellte nämlich Sun-Kun Lee, den er aufgrund ihres gemeinsamen Studiums in Japan kannte und der wegen seinen nationalistischpolitischen Tätigkeit während seiner Studienzeiten bisher keine Stelle bekommen hatte, als Geschäftsführer ein. Dabei bestand das Ungewöhnliche weniger darin, daß Lee seinen gleichnamigen Freund trotz seiner politischen Vergangenheit in seinem Unternehmen einstellte, sondern vielmehr darin, daß er seine Geschäfte überhaupt einem Geschäftsführer anvertraute. Denn dies war in der damaligen Zeit bei den koreanischen Unternehmern noch keineswegs gängige Praxis. Später führte Lee den großen Erfolg von Samsung nicht zuletzt auf seine mutige Personalpolitik zurück. So vertrat er die Meinung, daß es zwar immer ein Risiko darstelle, eine fremde (nicht zur Familie gehörende Person) Person als Mitarbeiter einzustellen, daß aber eine erfolgreiche Personalpolitik nicht denkbar sei, wenn der Unternehmer seinem Mitarbeiter nicht vertraue. Er müsse bereit sein, die potentiellen Fähigkeiten seines Mitarbeiters zu erkennen und inm Vertrauen und das Gefühl von Verantwortung zu vermitteln. Daraus leitete er später seine berühmte Managementphilosophie ab, deren Grundsatz lautet: "Wer nicht vertrauenswürdig erscheint, sollte nicht eingestellt werden. Aber wenn einer vertrauenswürdig ist, dann sollte man den Mut haben, ihn auch einzustellen."27

${ }^{24}$ Sang-Hun Choe, Der Stellenwert der Mischkonzerne (Chaebol) im koreanischen hdustrialisierungsprozeß: Dargestellt am Beispiel des Werdegangs und der Strukturmerkmale Samsungs, Hamburg 1994, S. 63.

${ }^{25} \mathrm{Heutzutage}$ bezeichnet "Sang-Hoe" nur noch einen Lebensmitteladen.

26Byong-Chul Lee, Hoam Chacheon (Hoams Autobiographie), Seoul 1985, S. 34.

27Ebenda, S. 35. 
Nachdem sein Lebensmittelhandel etabliert war und Gewinn abwarf, übernahm Lee zusätzlich eine Brauerei zur Herstellung von Reiswein in Taegu. Da es seit Beginn der japanischen Kolonialzeit verboten war, daß die Koreaner wie in der Zeit der Yi-Dynastie Zuhause selbst Alkohol herstellten, war das Brauen von Reiswein ein sehr privilegiertes und lukratives Geschäft, mit dem sich auch während des Krieges (trotz der erzwungenen Abgabe von Kriegskontingenten) große Gewinne machen ließen.

Während des Krieges überließ Byong-Chul Lee die Führung seiner Geschäfte allerdings mehr und mehr seinem Freund Sun-Kun Lee, zog sich 1941 schließlich ganz in sein Heimatdorf zurück und nahm nach erst nach dem Ende des Krieges 1945 seine Geschäfte in Taegu wieder auf. 28

Lee galt zumindest in der Region von Masan und Taegu schon während der japanischen Kolonialzeit als erfolgreicher koreanischer Unternehmer. Anders als Ku zog er aber weniger Selbstbestätigung aus der unternehmerischen Tätigkeit als solcher, sondern delegierte diese an seinen Geschäftsführer, wodurch er - wenn man so will - den engen Kreis der Kleinunternehmer eigentlich schon verließ, wie ja auch seine Unternehmungen bezogen auf das eingesetzte Kapital sehr viel größer waren als die von Ku. Meines Erachtens erwuchs die unternehmerische Betätigung von Lee, hinter der ja anders als bei $\mathrm{Ku}$ und Cheong keine ökonomische Notwendigkeit steckte, aus der während seiner Jugend noch eher diffusen, dann aber sich immer stärker konkretisierenden Sehnsucht nach einem modernen Leben.

Joo-Young Cheong: Nach seinem vierten und erfolgreichen Fluchtversuch verdiente Joo-Young Cheong zunächst seinen Lebensunterhalt als Tagelöhner, wobei aber sein Lohn so niedrig war, daß er nur für Essen und Schlafen reichte. ${ }^{29}$ Danach arbeitete er ein Jahr als einfacher Arbeiter in einer Keksfabrik, und nahm, nachdem sich seine Hoffnung, in der Fabrik weiterzukommen, nicht erfültt hatte, anschließend eine Aushilfsstelle in einem kleinen Reisgeschäft an.

28Nach dem Ende des Krieges übernahm Sun-Kun Lee eine poltitische Tätigkeit und ging dann während des Koreakrieges in das kommunistische Nordkorea.

29Die folgenden Angaben stammen aus: Joo-Young Cheong, Sireonun Issedo Silpae nun Eopda (Es gibt zwar Schwierigkeiten, aber keinen Mißerfolg), Seoul 1991, S. 5873; Ders., I Tange Taenaseo (Geboren in diesem Lande), Seoul 1998, S. 31-44. 
Diesmal bekam er monatlich einen Sack Reis als Lohn, sein Essen war frei. Den Reis verkaufte er, und so hatte er endlich die Möglichkeit, Geld zu sparen.

Da Cheong der Arbeit in diesem Reisgeschäft so engagiert nachging, als ob es sich um sein eigenes Geschäft handelte, brachte inm sein Chef, der keinen Schulabschluß hatte und nicht einmal wußte, wie man die Bücher führt, bald so großes Vertrauen entgegen, daß er Cheong beauftragte, für inn die Buchführung zu machen. Zwei Jahre später bekam Cheong von seinem Chef das Angebot, das Geschäft zu übernehmen. Obwohl er kein eigenes Kapital besaß, nahm er dieses Angebot an. Denn er übernahm damit den alten Kundenstamm und erhielt außerdem von dem Reislieferanten günstige Zahlungsbedingungen, die vorsahen, daß er den gelieferten Reis erst nach dem Verkauf bezahlen mußte. Also holte Cheong als neue Aushilfe einen seiner Cousins nach Seoul und begann im Januar 1938 seine erste, eigenständige unternehmerischeTätigkeit.

Doch schon im Dezember 1939 wurde sein Reisgeschäft aufgrund des Krieges zwischen Japan und China zwangsweise geschlossen. Doch inzwischen hatte er Geld gespart, so daß er, als er von einem seiner ehemaligen Kunden, der Ingenieur in einer Autowerkstatt war, erfuhr, daß diese Werkstatt zum Verkauf stehe, zugreifen konnte. Gemeinsam mit diesem Ingenieur und einem von dessen Freunden kaufte Cheong die Werkstatt. Da ihr Geld nicht ganz reichte, hatten sie sich allerdings an einen Wucherer wenden müssen, der zwar hohe Zinsen, aber anders als die Bank keine Bürgschaft verlangte. Obwohl Cheong keine Ahnung von Autos hatte, begann er sich voller Neugier mit Autotechnik zu beschäftigen. Später führte er seinen Entschluß, sich in der Automobilindustrie zu engagieren, vor allem auf diese damals gemachten ersten Erfahrungen mit der Autotechnik zurück.

Doch bevor die Autowerkstatt die Arbeit richtig aufnehmen konnte, brach in der Werkstatt ein Brand aus und zerstörte diese vollständig. ${ }^{30}$ Also ging Cheong nochmals zu dem Wucherer, und bat inn erneut um Geld. In seiner Biographie

30 In seiner ersten Biographie schrieb Cheong, daß dieser Brand durch einen seiner Angestellen verursacht worden sei (Cheong, 1991, S. 65), in der zweiten Biographie aber gab er zu, daß er selbst inn verursacht hatte (Cheong, 1998, S. 38). 
schrieb Cheong dann, daß dieser Wucherer nur wegen seines Vertrauen in Cheongs Fähigkeiten ihm nochmals ohne jegliche Bürgschaft Geld lieh. ${ }^{31}$

Doch dann tauchte ein neues Problem aus: Die japanische Polizei genehmigte die Gründung der neuen Autowerkstatt nicht. Da es um seine Existenz ging, vergaß Cheong allen Nationalstolz und bettelte bei der zuständigen japanischen Polizei um die Genehmigung. Cheong schien die japanische Kolonialherrschaft sowieso als etwas Unveränderliches anzusehen, so daß er sich fast fatalistisch diesem System anpaßte. Die Genehmigung erhielt er dennoch nicht, lediglich den Tip, die Werkstatt illegal zu betreiben, was er mit - natürlich nur mäßigem geschäftlichen Erfolg - auch tat. Auf Befehl der japanischen Kolonialregierung wurde Cheongs Werkstatt dann 1943 mit einer größeren Werkstatt fusioniert und Cheong und seine beiden Freunden verließen die Werkstatt kurz danach endgültig.

Während die Mehrheit der anderen kleinen koreanischen Unternehmer angesichts des nahenden Kriegsendes keine Versuche mehr machte, privatwirtschaftliche Interessen zu verfolgen, unternahm Cheong nach fast einem Jahr Arbeitslosigkeit einen erneuten Versuch, sich unternehmerisch zu betätigen. Auf Vermittlung eines Japaners, der Kunde in seiner Autowerkstatt gewesen war, gründete er ein Speditionsbüro, das vertraglich fest für ein japanisches Bergbauunternehmen und damit direkt für die japanische Rüstungsindustrie arbeitete. In seiner Biographie begründete Cheong diese unter nationalen Gesichtspunkten äußerst fragwürdige Entscheidung damit, daß er durch diese Arbeit verhindern konnte, daß seine jüngeren Brüder als japanische Soldaten an die Front geschickt wurden. Denn wer im Bergbau arbeitete, dessen Familie war von der Zwangsrekrutierung befreit. 32 Erst im Mai 1945, kurz vor der japanischen Niederlage gab Cheong dieses Geschäft auf. Bis zu diesem Zeitpunkt hatte er 50000 Yen damit verdient, die er später in die Wiederaufnahme seiner Autowerkstatt investieren konnte.

Zusammenfassend läßt sich sagen, daß alle die späteren so erfolgreichen Chaebolgründer, Ku, Lee und Cheong, die sich ja alle drei dem ökonomischen

31Joo-Young Cheong, I Tange Taenaseo (Geboren in diesem Lande), Seoul 1998, S. 39. ${ }^{32}$ Ebenda, S. 44. 
Handeln weniger aus innerer Überzeugung als vielmehr wegen der ihnen für andere Berufe fehlenden schulischen Qualifikation zugewandt hatten, ihre unternehmerischen Erfahrungen in einem ständigen Prozeß des Trial und Error machten. Die innen in fast allen Bereichen fehlenden Kenntnisse verstärkten ihren Pragmatismus und vor allem ihre hohe Anpassungsfähigkeit an die sich wandelnden politischen und ökonomischen Rahmenbedingungen in der japanischen Kolonialzeit. Sie ließen sich z. B. niemals auf ein unmittelbares Konkurrenzverhältnis zu japanischen Unternehmern ein und richteten ihr unternehmerisches Interesse entweder auf Regionen, in denen die Japaner nicht präsent waren, in denen für sie selbst aber der in Korea herrschende Regionalismus ein wichtiges soziales Kapital darstellte, oder auf Bereiche, in denen sich nur kleine koreanische Unternehmer betätigten.

Entsprechend begannen alle drei ihre unternehmerische Karriere in der weitgehend Koreanern vorbehaltenen Nahrungs- und Konsumgüterbranche, scheuten sich aber nicht, sich auch in innen völlig unbekannten anderen Branchen zu engagieren, was allerdings nicht nur eine Folge ihrer hohen Risikobereitschaft, sondern auch der durch den Krieg bedingten veränderten ökonomischen Lage war. Um ihres ökonomischen Interesses wegen vernachlässigten sie dabei auch weitgehend den nationalen Aspekt des ökonomischen Handelns, der in Korea vor allem in den 20er und 30er Jahren eine so große Rolle gespielt hatte, und paßten sich mit mehr oder weniger Skrupeln den Erfordernissen der japanischen Kriegspolitik an. ${ }^{33} \mathrm{Im}$ Gegensatz zu den von den Japanern gestützten koreanischen Großunternehmern, von denen im letzten Kapitel die Rede war, war allerdings ihr unternehmerisches Betätigungsfeld zu klein und der Umfang ihrer Geschäfte zu unbedeutend, um ihren Neuanfang in der postkolonialen Gesellschaft Koreas nachhaltig zu belasten.

Die Investition ihres Gewinns in Grundbesitz, wie dies Ku und Lee (auch Cheong hatte trotz seiner vergleichsweise begrenzten Mittel seinen Eltern ztmindest ein kleines Stück Land gekauft) taten, erinnert deutlich an das ökonomische Handeln der traditionellen Händler "Kaekchu", die ihr mangelndes ge-

33Byong-Chul Lee, der ja zumindest nachträglich seinen Unternehmungen am deutlichsten eine nationale Motivation unterlegte, war während der Kriegszeit wohl tatsächlich am wenigstens in die japanische Kriegswirtschaft im engeren Sinne involviert (wenn man einmal von seinem, von einer japanischen Lizenz abhängigen Engagement in der Brauerei absieht). 
sellschaftliches Ansehen auch durch den Kauf von Land ausgleichen wollten. Selbst wenn das unternehmerische Engagement der späteren Chaebolgründer durchaus den Eindruck erweckte, als hätten sie die traditionell konfuzianisch geprägte Vorstellung mit einer strikten Scheidung zwischen achtbaren und weniger achtbaren Berufen überwunden, bedeutete dies nicht, daß sie sich damit wirklich an einem völlig neuen Typus des ökonomischen Handelns orientierten. Vielmehr ging ihr unternehmerisches Handeln zu großen Teilen (hier ist in erster Linie ihr Engagement im Reis- oder Textilhandel gemeint) nicht über die Aktivitäten der traditionellen koreanischen Kaekchu hinaus, wobei ihr Erfolgsrezept wie bei den Kaekchu vor allem in einer geschickten Ein- und Verkaufsstrategie bestand.

Für die koreanische Gesellschaft insgesamt bestand das Verdienst dieser koreanischen Kleinunternehmer, zu denen auch Ku, Lee und Cheong trotz ihrer beachtlichen ökonomischen Erfolge bis 1945 noch immer gehörten, vor allem darin, die Gründung von Unternehmen in Korea als eine schichtübergreifende, nicht mehr nur auf eine kleine, gut ausgebildete und wohlhabende Elite beschränkte, existenzsichernde Möglichkeit für alle Koreaner ins öffentliche Bewußtsein gehoben zu haben.

\section{IV.3 "Familie" im Verständnis des koreanischen Unternehmers}

In der Regel geht man in der Soziologie davon aus, daß die neue junge koreanische Generation mit dem Übergang zur modernen westlichen unternehmerischen Denkweise zu Beginn der japanischen Kolonialzeit einen totalen kulturellen Bruch erlebt hat. ${ }^{34}$ Aber ich habe große Zweifel, daß die Sozialisation der ersten Gründerväter allein durch den Rückgriff auf diesen kulturellen Bruch zu erklären ist. Meine These ist vielmehr, daß das neue koreanische Verständnis des ökonomischen Handelns weder durch den Bruch mit noch durch die Kontinuität der traditionellen konfuzianischen Kultur zu erklären ist.

${ }^{34}$ Vgl. dazu beispielsweise Edward S. Mason u. a., The Economic and Social Modernization of the Republic of Korea: Studies in the Modernization of The Republic of Korea: 1945-1975, Cambridge u. a. 1980, S. 74-91. 
Denn obwohl die protestantische Ethik, wie wir seit Max Weber wissen, ein wichtiger Motivationsfaktor für die Entwicklung des modernen Unternehmertums in den westlichen Ländern war, läßt sich ein Äquivalent zur protestantischen Ethik in der Sozialisation der koreanischen Chaebolgründer nicht finden. Diese interessierten sich weniger für Religion, sprich den Konfuzianismus, als vielmehr für ihre veränderte Rolle in der Familie, die sich mit Beginn der japanischen Kolonialzeit fundamental verändert hatte. Die konfuzianische Bildung, die eine wichtige Basis der traditionellen Familie gewesen war, verlor ihre statusund berufszuweisende Funktion, und die Eltern konnten daher gegenüber ihren Kindern die alten Erziehungsideale nicht mehr durchsetzen, sondern mußten diesen weitgehend selbst überlassen, sich auf die veränderte gesellschaftliche Realität einzustellen. Die Gründungsväter der koreanischen Chaebol fanden zum Unternehmertum daher gerade durch Überwindung des Konfuzianismus und der durch inn gegebenen traditionellen Bindungen. Dies bedeutete jedoch nicht, daß sie die traditionellen konfuzianischen Werte nicht weiter hochhielten oder nicht sogar, wie Lee, offiziell zur Grundlage ihrer Geschäftsphilosophie machten. Es ist dabei meines Erachtens jedoch bemerkenswert, daß ausgerechnet Lee, dessen unternehmerisches Engagement aufgrund des Reichtums seiner Familie am wenigstens von ökonomischen Notwendigkeiten verursacht war, sich am deutlichsten weiterhin auf den Konfuzianismus berief. Vor dem Hintergrund einer wohlhabenden alten Yangban-Familie überlebten die konfuzianischen Werte also offensichtlich am ungebrochensten.

Für alle drei Chaebolgründer aber gilt, daß die traditionelle Wertschätzung der Familie weiterhin ungeschmälert blieb und sich aufgrund der beruflichen Perspektivlosigkeit, in der sich alle drei zu Beginn ihrer unternehmerischen Tätigkeit befanden, sogar noch verstärkte. Denn die Familie war und blieb die einzige gesellschaftliche Institution, auf die sich jeder Koreaner verlassen konnte und auf die sich entsprechend auch die drei späteren Chaebolgründer zumindest bei der Finanzierung ihrer ersten unternehmerischen Aktivitäten fast ausschließlich stützten. Dabei war einerseits das Zuverfügungstellen des Startkapitals eine Folge der herrschenden familiären Solidarität und andererseits wurde durch diesen Akt der Unterstützung und die damit gegebene (objektive), wechselseitige finanzielle Abhängigkeit diese Solidarität noch befestigt. 
Nach der klassischen soziologischen Lehre sind Unternehmen und Familie zwei strukturell verschiedene Dinge. ${ }^{35}$ Während eine Familie durch die starke emotionale Bindung zwischen ihren Mitgliedern geprägt ist, zeichnet sich ein Unternehmen durch sachliche und ökonomisch kalkulierte Beziehungsformen aus. Nur in dem Begriff des "Familienunternehmens" verschwimmt diese strikte Unterscheidung. In der Regel versteht man darunter ein Unternehmen, in dem die Gründerfamilie einen hohen Kapitalanteil besitzt und auch einen großen Teil des Management stellt. Im Hinblick auf die Existenz dieser eigenartigen Mschung von Unternehmen und Familie beschäftigen sich sowohl Soziologen als auch Sozialhistoriker schon lange mit der Frage, aus welchen Gründen die Familie in das unternehmerische Handeln einbezogen wurde. ${ }^{36}$ Jürgen Kocka kam in diesem Zusammenhang zu dem Schluß, daß man den Typus des Familienunternehmens vorwiegend in der Gründungsphase von Unternehmen finde, in der der Unternehmer in besonderer Weise unter der finanziellen Zurückhaltung anderer potentieller Geldgeber leide. 37

Kockas Feststellung scheint zumindest auf die unternehmerischen Anfänge der späteren Chaebolgründer genau zuzutreffen, und man kann daher fragen, ob der hohe familiäre Anteil in den koreanischen Chaebol darauf deutet, daß es sich bei den Chaebol um Familienunternehmen im westlichen Sinne handelt. Anders formuliert: Erinnert die koreanische Entwicklung der Chaebol an die Entstehungsgeschichte westlicher Familienunternehmen? Während die bisherige koreanische Charakterisierung der Chaebol davon ausgeht, daß dies der Fall ist, ${ }^{38}$ bin ich der Meinung, daß den koreanischen Chaebol bei allen äußerlichen Ähnlichkeiten ein anderes Verständnis von Familie zugrundeliegt als im

\footnotetext{
${ }^{35} \mathrm{Am}$ deutlichsten findet sich diese scharfe Trennung bei dem deutschen Klassiker Ferdinand Tönnies in seinem 1935 erschienenen Buch "Gemeinschaft und Gesellschaft".

36Die amerikanischen Sozialwissenschaftler Piore und Sabel beispielsweise bringen den Aufschwung der Region "Emilia Romagna" in Italien vor allem mit der Tradition der Großfamilie bzw. Familialismus im Zusammenhang. Siehe dazu Michael Piore/Charles F. Sabel, Das Ende der Massenproduktion: Studie über die Requalifizierung der Arbeit und die Rückkehr der Ökonomie in die Gesellschaft, Berlin 1985, S. 250-254.

37Jürgen Kocka, Unternehmer in der deutschen Industrialisierung, Göttingen 1975, S. 67.

${ }^{38}$ Es handelt sich hierbei allerdings weniger um explizite Anwendung dieses Begriffes als vielmehr um die implizite Interpretation der koreanischen Chaebol als Familienunternehmen. Vgl. dazu Dong-Sung Cho, Hanguk Chaebol (Die Organisation der Chaebol), Seoul 1997, S. 12.
} 
Westen. Dies wiederum hängt mit dem ungewöhnlichen ökonomischen Entwicklungsprozeß zusammen, den Korea zwischen 1945 und 1960 durchlief. In dieser Zeit fand der ökonomische Aufstieg von Ku, Lee und Cheong statt, die nun - obwohl ihre Unternehmen nach westlichen Maßstäben nicht mehr als Klein- und Mittelunternehmen waren - die ehemals großen Unternehmer der japanischen Kolonialzeit wie Min, Kim und Park, von denen in Kapitel III die Rede war, ablösten. Es stellt sich nun die Frage, worauf dieser radikale Aufstieg der drei Chaebolgründer zurückzuführen ist. Beruhte dieser Erfolg der drei Gründerväter wie in der Anfangszeit ihrer unternehmerischen Laufbahn tatsächlich in erster Linie auf der finanziellen Hilfeleistung bzw. Loyalität ihrer Familienmitglieder oder aber verbarg sich dahinter vielleicht, wie ich vermute, eine ganz andere soziale Verflechtungslogik, die mit dem herkömmlichen westlichen Begriff der Familie nur unvollkommen beschrieben ist? Diese Frage, die in der bisherigen Chaebol-Forschung kaum berücksichtigt worden ist, halte ich zur Klärung des Verständnisses der Entstehungsgeschichte der koreanischen Chaebol für unentbehrlich.

Für die folgende Schilderung des unternehmerischen Werdegangs der Gründerväter der koreanischen Chaebol zwischen 1945 und 1960 interessieren mich daher nicht die persönlichen bzw. privaten Beziehungen der Gründerväter zu ihren Familienmitgliedern, sondern die spezifischen unternehmerischen Rahmenbedingungen, die ihr Verständnis und ihre Beziehung zu den Familienmitgliedern beeinflußten. Zu diesen gesellschaftlichen Faktoren gehören sowohl die alle drei Chaebolgründer gleichermaßen betreffende und daher vorab gesondert dargestellte ökonomische Entwicklung Koreas in der postkolonialen Ära, als auch die im folgenden im einzelnen zu analysierende kulturbedingte soziale Verflechtungslogik, in der die drei Chaebolgründer jeweils befangen waren.

\section{IV.4 Die ökonomische Entwicklung Koreas zwischen 1945 und 1960}

Nach der Kapitulation Koreas am 15. August 1945 wurde Korea in zwei Besatzungszonen - die sowjetische im Norden und die amerikanische im Süden - 
aufgeteilt. Während die Sowjetunion in ihrer Besatzungszone die Volksrepublik Korea anerkannte, wurde im Süden das United States Army Military Government in Korea (USAMGIK) gebildet, das bis 1948 die koreanische Verwaltung kontrollierte. 39

Als eine der ersten wirtschaftlichen Maßnahmen ordnete die amerikanische Besatzungsmacht nicht nur die sofortige Verstaatlichung der ehemaligen japanischen Vermögenswerte wie Fabrikanlagen und Privathäuser an, sondern auch die Einführung der privaten Marktwirtschaft, wodurch die frühere staatliche Kontrolle über privatwirtschaftliche Aktivitäten aufgehoben wurde.40

Damit diese ohne Unterbrechung weiter produzieren würden, übergab die amerikanische Besatzungsmacht die enteigneten japanischen Produktionsanlagen möglichst schnell in koreanische Hände, mußte dabei aber - weil es kein ausgebildetes koreanisches Unternehmertum gab - häufig auf einfache ehemalige Mitarbeiter des Unternehmens zurückgreifen, die nun kurzerhand zu Direktoren gemacht wurden. Doch waren diese neuen Direktoren häufig mehr an dem lukrativen Weiterverkauf von Maschinen und Rohstoffen aus den Lagerbeständen interessiert als an der Aufrechterhaltung der Produktion, wofür sie in der Regel auch gar nicht qualifiziert waren. ${ }^{41}$ Dies hatte zur Folge, daß die Fabriken nicht mehr oder zumindest nicht mehr ausreichend arbeiteten und sich der Versorgungszustand der koreanischen Bevölkerung immer mehr verschlechterte, was sich durch die Rückkehr von Emigranten und Exilanten aus dem Ausland und die vielen Flüchtlinge aus Nordkorea noch verschlimmerte. 42

Zwar versuchte die amerikanische Besatzungsmacht dem drohenden Versorgungsnotstand durch die Lieferung von Hilfsgütern wie Mehl, Zucker und Baumwolle zu begegnen, doch fehlten dennoch andere Konsumgüter, wie beispielsweise Pflanzenöl, Kosmetika, Uhren und Medikamente, die wegen der gestörten landeseigenen Produktion nun aus anderen Ländern importiert wer-

\footnotetext{
39Manfred Pohl, Die Entstehung zweier Staaten, in: Rüdiger Machetzki/Ders. (Hrsg.), Korea, Stuttgart-Wien 1988, S. 76.

40Ki-Jun Cho, Hanguk Chabonjueui Balcheonsa (Die Geschichte des koreanischen Kapitalismus), Seoul 1991, S. 31.

${ }^{41}$ Ebenda, S. 31; Cheong-Jae Lee, Chaebol Yireokseo (Die Entwicklungsgeschichte der Chaebol), Seoul 1993, S. 47.

42Ebenda, S. 39.
} 
den mußten. ${ }^{43}$ Aufgrund dessen kam es in Korea zu einem Gründungsboom von Handelsfirmen (und auch der Schmuggel blühte auf). Die wichtigsten Handelspartner Südkoreas waren nach wie vor Japan, dann Nordkorea und auch China, in das Korea seinerseits chemische Produkte zur Waffenherstellung, die von den Japanern in Korea zurückgelassen worden waren, exportierte. ${ }^{44} \mathrm{Zwi-}$ schen Nord- und Südkorea wurden chemische Düngemittel und andere industrielle Rohstoffe gegen Reis und Textilien getauscht. Schon während der japanischen Kolonialzeit hatte sich die Wirtschaft Nordkoreas und Südkoreas in zwei verschiedene Richtungen entwickelt. Im Norden Koreas konzentrierte sich die Schwerindustrie, insb. die Stahlindustrie, die stromerzeugende Industrie und die chemische Düngemittelindustrie, während sich im Süden Koreas die Zentren der Landwirtschaft und der Baumwollindustrie befanden. Nach der Wahl zur Nationalversammlung Südkoreas am 10. Mai 1948 stoppte das kommunistische Regime in Nordkorea seine Stromlieferungen nach Süden und stellte auch den Handel mit chemischen Düngemitteln ein. Dies bedeutete nicht nur das vorläufige Ende der Handelsbeziehungen zwischen Nord- und Südkorea, sondern vor allem aufgrund des Strommangels zumindest vorübergehend eine fast vollständige Lähmung der südkoreanischen Wirtschaft. 45

Um das Stromproblem zu lösen, förderte die südkoreanische Regierung verstärkt den Abbau von Kohle und anderer Mineralien. Letztere wurden exportiert, die Kohle für neu errichtete Kohlekraftwerke verwendet. Dadurch verbesserte sich die südkoreanische Infrastruktur allmählich und die ökonomische Wachstumsrate in Südkorea betrug 1949 immerhin schon 9,7\%. ${ }^{46}$ Doch dauerte diese Stabilisierungs- und Aufschwungphase nicht lange, denn am 25. Juni 1950 brach der Koreakrieg aus.

Obwohl der Krieg nach der schnellen Intervention der UN-Truppen schon 1953 mit einem Waffenstillstandsabkommen beendet war, führte er dazu, daß $44 \%$ der gesamten Produktionsanlagen in Südkorea zerstört wurden. 47 Vor al-

\footnotetext{
43Ki-Jun Cho, Hanguk Chabonjueui Balcheonsa (Die Geschichte des koreanischen Kapitalismus), Seoul 1991, S. 51.

${ }^{44}$ Cheong-Jae Lee, Chaebol Yireokseo (Die Entwicklungsgeschichte der Chaebol), Seoul 1993, S. 49.

${ }^{45}$ Ebenda, S. 55.

46Ki-Jun Cho, Hanguk Chabonjueui Balcheonsa (Die Geschichte des koreanischen Kapitalismus), Seoul 1991, S. 42.

47Ebenda, S. 43.
} 
lem die Fabriken, die in Seoul oder der benachbarten Keongi-Region angesiedelt waren, waren nicht mehr produktionsfähig, so daß der allgemeine Mangel an alltäglichen Konsumgütern erneut die Nachfrage ansteigen und Handelsunternehmen ein zweites Mal boomen ließ.

Sowohl die koreanische Regierung unter dem 1948 gewählten Präsidenten Syung-Mann Rhee als auch die amerikanische Regierung, die beide befürchteten, die Bevölkerung in Südkorea könne sich unter dem Druck der allgemeinen Armut dem Kommunismus zuwenden, bemühten sich, die Versorgungsnot zu mildern. ${ }^{48}$ Rhee forderte dabei, daß vor allem die durch den Krieg zerstörten industriellen Anlagen im Süden möglichst schnell wieder aufgebaut werden sollten, doch die amerikanische Regierung verlangte, daß das von ihr zur Verfügung gestellte Geld in erster Linie für den Import von amerikanischen Konsumgütern verwendet werden sollte. 49 Obwohl, wie zumindest der koreanische Nationalökonom Heon-Chae Park behauptet, das koreanische Konsumniveau nach dem Koreakrieg sehr schnell das Niveau der wohlhabenden westlichen Ländern erreichte, entwickelte sich daher ein großes Ungleichgewicht zwischen dem Konsumniveau der koreanischen Bevölkerung und dem realen Produktionsniveau der koreanischen Ökonomie. 50

Weil die im Inland hergestellten koreanischen Produkte von der Qualität und vom Preis her weder mit den amerikanischen noch mit anderen ausländischen Gütern konkurrieren konnten, interessierten sich die koreanischen Unternehmer entweder für den Konsumgüterimport oder für die Gründung von Unternehmen der Importsubstitutionsindustrie, für die Rohstoffe und Produktionsanlagen aus dem Ausland importiert werden mußten. Am konkreten Beispiel gesagt: Weil die Qualität der von Amerika importierten Baumwolle besser war als die im Süden von Korea angebaute Baumwolle, importierten die koreanischen Baumwollproduzenten Rohstoffe und ausländische Maschinen. Die Zahl der koreanischen

\footnotetext{
${ }^{48}$ Chan-II Park, Migukeui Keongje Weonjo eur Seonggeok kwa Gu Keongjejeok Guikeol (Der Charakter der amerikanischen Wirtschaftshilfe und deren ökonomische Folgen), in: Yun-Hwan Kim u.a., Hanguk Keongje eui Cheongae Kujo (Die Entwicklung der koreanischen Ökonomie), Seoul 1981, S. 89.

49Wirtschaftshistoriker wie Chan-II Park kritisierten daher, daß die amerikanische Wirtschaftshilfe nach dem Koreakrieg für den Wiederaufbau des Landes nicht besonders hilfreich gewesen sei. Ebenda, S. 94.

${ }^{50 H e o n-C h a e ~ P a r k, ~ H a n g u k ~ K e o n g j e ~ K u c h o r o n ~(L e h r e ~ d e r ~ k o r e a n i s c h e n ~ o ̈ k o n o m i s c h e n ~}$ Struktur), Seoul 1986, S. 76 f.
} 
Bauern, die sich mit dem Anbau von Baumwolle beschäftigten, nahm daher weiter ab, und entsprechend erhöhte sich die Rohstoffabhängigkeit der koreanischen Wirtschaft von den Vereinigten Staaten. ${ }^{51}$

Dies aber hatte zur Folge, daß die koreanische Ökonomie, nachdem sich 1958 die amerikanische Regierung entschlossen hatte, die bisher gewährte Entwicklungshilfe durch Kredite zu ersetzen, ${ }^{52}$ völlig gelähmt wurde. Das große Problem bestand darin, daß die Importsubstitutionsindustrie zwar aufgrund der großen Nachfrage florierte, durch den rasanten Verarmungsprozeß in der Bevölkerung aber zunehmend belastet wurde. 53

Da diese Industrie vor allem Halbfertigwaren importierte, wurden dadurch auch kaum Arbeitsplätze geschaffen, so daß viele junge Koreaner, vor allem die aus dem Krieg zurückgekehrten Soldaten, keine Arbeit fanden. Insbesondere unter den jungen Universitätsstudenten, deren Zahl nach der Beendung der japanischen Kolonialzeit rapide gestiegen war, nahm die Unzufriedenheit mit der ökonomischen Entwicklung zu. Sie betrachteten sich selbst als Elite der Nation und sahen es als ihre Pflicht, die durch die amerikanische Hilfeleistung verursachte wirtschaftliche Fehlentwicklung Koreas aufzudecken. Nach ihrer Auffassung hatte die ausländische ökonomische Entwicklungshilfe lediglich einige wenige Unternehmer sehr reich gemacht, während gleichzeitig die Mehrheit der koreanischen Bevölkerung unterhalb der Armutsgrenze lebte. ${ }^{54}$ Die allgemeine Unzufriedenheit entlud sich am 19. April 1960 in massiven Schüler- und Studentenprotesten gegen das Regime unter Präsident Rhee, die schließlich zum Sturz von Rhee führten. Auf ihren Demonstrationen hatten die Studenten übrigens nicht nur den Wechsel der Regierung, sondern auch die Bestrafung der nach der Befreiung von der japanischen Kolonialmacht reich gewordenen Unternehmer wie In-Hoe Ku, Byong-Chul Lee und Joo-Young Cheong gefordert.

${ }^{51} \mathrm{Ki}$-Jun Cho, Hanguk Chabonjueui Balcheonsa (Die Geschichte des koreanischen Kapitalismus), Seoul 1991, S. 47.

52 Yun-Heong Cheong, Keongje Seongjang kwa Dokcheom Chabon (Das ökonomische Wachstum und das Monopolkapital), in: Yun-Hwan Kim u.a., Hanguk Keongje eui Cheongae Kujo (Die Entwicklung der koreanischen Ökonomie), Seoul 1981, S. 143.

53Heung-Yun Byon, Hanguk Keongje Kaebal Gaeheok eui Banghyang (Die ökonomische Entwicklung in Korea), in: Shin, II-Chul (Hrsg.), Hangukineui Sasang (Das Denken in Korea), Seoul 1984, S. 188.

${ }^{54}$ Chan-II Park, Migukeui Keongje Weonjo eur Seonggeok kwa Gu Keongjejeok Guikeol (Der Charakter der amerikanischen Wirtschaftshilfe und deren ökonomische Fol- 


\section{IV.5 "Kapital Familie": der unternehmerische Aufstieg}

In-Hoe Ku: Als einer der wenigen Koreaner mit unternehmerischen Erfahrungen nutzte In-Hoe Ku sofort die historisch einmalige Chance, die sich inm mit dem Ende der japanischen Kolonialzeit und dem damit gegebenen Wegfall der übermächtigen japanischen Konkurrenz bot. ${ }^{55} \mathrm{Er}$ verkaufte seinen gesamten Landbesitz, verließ die kleine Provinzstadt Jinju schon im September 1945, zog mit seiner gesamten Familie nach Pusan, wo sich unter den Japanern ein groBes Wirtschafts- und Handelszentrum entwickelt hatte, und investierte dort sein gesamtes Vermögen in die erste, von der amerikanischen Besatzungsmacht genehmigte koreanische Außenhandelsfirma.

Da die in Korea nach japanischem Vorbild gebauten Häuser vor allem mit Holzkohle beheizt wurden, in Korea aber wegen der durch den Krieg ausgebeuteten und verwüsteten Wälder ein massiver Mangel an Holzkohle herrschte, versprach sich Ku von dem Import von Holzkohle nach Korea große Gewinne. Doch wie naiv Kus unternehmerisches Vorgehen trotz seiner bisher gesammelten Erfahrung noch immer war, läßt sich daran erkennen, daß er sich keinerlei Gedanken gemacht hatte, woher er die Kohle bekommen und wie er sie transportieren wollte. Auf das bloße Gerücht hin, daß es auf einer von Pusan nicht weit entfernten japanischen Insel Holzkohle gäbe, mietete er sich ein Fischerboot, geriet damit in einen Sturm, den er nur knapp überlebte und landete schließlich auf einer anderen Insel, auf der es keine Holzkohle gab. Zum Ausgleich versucht er andere Konsumgüter für den Weiterverkauf in Korea zu erwerben, aber es gab einfach nichts zu kaufen. Denn die japanische Bevölkerung litt selbst erheblichen Mangel.

Nach diesem Mißerfolg konzentrierte sich Ku auf den inländischen Handel mit Holzkohle. In seinem Geschäft, das allerdings nicht besonders gut lief, beschäftigte Ku die beiden ältesten der inm nachfolgenden jüngeren Brüder Chul-Hoe, mit dem er schon vor 1945 zusammengearbeitet hatte, und CheongHoe - und den Schwiegersohn seines ersten jüngeren Bruders, Chun-Ku Hur,

gen), in: Yun-Hwan Kim u.a., Hanguk Keongje eui Cheongae Kujo (Die Entwicklung der koreanischen Ökonomie), Seoul 1981, S. 93.

55Die folgenden Angaben stammen aus: Lucky-Goldstar (Hrsg.), Hanbeon Midemyeon Modu Matkeora (Wenn du anfängst, jemandem einmal zu glauben, dann sollst du bereit sein, ihm alles anvertrauen zu können), Seoul 1979/1993, S. 94-222. 
der der Sohn des wohlhabendsten Grundbesitzers in Kus Heimatregion war. Chun-Kus Vater hatte In-Hoe Ku gebeten, seinen Sohn, der zur Freude Kus in Japan studiert hatte, in seinem Unternehmen zu beschäftigen und inm dafür einen Teil des Startkapitals zur Verfügung gestellt.

Der geschäftliche Wendepunkt kam durch eine zufällige Bekanntschaft von Cheong-Hoe Ku mit dem Ingenieur Jun-Hwan Kim, der in einem ehemaligen japanischen Kosmetikbetrieb in Pusan angestellt war. Von diesem erfuhr er, daß die Nachfrage nach den in seinem Unternehmen hergestellten koreanischen Kosmetikartikeln sehr hoch war, obwohl diese - nachdem die Japaner mit dem Abzug ihrer Ingenieure auch die entsprechenden Rezepte und Herstellungsverfahren mitgenommen hatten - nur von vergleichsweise geringer Qualität waren. Doch vor allem die Frauen, die sich bisher die teuren japanischen Produkte nicht hatten leisten können, kauften nun die billigeren koreanischen Artikel.

In-Hoe Ku fürchtete zunächst vor allem die amerikanische Konkurrenz auf dem Kosmetikmarkt, ließ sich dann aber doch von seinem Bruder zu einem Engagement in der Kosmetikbranche überreden, nachdem er erfahren hatte, daß die entsprechenden Produkte in Seoul noch nicht sehr verbreitet waren. So wurde Ku geschäftlich in Seoul tätig, wo sein dritter und sein vierter jüngerer Bruder an der Seoul-National-Universität studierten. Zunächst verteilte er seine Waren einfach bei den kleinen Ladenbesitzern, doch schon Anfang 1946 übertrug In-Hoe Ku die Aufgabe des Kassierers seinem dritten jüngeren Bruder TaeHoe, der als erster der Brüder eine moderne Ausbildung vollständig durchlaufen hatte und nun auf diese Weise ebenfalls die unternehmerischen Aktivitäten seines ältesten Bruders unterstützte.

Die sehr schnell ansteigende Nachfrage nach einfacher Hautcreme konnte Ku jedoch schon bald nicht mehr befriedigen, da die Fabrik in Pusan, von der er die Ware bezog, nur die Hälfte ihrer Produktion an inn verkaufen wollte. Da traf es sich gut, daß der Freund seines Bruders, der Ingenieur Kim wegen eines Streits mit dem Unternehmensleiter den Betrieb verlassen und eine eigene Kosmetikfirma gründen wollte. Kim war nicht nur Fachmann für die Herstellung von Hautcremes, sondern wußte auch, wo er die für die Herstellung benötigten Rohstoffe beziehen konnte, was in der Nachkriegszeit, in der viele Betriebe wegen Rohstoffmangels nicht richtig arbeiten konnten, überlebenswichtig war. Die Beschaffung dieser Rohstoffe sollten In-Hoe Ku und seine Brüder übernehmen, 
die das dafür notwendige Kapital besaßen. Das aber verschaffte Ku einen groBen Vorteil gegenüber anderen Kosmetikherstellern. Denn obwohl er nichts von der Herstellung von Kosmetik verstand, verfügte er nun durch den Aufkauf von großen Mengen des Rohmaterials über die Möglichkeit, seine Konkurrenten sehr weitgehend an den Rand zu drängen. Allerdings führte dies dazu, daß Ku von den Studenten Anfang der 60er Jahre als "illegaler Kapitalakkumulator" beschimpft wurde, da sein unternehmerischer Erfolg auf der Monopolisierung von Rohstoffen beruhte. ${ }^{56}$

Auf diese Weise verwandelte sich In-Hoe Ku 1947 von einem Händler in einen Hersteller, was sich auch daran zeigte, daß er sein Textilgeschäft in Jinju, das bis zu diesem Zeitpunkt von Verwandten in kleinem Rahmen noch weitergeführt worden war und In-Hoe formal noch immer gehörte, endgültig verkaufte und sein Wohnhaus in Pusan in eine Fabrik umwandelte. Wegen des allgemeinen Mangels an Konsumgütern war es für Ku zunächst kein Problem, die produzierten Waren auf dem Markt zu bringen. Obwohl der Preis seines Produkts doppelt so hoch war wie der anderer koreanischer Produkte, war die Nachfrage immer noch viel größer als das Angebot. Dies änderte sich mit der zunehmenden Zahl koreanischer Händler, die ausländische Produkte importierten, so daß die Kunden die Möglichkeit hatten, die Qualität der ausländischen Produkte mit der der einheimischen zu vergleichen. Während seine Konkurrenten dem wachsenden Marktanteil ausländischer Produkte nichts entgegenzusetzen wußten, reagierte $\mathrm{Ku}$, indem er versuchte, die japanischen Produkte nachzuahmen.

Doch dies war einfacher gesagt als getan. Es war nicht möglich, für den notwendigen Technologietransfer einfach einen japanischen Kosmetikingenieur in Kus Firma zu holen. Denn Japaner erhielten wegen des extremen Antijapanismus von Präsident Rhee zu dieser Zeit grundsätzlich keine Einreisegenehmigung nach Korea. In Korea gab es zwar einige Naturwissenschaftler, aber sie verfügten nicht über ein industriell anwendbares technologisches Know-how. Deshalb beauftragte In-Hoe Ku schließlich seinen dritten jüngeren Bruder TaeHoe mit der Lösung des Problems. Obwohl dieser Politikwissenschaften und

56Hinter dieser Verurteilung steckte die Annahme, daß das ökonomische Handeln durch den freien Markt reguliert werden sollte. Aber in Wirklichkeit gab es in Korea zu 
nicht Naturwissenschaften studiert hatte, verwandelte Tae-Hoe sein Wohnhaus in Seoul in ein Labor und begann nach der Lektüre entsprechender Fachbücher mit der chemischen Analyse der ausländischen Kosmetikprodukte. Seine Aufgabe war es, eine transparente Hautcreme zu entwickeln. Unterstützt wurde er dabei von seinem jüngeren Bruder, Peong-Hoe, der ebenfalls an der sozialwissenschaftlichen Fakultät der Seoul-National-Universität immatrikuliert war. Das innen fehlende Fachwissen besorgten sie sich bei den Professoren der Naturwissenschaft an ihrer Universität. Zu innen stieß dann noch In-Hoe Kus ältester Sohn, Cha-Keong Ku, der damals als Lehrer an einer Grundschule tätig war. Kurz vor dem Ausbruch des Koreakrieges schafften sie es gemeinsam, die Herstellungsformel für die Creme der ausländischen Konkurrenz herauszufinden. Damit hatte In-Hoe Ku einen großen technologischen Vorsprung vor den anderen koreanischen Kosmetikproduzenten, die sich entweder wegen Kapitalund Personalmangels ein derartiges Experiment nicht hatten leisten können oder aber gar nicht auf die Idee gekommen waren, ein solches zu unternehmen.

Ku hatte zudem das Glück, daß seine Fabrik in Pusan während des Koreakrieges unzerstört blieb, und Pusan, die die einzige Großstadt in Südkorea war, die nicht von nordkoreanischen Truppen besetzt worden war, nach dem Krieg nicht nur provisorischer Regierungssitz wurde, sondern auch mit Flüchtlingen völlig überfüllt war. Weil die anderen Kosmetikhersteller wegen der Zerstörung ihrer Fabriken und des Rohstoffmangels nicht produzieren konnten, erhielt Ku, der sich die benötigten Rohstoffe erneut durch den Aufkauf eines ehemaligen japanischen Lagers gesichert hatte, sämtliche Kaufaufträge für Hautcreme. Damit monopolisierte Ku den gesamten Kosmetikmarkt in Korea.

Mit den amerikanischen Militärs kamen während des Koreakrieges erstmals auch Plastikwaren nach Korea. Als In-Hoe Ku zum ersten Mal eine in eine Plastikdose gefültte amerikanische Creme sah, war er sofort begeistert. Er hatte mit seinen Dosen aus Glas, deren Deckel beim Transport sehr häufig zu Bruch gingen, schon spürbare Verluste gehabt, und die Plastikdose war daher die LÖsung seines Problems. Aber in Korea gab es keinen Fachmann für die Herste I-

diesem Zeitpunkt überhaupt noch keinen freien Markt, an dem sich die Unternehmer als Regulierungsinstanz hätten orientieren können. 
lung von Plastikwaren. Also wandte sich In-Hoe Ku erneut an seinen dritten jüngeren Bruder, Tae-Hoe, der inzwischen Manager in Kus Unternehmen war.

Wieder begann Tae-Hoe mit der Lektüre entsprechender ausländischer Fachbücher und stellte fest, daß zum einen die Herstellung von Plastikwaren in Korea leicht möglich sei, wenn man aus dem Ausland die notwendigen Maschinen importiert, und daß zum anderen die vielseitig einsetzbaren Plastikprodukte in Zukunft viele alltäglichen Konsumgüter aus anderen Materialien ersetzen würden. Tae-Hoe war sich aber auch bewußt, daß der unternehmerische Einstieg in diese neue chemische Branche wegen des hohen Startkapitals sehr riskant war. Dabei hatte er vor allem die Befürchtung, daß die koreanischen Plastikprodukte der Konkurrenz aus dem Ausland nicht gewachsen sein könnten. Dennoch entschloß sich In-Hoe Ku, das Kapital, das er in den letzten Jahren durch die Kosmetikfirma verdient hatte, zum Einstieg in die Plastikproduktion zu verwenden. Seine Mitarbeiter, die alle Familienmitglieder waren und ohne deren Einsatz Ku niemals das notwendige Kapital hätte anhäufen können, widersprachen seiner Entscheidung nicht. Diese einhellige Unterstützung wurde von koreanischen Journalisten später als Beleg für eine vorbildliche konfuzianische Großfamilie interpretiert. 57

Obwohl Ku nur eine kleine maschinelle Anlage bei einer amerikanischen Firma bestellte, mußte er dafür 3 Milliarden Won, sein gesamtes Kapital zu dieser Zeit, aufwenden. Das erste Produkt, das er herstellte, war ein Kamm, wobei er täglich nicht mehr als dreihundert Stück produzierte. Die koreanischen Konsumenten, die bis dahin nur den groben Holzkamm kannten, waren von diesem neuen, leichten und farbigen Plastikprodukt sehr begeistert, so daß sich die Sorge seines Bruders wegen der ausländischen Konkurrenz als völlig unbegründet erwies.

Von nun an konzentrierten sich die unternehmerischen Aktivitäten Kus auf die Probleme bei der Auswahl neuer Produkte, auf die Beschaffung des Kapitals für den Kauf von Rohstoffen, sowie auf die Erweiterung der Verkaufsmöglichkeit und die Rekrutierung neuer Arbeitskräfte. Denn sein expandierendes Unternehmens benötigte immer mehr qualifizierte Leute. Nachdem alle Famili-

57Jin-Heon Kim, Kiupineui Sahoejeok Chaekim Nopyeoya (Die Unternehmen sollten ein größeres gesellschaftliches Verantwortungsbewußtsein entwickeln), in: Sintonga, Heft März (1987), S. 333. 
enmitglieder in der Firma untergebracht worden waren, richtete sich Kus Augenmerk nicht nur auf Verwandte seiner Mitarbeiter, sondern auch auf den Freundeskreis seiner beiden jüngeren Brüder, die anders als Ku die beste Universität Koreas besucht und daher einflußreiche Freunde hatten. Ein Beispiel dafür war Sung-Chan Park, der wegen seiner guten Englischkenntnisse während des Koreakrieges bei einer amerikanischen Hilfsorganisation gearbeitet hatte und den Ku von einer anderen Firma abwerben konnte. Park war mit Kus viertem jüngeren Bruder, Peong-Hoe, befreundet, der wie alle anderen Brüder schon lange Manager in Kus Firma war. Da In-Hoe Ku Park als dem Freund seines Bruders einmal durch einen formlosen Sofortkredit aus einer finanziellen Notlage geholfen hatte, hatte Park Kus Bitte, in seine Firma zu kommen, schlecht abschlagen können. Obwohl Park das geliehene Geld später zurückzahlte, bildete diese gegenseitige Verpflichtung die Basis für die enge Vertrauensbeziehung, die sich zwischen Ku und Park entwickelte.

Für Ku bedeutete die Einstellung von Park einen großen personalpolitischen Erfolg. Denn da er selbst weder technologisches Know-how noch eine betriebswirtschaftliche Ausbildung hatte, benötigte er Mitarbeiter, die inm loyal ergeben sein mangelndes Wissen nicht ausnutzten, sondern als sein verlängerter unternehmerischer Arm arbeiteten. Obwohl Park nicht zu den engsten Familienmitgliedern gehörte, machte er sehr schnell Karriere in Kus Unternehmen.

Nachdem Ku schon durch die von ihm produzierte Plastikzahnbürste bekannt geworden war, entschloß er sich um das Jahr 1954 herum, die erste koreanische Zahncremefirma zu gründen, die er Lucky nannte. Damals gab es auf dem koreanischen Markt nur die amerikanische Zahnpaste "Colgate" und einige koreanische Zahncremes von so schlechter Qualität, daß sie kaum gekauft wurden. Wieder fehlte es Ku und seinen Mitarbeitern an technologischem Knowhow. Wieder beschaffte Ku über einen seiner Brüder die notwendigen Informationen. Diesmal war es der vierte jüngere Bruder, Peong-Hoe, der anläßlich seiner Teilnahme an einer internationalen Konferenz für jüngere Unternehmer in Mexiko, nach New York flog und dort - obwohl das Produktionsverfahren für die amerikanische Zahnpaste natürlich geheim war - tatsächlich genügend $\mathbf{h}$ formationen zusammentragen konnte, um mit Experimenten beginnen zu können. Nach einigen Mißerfolgen gelang es Ku und seinen Mitarbeitern schließlich die erste koreanische Zahnpasta herzustellen, deren Qualität nicht schlechter 
als die des amerikanischen Produktes war. Am Anfang hatten die koreanischen Konsumenten wenig Vertrauen in Kus Produkt, das sich dann aber aufgrund seiner Qualität so schnell durchsetzte, daß Ku in kürzester Zeit auch auf dem koreanischen Zahnpastamarkt eine Monopolstellung innehatte. Kus Erfolgsgeheimnis war dabei weniger sein technologischer Vorsprung als vielmehr seine große Kapitaldecke, die inm bei ausbleibendem Erfolg auch größere Durststrecken erlaubt hätte, wohingegen sich keiner der herkömmlichen kleinen koreanischen Zahnpastahersteller ein derartiges Risikogeschäft hätte leisten können.

Dank seines durch seine unternehmerischen Erfolge erworbenen Wohlstandes konnte sich Ku auch an der 1957 durchgeführten Privatisierung der bisher staatlichen Banken in Korea beteiligen und erwarb einen hohen Aktienanteil an der großen koreanischen Bank "Hanil", die in der japanischen Kolonialzeit der Großgrundbesitzerfamilie Min gehört hatte. 58 Damit war Ku einer der wenigen unternehmerischen Aufsteiger in Korea, der sich für neue kapitalintensive Investitionssektoren interessieren konnte, wobei er sich, ohne sich Sorgen wegen des notwendigen Kapitals machen zu müssen, ganz auf die Frage konzentrieren konnte, wie in dem anvisierten Bereich die Aussichten für inn waren, erneut Marktführer zu werden.

Diese Denklogik zeigte sich auch in seiner Entscheidung, als er sich ebenfalls 1957 gegen den Rat seiner Mitarbeiter entschloß, in der Elektroindustrie zu investieren. Es gab zu dieser Zeit in Korea noch kein Elektrounternehmen, obwohl die koreanische Nachfrage nach Radios in den letzten Jahren enorm gestiegen war, da die Koreaner während des Krieges den Wert von aktuellen Nachrichten hautnah erfahren hatten und zugleich das Bildungsniveau der koreanischen Bevölkerung so gestiegen war, daß es ein breites Interesse an Politik, Wirtschaft und Kultur gab. Um das Problem des fehlenden technologischen Know-hows zu lösen, stellte Ku diesmal einen deutschen Ingenieur ein, außerdem drei an der Hochschule ausgebildete Techniker und zwanzig technische Facharbeiter. Da damals viele Absolventen der technischen Highschool und der technischen Hochschule arbeitslos waren, hatte Ku keine Probleme bei der Rekrutierung der Arbeitskräfte.

58Siehe oben Abschnitt III.6 (S. 91 f.). 
Für die Produktion seines Radios ließ Ku, wie in der damals in Korea weit verbreiteten Importsubstitutionsindustrie üblich, alle Teile aus dem Ausland importieren, die dann in seiner Fabrik nur fertig montiert werden mußten. Seine neue Elektrofirma, die er erstmals als Aktiengesellschaft organisierte, da er sich so bessere Chancen bei der Verteilung der von den Amerikanern nach dem Krieg Korea zur Verfügung gestellten Kredite ausrechnete, nannte er 'Kumsung" (Goldstar).

Doch diesmal ging Kus erprobtes Erfolgsrezept nicht auf. Zum einen war der Preis seiner Radios im Verhältnis zum durchschnittlichen Einkommen der koreanischen Bevölkerung einfach zu hoch, zum anderen gab es auf dem Schwarzmarkt einen blühenden Handel mit geschmuggelten, billigeren Radios. So machte sein neues Unternehmen nur Verluste, die er auch nicht durch die ausgegebenen Aktien, sondern nur durch die Gewinne aus seinen anderen Firmen ausgleichen konnte. Obwohl sich unter seinen Mitarbeitern Unmut breit machte, investierte Ku, der allein über den Verwendungszweck seines Kapitals bestimmen konnte, weiter Gelder in sein unrentables Elektrounternehmen.

Das Blatt wendete sich für Ku erst, als nach dem auf die Absetzung von Präsident Rhee folgenden Militärputsch im Mai 1961 der Staat selbst die Fürsorge für die Entwicklung der koreanischen Großunternehmen übernahm und im Fall Kus beispielsweise dafür sorgte, daß der Radioschmuggel unterbunden wurde. Erst mit der erfolgreichen Verflechtung familiärer und politisch-staatlicher Beziehungen gelang Ku der im nächsten Kapitel zu schildernde Aufstieg zum führenden Elektrounternehmer Koreas.

Byong-Chul Lee: Auch nach dem Ende des Krieges konzentrierte Byong-Chul Lee seine unternehmerischen Aktivitäten zunächst weiterhin vollständig auf Taegu, wo sein während des Krieges von seinem Freund und Geschäftsführer Sun-Kun Lee geführter Lebensmittelhandel Samsung ebenso weiter bestand wie seine Reisbrauerei.59 Als es in Taegu, das ein Zentrum der kommunistischen Bewegung im Süden Koreas war, zu ideologischen Auseinandersetzungen zwischen Anhängern der Plan- und Vertretern der freien Marktwirtschaft

59Die folgenden Angaben stammen aus: Byong-Chul Lee, Hoam Chacheon Hoams Autobiographie), Seoul 1985, S. 39-103. 
kam, bezog Lee Partei und schloß sich der liberal gesinnten Unternehmergruppe "Eulyuhoe" an, die nicht nur Unternehmer wie Byong-Chul Lee, sondern beispielsweise auch koreanische Mitarbeiter der einflußreichen und mächtigen amerikanischen Besatzungsverwaltung als Mitglieder angehörten. Später erinnerte sich Byong-Chul Lee in seiner Autobiographie, daß inm die Verbindungen zu den Mitgliedern dieser Gruppe für seine unternehmerischen Aktivitäten sehr nützlich gewesen seien. ${ }^{60}$

Obwohl Lee in seiner Autobiographie ansonsten eher bemüht war, den Einfluß dieser Gruppe herunterzuspielen, bin ich der Auffassung, daß Lees wichtigstes unternehmerisches "Kapital" damals aus der Mitgliedschaft in diesem kleinen, aber einflußreichen Unternehmerverein bestand, der niemals mehr als neun Mitglieder hatte. Nach Lee bestand das Hauptziel des Vereins darin, einen Beitrag zur zukünftigen wirtschaftlichen Entwicklung der Region von Taegu zu leisten. Doch scheint es den Vereinsmitgliedern - meinem Eindruck nach - dabei weniger um die wirtschaftliche Entwicklung der Region als vielmehr um die Förderung und Sicherung ihrer persönlichen wirtschaftlichen Entwicklung gegangen zu sein. So wurden nach der militärischen Niederschlagung des kommunistischen Taegu-Aufstandes vom Oktober 1946 alle Vorstandsposten einer von der amerikanischen Besatzungsmacht enteigneten und einem Vereinsmitglied übergebenen linksliberalen Tageszeitung selbstverständlich mit weiteren Vereinsmitgliedern besetzt. Auf diese Weise kam auch Lee an den Vorstandsposten in einer Zeitung, während er im Gegenzug Jae-So Kim, ebenfalls ein Vereinsmitglied, zum Geschäftsführer seiner Reisbrauerei machte, die er nach Kriegsende durch die Übernahme einer weiteren Brauerei noch vergrößert hatte.

Es fällt auf, daß Lee - anders als Ku - die Mitarbeiter seines Unternehmens nicht aus seiner Familie rekrutierte. Als jüngster Sohn einer wohlhabenden Grundbesitzerfamilie hatte er keine jüngeren Brüder, die er als älterer Bruder zu unternehmerischer Zusammenarbeit mit inm hätte auffordern können. Daß sein wohlhabender ältere Bruder in seinem Unternehmen die Rolle eines untergeordneten Mitarbeiters übernahm, war dagegen undenkbar. Die familiäre Einbettung des Unternehmens erfolgte bei Lee erst ab der Mitte der 50er Jahre,

60Ebenda, S. 42. 
nachdem seine beiden ältesten Söhne ihr Studium im Ausland (in Japan und den USA) beendet hatten.

Ungeachtet der politischen Unruhe in der postkolonialen koreanischen Gesellschaft expandierten Lees Geschäfte aufgrund des in der Nachkriegszeit herrschenden Versorgungsmangel, wobei sich auch die Verkleinerung des Marktes nach der Abspaltung Nordkoreas nicht nachhaltig negativ auswirkte. Im Mai 1947 entschloß sich Lee, seine Gewinne in neue Unternehmen zu investieren, und überließ Samsung und die Brauerei seinen beiden Geschäftsführern.

Nachdem Lee ausführlich den koreanischen Handel mit China und die sich wandelnde Nachfrage untersucht hatte, wandte er sich an seinen Schulfreund Hong-Che Cho, der - ebenfalls der Sohn eines Grundbesitzers - nicht nur aus der gleichen Heimatregion wie Lee stammte, sondern auch mit inm zusammen in Japan studiert hatte. Gemeinsam gründeten sie im November 1948 mit unächst 20 Mitarbeitern eine in Seoul angesiedelte Außenhandelsfirma, wobei $75 \%$ des Startkapitals von Lee und $25 \%$ von Cho und anderen Firmenmitarbeitern stammten.

Um die für den Import der ausländischen Waren nötigen Devisen zu beschaffen, exportierte Lees Firma, die wie sein Lebensmittelhandel und die Brauerei zur Samsung-Korporation gehörte, auch Waren, wobei er zunächst auf die Lagerbestände (wie z. B. Baumwollsamenrückstände) der ehemaligen japanischen Fabriken zurückgriff. Als diese Lager leer waren, exportierte er getrocknete koreanische Fischwaren, vor allem nach Singapur, Hongkong und Macao. Beim Import konzentrierte sich sein unternehmerisches Interesse hauptsächlich auf alltägliche Konsumgüter. Seine Importwarenliste enthielt über 100 einzelne Posten, darunter auch Baumwollgarn und Nadeln. Lee gelang es dabei, seine Lieferfristen sehr kurz zu halten und so die Zirkulation seines Kapitals zu beschleunigen. Schon im März 1950 rangierte Lees Außenhandelsunternehmen unter den 543 beim Handelsministerium registrierten Außenhandelsunterne hmen Koreas auf dem siebenten Platz. 61

Seinen ökonomischen Erfolg führte Lee später vor allem auf seine geschickte Personalpolitik zurück. Die Mitarbeiter seines Unternehmens bekamen nicht nur

${ }^{61}$ Sang-Hun Choe, Der Stellenwert der Mischkonzerne (Chaebol) im koreanischen $\mathrm{h}$ dustrialisierungsprozeß. Dargestellt am Beispiel des Werdegangs und der Strukturmerkmale Samsungs, Hamburg 1994, S. 68. 
ein sehr gutes Gehalt und waren durch Provisionen am Gewinn beteiligt, sondern sollten sich - wie oben schon an Chos Beispiel ausgeführt - möglichst auch mit eigenem Kapital an der Firma beteiligen. Auf diese Weise sollten sie sich soweit mit der Firma identifizieren, daß sie nicht nur deren Erfolg als ihren eigenen betrachteten, sondern daß sie sich zu dieser loyal wie zu ihrer eigenen Familie verhielten. $62 \mathrm{Da}$ Lee, anders als $\mathrm{Ku}$, nicht die eigenen Familienmitglieder als Mitarbeiter der Firma einstellen konnte, versuchte er auf diese Weise das Familiengefühl sozusagen künstlich in seiner Firma zu verankern, was ihm wohl auch weitgehend gelang. So scheint zwischen Lee und seinen Angestellten eher eine von gegenseitigem Vertrauen geprägte, kollegiale als eine hierarchische Beziehung geherrscht zu haben, und Lees Mitarbeiter scheinen tatsächlich weitgehend als verlängerter Arm seines unternehmerischen Handelns fungiert zu haben. 63

Diese gemeinschaftsstiftende Personalpolitik erwies sich als besonders nützlich, als Lee nach dem Ausbruch des Koreakrieges sein gesamtes Vermögen verlor, das er durch den Außenhandel in den letzten Jahren verdient hatte. Seine Warenlager wurden in den Kriegswirren von beiden kriegführenden Seiten geplündert und sein letztes Bargeld mußte er für den Fluchtwagen verwenden, mit dem er, seine Familie und seine Mitarbeiter aus Seoul nach Taegu flohen. Dort erfuhr Lee von Jae-So Kim, der für ihn die Reisbrauerei verwaltet hatte, daß er immer noch ein reicher Mann sei. Kim konnte Lee 300 Millionen Won für die Gründung einer neuen Handelsfirma zur Verfügung stellen. Von diesem Zeitpunkt an behandelt Lee Jae-So Kim als sein Alter Ego und überließ ihm bei seinen späteren Unternehmensgründungen stets einen höheren Posten als Vorstandsmitglied oder Geschäftsführer.

Seine neue Handelsfirma gründete Lee diesmal in Pusan und wie Ku profitierte auch er von den dort sich sammelnden Flüchtlingsströmen und die dadurch enorm steigende Nachfrage nach Konsumgütern, die das kriegsbedingte Risiko im Außenhandel mehr als ausglich. Die notwendigen Devisen beschaffte sich Lee durch eine noch ausstehende Zahlung von 30000 Dollar bei einem seiner früheren Geschäftspartner in Hongkong, so daß er ein Jahr nach Beginn

62Byong-Chul Lee, Hoam Chacheon (Hoams Autobiographie), Seoul 1985, S. 48 f. 63 Vgl. dazu auch die Ausführungen zu Lees Personalpolitik in Abschnitt IV.2 (S. 122). 
seines Importgeschäftes sein Startkapital bereits verzwanzigfacht hatte, wobei bei diesem Faktor allerdings die kriegsbedingte Inflation nicht vergessen werden darf. Dennoch war sein Gewinn so groß, daß er erneut über neue, möglichst inflationssichere Investitionsmöglichkeiten nachdachte.

Wie schon für sein unternehmerisches Engagement insgesamt bestand Lee in seiner Autobiographie darauf, daß er auch die erste große Zuckerfabrik in Südkorea in erster Linie aus patriotischen bzw. nationalen Motiven gegründet habe. Um den Leser davon zu überzeugen, wies er darauf hin, daß sein Plan, sich als Export- und Importkaufmann nun - wie auch Ku dies getan hatte - der Produktionsindustrie zuzuwenden, sogar bei seinen engsten Mitarbeitern auf Widerstand gestoßen sei. Sie hätten inn davor gewarnt, sein durch das Importgeschäft verdientes Kapital in eine vor Zerstörung durch den Krieg nicht sichere Produktionsanlage zu investieren, die zudem auch noch nur in sehr weiter Zukunft Gewinn abwerfen würde. Selbst wenn die Fabrik jemals Zucker produzieren würde, sei nicht sicher, ob die Konsumenten, die inzwischen an amerikanischen Zucker gewöhnt seien, diesen annehmen würden. Er, Lee, habe deshalb diese Entscheidung ganz allein treffen müssen. 64

Doch wie überzeugend dies auch klingen mag, ein wichtiges, wenn nicht sogar das entscheidende ökonomische Motiv hat Lee dabei unterschlagen. Denn schon vor Beendigung des Koreakrieges war klar, daß die USA den wirtschaftlichen Wiederaufbau Koreas großzügig finanziell unterstützen würden. So war es kein Einzelfall, daß sich koreanische Unternehmer wie Lee schon vor Beendigung des Krieges mit Investitionsplänen an die koreanische Regierung oder an amerikanischen Hilfsorganisationen, wie etwa die UNKRA (United Nations Korea Reconstruction Agency) wandten, um sich die entsprechende Unterstützung zu sichern. ${ }^{65}$ Auch wenn die zur Verfügung stehenden Gelder hauptsächlich für durch den Krieg zerstörte Unternehmen gedacht waren, ließ sich der Begriff des "industriellen Wiederaufbaus" doch weit genug auslegen, um auch Neugründungen zu umfassen. Lee argumentierte damit, daß durch die Errichtung der ersten großen Zuckerfabrik in Korea die bisher für den Import von Zucker ausgegebenen Devisen gespart werden könnten. Ironischerweise war Lee übrigens

${ }^{64}$ Byong-Chul Lee, Hoam Chacheon (Hoams Autobiographie), Seoul 1985, S. 62 f. ${ }^{65}$ Cheong-Jae Lee, Chaebol Yireokse (Die Entwicklungsgeschichte der Chaebol), Seoul 1993, S. 94. 
bis zu seinem Engagement in der Zuckerproduktion der größte Zuckerimporteur in Korea gewesen.

Der amerikanische Hilfsfond stellte Lee die Devisen für den Import der japanischen Maschinen zur Herstellung von Zucker zur Verfügung. Gleichzeitig bekam er von der Regierung unter Präsident Rhee, den er bei einem Besuch in Taegu kurz nach Kriegsende persönlich kennengelernt hatte und der inn seitdem bevorzugt förderte, einen 180000 Dollarkredit und außerdem einen äuBerst günstigen Bankkredit von zwanzig Millionen Won. Das von inm und seinen Mitarbeitern aufgebrachte Startkapital betrug dreißig Millionen Won.

Nicht nur das finanzielle, auch das technische Risiko war - entgegen Lees Behauptungen in seiner Autobiographie - nur relativ gering. Zwar mußte die neue Fabrikanlage ohne jegliche Hilfe erfahrener Techniker errichtet werden, da Präsident Rhee wegen seines Antijapanismus den japanischen Technikern die Aufenthaltsgenehmigung in Korea verweigerte. Doch die Produktionstechnologie war extrem einfach, da man nur die Rohstoffe in entsprechenden Mengen in die Maschinen einfüllen mußte. Auch die Beschaffung des Rohmaterials war für Lee kein Problem, weil Taiwan ebenfalls als Wiederaufbauhilfe bereit war, Korea die Rohstoffe für die Zuckerherstellung zu liefern. ${ }^{66}$ Aufgrund dieser günstigen Produktionsbedingungen erstaunt es nicht, daß der Preis des ersten toreanischen Zuckers viel niedriger war als der des Importzuckers. So dauerte es nicht einmal einen Monat, bis Lees Zuckerfabrik in Pusan der steigenden Nachfrage nicht länger nachkommen konnte. Trotz des niedrig kalkulierten Preises waren Lees Gewinne so groß, daß er bereits zwei Jahre später seine unternehmerischen Aktivitäten erneut ausweiten konnte.

Als Lee am 15. September 1954 seinen Plan zur Gründung einer eigenen koreanischen Wollfabrik bekannt gab, bekam er von allen Seiten Kritik. Denn anders als in der Zuckerindustrie sei, so das Hauptargument, der Aufbau einer Wollindustrie ohne eine entsprechende industrielle Tradition, wie es sie z. B. in England gebe, nicht möglich. Weil auf dem damaligen koreanischen Textilmarkt hauptsächlich mit Wolltextilien aus England, die über Macao nach Korea geschmuggelt wurden, gehandelt wurde, klang Lees Plan für viele so, als wolle er

${ }^{66}$ Lee selbst schreibt darüber nichts, doch sein ältester Sohn erwähnt dies in seiner eigenen Biographie: Maeng-Hee Lee, Mudedun Yiyaki (Die unbekannte Geschichte), S. 83. 
mit den traditionsreichen englischen Herstellern konkurrieren. In Wahrheit ging Lee, der als einziger unter den damaligen koreanischen Unternehmern überhaupt in der Lage war, ein derart kapitalintensives Vorhaben in Angriff zu nehmen, mit seinem Plan jedoch überhaupt kein unkalkulierbares Risiko ein. Denn die Entscheidung zum Aufbau einer koreanischen Wollfabrik war nicht von inm oder seinen Mitarbeitern, sondern von den Regierungsbehörden getroffen wo rden.

In seiner Autobiographie schrieb Lee, daß er und seine Mitarbeiter wegen des geringeren Risikos die Baumwollindustrie der Wollindustrie vorgezogen hätten. ${ }^{67}$ Doch da es in Korea seit der japanischen Kolonialzeit schon mehrere Baumwollunternehmen gab, hätte Lees Einstieg in die Baumwollindustrie der damaligen wirtschaftspolitischen Förderung der Importsubstitutionsindustrie widersprochen. Im Wirtschaftsministerium teilte man Lee daher mit, daß die Regierung nur dann zu einer finanziellen Unterstützung seines Unternehmens bereit wäre, wenn er sich mit der Wollindustrie beschäftigen würde. Der Grund dafür lag darin, daß die Regierung selbst bei der deutschen Maschinenbaufirma "Spinnbau" 5000 Maschinen bestellt hatte, um eine staatliche Wollindustrie zu gründen. Staatliche Unternehmen aber wollten die Amerikaner als den Grundprinzipien des freien Kapitalismus zuwiderlaufend nicht zulassen, so daß die Regierung gezwungen war, den Auftrag einem privaten Unternehmer zu übergeben. Lee konnte sich deshalb darauf verlassen, bei der staatlichen Verteilung ausländischer Devisen bevorzugt behandelt zu werden. Da Präsident Rhee gegen die Einreise deutscher Techniker keine Einwände hatte, hatte Lee auch keine technischen Probleme bei der Aufstellung der neuen Spinnmaschinen. Die Gründung der Wollfabrik barg für inn daher von Anfang an mehr Chancen als Risiken.

Die Devisen, die Lee von der Regierung bekommen hatte, waren eigentlich an das beantragte Projekt gebunden, doch gelang es Lee so sparsam damit umzugehen, daß er von dem gleichen Geld seine Wollfabrik noch um weitere (im ersten Antrag nicht enthaltene) Produktionsstätten erweitern konnte. Dies erreichte er vor allem dadurch, daß er die Zahl der deutschen Techniker, die für den Techniktransfer zuständig waren, reduzierte. Denn er war der Meinung, das

67Byong-Chul Lee, Hoam Chacheon (Hoams Autobiographie), Seoul 1985, S. 73. 
größte Potential der koreanischen Ökonomie bestehe in den gut ausgebildeten und motivierten Arbeitskräfte, die es im Lande gebe. Um diese Arbeiter zu gewinnen und zu größerer Leistung anzufeuern, gab er die nationalistische Parole aus: "Wenn die von uns aufgebaute Fabrik nicht funktioniert, verlieren unsere koreanischen Techniker das Gesicht." 68

Der Preis der von Lees Wollunternehmen auf den Markt gebrachten Produkte betrug nur $1 / 5$ des Preises der aus Macao eingeschmuggelten englischen Wolltextilien. Dieser niedrige Preis beruhte aber nicht etwa auf der Rationalisierung des Produktionsprozesses, sondern auf den niedrigen Produktionskosten. Diese wiederum waren so niedrig, weil die koreanische Währung zu hoch bewertet war. ${ }^{69} \mathrm{Da}$ die Rohstoffe für die Wolltextilien zu 100\% aus dem Ausland importiert wurden, profitierte Lee erheblich von dem starken Won. Zusätzlich konnte er den Wert des von der Regierung erhaltenen Devisenkredits durch Geschäfte auf dem Schwarzmarkt, wo der Dollarkurs erheblich höher als offiziell festgelegt war, erhöhen. Als der bis 1956 einzige koreanische Hersteller von Wolltextilien erzielte Lee daher enorme Gewinne und zählte daher schon Mitte der 50er Jahre zu den reichsten Unternehmern Koreas.

Sein Kapital, das er durch die Zucker- und die Wollfabrik erworben hatte, investierte Lee, nicht nur in Aktien der Düngemittel- (Honam), Reifen- (Hanguk) und Zementindustrie (Sambo), sondern auch - wie Ku - in Beteiligungen an den 1957 wieder privatisierten Banken. Wenn man bedenkt, daß sich die Mehrheit der koreanischen Unternehmer wegen des niedrigen Zinssatzes um Bankkredite bemühte, dann wird klar, welchen enormen finanziellen Handlungsspielraum Lee durch seinen Aufstieg zum Bankier gewann.

Obwohl Präsident Rhee mit der Bewilligung von Devisen sehr zurückhaltend war, weil er fürchtete, daß die Souveränität der koreanischen Nation durch ausländische Kredite beeinträchtigt werden könnte, genehmigte er Lee zu dessen eigenem Erstaunen Anfang 1960 (kurz vor den Studentendemonstrationen) noch die Gründung eines dritten Importsubstitutionsunternehmens, nämlich einer Düngemittelfabrik, für die sich Lee nun allerdings nach Einstellung der ame-

\footnotetext{
68Ebenda, S. 80.

${ }^{69}$ Der Grund dafür war, daß die koreanische Regierung seit Ausbruch des Koreakrieges die Kosten für die amerikanische Armee getragen hatte und die Rückzahlung nun in Dollar erfolgte. Je höher nun die koreanische Währung bewertet war, desto höher war diese Rückzahlung.
} 
rikanischen Entwicklungshilfe um ausländische Kredite bemühen mußte. Über seine Bekanntschaft mit dem deutschen Botschafter erhielt er einen großen Kredit von Krupp, wofür Krupp lediglich eine Zahlungsgarantie der Bank verlangte, bei der Lee Mehrheitsaktionär war. Wegen weiterer Kredite reiste Lee dann nach Italien und in die Vereinigten Staaten, wo inn im April 1960 die Nachricht vom Sturz der Regierung Rhee erreichte. Vorsichtshalber kehrte er deshalb nicht nach Korea zurück, sondern fuhr zunächst nach Japan, wo er sich bis zum Juli 1960 aufhielt.

Joo-Young Cheong: Nach der Kapitulation Japans zog Cheong mit seiner gesamten Familie (einschließlich der verheirateten Brüder und Schwestern) nach Seoul.70 Dort gründete er 1946 gemeinsam mit seinem Schwager Young-Joo Kim und seinem alten Freund In-Bo Oh, der inm früher einmal bei einem seiner Fluchtversuche finanziell geholfen hatte und mit dem ihm seitdem eine tiefe, von Dankbarkeit erfülte Freundschaft verband, eine neue Autowerkstatt. Cheong nannte die neue Werkstatt voller stolz "Hyundai", was modern bedeutet - ein Name, den er später für seinen gesamten Konzern beibehielt. Sein größter Kunde war die amerikanische Besatzungsmacht, die alle ihre Autos wegen des herrschenden Benzinmangels mit einem Kohlevergaser ausrüsten ließ, so daß sein Geschäft rasch florierte. Doch stellte Cheong bald fest, daß die Baufirmen, die damals wie Pilze aus dem Boden schossen, sehr viel mehr verdienten. Die Baubranche war damals ein unternehmerisches Betätigungsfeld, für das man weder besonders viel Kapital noch großes technisches Wissen benötigte. Man brauchte nur ein paar Facharbeiter und sobald man einen Auftrag hatte, war auch die Kapitalbeschaffung kein Problem mehr. Viele ehemalige Handwerker gründeten damals Baufirmen, und so überließ Cheong 1947 die Leitung seiner Autowerkstatt wie schon im Krieg wieder seinem Schwager und seinem Freund und errichtete seine erste Baufirma.

Cheong stellte zunächst zehn Bauarbeiter und einen ehemaligen Lehrer, der in der technischen Schule unterrichtet hatte, als Bauleiter ein, und versuchte aufgrund seiner über die Autowerkstatt geknüpften Beziehungen Aufträge von

70Die folgenden Angaben stammen aus: Joo-Young Cheong, Sireonun Issedo Silpae nun Eopda (Es gibt zwar Schwierigkeiten, aber keinen Mißerfolg), Seoul 1991, S. 71 94; Ders., I Tange Taenaseo (Geboren in diesem Lande), Seoul 1998, S.45-74. 
der amerikanischen Besatzungsmacht zu bekommen. Doch bekam er im ersten Jahr nur einen kleinen Auftrag, so daß seine Position anfänglich nicht sehr viel anders war als die der Mehrheit der Baufirmen, die zumeist als Subunternehmer für die großen Baufirmen arbeiteten. Doch zeigte inm schon sein erster Auftrag, daß sich aufgrund der hohen Gewinnspanne im Baugeschäft leicht Geld verdienen ließ. Daher entschloß er sich 1950, seine Baufirma zu vergröBern und fusionierte zu diesem Zweck seine beiden bisherigen Firmen in einer Aktiengesellschaft.

Bei Ausbruch des Koreakrieges floh Cheong mit seinem ersten jüngeren Bruder, In-Young Cheong, der in Japan studiert hatte und als Zeitungsjournalist tätig war, nach Pusan, wo wegen der dort stationierten amerikanischen und UNTruppen die Bauindustrie trotz des Krieges nach wie vor boomte. In-Young, der gut Englisch sprach, gelang es, einen Dolmetscherposten in den Versorgungseinheiten der amerikanischen Armee zu erhalten, so daß er seinem Bruder Aufträge - hauptsächlich für die Errichtung von Schlafstätten für die Soldaten vermitteln konnte. Dies war der Anfang der unternehmerischen Zusammenarbeit zwischen den beiden Brüdern.

Wie schon im zweiten Weltkrieg durch seine Tätigkeit für die Japaner gelang es Joo-Young Cheong diesmal durch seine Arbeit für die Amerikaner für sich und seine Brüder eine Freistellung von der Front zu erreichen. Statt dessen verdienten sie durch die amerikanische Aufträge viele Dollar.

Als am 28. September 1950 die Amerikaner Seoul von Nordkorea zurückeroberten, ging Cheong mit der amerikanischen Armee nach Seoul. Da er bei den Amerikanern aufgrund seiner Arbeit in Pusan bereits bekannt war, hatte er auch in Seoul keine Schwierigkeiten Bauaufträge zu bekommen. Er sagte auch zu, als er den Auftrag bekam, die Truppenwohnungen nach westlichem Standart Einbau von Innentoiletten mit Wasserspülung und Installation von Heizungen zu renovieren. Obwohl Cheong nur die traditionellen koreanischen Außentoiletten kannte und auch vom Heizungsbau keine Ahnung hatte, bewältigte er den Auftrag, indem er einfach die gebrauchten Teile von Toiletten und Heizungen aus den früheren Wohnungen der Ausländer sammelte, und gewann so nicht nur endgültig das Vertrauen der amerikanischen Armee, die inm danach fast alle Aufträge übertrug, sondern auch sehr viel Selbstvertrauen in seine Fähigkeiten und vor allem sein Improvisationstalent als Bauunternehmer. 
Der Höhepunkt seiner Arbeit für die amerikanische Armee war, als er im Winter 1952 den Auftrag bekam, den internationalen Soldatenfriedhof in Pusan innerhalb von fünf Tagen zu begrünen. An der Einweihung des Friedhofes sollte auch der amerikanische Präsident Eisenhower teilnehmen. Cheong hatte damals die geniale Idee, statt Gras, das viel zu langsam gewachsen wäre, junge Gerstenkeime, die sich auf den ersten Blick nicht von Gras unterscheiden lieBen und damals auf den Feldern überall zu finden waren, anzupflanzen. Dafür verlangte er allerdings den dreifachen Preis von der amerikanischen Armee, deren Vertrauen zu ihm von da an nahezu unerschütterlich war.

Nach dem Ende des Krieges, der Cheong zu einem wohlhabenden, landesweit bekannten Bauunternehmer gemacht hatte, trat die koreanische Regierung als neuer großer Auftraggeber auf, weil der Staat die zerstörte Infrastruktur in Südkorea wiederaufbauen wollte. Obwohl es auch zahlungskräftige private Auftraggeber (etwa für den Firmen- und Fabrikenbau) gab, bevorzugte die Baufirma von Cheong staatliche Aufträge, da nicht nur der Straßen-, Brücken- oder auch der Bau von öffentlichen Gebäuden jeweils ein sehr hohes Auftragsvolumen darstellte, sondern der Staat als Auftraggeber auch immer großzügiger als private Auftraggeber war. Der Konkurrenzkampf um die staatlichen Bauaufträge war allerdings aus eben diesem Grund auch sehr hart. Bei den Ausschreibungen für die staatlichen Aufträge versuchten sich die verschiedenen Bauherren daher durch möglichst niedrige Kostenvoranschläge gegenseitig auszustechen, was für einige bedeutete, daß sie auch Angebote machten, die ihnen Verluste brachten. Natürlich konnten sich ein solches ruinöses Verhalten nur Bauunternehmer leisten, die wie Cheong eine große Kapitaldecke besaßen.

Im Jahr 1954 gelang es Cheong auf diese Weise ein staatliches Bauprojekt übertragen zu bekommen, das bis dahin sein größter Bauauftrag war. Es ging um den Wiederaufbau der durch den Krieg zerstörten großen Brücke zwischen Taegu und Keochang. Weil seine Baufirma keine Erfahrung mit dem Bau von Brücken hatte, stellte Cheong zwei Bauingenieure ein: Young-Phil Kim, der in der japanischen Kolonialzeit bei einer japanischen Baufirma gearbeitet hatte, und Yeon-Sul Lee, der an einer japanischen Universität studiert hatte. Dies waren die ersten beiden Mitarbeiter, die Cheong außerhalb seines Familienkreises nur aufgrund ihrer Qualifikation einstellte. Für die Finanzen war weiterhin sein Freund In-Bo Oh aus seinem Heimatdorf zustä ndig. 
Es dauerte nicht lange, bis Cheong erkannte, daß sein blindes Bemühen um staatliche Aufträge ein großer Fehler gewesen war. Denn anders als seine Konkurrenten, die ihre Kostenvoranschläge in der Regel mehrfach nachbesserten, hatte er die in Korea herrschende Inflation nicht einkalkuliert und daher einen Vertrag mit einem festen Kostenvoranschlag abgeschlossen. Für den Auftraggeber war Cheongs Angebot natürlich auf diese Weise konkurrenzlos günstig, so daß Cheong sofort den Auftrag bekam. Cheong erinnerte sich später, daß er von vielen Leuten verspottet worden war, weil er wegen seiner geringen Schulbildung keine Ahnung von der Inflation hatte. Doch die weit über Cheongs Kalkulation liegenden Produktionskosten waren nicht nur inflationsbedingt, sondern hatten auch mit seiner fehlenden Erfahrung mit einem so großen Bauprojekt zu tun. Cheong hatte nicht geprüft, ob dieses Projekt mit den damaligen primitiven koreanischen Baugeräten überhaupt $\mathrm{zu}$ bewältigen war. Cheong führte diesen kapitalen Fehler später auf sein fehlendes Fachwissen als Bauunternehmer zurück. ${ }^{71}$ Wegen der hohen Inflation konnte Cheong bald noch nicht einmal mehr die Löhne seiner Bauarbeiter bezahlen. Doch führte er das Projekt trotz seiner hohen Verluste beharrlich und stur zu Ende, wobei er, seine Brüder und sein Schwager zum Schluß sogar ihre Häuser verkaufen mußten, um den Brückenbau zu vollenden.

Als dieses Projekt endlich beendet war, hatte Cheong zwar der Regierung gegenüber seine Qualifikation als zuverlässiger Bauunternehmer bewiesen, aber er hatte dafür Schulden aufgehäuft, die er erst zwanzig Jahre später abbezahlt hatte. Nach diesem unternehmerischen Fehlschlag übernahm Cheong nur noch Bauaufträge der amerikanischen Armee, die nach der Beendigung des Koreakrieges weiter im Land geblieben war. Außerdem holte er seinen jüngeren Bruder, In-Young Cheong, der sich zwischenzeitlich mit der Gründung einer Zeitschrift beschäftigt hatte, endgültig als engsten Mitarbeiter in sein Unternehmen. ${ }^{72}$

71Joo-Young Cheong, Sireonun Issedo Silpae nun Eopda (Es gibt zwar Schwierigkeiten, aber keinen Mißerfolg), Seoul 1991, S. 87.

72Diese enge Zusammenarbeit zwischen den Brüdern endete allerdings Ende der 60er Jahre im Streit. In-Young gründete daraufhin den Chaebol "Hanra", der allerdings schon vor Ausbruch der Asienkrise im Herbst 1997 Bankrott ging. Trotz des Streites hörten die unternehmerischen Beziehungen zwischen den Brüdern allerdings nicht ganz auf. So gehörte Hanra beispielsweise zu den wichtigsten Zulieferunternehmen des Hyundai-Automobil-Unternehmens, und als die Finanzlage von Hanra wegen In- 
Die neuen Bauaufträge der amerikanischen Armee, die nicht länger nur provisorische Lager benötigten, sondern anspruchsvolle Bauprojekte realisiert haben wollten, nutzte Cheong zur Erweiterung des technologischen Know-hows seiner Firma. Er erreichte, daß er immer als erster informiert wurde, wenn die amerikanische Armee überflüssig gewordene Baumaschinen auf dem koreanischen Markt verkaufte. Mithilfe des Fachwissens seines Schwagers Young-Joo Kim modernisierte Cheong auf diese Weise seinen Maschinenpark und war daher künftig sehr viel besser als zuvor und besser als die meisten seiner Konkurrenten auch für anspruchsvolle Regierungsaufträge gerüstet.

Im September 1957 gewann Cheong noch einmal einen großen Bauauftrag der Regierung. Diesmal ging es auch um den Wiederaufbau einer Brücke in Seoul - ein nicht ganz so aufwendiges und langwieriges Projekt wie die Brücke von Taegu, so daß die Inflationsgefahr nicht ganz so groß war wie bei seinem ersten Brückenprojekt. Dank seiner modernen Ausrüstung und seiner früheren Erfahrung mit dem Wiederaufbau von Brücken konnte Cheong dieses Projekt daher sogar mit einem Gewinn von $40 \%$ abschließen. Danach war er einer der fünf größten Bauunternehmer in Korea und hatte seitdem kaum noch Schwierigkeiten bei der Zuteilung von Bauaufträgen. Denn diese fünf führenden Bauunternehmer bildeten eine Art Kartell und schoben sich auf diese Weise gegenseitig die Aufträge zu. Da der Initiator des Kartells zugleich Abgeordneter der Regierungspartei war, war es für inn und damit auch für die anderen Kartellmitglieder ein leichtes, an Regierungsaufträge zu kommen. Die Beteiligung an diesem Kartell war dann der Grund, daß auch Cheong, obwohl seine Firma und sein Kapitalvermögen nicht annähernd so groß waren wie die von Ku und Lee, nach dem Sturz der Regierung Rhee als "illegaler Kapitalakkumulator" angeklagt wurde.

Youngs Expansionismus immer schlechter wurde, unterstützte Joo-Young seinen jüngeren Bruder finanziell. Er brach diese Hilfe erst ab, als klar war, daß der Bankrott von Hanra nicht mehr zu verhindern war. Siehe dazu den Artikel in der Tageszeitung Chosun-llbo vom 19.1.1998: Hyundi seo Hanra Insu Pogi (Hyundai will Hanra nicht übernehmen). 


\section{IV.6 Resümee}

Das Geheimnis des Erfolgs der oben vorgestellten drei Chaebolgründer besteht nicht in ihrer unternehmerischen Qualifikation als technologische Erneuerer, wie wir dies in der früheren Industrialisierungsphase in den westlichen Ländern häufig finden, sondern vielmehr fast ausschließlich in ihrer schon vor und während des Krieges bewiesenen Fähigkeit, auf sich bietende Chancen schnell und mit teilweise auch erheblicher Risikobereitschaft zu reagieren. Denn zwischen 1945 und 1960 boten sowohl das zurückgelassene ehemalige japanische Eigentum als auch die großzügige amerikanische Entwicklungshilfe historisch einmalige Möglichkeiten, um ohne großes Startkapital und technologisches Know-how schnell Geld zu machen. Dabei soll jedoch nicht vernachlässigt werden, daß alle drei Chaebolgründer schon vor 1945 unternehmerische Erfolge aufzuweisen hatten und auf diese Weise zwar unterschiedlich viel, jedoch auf jeden Fall genügend Kapital angesammelt hatten, um nach dem Krieg die sich innen bietenden Chancen nutzen zu können.

Für diese ersten Unternehmungen hatten die späteren Chaebolgründer noch soweit wie möglich auf die finanzielle Unterstützung ihrer Familien zurückgriffen, um so auffälliger ist, daß dies für ihren unternehmerischen Werdegang nach 1945 nicht mehr zutrifft. Zwar war auch nach dem Krieg die Ausnutzung familiärer Ressourcen für die drei Chaebolgründer selbstverständlich, aber sie bezog sich nicht mehr auf eine finanzielle Beteiligung, sondern auf eine funktionelle: Die (jüngeren) Brüder, Söhne, Schwäger, Schwiegersöhne usw. wurden als Mitarbeiter mit inrem Wissen und ihren Fähigkeiten so in das Unternehmen eingebunden, daß sie als Alter Ego, als "verlängerter Arm" des Unternehmensgründers fungieren konnten. Für eine besonders extensive Einbindung der engeren Familie in seine Unternehmungen bietet Ku das eindrücklichste Beispiel, aber auch bei Cheong, der als Ältester wie Ku mehrere jüngere Brüder wie eigene Söhne aufgezogen hatte, findet sich dieses Verhalten. Dabei konnte sich die Rekrutierung von absolut zuverlässigen und vertrauenswürdigen Mitarbeitern auch auf Freunde ausdehnen, vorausgesetzt diese Freundschaft bestand schon lange (etwa, weil beide aus dem selben Dorf stammten oder zusammen studiert hatten) oder aber die Stellung in der Geschwisterkonstellation ließ wie bei Lee als jüngstem Sohn die Rekrutierung von direkten Familienmitgliedern 
wegen des streng hierarchischen Denken in der konfuzianischen Familie nicht zu (beide Gründe konnten natürlich auch gleichzeitig zutreffen). Lee ersetzte daher, bis er auf seine Söhne zurückgreifen konnte, die inm nicht als Ressourcen zur Verfügung stehenden Familienbeziehungen zunächst durch Freundschaftsbeziehungen wie beispielsweise zu seinen schon vor dem Krieg eingestellten Geschäftsführer, der ein Studienkollege von inm war, und nach dem Krieg dann vor allem durch seine von gleichen Interessen getragene Verbindung zu den Mitgliedern des exklusiven Unternehmervereins Eulyuhoe.

Dies aber bedeutet, daß dem Familienbegriff der Chaebolgründer kein enges auf Blutsverwandtschaft gegründetes Familienmodell zugrundelag, wie dies in den modernen westlichen Staaten der Fall war, sondern insofern einen offenen Charakter hatte, als er enge Mitarbeiter, die außerhalb des familiären Kreises rekrutiert worden waren, als Mitglieder einer "fiktiven Familie" einschloß.

Wie die obigen Ausführungen zeigen, ist es daher durchaus richtig, wenn in der bisherigen koreanischen Chaebol-Forschung, der hohe Anteil von Familienmitgliedern als Kapitaleigner und im Management als charakteristisch herausgestellt wird. Doch bedeutet dies meines Erachtens nicht, daß die koreanischen Chaebol tatsächlich mit westlichen Familienunternehmen gleichzusetzen sind. Denn die besondere Eigenart der koreanischen Chaebol besteht darin, daß deren Gründerväter die Bedeutung der Familie im Zusammenhang mit inrem expandierenden unternehmerischen Interesse sozusagen neu entdeckt und neu definiert haben. Für sie hatte die Familie nicht mehr nur die traditionelle Bedeutung einer engeren oder weiteren verwandtschaftlichen Gemeinschaft, für die sie verpflichtet waren zu sorgen, sondern stellte ein unternehmerisches "Kapital" dar, das sie innerhalb der Grenzen der konfuzianischen Familientradition nutzen konnten und das sich (u. a. wegen dieser Grenzen) bei Bedarf auch auf "blutsfremde" Freunde ausweiten ließ. Die Einbindung dieser "Familienmitglieder" im weiteren Sinne in ein Unternehmen definierte dann sozusagen eine neue Familieneinheit, nämlich genau die, die durch das Unternehmen gegeben war. Doch wie neu diese Auffassung in der koreanischen Gesellschaft auch immer gewesen sein mag, es lassen sich meiner Meinung nach auch für diese Ausweitung des Familienbegriffs historische Wurzeln ausmachen. Denn die koreanische Familie umfaßte schon in der Yi-Dynastie und auch noch während der japanischen Kolonialzeit alle, auch sehr weitläufige Verwandten des Famili- 
envaters und war in erster Linie dadurch definiert, daß dieser Familienvater für den Unterhalt (für die Ernährung) aller dieser Familienmitglieder zuständig war. Familie bedeutete also - ähnlich wie in der Hausherrschaft des europäischen Mittelalters - eine gemeinsame "Nahrungsquelle". Ein alter koreanischer Spruch lautet denn auch: "Wir sind eine Familie, weil wir aus einem gemeinsamen Topf essen." Diese "Nahrung", diesen Unterhalt aber stellte nun das Unternehmen, das dadurch familiendefinierende Funktion erhielt: Wer zum Unternehmen gehörte, gehörte auch zur Familie bzw. wer zum Unternehmen gehören wollte, mußte sich als Familienmitglied verhalten.

Am deutlichsten läßt sich diese Auffassung wieder bei Lee erkennen, der die Loyalität seiner Mitarbeiter ihm gegenüber als wichtigstes Kriterium für deren Leistung betrachtete, so daß er diese ungeachtet ihrer Qualifikation auch in anderen, ihnen fremden unternehmerischen Bereichen einsetzte. In den obigen Schilderungen der unternehmerischen Werdegänge von Ku, Lee und Cheong finden sich nur ganz wenige Beispiele, wo die Einstellung eines Mitarbeiters, und sei es auch nur auf einer mittleren Führungsebene, ausschließlich aufgrund von dessen Qualifikation (als Techniker oder Ingenieur z. B.) erfolgte. Es ist daher nicht verwunderlich, daß sich in Korea keine professionelle Managerschicht entwickelte. 


\section{Verflechtung zwischen Staat und Chaebol}

\section{V.1 Eine soziologische Betrachtung der Beziehungslogik zwischen Staat und Unternehmen in Korea}

In der Literatur wird - zu Recht - häufig betont, daß sich die rapide Expansion der koreanischen Chaebol als Hauptakteure des aufholenden Industrialisierungsprozesses ohne Rückgriff auf die Einflußnahme des Staates nicht nachvollziehen läßt. ${ }^{1}$ Im Fall von Korea wird dabei vor allem darauf hingewiesen, daß sich der Staat nicht allein mit der Rolle des herkömmlichen Entscheidungsträgers der makrowirtschaftlichen politischen Maßnahmen begnügte, sondern daß er sich an dem konkreten unternehmerischen Entscheidungsprozeß unmittelbar beteiligte. Ein prägnantes Beispiel dafür sind die Investitionen in der Elektro-, Automobil- und Schiffsbauindustrie bei Samsung, Lucky-Goldstar und Hyundai, die nicht auf Initiative der Unternehmer, sondern mehr oder weniger auf staatliche Anweisung erfolgte. ${ }^{2}$

Doch bleibt dabei die Frage offen, ob es Zufall war, daß der Staat als Motor des Industrialisierungsprozesses ausgerechnet in Korea so erfolgreich war? Woran liegt es, daß das politische Rezept des sog. starken Staates in den anderen aufholenden Entwicklungsländern im Nahen Osten oder in Afrika nicht so gut funktioniert hat wie im Fall von Korea? Mit dieser Frage soll nicht die Bedeutung des starken Staates grundsätzlich bezweifelt werden. Sie zielt vielmehr auf den tatsächlichen gesellschaftlichen Wirkungsmechanismus, der hinter der Beziehung zwischen Staat und Unternehmen steht. Hintergrund dieser Fragestellung ist, daß der bisherige ökonomische bzw. institutionalistische Erklärungsansatz, in dem die Ursache des rapiden Industrialisierungsprozesses hauptsächlich an der Rolle des

\footnotetext{
${ }^{1}$ Eun-Mee Kim, The Industrial Organization and Growth of the Korean Chaebol: Integrating Development and Organizational Theories, in: Gary G. Hamilton (Ed.), Asian Business Networks, Berlin/New York 1996, S. 231-251.; Alice Amsden, Asia's Next Giant: South Korea and Late Industrialization, Oxford University Press 1989.; Robert Wade, Governing the Market: Economic Theory and The Role of Government in East Asian industrialization, Princeton/New Jersey 1990. Vgl. dazu oben auch Abschnitt II.2 (S. 19 f). ${ }^{2}$ Nicht unumstritten ist allerdings, ob diese staatliche Anweisung tatsächlich auf Initiative des Staates oder eher aufgrund der geschickten lobbyistischen Aktivitäten der Unternehmen erfolgte.
} 
starken Staates festgemacht wird, für die Erklärung der koreanischen Entwicklung der Chaebol nicht geeignet ist. Denn meines Erachtens ist die koreanische Beziehungslogik zwischen Staat und Unternehmen keineswegs so rational, wie es in diesem Zusammenhang häufig unterstellt wird. Selbst wenn der Staat keine Person, sondern eine gesellschaftliche Institution ist, hat das nicht zu bedeuten, daß diese Institution ohne menschliches Handeln auskommt. Bevor der Unternehmer als ökonomischer Agent des starken Staates überhaupt fungieren kann, ist es nötig, daß er das vorgegebene staatliche Ziel zunächst im Zusammenhang mit dem koreaspezifischen Kontext der sozialen Beziehungen interpretiert und dann in geeignete Handlungsformen umsetzt. ${ }^{3}$

Die westliche Soziologie seit Ende des Zweiten Weltkrieges neigte unter dem Einfluß des amerikanischen Strukturfunktionalismus dazu, das menschliche Handeln, das durch die soziale Verflechtungslogik geprägt ist, von vornherein als irrational bzw. nicht-ökonomisch zu charakterisieren. ${ }^{4}$ Doch liegt für Korea der Nutzen der soziologischen Analyse der spezifischen sozialen Verflechtungslogik auf der Hand, da sie verdeutlicht, auf welchem gesellschaftlichen Wirkungsmechanismus die Rolle des starken Staates beruht. Wenn man die soziale Verflechtungslogik zwischen Staat und Unternehmen in Korea vor Augen hat, dann läßt sich auch erschließen, warum die Chaebol diese enge Beziehung zum Staat bzw. die staatliche Kontrolle über ihre unternehmerischen Angelegenheiten überhaupt hinnahmen.

Der Staat hat bei der Allokation der ökonomischen Ressourcen seine Macht hauptsächlich zugunsten seiner unternehmerischen Günstlinge, die später als Chaebol bezeichnet wurden, ausgeübt. Die spezifische soziale Verflechtungslogik zwischen Staat und Chaebol in Korea wird daher im folgenden von mir als "Patron-Klientel-Verhältnis" bezeichnet. ${ }^{5}$ Die Analyse zielt dabei nicht nur darauf ab,

\footnotetext{
${ }^{3} \mathrm{Vgl}$. dazu oben auch die Abschnitte II.2 (S. 20 f.) und II.5 (S. 38 ff.).

${ }^{4}$ Es gibt jedoch viele Hinweise darauf, daß das soziologische Interesse an der Rolle der "Tradition" im modernen Leben sehr stark geworden ist. Dafür spricht die zunehmende Forderung, die bisherigen modernisierungstheoretischen Annahmen im Kontext der sogenannten nicht-westlichen Gesellschaften (vor allem Japan) neu zu reflektieren. Vgl. dazu Mark Granovetter, Entrepreneurship, Development and Emergence of Firms, 1990.; Christoph Deutschmann, Der Betriebsclan: Der japanische Organisationstyp als Herausforderung an die soziologische Modernisierungstheorie, in: Soziale Welt, Heft 2 (1987), S. 133-147.

5Eigentlich gelten "Patron" und "Klient" in den führenden deutschen Lexika der Gegenwart als Begriffe aus der antiken Geschichte (vgl. dazu z. B. Brockhaus Enzypklopädie,
} 
das koreanische Verständnis des starken Staates als "Patron" der Chaebol im konkreten historischen Zusammenhang zu rekonstruieren, sondern will auch herausarbeiten, worin die schützende Rolle des koreanischen Staates für die Entwicklung der Chaebol konkret bestand und wie dieser koreaspezifische Wirkungsmechanismus des Staates die Aktivität der koreanischen Chaebol und ihr Verständnis des ökonomischen Handelns beeinflußte. Auf diese Weise soll auch der Unterschied zwischen einem westlichen Familienunternehmen und den koreanischen Chaebol verdeutlicht werden.

\section{V.2 Der Staat als "Patron" - staatliche Wirtschaftslenkung nach dem Militärputsch von 1961}

Wie machthungrig Präsident Rhee auch immer gewesen sein mag, vertrat er doch die von dem amerikanischen Modell ausgehende Auffassung, daß staatliche Intervention bzw. die Kontrolle unternehmerischer Tätigkeiten durch den Staat möglichst vermieden werden sollten. ${ }^{6}$ Die strikte Trennung zwischen Staat und Wirtschaft war für Rhee ein Indikator für ein funktionierendes demokratisches Verfassungssystem. Die höheren Verwaltungsposten in der Regierung besetzte er möglichst mit koreanischen Eliten, die im Ausland (vor allem in Japan und USA) ausgebildet worden waren, und hoffte so, den Staat in Korea so funktionstüchtig zu machen, wie es in den kapitalistischen westlichen Ländern der Fall war. Entsprechend zielte auch seine Bildungspolitik darauf ab, den Koreanern die Ideen der westlichen Demokratie nahe zu bringen. ${ }^{7}$ So war zumindest Rhees offizieller An-

Leipzig/Mannheim 1996, Bd. 12, S. 91.; Bd. 16, S. 640). Ich dagegen lehne mich hier an die für die Frühe Neuzeit von Wolfgang Reinhard entwickelte Definition an: "PatronKlient-Beziehung, definiert als relativ dauerhaftes Zweckbündnis von Ungleichen, bei dem der mächtigere Partner dem schwächeren Schutz gewährt und dafür Gegenleitungen beanspruchen darf." (Wolfgang Reinhard, Oligarchische Verflechtung und Konfession in oberdeutschen Städten, in: Maczak, Antoni (Hrsg.), Klien-telsysteme im Europa der Frühen Neuzeit, Oldenburg 1988, S. 50).

${ }^{6}$ Ki-Jun Cho, Hanguk Chabonjueui Balcheonsa (Die Entwicklungsgeschichte des toreanischen Kapitalismus), Seoul 1991, S. 316 ff.

${ }^{7}$ Edward Mason u. a., The Economic and Social Modernization of the Republic of Korea: Studies in the Modernization of The Republic of Korea: 1945-1975, Cambridge u. a., S. 23, hält diese Bildungspolitik für gescheitert. 
spruch, in der Realität aber geriet sein Regime zunehmend in Mißkredit, weil der Staat immer mehr zu einem Machtinstrument des Präsidenten degradiert wurde, in dem sich die Behörden nur für die Wiederwahl des Präsidenten und der regierenden Partei interessierten. Als die Polizei einen Studenten, der gegen Wahlfälschungen demonstriert hatte, erschoß, erreichten die schon seit langem schwelende Wut und das Mißtrauen der Bevölkerung gegen den Staat ihren Höhepunkt. ${ }^{8}$ Angesichts der massiven Proteste gegen die Regierung entschloß sich Präsident Rhee im April 1960 schließlich zum Rücktritt, was als ein Sieg der koreanischen Demokratie in die Geschichte einging.

Die neu gebildete Regierung unter Ministerpräsident Meon Chang, der in den USA studiert hatte, hatte allerdings von Anfang an keine Kontrolle über das Land. Chang versprach zwar Demokratie, aber er war nicht imstande, Stabilität und Ruhe im Land durchzusetzen. Im Namen der Demokratie wurde überall demonstriert, wo es Konflikte gab: So gab es zum Beispiel auch eine Demonstration von Frauen, die nur Geliebte waren und auf die Straße gegangen waren, um für die Abschaffung ihrer rechtlosen gesellschaftlichen Stellung gegenüber der rechtmäßigen Ehefrau zu demonstrieren. ${ }^{9}$ Obwohl dieser anarchische Zustand im Zeichen von mehr "Demokratie" und "Freiheit" stand, entwickelte sich bei der koreanischen Bevölkerung zunehmend der Wunsch nach einem funktionierenden Staat, der vor allem das Problem der chronischen Armut bzw. Arbeitslosigkeit lösen würde. Während die Regierung Chang den Versuch unternahm, ausgerechnet von den von ihr als "illegale Akkumulatoren" bezeichneten Unternehmern politisch und $\mathfrak{f}$ nanzielle Unterstützung zu erhalten, fand sich in der Armee eine Gruppe von Offizieren zusammen, die sich als "Retter der Nation" verstanden und am 16. Mai 1961 putschten. $^{10}$

\footnotetext{
${ }^{8}$ Ki-Baik Lee, Hanguksa Sinron (Die neuere koreanische Geschichte), Seoul 1976, S. 449.

${ }^{9}$ Joeng-lk Kim, Gregory Henderson eui Hoigo (Erinnerungen von Gregory Henderson), in: Sintonga, Heft Mai (1987), S 222. Henderson war 1961 amerikanischer Kulturattache in Korea; später lehrte er als Professor für koreanische Geschichte in den Staaten. Der hier zitierte Artikel basiert auf einem Interview, das der Verfasser, ein koreanischer Professor, mit Henderson führte.

${ }^{10}$ Yong-Chung Cho, Kukga Chaegon Choigo Hoeeui (Das Komitee für den Wiederaufbau des Staates), in: Sintonga, Heft Mai (1983), S. $121 \mathrm{ff}$.
} 
Für Koreaner, die von der konfuzianischen Tradition geprägt waren, war eine Armeekarriere ursprünglich keine erstrebenswerte Laufbahn gewesen, weil das Militär in der konfuzianischen Herrschaftszeit der Yi-Dynastie nicht zur Führungsschicht gehört hatte. Daher interessierten sich für den Eintritt in die Armee zunächst vor allem Koreaner, die aus dem kommunistischen Norden geflüchtet waren und keinen Rückhalt in einer der etablierten Führungsgruppen hatten, sowie junge Koreaner, die aufgrund ihrer einfachen familiären Herkunft keinen Zugang zu eben diesen Führungsschichten hatten. ${ }^{11}$ Denn eine militärische Karriere konnte man ohne jeglichen finanziellen Aufwand verfolgen. Man benötigte lediglich einen Abschluß der Militärakademie, deren Aufnahmebedingungen im Vergleich zur Aufnahmeprüfung der Universität relativ einfach waren. Zugleich war die neu gebildete koreanische Armee aber auch Fluchtort für einige ehemalige koreanische Offiziere, die früher zur japanischen Armee gehört hatten. General Cheong-Hee Park, der den Militärputsch am 16. Mai 1961 organisiert hatte und später zum Präsidenten der dritten koreanischen Republik gewählt wurde, war ein Absolvent der japanischen Militärakademie in der Mandschurei.

Mit der aufgrund der angespannten Beziehungen zwischen Süd- und Nordkorea 1949 eingeführten allgemeinen Wehrpflicht wurde die Militärakademie dann auch für viele Highschool- und Universitätsabsolventen interessant, da diese es vorzogen, ihren Militärdienst nicht als einfache Soldaten, sondern gleich als Offiziere zu beginnen. ${ }^{12}$ Dies führte dazu, daß die Militärakademie, die bis dahin keine Elitebildungsstätte gewesen war, bald von einer Vielzahl gut ausgebildeter junger Männer besucht wurde.

Als im Juni 1950 der Koreakrieg ausbrach, wurden diese neu ausgebildeten Offiziere an die Front geschickt. Während des Krieges lernten sie nicht nur die moderne westliche Waffentechnik, sondern auch verschiedene Planungs- und Organisationstechnologien kennen. Obwohl der Beruf des Offiziers nicht dem traditionellen koreanischen Berufsbild entsprach und nicht mit hohem gesellschaftlichen Ansehen verbunden war, veränderte sich ihr eigenes Selbstbild durch diesen Krieg radikal. Auch allgemein stieg das gesellschaftliche Ansehen der Armee seit

\footnotetext{
${ }^{11}$ In-Seop Kang, Yuksa 8ki-Saeng (Der achte Jahrgang der Militärakademie), in: Sitonga, Heft Oktober (1964), S. 172 f.
} 
Ausbruch des Koreakrieges kontinuierlich, und nach Beendigung des Krieges wurde die Armee nicht nur vergrößert, sondern verwandelte sich in eine Art moderner Bildungsstätte für eine junge Elite voller Nationalstolz. ${ }^{13}$

Die koreanischen Offiziere, die sich am Militärputsch vom 16. Mai 1961 beteiligten und die danach die neuen Führungskräfte des Staates wurden, gehörten zu dieser gut ausgebildeten neuen Elite. Ihre Kritik war anfänglich zunächst weitgehend armeeintern gewesen. Denn obwohl die Armee bei seiner Gründung durch Präsident Rhee im Jahre 1948 zu einer politisch neutralen Institution erklärt worden war, hatte sich im Laufe der Jahre zunehmend die Tendenz gezeigt, daß vor allem die führenden Militärs im Interesse führender Politiker handelten. So erfuhren schon während der Expansion der Armee in der Kriegszeit viele Offiziere, die sich den schnellen Aufstieg gewünscht hatten, daß ihre Karriere durch Korruption blokkiert bzw. behindert wurde. Ihre Wut gegen die Korruption innerhalb der Armee verwandelte sich dann schnell in eine allgemeine scharfe Kritik an der Unfähigkeit des Staates, die sich nicht nur gegen die herrschenden politischen Führungskräfte im Land, sondern auch gegen korrupte Unternehmer richtete, die sich nur für das eigene ökonomische Wohl interessierten. ${ }^{14}$ Die allgemeine Wut entlud sich schließlich in dem Putsch vom 16. Mai 1961.

Nach dem Putsch lag die Macht in Korea beim militärischen Revolutionskomitee, das sich "Kukgachaegeon Wiwonhoe" ("Komitee für den Wiederaufbau des Staates") nannte. Die Putschisten rechtfertigten die Gründung dieser über der Regierung stehenden Institution damit, daß Staat und Regierung in Korea durch Korruption völlig gelähmt seien. Dabei betonte der Führer des Militärputsches, General Cheong-Hee Park, ausdrücklich, daß das Ziel der "Revolution" nur darin bestehe, die alte korrumpierte Führungsgruppe durch eine neue, zivile und gewissen-

\footnotetext{
${ }^{12}$ Ebenda, S. 176.

${ }^{13}$ Heung-Yun Byon, Hanguk Keongje Kaebal Gaeheok eui Banghyang (Die ökonomische Entwicklung in Korea), in: Shin, II-Chul (Hrsg.), Hangukineui Sasang (Das Denken in Korea), Seoul 1984, S. 189.

${ }^{14}$ In-Seop Kang, Yuksa 8ki-Saeng (Der achte Jahrgang der Militärakademie), in: Sitonga, Heft Oktober (1964), S. 186.
} 
hafte Führung zu ersetzten. ${ }^{15}$ Wenn dieses Ziel erreicht sei, dann werde er mit seiner Gefolgschaft in die Armee zurückkehren - ein Versprechen, das er nicht hielt.

Obwohl zeitgenössische Beobachter Parks spätere unmittelbare Beteiligung an der aktiven politischen Führung lediglich als Zeichen seines blinden Machthungers $\mathrm{zu}$ interpretieren pflegten, ${ }^{16}$ bin ich der Meinung, daß sich seine politischen und wirtschaftlichen Aktivitäten ohne Beachtung seiner patronalistischen Haltung gegenüber dem Staat nicht angemessen würdigen lassen. Um diese These belegen zu können, werde ich im folgenden die drei wichtigsten staatlich-wirtschaftlichen Aktivitäten unter Präsident Park genau unter die Lupe nehmen:

Der Staat als Planer der ökonomischen Entwicklung: In ihrer ersten Rundfunkerklärung nach der Machtübernahme betonten die Militärs - um Legitimation für ihre Intervention bemüht -, daß sich die neue Regierung vor allem um die Befreiung der koreanischen Bevölkerung von der Hungersnot kümmern werde. Die Offiziere gingen dabei davon aus, daß sie im Namen der Revolution auch nicht durch die vorhandenen Gesetze abgedeckte politische Maßnahmen durchführen könnten, wie beispielsweise die Abschaffung der Schulden von Bauern und Fischern, die seit der Landreform zum Teil hoch verschuldet waren. ${ }^{17}$ Weil die Offiziere meistens selbst aus armen bäuerlichen Verhältnissen stammten, legten sie viel Wert gerade auf diese Maßnahme, die sich in Wirklichkeit aber nur als ein Tropfen auf den heißen Stein erwies. Denn die wirtschaftliche Lage dieser Bauern und Fischer war so schlecht, daß sie nach der Annullierung alter Schulden sofort neue Schulden aufnehmen mußten. ${ }^{18}$

Nach diesem Fehlschlag konzentrierte sich die Militärs auf die Umsetzung eines staatlichen Wirtschaftsplans, der schon von der Regierung Chang vorgelegt

\footnotetext{
${ }^{15}$ Yong-Chung Cho, Kukga Chaegon Choigo Hoeeui (Das Komitee für den Wiederaufbau des Staates), in: Sintonga, Heft Mai (1983), S.150.

${ }^{16}$ Unter den Repräsentanten dieser Auffassung befindet sich beispielsweie der Journalist Young-Hee Lee, der als der berühmteste Kritiker gegen das Regime Park sehr lange im Gefängnis war.

${ }^{17}$ Yong-Chung Cho, Kukga Chaegon Choigo Hoeeui (Das Komitee für den Wiederaufbau des Staates), in: Sintonga, Heft Mai (1983), S. 135.

${ }^{18}$ Ebenda, S. 175.
} 
worden war und dessen Wurzeln bis in die Regierung Rhee zurückreichten. ${ }^{19}$ Denn schon in den 50er Jahren hatte die amerikanische Regierung gefordert, daß die koreanische Wirtschaft nicht länger allein durch ihre Entwicklungshilfe finanziert werden sollte. Sie forderte daher von der koreanischen Regierung einen Wirtschaftsplan, der die Investitionspläne der koreanischen Regierung enthalten sollte. Für die koreanische Regierung war dieser Plan allerdings nur eine Art Projektantrag, um weitere amerikanische finanzielle Hilfe zu bekommen. ${ }^{20}$ Weil der Plan jedes Jahr neu erstellt werden mußte, schlug die amerikanische Regierung vor, einen längerfristigen Wirtschaftsplan zu entwickeln. Der erste langfristige Plan, der 1958 aufgestellt wurde, erstreckte sich auf sieben Jahre. Dafür wurde zum ersten Mal ein koreanisches Komitee für Wirtschaftsplanung ins Leben gerufen. In diesem Komitee waren nicht nur amerikanische Professoren, sondern auch koreanische Ökonomen vertreten. Bei der Erstellung des Plans richtete sich das Augenmerk der Beteiligten hauptsächlich darauf, einen zahlenmäßigen Überblick über die gesamtökonomische Entwicklung in Korea zu gewinnen. So enthielt der Plan nicht nur den Prozentsatz einer möglichen jährlichen Wachstumsrate, sondern auch die Summe des dafür benötigten Kapitals. Das Konzept sah vor, die ökonomische Entwicklung in Korea vor allem durch die Landwirtschaft und die kleinen und mittleren Unternehmen anzukurbeln. ${ }^{21}$

Doch als die Studentendemonstrationen im April 1960 begannen, wurde dieser Plan Makulatur. Es kam zu Neuwahlen. Nach dem Sieg der Oppositionspartei unter Chang war die amerikanische Regierung endgültig nicht länger bereit, Entwicklungshilfe in Korea zu leisten, und daher beauftragte Chang das Planungskomitee mit der Entwicklung eines neuen längerfristigen Wirtschaftsplans. Aber auch der Anfang 1960 von Chang vorgelegte Fünfjahresplan kam wegen des Militärputsches im Mai 1961 nie zur Ausführung.

Nach dem erfolgreichen Putsch ließ sich die neue Regierung sofort von JongDae Kim, den stellvertretenden Vorsitzenden des früheren Planungskomitees,

\footnotetext{
${ }^{19}$ Jin-Heon Kim, Dong-Uk Chi, Hanguk Changi Kaebal Kaehoek eui Naimak (Der Hintergrund des langfristigen Entwicklungsplans in Korea), in: Sintonga, Heft September (1966), S. 107.

${ }^{20}$ Ebenda, S. 103.

${ }^{21}$ Ebenda, S. 104.
} 
über den Fünfjahresplan berichten. ${ }^{22}$ Zwar hatte die Mehrheit der Putschisten (einschließlich General Park) keine konkrete Vorstellung von staatlicher Wirtschaftsplanung, doch befand sich unter innen ein Offizier namens Won-Sik Yu, der ausgehend von einem ökonomischen Entwicklungsmodell, wie man es auf Dritte-WeltLänder anwandte, im Komitee für den Wiederaufbau des Staates die staatliche Wirtschaftslenkung in die Hand nahm. Unter seiner Leitung bildete sich ein neues Planungsteam, das im Namen eines "geführten Kapitalismus" einen neuen Fünfjahresplan entwarf. ${ }^{23}$ Da Yu selbst kein Ökonom war, nutzte er seine Machtbefugnis als Mitglied des Komitees für den Wiederaufbau des Staates und zwang die mehrheitlich antiamerikanisch bzw. nationalistisch gesinnten koreanischen Ökonomen zur Beteiligung an seinem Planungsteam.

Als der erste Fünfjahresplan (1962-1966) fertiggestellt war, sah er im Grunde nicht viel anders aus als der Plan, der unter der Regierung Chang konzipiert worden war. Der Unterschied bestand lediglich darin, daß Yu und sein Planungsteam fest davon überzeugt waren, daß die Umsetzung dieses Plans, in dem Investitionspläne und eine jährliche Wachstumsrate festgelegt worden waren, der unmittelbaren Intervention des Staates bedurfte. Sie erkannten auch, daß diese neuen Investitionspläne ohne Mobilisierung des Großkapitals nicht auszuführen waren. Während die Mitglieder des früheren Wirtschaftsministeriums, die unter der Regierung von Rhee und Chang gearbeitet hatten, nach dem Vorbild des westlichen Kapitalismus zur Finanzierung von Investitionen das Bankensystem genutzt hatten, griffen $\mathrm{Yu}$ und die Militärputschisten zu dem radikalen Mittel einer Währungsreform. ${ }^{24}$ Dabei gingen sie von der Annahme aus, daß das Kapital für die Finanzierung des ersten Fünfjahresplanes deshalb fehle, weil die koreanische Bevölkerung ihre Ersparnisse nicht zur Bank, sondern auf den schwarzen Markt trage. In erster Linie richtete sich das Augen-

\footnotetext{
${ }^{22}$ Ebenda, S. 106.

${ }^{23}$ Ebenda, S. 110.

${ }^{24}$ Cheong-Reom Kim, Hanguk Keongje Cheong-Chaek 30 Yeonsa (Dreißig Jahre koreanische Wirtschaftspolitik), Seoul 1995, S. 185.
} 
merk der Planungsgruppe um Yu dabei auf die Unternehmer, die schon von Chang als "illegale Akkumulatoren" verurteilt wurden waren. Man hoffte, daß der Staat diese durch die Währungsreform dazu zwingen könnte, ihr Geld in den ersten Fünfjahresplan zu investieren, da auch reichen Koreanern durch die Währungsreform nur noch eine bestimmte Geldmenge zur Verfügung stehen sollte. Dabei wußten Yu und sein Team zwar, daß ein derartiger unmittelbarer staatlicher Eingriff in das private Eigentumsrecht von der amerikanischen Regierung sehr mißtrauisch betrachtet werden würde, argumentierten aber damit, daß die erfolgreiche Umsetzung der Währungsreform nicht zuletzt finanzielle Unabhängigkeit von der amerikanischen Regierung bedeute. Als die amerikanische Regierung von dem Plan der neuen Währungsreform erfuhr, reagierte sie darauf erwartungsgemäß mit dem Stop des versprochenen Entwicklungsprogramms in Korea. ${ }^{25}$ Gleichzeitig erwies sich die Erwartung des Militärs, daß die reichen Koreaner ihr Geld zu Hause versteckt hätten, als völlig falsch. Außerdem mehrten sich die Stimmen, daß die Mitglieder des Komitees für den Wiederaufbau des Staates im Grunde nichts anderes seien als Sozialisten. Daraufhin wurde Yu gezwungen, sein Amt als Mitglied des Komitees aufzugeben.

Am 22. Juli 1961 billigte das Komitee für den Wiederaufbau des Staates die Gründung eines neuen Ministeriums für Wirtschaftsplanung, das auf koreanisch "Keongje Kihoekwon" hieß ${ }^{26}$ In Wirklichkeit handelte es sich dabei nur um eine Namensänderung für das Planungsteam, das unter der Leitung von Yu den ersten Fünfjahresplan entworfen hatte. Von Anfang an stand dieses Ministerium über alle anderen mit wirtschaftlichen Fragen befaßten Ministerien (wie dem Finanz-, dem Handels- und dem Landwirtschaftsministerium), da der Minister für Wirtschaftsplanung zugleich stellvertretender Ministerpräsident war. Obwohl viele ehemalige Offiziere, die sich an dem Putsch beteiligt hatten, wichtige Posten in der Regierung

\footnotetext{
${ }^{25}$ Ebenda, S. 23.

${ }^{26}$ Obwohl dieses Ministerium für die Erstellung eines langfristigen Wirtschaftsplans geschaffen worden war, erhielt es nicht den Namen "Kaehoek", was Planung bedeutet, sondern "Kihoek", was nur ein Synonym für Planung ist. Wahrscheinlich hängt diese Namensgebung damit zusammen, daß die neue Regierung möglichst keinen Namen verwenden wollte, der an die Terminologie eines sozialistischen Staates erinnerte. Schon durch die Tatsache, daß das Komitee für den Wiederaufbau des Staates das Parlament und die Regierung kontrollierte, war der Verdacht entstanden, daß es sich
} 
übernommen hatten, wagte niemand von ihnen, dieses neue Wirtschaftsministerium zu leiten, da schnell deutlich geworden war, daß ihr Wirtschaftsplan so naiv war, daß ihre als revolutionär ausgegebenen ökonomischen Maßnahmen scheitern mußten. ${ }^{27}$ Doch Park hielt an dem neuen Wirtschaftsministerium fest.

Weil es damals große Mode war, langfristige Wirtschaftspläne mithilfe von statistischen Analysemethoden zu erstellen, wurde das frühere Amt für Statistik diesem neuen Ministerium untergeordnet. Eine andere Eigentümlichkeit dieses Ministeriums bestand darin, daß inm die Abteilung für den Staatshaushalt unterstand. Früher war diese Abteilung - wie allgemein üblich - dem Finanzministerium untergeordnet gewesen. Doch hielt man nun offenbar den staatlichen Haushaltsplan für ein Element allgemeiner Wirtschaftsplanung. Seit 1962 oblag dem Ministerium zudem nicht nur die Planungsarbeit, sondern auch die Aufgabe, für die ausländischen Kreditgeber als Träger einer staatlichen Bürgschaft aufzutreten, die die ausländischen Kreditgeber verlangt hatten, weil sie kein Vertrauen in die koreanischen Unternehmen hatten. Auf diese Weise kontrollierte das Ministerium für Wirtschaftsplanung auch die ausländischen Kredite für koreanische Unternehmen. ${ }^{28}$

Das neu gegründete Ministerium benötigte vor allem Leute, die sich mit statistischer Arbeit auskannten. In der Regel waren dies Ökonomen, die in den USA statistische Ökonomie studiert hatten. ${ }^{29}$ Natürlich bestimmte diese hohe Konzentration eines bestimmten Typus von Ökonomen den Charakter dieses Ministeriums sehr stark, so daß der Fünfjahresplan ungeachtet der in Korea existierenden realen gesellschaftlichen und historischen Rahmenbedingungen nur an reinen Zahlen (z. B. der jährlichen Wachstumsrate, der Exportquote und der Zahl der Beschäftigten) orientiert war.

Nachdem General Park sich im Jahr 1964 zum neuen Präsidenten in Korea hatte wählen lassen, war schon klar, daß der eigentich bis 1966 projektierte erste Wirtschaftsplan wegen vieler unvorhergesehener Hindernisse (wie z. B. der feh-

hier um ein sozialistisches Modell des Staates handelte. Doch das Militär gab sich dezidiert antikommunistisch.

${ }^{27}$ Leroy Jones, II Sakong, Government, Business, and Entrepreneurship in Economic Development: The Korean Case, Cambridge u. a. 1980, S. 48.

${ }^{28}$ Ebenda, S. 19.

${ }^{29}$ Ki-Jun Cho, Hanguk Chabon Jueui Balcheonsa (Die Entwicklungsgeschiche des koreanischen Kapitalismus), Seoul 1991, S. 53 f. 
lende Bereitschaft der ausländischen Kreditgeber wie des IWF) nicht verwirklicht werden konnte. Darauf entließ Park den zuständigen Minister. Neuer Wirtschaftsplanungsminister wurde Ki-Young Chang, der in Korea sowohl als Bankier als auch Gründer der Zeitung "Hanguk-llbo" bekannt war. Cheong-Reom Kim, der damals in der Zentralbank in Korea tätig war, schrieb später in seiner Autobiographie, daß Chang, der kein Offizier war, nur unter der Voraussetzung diesen Posten übernommen habe, daß er als stellvertretender Ministerpräsident die volle Rükkendeckung von Präsident Park habe. ${ }^{30}$ Das heißt: Der neue Wirtschaftsplanungsminister sicherte sich vor Amtsantritt den Präsidenten als Patron.

Chang unterschied sich dabei von Präsident Park und dessen militärischer Gefolgschaft durch sein solides ökonomisches Wissen. Er hatte in der japanischen Kolonialzeit nicht nur an einer Handelsschule studiert, sondern auch an Banken gearbeitet, wo er viele Informationen über koreanische Unternehmen sammeln konnte. Nach der Kolonialzeit betätigte er sich als Wirtschaftsjournalist und gründete dann selbst eine Zeitung. Außerdem war er ein wichtiger Unterhändler bei der Erneuerung der diplomatischen Beziehungen zu Japan, bei denen Japan der neuen koreanischen Regierung unter Präsident Park eine große Entschädigungszahlung versprach. ${ }^{31}$

Unter Chang begnügte sich das Ministerium nicht mit dem Entwurf eines weiteren Fünfjahresplanes, sondern bemühte sich vor allem um den Dialog mit den Unternehmern. ${ }^{32}$ Seitdem die Unternehmer von der Bewilligung einer staatlichen Bürgschaft für ausländische Kredite abhängig waren, verfügte das Ministerium über die Möglichkeit, selbst auszuwählen, welches Unternehmen und welche Industriesektoren die durch das Ministerium genehmigten Kredite erhielten. Chang sah nun seine Aufgabe darin, möglichst viele staatliche Projekte durch private Unternehmer ausführen zu lassen, und nutzte sein Amt, um dies durchzusetzen. Dabei duldete er es nicht, wenn ein von inm betreutes Unternehmen bzw. Projekt durch Einwände eines benachbarten Ministeriums blockiert wurde. Wenn es sich um ein großes und schwieriges Projekt (z. B. einen kapitalintensiven Investitionsplan)

\footnotetext{
${ }^{30}$ Cheong-Reom Kim, Hanguk Keongje Cheong-Chaek 30 Yeonsa (Dreißig Jahre toreanische Wirtschaftspolitik), Seoul 1995, S. 111.

${ }^{31}$ Ebenda, S. $31 \mathrm{ff}$.
} 
handelte, versuchte er sogar den Präsidenten an den Verhandlungen zu beteiligen. Das heißt: Er scheute sich nicht, die Person des Präsidenten als Druckmittel für die erfolgreiche Durchsetzung des Fünfjahresplans einzusetzen. ${ }^{33}$ Wegen dieser engen Zusammenarbeit zwischen dem Präsidenten und dem Ministerium gelang es Park, anders als dem früheren Präsidenten Rhee, die Umsetzung des Fünfjahresplans in den Unternehmen sehr weitgehend zu kontrollieren. Die Nähe zum Präsidenten führte überdies dazu, daß sich die Mitarbeiter dieses Ministeriums besonders motiviert fühlten, den Fünfjahresplan möglichst erfolgreich umzusetzen. Wegen des großen politischen Handlungsspielraumes wurde das Ministerium auBerdem zum begehrtesten Arbeitsplatz innerhalb Regierung, so daß dort nur die Elite unter den Regierungsbürokraten beschäftigt war. ${ }^{34}$

Durch Changs Erfolge änderte sich auch die Einstellung der Unternehmer gegenüber dessem Ministerium. Weil durch ein Gespräch mit Minister Chang bzw. Präsident Park die früheren bürokratischen Blockaden schnell und einfach beseitigt werden konnten, wandten sich die Unternehmer nun mit allen Investitionsplänen von selbst direkt an Changs Ministerium. Selbst wenn der vorgelegte Unternehmensplan nicht mit dem staatlichen Fünfjahresplan übereinstimmte, war es fast immer möglich, durch eine Unterredung mit dem Minister die staatliche Unterstützung dennoch zu erhalten. ${ }^{35}$ Vor diesem Hintergrund entwickelte sich ein Verhaltenmuster zwischen den Mitarbeitern des Ministeriums und den Unternehmern, daß sich am besten dadurch beschreiben läßt, daß sich die Mitarbeiter des Ministeriums (einschließlich Minister Chang) jeweils als Patrone des antragstellenden Unternehmers verstanden. Das heißt: So wie Präsident Park als Patron auf oberster Ebene fungierte, begann sich auf einer untergeordneten Ebene ein PatronKlientel-Verhältnis zwischen den Mitarbeitern des Ministeriums und den Unternehmern zu entwickeln.

\footnotetext{
${ }^{32}$ Won-Chul Oh, Hangukheong Keongje Keonsul (Das koreanische Entwicklungsmodell), Seoul 1995, Bd. 1, S. 72.

${ }^{33}$ Cheong-Reom Kim, Hanguk Keongje Cheong-Chaek 30 Yeonsa (Dreißig Jahre toreanische Wirtschaftspolitik), Seoul 1995, S. 111.

${ }^{34}$ Leroy Jones, II Sakong, Government, Business, and Entrepreneurship in Economic Development: The Korean Case, Cambridge u. a. 1980, S. 50.

${ }^{35}$ Alice Amsden, Asia's next Giant, New York/Oxford 1989, S. 81.
} 
Die Amtszeit von Chang dauerte drei Jahre. Während dieser Zeit etablierte er den wichtigsten Funktionsmechanismus seines Superministeriums: Unter dem Schutz des Ministers und des Präsidenten war es für die Mitarbeiter völlig normal, ungeachtet aller geltender gesetzlicher oder bürokratischen Regelungen ihre schützende Hand über die Unternehmen zu halten. Abgesegnet war dieses Verhalten durch Präsident Park persönlich, der nicht nur die Patronage über das Ministerium übernommen hatte, sondern auch gesagt hatte, daß der Erfolg des einzelnen Unternehmens letztlich eine staatliche Angelegenheit sei, ${ }^{36}$ womit er persönlich das Patronagesystem auch auf die Unternehmen ausgedehnt hatte.

In seiner Autobiographie beschrieb ein ehemaliger Mitarbeiter des Wirtschaftsministeriums, Won-Chul Oh, das übliche Vorgehen: "Eines abends rief Minister Chang mich an. Er sagte mir, daß das Projekt, an dem ich gerade arbeite, aus staatlicher Perspektive eine sehr wichtige Angelegenheit sei und ich deswegen schon am nächsten Tag eine Bewilligung des Antrags für den Techniktransfer erteilen sollte." Oh verglich das Verhalten von Minister Chang diesbezüglich mit dem eines "wilden Pferdes", das zügellos in fremde Felder springt und alles kaputt macht. $^{37}$

Chang, der das Ministerium zwischen 1964 und 1967 leitete, hatte an der Herausbildung des Staates als Planer in der Rolle des Patrons, der uneingeschränkt zum Schutz und zur Förderung seiner Klienten (in diesem Fall der Unternehmer) wirkte, großen Anteil. Die spätere Amtsauffassung des Präsidenten, die sich von der eines Großpatrons, der sich uneingeschränkt und ohne Rücksicht auf übergeordnete Belange für die Begünstigung seiner Gefolgschaft einsetzt, nicht mehr unterscheiden ließ, bildete sich in dieser Zeit heraus.

Der Staat als Förderer der unternehmerischen Exportstrategie: 1963 erreichte der koreanische Devisenstand einen Tiefpunkt, so daß der erste Fünf-

\footnotetext{
${ }^{36}$ Cheong-Reom Kim, Hanguk Keongje Cheong-Chaek 30 Yeonsa (Dreißig Jahre toreanisches Wirtschaftssystem), Seoul 1995, S. 435.

${ }^{37}$ Won-Chul Oh, Hanguk heong Keongje Keonseol (Das koreanische Entwicklungsmodell), Seoul 1995, Bd. 1, S. 193.
} 
jahresplan wegen mangelnder Finanzmittel modifiziert werden mußte..$^{38}$ Unter Präsident Rhee hatten sich die führenden koreanischen Unternehmen - wie im vorigen Kapitel ausgeführt - auf die Importsubstitutionsindustrie konzentriert. Weil die Mehrheit der koreanischen Bevölkerung in der Landwirtschaft beschäftigt war, wurden nur Lebensmittel wie beispielsweise getrockneter Fisch oder in geringem $\mathrm{Maße}$ auch Bodenschätze exportiert. Daher war der Export so gering, daß man diesen kaum als Quelle für neue Devisen betrachten konnte.

Zwar gab es in Korea ein auch für den Export zuständiges Handels- und Industrieministerium, aber die Tätigkeit dieses Ministeriums bestand hauptsächlich darin, auszuwählen, welches Unternehmen welche Produkte importieren durfte. ${ }^{39}$ Dieses Ministerium versuchte nun das Problem der mangelnden Devisen dadurch zu lösen, daß es den Import reduzierte. Als Folge davon litten viele koreanische Fabriken unter Mangel an Rohstoffen. Natürlich beeinträchtigte diese Maßnahme das gesamte ökonomische Wachstum in Korea und erregte gleichzeitig den Unwillen der koreanischen Unternehmer, weil sie nichts produzieren konnten.

Als die Militärregierung im Jahr 1963 von der Devisenkrise unterrichtet wurde, konzentrierte sich ihr Interesse folgerichtig auf die Suche nach neuen Exportmöglichkeiten, zumal die Regierung seit 1962 ja auch zu den unmittelbar Verantwortlichen gegenüber den ausländischen Schuldnern gehörte und die amerikanische Regierung ja schon 1958 ihre direkte finanzielle Hilfe, durch die bisher der größte Teil des koreanischen Devisenbedarfes gedeckt worden war, auf Kredite umgestellt hatte. ${ }^{40}$

Vor diesem Hintergrund erklärte Park, als er 1964 sein Präsidentenamt antrat, die Förderung des Exportes zum vorangigen Ziel seiner neuen Wirtschaftspolitik und verpflichtete sein Ministerium für Wirtschaftsplanung dazu, sich im zweiten Fünfjahresplan (1967-1971) nicht länger auf die herkömmliche

\footnotetext{
${ }^{38}$ Jin-Heon Kim, Dong-Uk Chi, Hanguk Changi Kaebal Kaehoek eui Naimak (Der Hintergrund des langfristigen Entwicklungsplans in Korea), in: Sintonga, Heft September (1966), S. 110.

${ }^{39}$ Won-Chul Oh, Hangukheong Keongje Keonsul (Das koreanische Entwicklungsmodell), Seoul 1995, Bd. 1, S. 233.

${ }^{40}$ Chong-Chul Lim, Chakwan Uddeke Ssyeochigo Issnunga? (Wie werden ausländische Kredite verwendet?), in: Sintonga, Heft Mai (1967), S. 79.
} 
Importsubstitutionsindustrie zu konzentrieren, sondern eine exportorientierte industrielle Entwicklungsstrategie zu verfolgen. Die jährliche Wachstumsrate sollte von nun an durch Exportzuwachs untermauert werden. Daher wurde der Schwerpunkt der staatlichen Förderung von dem traditionellen Sektor der Landwirtschaft auf die Schwerindustrie verlegt. ${ }^{41}$

Das Problem dieser auf Exportzuwachs angelegten Wirtschaftspolitik war allerdings, daß die damalige koreanische Gesellschaft außer niedrigen Löhnen über keine nennenswerten internationalen komparativen Vorteile verfügte. Anders als in den südamerikanischen Ländern gab es nicht einmal genügende Rohstoffe, die man auf dem Weltmarkt hätte anbieten können. Es gab zwar einige Industrieunternehmen, aber die Qualität ihrer Produkte und Produktionsverfahren orientierte sich nicht am Weltmarkt, sondern an der einheimischen Gesellschaft. Viele technische Anlagen waren veraltet, und es gab auch keine technologische Innovation, weil die Produkte innerhalb der einheimischen Gesellschaft in der Regel nicht mit importierten Gütern konkurrieren mußten. Die koreanischen Unternehmer, die zumeist keine Erfahrung mit ausländischen Märkten hatten, standen daher ausländischen Konkurrenten gegenüber, deren technischem und wirtschaftlichem Know-how sie sich unterlegen fühlten. Ihr Interesse an einer Steigerung ihrer Exportrate war daher eher gering. ${ }^{42}$

Die Initiative für eine neue am Export orientierte unternehmerische Produktionsstrategie ging daher vom Staat und nicht von den Unternehmen aus. Daher verstanden die Unternehmer die neue Exportstrategie nicht als eine selbstbestimmte, ökonomische Produktionsstrategie, sondern vielmehr als einen Vertrag zwischen Staat und Unternehmen. Nach ihrem Verständnis entsprach die staatliche Förderung des Exports nämlich keineswegs ihren unmittelbaren ökonomischen Interessen, da die bisherige am Binnenmarkt orientierte Marktstrategie ja für sie als Unternehmer durchaus erfolgreich gewesen war. Nur der Staat hatte Probleme, weil die koreanische Ökonomie durch die Devisenkrise massiv gefährdet war. Damit geriet der Staat in Korea in eine Situation, in der

\footnotetext{
${ }^{41}$ Cheong-Reom Kim, Hanguk Keongje Cheong-Chaek 30 Yeonsa (Dreißig Jahre toreanischen Wirtschaftspolitik), Seoul 1995, S. 134.

42 Jeong-Tae Kim, Hanguk eui Keonjesang (Die Gegenwart der koreanischen Ökonomie), in: Sintonga, Heft März (1966), S. 64.
} 
er im eigenen politischen Interesse den Unternehmen Gegenleistungen bieten mußte, damit diese ihre bisherige binnenmarktorientierte Produktionsstrategie aufgaben und sich am Export beteiligten. Deshalb bot das Handels- und Industrieministerium als zuständige Abteilung der Regierung den Unternehmern vor allem Unterstützung bei der Modernisierung von Produktionsanlagen durch den bevorzugten Zugang zu Devisen (für den Import ausländischer Maschinen) und die Gewährung äußerst günstiger Kredite. ${ }^{43}$

Angesichts dieser staatlichen Gegenleistungen für ihre Exportunternehmungen scheuten die koreanischen Unternehmen sich nicht, trotz der zu erwartenden Verluste ihre Produkte zu exportieren. Unter Hinweis auf die fehlenden komparativen Vorteile der koreanischen Produkte erreichten sie darüber hinaus, daß der Staat zuließ, daß ein Teil der Rohstoffe, die nur zum Zweck des Exports importiert worden waren, später auf dem einheimischen Markt mit erheblichen Gewinnen weiterverkauft werden durfte. ${ }^{44}$ Das heißt: Die Verluste der Unternehmen, die durch den Export verursacht worden waren, wurden durch Gewinne auf dem Binnenmarkt, der unter Kontrolle des Staates stand, ersetzt. Diese Strategie führte dazu, daß der koreanische Export tatsächlich ohne Komplikationen rapide stieg und damit auch die Devisen in Korea zunahmen. Weil dieser Export durch schnell wachsende Importe von Gütern, die als Rohstoffe verwendet wurde, begleitet wurde, hatten ausländischen Gläubiger (insb. der IWF) den Eindruck, als ob sich die koreanische Ökonomie endlich auf die freie Marktwirtschaft eingelassen hätte. Die Folge war eine hohe Bereitschaft der westlichen und japanischen Gläubiger, Korea Kredite zu gewähren. ${ }^{45}$

Weil aber die koreanischen Unternehmer nicht aus eigener Kraft große unternehmerische Projekte finanzieren konnten, nutzte der Staat die Tatsache, daß er nach der Verstaatlichung der Banken im Jahre 1961 der einzige größe-

\footnotetext{
${ }^{43}$ Cheong-Reom Kim, Hanguk Keongje Cheong-Chaek 30 Yeonsa (Dreißig Jahre toreanische Wirtschaftspolitik), Seoul 1995, S. 114.

${ }^{44} \mathrm{Amsden}$ hält diese staatliche Intervention für den Binnenmarktpreis für einen wichtigen Indikator für die Rolle des starken Staates (Alice Amsden, Asia's Next Giant, New York/Oxford 1989, S. 172 f.).

${ }^{45}$ Cheong-Reom Kim, Hanguk Keongje Cheong-Chaek 30 Yeonsa (Dreißig Jahre toreanische Wirtschaftspolitik), Seoul 1995, S. 112.
} 
re Kapitalgeber war, und förderte nur einen bestimmten Typus des Unternehmens, nämlich das erfolgreiche Großunternehmen, dem allein die Steigerung des Exportes zugetraut wurde. Der Staat machte sich damit zum Patron des exportorientierten koreanischen Großunternehmen. Dabei interessierte sich Präsident Park und sein Ministerium für Handel und Industrie nicht für die gesamtwirtschaftliche Entwicklung in Korea, nicht für die Entwicklung von Klein- und mittleren Unternehmen oder gar für die Lage des ständig wachsenden Heeres der Industriearbeiter, sondern ausschließlich für die Steigerung der Exportrate. Nachdem die Exportquote in den Jahren 1966 und 1967 dann sogar das geplante Niveau überstiegen hatte, fühlte sich die Regierung natürlich ermutigt, die so erfolgreiche, bisherige Exportstrategie noch zu verschärfen, was insbesondere eine weitere Konzentration auf die Förderung von Großunternehmen bedeutete. ${ }^{46}$

Der Staat als Regulator für unrentable Unternehmen: Im Mai 1969 bildete Präsident Park ein Sonderkomitee für die "Säuberung von unrentablen Unternehmen". Die Aufgabe dieses Komitees, das direkt dem Präsidentenbüro untergeordnet war, bestand darin, zu prüfen, welche Unternehmen nicht rentabel seien, so daß die Regierung möglicherweise gezwungen sein könnte, deren Schulden gegenüber ausländischen Kreditgebern übernehmen zu müssen. ${ }^{47}$ Obwohl die ökonomische Wachstumsrate zwischen 1966 und 1968 um über $10 \%$ gestiegen war, hatte der Finanzminister Anfang 1969 den Präsidenten davor gewarnt, daß die Regierung durch die staatliche Bürgschaft für ausländische Kredite in eine Finanzkrise geraten könnte. Es zeige sich, daß viele koreanische Unternehmen, die mit ausländischen Krediten während der letzten Jahre gegründet worden waren, nicht imstande seien, diese Kredite, deren Rückzahlungstermin immer näher rücke, selbst zurückzuzahlen. Daher sei es durchaus denkbar, daß die Regierung, die Schulden aus der staatlichen Kasse zurückzahlen müsse. ${ }^{48}$ Für den Präsidenten

\footnotetext{
${ }^{46}$ Yun-Hwan Kim, Hanguk Nodong Undong eui Reoksajeik Kwaje wa Banghyang (Die historische Aufgabe der koreanischen Arbeiterbewegung und die Zukunft), in: Kim, Byong-Tae u. a., Hanguk Keongje eui Cheongaekwajeong (Der Entwicklungsprozeß der koreanischen Ökonomie), Seoul 1981, S. 260.

${ }^{47}$ Duk-Jin Chang, Busil Kiup Cheongri eui Silmal (Die Säuberung von unrentablen Unternehmen), in: Sintonga, Heft Oktober (1969), S. 99.

${ }^{48}$ Ebenda, S. 104.
} 
war dieser Bericht ein großer Schock, weil er bis dahin fest davon überzeugt gewesen war, daß die zunehmende Zahl der koreanischen Unternehmen gleichzusetzen sei mit einer schnell wachsenden ökonomischen Entwicklung in Korea. Seine größte Sorge dabei war: "Wenn die oppositionelle Partei und das Volk von der Zahlungsunfähigkeit dieser Unternehmen erfahren, was werden sie über mich und mein politisches Versprechen über die Befreiung von der Hungersnot denken?"199

Trotz der Einwände der oppositionellen Partei und der Unternehmer, die selbst handeln wollten, entschloß sich Park, das Problem der zahlungsunfähigen Unternehmen auf der Ebene des Staates zu regulieren. ${ }^{50}$ Der Staat sollte die in eine Krise geratenen Unternehmen, die mit ausländischen Krediten gegründet worden waren, genau unter die Lupe nehmen, um zu entscheiden, ob sich diese Unternehmen mit Hilfe von neuen staatlichen Subventionen in ein rentables Unternehmen verwandeln ließen. Diese Überprüfungsaufgabe übernahm das oben genannte Komitee für die Säuberung von unrentablen Unternehmen.

Die Mitarbeiter dieses Komitees wurden aus der jungen Elite des Finanz-, des Planungsministeriums und der verschiedenen Banken gewonnen. ${ }^{51}$ Nach dreimonatiger geheimer Prüfungsarbeit entschloß sich dieses Komitee im Namen des Präsidenten 30 von den untersuchten 100 Unternehmen, die als "unrentabel" beurteilt worden waren, zum Verkauf zu zwingen. Das heißt: Der jeweilige Unternehmer wurde gezwungen, seinen Eigentumsanspruch aufzugeben, und das Unternehmen wurde von den Banken übernommen, solange bis sich ein neuer Käufer fand. Auf den Versuch der Banken, die Angst vor ihrem eigenen Bankrott hatten, diese politische Maßnahme zu verhindern, reagierte der Staat mit dem Argument, daß die Banken bei der Vergabe der Kredite die Rentabilität der unternehmerischen Projekte nicht geprüft hätten und nun die Konsequenzen zu tragen hätten. ${ }^{52}$

\footnotetext{
${ }^{49}$ Cheong-Jae Lee, Chaeobol Yireokseo (Die Entwicklungsgeschichte der Chaebol), Seoul 1993, S. 234.

${ }^{50}$ Chae-Joo Lee, Busil Kiup Cheongri rul Bipanhanda (Kritik an der Säuberung von unrentablen Unternehmen), in: Sintonga, Heft Oktober (1969), S. 114.

${ }^{51}$ Duk-Jin Chang, Busil Kiup Cheongri eui Silmal (Die Säuberung von unrentablen Unternehmen), in: Sintonga, Heft Oktober (1969), S. 105.

${ }^{52}$ Chae-Joo Lee, Busil Kiup Cheongri rul Bipanhanda (Kritik an der Säuberung von unrentablen Unternehmen), in: Sintonga, Heft Oktober (1969), S. 111.
} 
Die Unternehmensprüfung hatte ergeben, daß es viele Fälle gab, wo der Unternehmer trotz fehlender Branchenkenntnisse nur aufgrund seiner engen Beziehung zu mächtigen Politikern in den Genuß der staatlichen Bürgschaft bei der Vergabe von ausländischen Kredite gekommen war, wobei er die Kredite häufig nicht für das Unternehmen, sondern zur Mehrung seines privaten Vermögens (insb. den Kauf von Grund und Boden) eingesetzt hatte. Der große, staatlich geförderte Unternehmensboom zwischen 1966 und 1968 ging lediglich darauf zurück, daß der Staat blind darauf aus war, den Export zu vermehren und daß die Unternehmer ihrerseits davon ausgingen, daß sich schon allein durch die Gründung eines Unternehmens Gewinn erzielen lasse. Denn die Inflationsrate in Korea war so hoch und der Anstieg der Bodenpreise dementsprechend so rasant, daß man durch Kaufund Wiederverkauf Grund- und Boden die hohen Kreditzinsen begleichen und sogar die Schulden tilgen konnte. Als dann der koreanische Bodenpreis durch die Stabilitätspolitik der Regierung nicht weiter stieg, erwarteten die Unternehmer, die auf dem Exportmarkt nicht erfolgreich konkurrieren konnten, eine zusätzliche finanzielle Unterstützung von den Banken bzw. dem Staat als ihrem Patron, der sie ja zur Gründung ihres Unternehmens veranlaßt hatte. Durch die neuen staatlichen Maßnahmen zur Säuberung von unrentablen Unternehmen fühlten sich diese Unternehmer nun persönlich betrogen. Sie empfanden die neue Politik als eine abrupte, durch nichts gerechtfertigte Kehrtwendung der Regierung und zogen daher deren bisherige Rolle als Patron in Zweifel. ${ }^{53}$

Weil der Staat die unrentablen Unternehmen nicht verstaatlichen wollte, bemühte er sich um neue Besitzer. Da das Interesse der koreanischen Unternehmer an der Übernahme dieser unrentablen Unternehmen verständlicherweise nicht sehr groß war, sah sich der Staat gezwungen, die Übernahme durch verschiedene Privilegien (z. B. die Reduzierung der Schulden und Begünstigung bei der Vergabe von Krediten) interessant zu machen. ${ }^{54}$ Dabei interessierte er sich nicht für die Schwierigkeiten der Banken, die das Geld für die neue Übernahme zur Verfügung stellen mußten.

\footnotetext{
${ }^{53}$ Ebenda, S. 113.

${ }^{54}$ Duk-Jin Chang, Busil Kiup Cheongri eui Silmal (Die Säuberung von unrentablen Uhternehmen), in: Sintonga, Heft Oktober (1969), S. 106.
} 
Angesichts dieser neuen Privilegien interessierten sich viele Unternehmer, deren Betriebe nicht zu den unrentablen Unternehmen gehörten, plötzlich für die Übernahme. Aber diesmal entschloß sich der Staat, die Auswahl nach strengen Leistungskriterien zu treffen. Nur die Unternehmer, die vom Präsidenten oder von seiner Gefolgschaft als erfolgreiche Unternehmer anerkannt waren, erhielten die Möglichkeit, an dem Übernahmeverfahren teilzunehmen. Die Unternehmer von unrentablen Unternehmen hatten keine Chance mehr, von den vielen staatlichen Förderungsmaßnahme für Unternehmen zu profitieren. Erfolg wurde damit die Voraussetzung für staatliche Förderung.

Obwohl die Regierung seit 1969 ihre finanziellen und rechtlichen Fördermaßnahmen für Unternehmen, vor allem Exportunternehmen, verstärkt hatte, gerieten immer mehr koreanische Unternehmen, auch Großunternehmen, in Schwierigkeiten. Ein Grund dafür war die hohe Zinsrate bei privaten Schulden. Denn Unternehmer, die sich dem Staat gegenüber als erfolgreiche Leiter eines expandierenden Unternehmen darstellen wollten, scheuten sich nicht, ihr Unternehmen auch mit hohen privaten Krediten zu finanzieren. Deshalb wandten sich die Vertreter der Großunternehmen an den Staat, mit der Bitte um eine außerordentliche Maßnahme. Sie schlugen dem Staat vor, daß die Banken die privaten Kredite übernehmen und die Zinsrate senken sollten. Als die Regierung keine klare Antwort auf diese Forderung gab, wandten sie sich an die Öffentlichkeit und forderten die sog. Halbierung des Haushalts. Dies bedeutete, daß die Unternehmer öffentlich erklärten, nicht imstande zu sein, ihren steuerlichen Verpflichtungen nachzukommen, was zur Folge gehabt hätte, daß die Regierung ihre Versprechen gegenüber ihren Wählern nicht würde einhalten können. ${ }^{55}$

${ }^{55}$ Cheong-Jae Lee, Chaeobol Yireokseo (Die Entwicklungsgeschichte der Chaebol), Seoul 1993, S. 244. 
Daraufhin gab die Regierung am 3. August 1972 plötzlich per Sondergesetzgebung bekannt, daß die Rückzahlung der privaten Kredite für drei Jahre ausgesetzt sei. Damit verloren die privaten Kreditgeber ihren Zugang zu dem Geld, das sie an die Unternehmen verliehen hatten. Gleichzeitig reduzierte der Staat die Zinsrate für private Kredite. Damit nahm der Staat wieder klar seine Rolle als schützender und fördernder Patron von Unternehmen ein, wieder beschränkt auf die erfolgreichen Großunternehmen. Denn diese waren zu mehr als der Hälfte die Schuldner privater Kreditgeber. Bei der Vergabe der neuen staatlichen Hilfeleistungen konzentrierten sich dann $74 \%$ der gesamten vergebenen Kreditsumme auf die Großunternehmen. ${ }^{56}$ Mit dieser Maßnahme überlebten viele Unternehmen, die damals schon Chaebol genannt wurden. ${ }^{57}$

Während zahlreichen Ökonomen angesichts der zunehmenden Patronalisierung des Staates die Konzentration der ökonomischen Macht auf die wenigen Großunternehmen bzw. Chaebol scharf kritisierten, ${ }^{58}$ hielten Park und seine Gefolgschaft daran fest, daß die koreanischen Großunternehmen auf dem Weltmarkt durchaus bestehen könnten. Dabei interessierten sie sich nach wie vor nicht für die Frage, ob die Konkurrenzfähigkeit der Unternehmen durch die Innovationsfähigkeit des einzelnen Unternehmers oder durch die patronalistische Intervention des Staates ermöglicht wurde, sondern nur für die jährliche Wachstums- und Exportrate und den Effekt auf die Beschäftigung - letzteres vor allem, um der Bevölkerung gegenüber einen sichtbaren Erfolg vorweisen zu können.

Die Regierung scheute sich auch nicht zu propagieren, daß der Staat durch die gezielte Förderung der Großunternehmen, zu denen an erster Stelle Samsung, Lucky-Goldstar und Hyundai gehörten, viel effektiver das Ziel des Fünfjahresplans erreichen könnte und das Volk deswegen eine Zeitlang eine gewisse Opferbereitschaft (z. B. in Bezug auf die politische Freiheit, niedrige Löhne und lange Arbeitszeiten) an den Tag legen müsse. Politischen Ausdruck fand diese Haltung in der


oul 1993, S. 93.

${ }^{57}$ Vgl. dazu oben Abschnitt II.1 (S. 7 Anm. 1) und Abschnitt II.2 (S. 9 f.).

${ }^{58}$ Zu den Kritikern gehörten z. B. die beiden Ökonomen Ki-Chun Han, Hanguk Ke-ongje eui Onul eul Chindan (Diagnose der gegenwärtigen koreanischen Ökonomie), in: Sintonga, Heft Juli (1970), S. 125, und Chong-Chul Lim, Konguphwa wa Bulpeondung 
Resolution zur Einführung eines neuen Verfassungssystems, das als "Yushin" bezeichnet wurde. ${ }^{59}$ Nach dieser 1972 eingeführten neuen Verfassung verfügte das Staatsoberhaupt allein über die absolute Macht, so daß weder Regierungsmitglieder noch das Parlament die wichtigen wirtschaftspolitischen Entscheidungen beeinflussen konnten. ${ }^{60}$ Das Staatsoberhaupt wurde nicht mehr direkt gewählt, sondern durch einen Wahlverein bestimmt. Damit war der Wahlmanipulation durch den Präsidenten Tür und Tor geöffnet. Unter der neuen Verfassung, die bis zur Ermordung von Präsident Park im Jahre 1979 in Kraft blieb, war es praktisch "verfassungswidrig", das enge Patron-Klient-Verhältnis zwischen Staat und Unternehmen als Problem der koreanischen Wirtschaft darzustellen. ${ }^{61}$

\section{V.3 Die Unternehmer als "Klientel"}

Am 11. Juni 1961 veröffentlichten die Putschisten eine Verhaftungsliste, die 30 Namen von Unternehmern enthielt, die als "illegale Kapitalakkumulatoren" bezeichnet wurden. Unter innen befanden sich auch die Byong-Chul Lee und In-Hoe Ku als die Gründerväter von Samsung und Lucky-Goldstar. Begründet wurde die Verhaftung damit, daß ein neuer Anfang in der koreanischen Wirtschaft ohne Entfernung der "illegalen Akkumulatoren" nicht möglich sei, da sie die Korruption in die koreanische Ökonomie eingeführt hätten. Die verhafteten Unternehmer wurden dazu gezwungen, ihre Schuld anzuerkennen und ihr gesamtes Vermögen freiwillig an den Staat abzugeben. Innerhalb der Putschisten gab es sogar die Auffassung,

Simhwa (Industrialisierung und Verschärfung der ökonomischen Ungleichheit), in: Stonga, Heft Juli (1970), S. 132.

${ }^{59} \mathrm{Jae}-\mathrm{Jin}$ Suh, Hanguk Chabonga Kaegup (Die koreanische Kapitalistenklasse), Seoul 1991, S. 95, vermutet eher, daß umgekehrt die Einführung des neuen diktatorischen Verfassungssystem das Regime von Park dazu veranlaßte, die Legitimität dieser politischen Entscheidung durch ökonomische Erfolge unter Beweis zu stellen.

${ }^{60}$ Was ich hierbei sehr eigenartig finde, ist die Tatsache, daß die Autobiographien von ehemaligen Regierungsbeamten wie Cheong-Reom Kim (Hanguk Keongje CheongChaek 30 Yeonsa, Seoul 1995) und Won-Chul Oh (Hangukheong Keongje Keonsul, Bd. 1-4, Seoul 1995) diesen politischen Einschnitt mit keinem Wort erwähnen.

${ }^{61}$ Wer die Wirtschaftspolitik der Regierung kritisierte, wurde sofort als Sympathisant des kommunistischen Nordkoreas verdächtigt. 
daß eine öffentliche Hinrichtung einiger Unternehmer als Symbol für die Ernsthaftigkeit der Revolution zelebriert werden sollte. ${ }^{62}$

Zweck der Verhaftung der führenden koreanischen Unternehmer war, die Unternehmen zu enteignen und anschließend die früheren Eigentümer als Verwalter dieser Unternehmen einzusetzen. Diese Verwalter wurden dann gezwungen, ein gewisses Strafgeld zu entrichten. Wenn dies erfolgt war, gab der Staat den Enteigneten die Eigentumsrechte zurück und schickte zugleich eine staatliche Aufsichtsperson in das Unternehmen.

Das Verhältnis zwischen den Putschisten und den koreanischen Unternehmern war also anfänglich keineswegs von der vertrauensvollen, sich gegenseitig fördernden Zusammenarbeit geprägt, wie es sich später in dem oben beschriebenen Patron-Klient-Verhältnis zeigte. Es ist daher zu fragen, wie sich dieser abrupte Wandlungsprozeß erklären läßt. Woran lag es, daß sich die Beziehung zwischen Putschisten und Unternehmern so schnell änderte?

In erster Linie ist dieser Wandel natürlich mit der anfänglichen Konzeptlosigkeit der Putschisten zu erklären, die im Zeichen des Antikommunismus zwar den ökonomischen Aufschwung proklamiert hatten, aber keinerlei Vorstellungen davon besaßen, wie dieser zu verwirklichen sei. Erst nachdem man die führenden Unternehmer als "illegale Akkumulatoren" ins Gefängnis gebracht hatte, stellte man offenbar fest, daß man, wenn man nicht ein staatssozialistisches System errichten wollte, für den ökonomischen Aufschwung auf deren Unterstützung angewiesen war.

Konkret läßt sich dieser Wandel daran festmachen, daß Byong-Chul Lee, der Gründer von Samsung, der seiner Verhaftung zunächst entgangen war, da er sich wie im vorigen Kapitel schon berichtet - zu der fraglichen Zeit in Japan aufhielt, bei seiner Rückkehr nach Korea nicht inhaftiert wurde. Der Autobiographie von Lees ältestem Sohn, Mang-Hee Lee, kann man entnehmen, daß während Lees Aufenthalt in Japan zwischen ihm und einem Abgesandten der Putschisten ein geheimes Treffen stattgefunden hatte, in dem die Putschisten Lee die Aufhebung des Haft-

${ }^{62}$ Jin-Heon Kim, Bucheong Chukchae Cheori Simalseo (Bericht über die Behandlung der illegalen Akkumulatoren), in: Sintonga, Heft November (1964), S. 170. 
befehls zugesichert hatten. ${ }^{63}$ Erst daraufhin hatte sich Lee zur Rückkehr entschlossen und traf schon einen Tag nach seiner Ankunft in Korea mit dem Führer des Militärputsches, General Park, zu einem Gespräch zusammen.

Lees Autobiographie zufolge schlug er in diesem Gespräch Park vor, die Unternehmer aus der Haft zu entlassen und zu Trägern des wirtschaftlichen Fünfjahresplans zu machen. ${ }^{64}$ Obwohl sich Park Sorgen darüber machte, wie die Bevölkerung auf die plötzliche Zusammenarbeit der Regierung mit den bereits verurteilten Unternehmern reagieren würde, folgte er Lees Vorschlag. Aus diesem ersten Gespräch entwickelte sich eine langjährige gute Zusammenarbeit zwischen Park und Lee. Bei einem zweiten Treffen forderte Lee Park auf, das Strafgeld, das den verhafteten Unternehmern auferlegt worden war, nicht als Bargeld, sondern in Form von Aktien der neu gegründeten Unternehmen zahlen zu lassen. Park setzte in dem Komitee für den Wiederaufbau des Staates durch, daß diese Idee in Form eines Investitionsbefehls an die Unternehmer umgesetzt wurde. Dafür forderte die Militärregierung, daß Lee einen Unternehmerverband gründete, dessen Aufgabe darin bestand, die Meinungen der Unternehmer den neuen militärischen Führungskräften zu vermitteln. Lee übernahm den Posten des ersten Vorsitzenden. ${ }^{65}$

Am meisten profitierten paradoxerweise ausgerechnet die als "illegale Akkumulatoren" verurteilten Unternehmer von der neuen Beziehung zwischen den Putschisten und den Unternehmern, da sie sich wegen der Begleichung des Strafgeldes an der Gründung von neuen, im ersten Fünfjahresplan aufgeführten Unternehmen beteiligen konnten. ${ }^{66}$ Der Höhepunkt dieser neuen Beziehung war die Zusage des Staates, eine spezielle Industrieregion (vergleichbar etwa dem Ruhrgebiet in Deutschland) zu entwickeln, um damit den ausländischen Gläubigern die staatliche

\footnotetext{
${ }^{63}$ Maeng-Hee Lee, Mudedun Yiyagi (Die unbekannte Geschichte), Seoul 1993, S. 22. ${ }^{64}$ Byong-Chul Lee, Hoam Chacheon (Hoams Autobiographie), Seoul 1985, S. 114. ${ }^{65}$ Duk-Yul Hong, Hanguk eui Dae Chabonga Chojik Yeongu (Studie über den Verband der koreanischen Großunternehmer), in: Hanguk Sahoesa Yeonguhoe, Hanguk Chabonjueui wa Chaebol (Der koreanische Kapitalismus und die Chaebol), Seoul 1992, S. 64.

${ }^{66}$ Jin-Heon Kim, Bucheong Chukchae Cheori Simalseo (Bericht über die Behandlung der illegalen Akkumulatoren), in: Sintonga, Heft November (1964), S. 174.
} 
Bereitschaft zur Förderung von Unternehmen unter Beweis zu stellen. Dies ging auf einen Vorschlag von Lees Unternehmerverband zurück. ${ }^{67}$

Obwohl der Staat immer häufiger seine schützende Hand über die Unternehmer hielt, bedeutete dies nicht, daß sich die Unternehmer als Klienten der neuen Führungsgruppe sicher fühlen konnten. Daran hinderte sie nicht nur die Erinnerung daran, daß sie von den Putschisten anfänglich wie Schwerverbrecher behandelt worden waren, sondern auch die Tatsache, daß sich die Putschisten weniger für gegenseitige Interessensvernetzung als für ihre eigene übergeordnete Rolle interessierten. Weil unternehmerische Aktivitäten aber ohne die schützende Rolle des Staates in Korea kaum auszuführen waren, nutzten die Putschisten ihre Position dazu, je nach Art der Gegenleistung bzw. der eigenen politischen Interessenlage inre Unternehmer-Klientel zu wechseln. Insofern war die Patron-Klient-Beziehung für die Unternehmer keine feste Konstante, sondern ein riskanter Seiltanz. Um unternehmerisch erfolgreich tätig zu sein, reichte es nicht mehr aus, über genügend Kapital und/oder unternehmerisches Know-how zu verfügen. Von nun an gehörte die Fähigkeit, sich als guter Klient zu erweisen, zum wichtigsten Erfolgsfaktor für den Unternehmer.

Um diese koreaspezifische instabile Patron-Klientel-Beziehung zu veranschaulichen, halte ich es für sinnvoll, im einzelnen nachzuzeichnen, mit welcher Strategie die drei Gründerväter der koreanischen Chaebol, In-Hoe Ku, Byong-Chul Lee und Joo-Young Cheong eine erfolgreiche Klientenbeziehung zum Staat aufbauen und aufrechterhalten konnten:

In-Hoe Ku: Als die Putschisten am 22. Mai 1961 die Liste der "illegalen Akkumulatoren" bekannt gaben, fand Ku auch seinen Namen darauf. Während In-Hoe sich der Verhaftung durch Fluchtort entziehen konnte, wurde sein jüngerer Bruder und Geschäftspartner, Peong-Hoe, am 2. November 1961 verhaftet. Die Anklage lautete auf "antirevolutionäre Handlung". ${ }^{68}$ Doch wurde er am 15. Februar 1962 ohne Urteil wieder freigelassen. Da das Komitee für den Wiederaufbau des

\footnotetext{
${ }^{67}$ Chang-Rae Park, Ulsan Kongup Center (Ulsan-Industrie-Zentrum), in: Sintonga, Heft November (1967), S. 175.
} 
Staates beschlossen hatte, die als "illegale Akkumulatoren" bezeichneten Unternehmer an der Gründung der im ersten Fünfjahresplan festgehaltenen fünf Kernindustriesektoren zu beteiligen, verfügte Ku von nun an über die Möglichkeit, sich ein neues Unternehmensfeld auszusuchen. Das Strafgeld wurde ihm - wie oben schon gesagt - erlassen, wenn er dem Staat Aktien des neuen Unternehmens überließ. Ku beantragte bei der Regierung, im Rahmen des ersten Fünfjahresplans ein Unternehmen zur Produktion von chemischen Fasern und ein zweites zur Herstellung elektronischer Apparate errichten zu dürfen. ${ }^{69}$

Nach erteilter Genehmigung reiste er zusammen mit Peong-Hoe nach Deutschland, um einen Kredit für die Gründung des chemischen Unternehmens zu bekommen. Doch nachdem die Kreditverhandlungen erfolgreich abgeschlossen waren, erhielt Ku aus Korea eine Nachricht, daß es sich die Regierung bei der Vergabe der unternehmerischen Beschäftigungsfelder anders überlegt hätte und Ku nun statt eines chemischen Unternehmens eine Kabelfirma gründen sollte. Obwohl Kus Verhandlungen mit den deutschen Kreditgebern ohne die Abgabe einer staatlichen Bürgschaft erfolgt waren, akzeptierte Ku ohne Widerspruch die Entscheidung der Militärregierung. Nach erneuten Verhandlungen bekam er von den deutschen Kreditgebern das benötigte Kapital für die Gründung des Kabelunternehmens. ${ }^{70}$

Trotz der staatlichen Zusage geriet Kus Vorhaben jedoch in eine Sackgasse, als die schon existierenden koreanischen Kabelhersteller diese Entscheidung der Regierung mit dem Argument rückgängig zu machen versuchten, daß der koreanische Kabelmarkt längst gesättigt sei und die Gründung eines neuen Kabelunternehmens eine unnötige Verschwendung von Devisen sei. Der wahre Grund war jedoch, daß die neue Fabrik mit aus Deutschland importierten modernsten Industrieanlagen ausgerüstet war, so daß zu befürchten war, daß diese sehr schnell große Marktanteile der schon vorhandenen Kabelunternehmen übernehmen und wahrscheinlich auf dem kleinen koreanischen Binnenmarkt bald eine Monopolstellung einnehmen werde. Doch Teile der Regierung, die sich über dieser Aus-

\footnotetext{
${ }^{68}$ Lucky-Goldstar (Hrsg.), Hanbeon Midemyeon Modu Matkeora (Wenn du anfängst, jemandem einmal zu glauben, dann sollst du bereit sein, ihm alles anvertrauen zu können), Seoul 1993, S. 233.

${ }^{69}$ Ebenda, S. 229.
} 
einandersetzung spaltete, argumentierten, daß sich die schon bestehenden Unternehmen ohne neuen Konkurrenten nicht um die Verbesserung ihrer Konkurrenzfähigkeit bemühen würden. Letztlich führte diese Kontroverse zwar zu einer Verzögerung bei der Gründung des neuen Kabelunternehmens, das Ku aber dennoch ausdrücklich belobigt durch Präsident Park - 1966 einweihen konnte. ${ }^{71}$

Obwohl Ku Präsident Park vor dem Militärputsch nicht persönlich kannte, führten die politischen Umstände nach dem 16. Mai 1961 dazu, daß Ku bald ohne große Anstrengung zum engeren Kreis von Park gehörte. Als das Komitee für den Wiederaufbau des Staates mit dem Verhör der verhafteten Unternehmer begann, zeigte sich, daß sich manche der für die Untersuchung zuständigen Offiziere aufgrund ihrer gemeinsamen regionalen oder sozialen Herkunft mit diesen solidarisierten und für eine milde Strafe plädierten. Damals wurde das Militär vor allem von den Leuten, die aus dem kommunistischen Nordkorea geflüchtet waren, beherrscht, und unter den sogenannten illegalen Akkumulatoren befanden sich ebenfalls viele Nordkoreaner. ${ }^{72}$ Als die Offiziere, die aus dem Süden kamen, von dieser Bevorzugung erfuhren, nahmen sie ihrerseits für die Unternehmer aus dem Süden Partei. Da aber Park und sein engster Mitarbeiter und Verwandter, JongPil Kim, aus dem Süden stammten, endeten diese internen Konflikte der Putschisten mit einem Sieg des Südens. Ku stammte wie auch Byong-Chul Lee aus dem Süden und gehörte damit zu quasi automatisch zu den von Präsident Park Protektionierten.

Um sein Interesse an der koreanischen Industrie in der Öffentlichkeit zu demonstrieren, pflegte Präsident Park unangemeldet Industrieanlagen zu besichtigen. Für den einzelnen Unternehmer war eine solche Besichtigung durch Park eine große Chance, für sein Unternehmen zu werben und gleichzeitig seine Beschwerden über die Regierung dem Präsidenten persönlich mitzuteilen. Eines Tages machte Park auch einen Besuch in Kus Elektrounternehmen Goldstar, in dem man damals mit importierten ausländischen Teilen Radios montierte. Auf Parks Frage, was der Staat für die Entwicklung der Elektroindustrie tun könnte, erfuhr er, daß

\footnotetext{
${ }^{70}$ Ebenda, S. 230.

${ }^{71}$ Ebenda, S. 232.

${ }^{72} \mathrm{Jin}-\mathrm{Heon}$ Kim, Bucheong Chukchae Cheori Simalseo (Bericht über die Behandlung der illegalen Akkumulatoren), in: Sintonga, Heft November (1964), S. 171.
} 
die aus dem Ausland geschmuggelten Radios ein großes Problem für das Unternehmen seien. ${ }^{73} \mathrm{Ku}$ hatte schon die vorherige Regierung Chang mehrmals erfolglos gebeten, die staatliche Kontrolle von Schmuggelwaren zu verstärken. Doch mit Parks Besuch änderte sich tatsächlich etwas, so daß man auf dem koreanischen Markt bald kaum noch geschmuggelte Radios finden konnte. Daraufhin verwandelte sich das Elektrounternehmen Goldstar, das bisher nur Verluste gemacht hatte, und von anderen erfolgreichen Unternehmen Kus finanziell gestützt werden mußte, fast umgehend in ein gewinnbringendes Unternehmen.

Ein entscheidender Faktor für Kus Erfolg war die Tatsache, daß er eine persönliche Beziehung zu dem neuen Minister für Öffentlichkeit, Won-U Lee, hatte. Won-U Lee war früher Professor gewesen und nach dem Miliärputsch in die Regierung geholt worden. Er hatte mit Peong-Hoe Ku und dessen Freund Sung-Chan Park, den - wie im vorherigen Kapitel geschildert - eine ganz besondere Vertrauensbeziehung mit In-Hoe Ku verband, an der Seoul National Universität studiert. Aufgrund dieser quasi-familiären Beziehung zu Sung-Chan Park, ${ }^{74}$ konnte In-Hoe Ku direkten Kontakt zu Lee aufnehmen. Als Ku anläßlich eines Besuches im Ministerium die Leistungen der neuen Militärregierung lobte, wandte Lee ein, daß es ein großes Problem sei, daß ausgerechnet die ländliche Bevölkerung über keine Möglichkeit verfüge, von diesen Leistungen zu erfahren. ${ }^{75}$ Damals war die Zeitung das einzige Medium, durch das man von der Arbeit der Regierung erfahren konnte, aber die meisten Bauern konnten sich die Zeitungen nicht nur finanziell nicht leisten, sondern auch nicht lesen, da sie Analphabeten waren. Ku schlug deshalb vor, die Regierung solle eine Spendenaktion organisieren, mit dem Ziel, der armen ländlichen Bevölkerung Radios zu schicken. Diese Aktion wurde sofort genehmigt, und Ku machte daraufhin so große Gewinne, daß er zum führenden Elektrounternehmer in Korea aufstieg.

\footnotetext{
${ }^{73}$ Lucky-Goldstar (Hrsg.), Hanbeon Midemyeon Modu Matkeora (Wenn du anfängst, jemandem einmal zu glauben, dann sollst du bereit sein, ihm alles anvertrauen zu können), Seoul 1993, S. 226.

${ }^{74}$ Vgl. dazu die Ausführungen im vorigen Kapitel, bes. Abschnitt IV.6 (S. 155 f.).

${ }^{75}$ Lucky-Goldstar (Hrsg.), Hanbeon Midemyeon Modu Matkeora (Wenn du anfängst, jemandem einmal zu glauben, dann sollst du bereit sein, ihm alles anvertrauen zu können), Seoul 1993, S. 227.
} 
Ebenfalls entscheidend für Kus Erfolg war die politische Tätigkeit seines Bruders Tae-Hoe Ku, der als Verbindungsmann Kus Klientenbeziehung zu Park festigen konnte. Tae-Hoe Ku, der unter Präsident Rhee Abgeordneter der Regierungspartei gewesen war, war nach dem Militärputsch zunächst zur Aufgabe seiner politischen Arbeit gezwungen worden. Doch als die Putschisten 1964 eine neue Partei gründeten, wurde er ein führendes Mitglied dieser "Konghwa Dang" genannten Partei. Park war Vorsitzender dieser Partei, deshalb kann man auch die Beziehung zwischen Tae-Hoe Ku und Park als ein Patron-Klient-Verhältnis bezeichnen. Die Folge davon war, daß sich auch zwischen Park und In-Hoe Ku ein persönliches Patron-Klient-Verhältnis entwickelte, daß so eng war, daß Park Ku respektvoll als seinen "Seon-Bae" (älteren Kollegen) bezeichnete. ${ }^{76}$

Kus Fähigkeit, seine Klientenbeziehung zum Staat erfolgreich aufrechtzuerhalten, beruhte nicht allein auf der Solidarität seines Bruders Tae-Hoe, der im Parlament den Finanzausschuß leitete, sondern auch auf seiner geschickten Personalpolitik: Er bemühte sich erfolgreich um die Abwerbung ehemaliger hoher Beamter als Vorstandsmitglieder für seine Unternehmen. Als er sich im Jahr 1965 entschloß, ein Petroleum-Unternehmen zu gründen, war ihm klar, daß es sich hier um eine heikle unternehmerische Angelegenheit handelte, denn der Staat hatte in seinem ersten Fünfjahresplan bestimmt, daß Energieunternehmen nur vom Staat betrieben werden dürften. Doch da die staatliche Raffinerie in Ulsan die zunehmende Nachfrage nach Öl nicht befriedigen konnte, waren Ku und seine Mitarbeiter fest davon überzeugt, daß der Staat die Beteiligung privater Unternehmer an der Raffinerie-Industrie auf Dauer nicht verhindern könne. Tatsächlich erreichte Ku die entsprechende offizielle staatliche Meinungsänderung im Ministerium für Wirtschaftsplanung schließlich durch seine unermüdliche Überzeugungsarbeit. ${ }^{77} \mathrm{Zu}$ Unterstützung seiner Lobbyarbeit hatte er zugleich einen ehemaligen Staatssekretär des Ministeriums, der ein ehemaliger Hochschulkollege von Park war, als Direktor dieses neuen Unternehmens eingestellt. ${ }^{78}$ Zwar schrieb der Staat im Mai 1966 die Beteiligung an der Gründung der Raffinerie öffentlich aus, doch Ku nutzte ge-

\footnotetext{
${ }^{76}$ Ebenda, S. 378.

${ }^{77}$ Ebenda, S. $334 \mathrm{f}$.

${ }^{78}$ Won-Chul Oh, Hangukheong Keongje Keonsul (Das koreanische Entwicklungsmodell), Seoul 1995, Bd. 3, S. 349.
} 
schickt sein persönliches Patron-Klienten-Verhältnis zu Park, indem er bekanntgab, daß seine neue Raffinerie in der Region von Honam, im südwestlichen Korea, errichtet werde. Entsprechend nannte er seine neue Firma auch "HonamRaffinerie". Diese Entscheidung aber kam Präsident Park deshalb sehr entgegen, weil er seit seiner Machtübernahme 1961 dem Vorwurf ausgesetzt war, daß seine gesamten wirtschaftspolitischen Aktivitäten nur der südöstlichen Region Youngnam, seiner Heimatregion, galten. Wenn Park nun Kus Plan genehmigte, war dies ein wichtiger Beweis dafür, daß dieser Vorwurf unberechtigt war. Nachdem Ku von der Regierung daraufhin den Zuschlag zur Gründung einer Raffinierie erhalten hatte, rückte er mit seinem Unternehmen in die Gruppe der Spitzen-Chaebol neben Samsung auf.

Im großen und ganzen läßt die Strategie, mit der Ku seine Klientenbeziehung zu Präsident Park bzw. zum Staat verbesserte, inn als den Typus des "aktiven Anpassers" erkennen. Obwohl seine enge Beziehung zum Staat niemals in einen "politischen Skandal" mündete, ist unverkennbar, daß er durch seine blinde Gefolgschaft bzw. seine kritiklose Haltung gegenüber der Wirtschaftspolitik von Park niemals seine untergeordnete Rolle als Unternehmer in Frage stellte. Ku starb im Jahr 1969 an Krebs. Danach wurde die Aufgabe, die Klienten-Beziehung zum Präsidenten weiterhin erfolgreich zu pflegen, von seinem Mitarbeiter und Vertrauten Sung-Chan Park übernommen. Sung-Chang Park war der Bruder von SungYeop Park, der als Gründer des ersten staatlichen Elektrounternehmens großes Vertrauen bei Präsident Park genoß, das dieser nun auch auf dessen Bruder übertrug. ${ }^{79}$

Byong-Chul Lee: Lee war - wie oben schon geschildert - der einzige Unternehmer, der trotz Anklage von den Putschisten nicht inhaftiert worden war und an seiner Sonderstellung änderte sich für inn auch dadurch nichts, daß er seine Bankaktien dem Staat übergeben mußte und wie alle anderen "illegalen Akkumulatoren" auch verpflichtet war, sein Strafgeld in Form einer Unternehmensgründung zurückzuzahlen. Er war der bedeutendste koreanische Unternehmer und übte als Vorsitzender des Verbandes der koreanischen Großunternehmer eine wichtige Funktion

${ }^{79}$ Ebenda, S. 324. 
als Vermittler zwischen Putschisten und Unternehmern aus. Viele Vorschläge von Lee, der fast wie ein persönlicher Berater von Präsident Park agierte, akzeptierten die Putschisten unbesehen und ohne jeden Einwand. ${ }^{80}$

Wie eng die Beziehung zwischen ihm und dem Führer des Militärputsches Park war, zeigt der folgende in seiner Autobiographie beschriebene Vorfall: Nachdem die Militärregierung am 9. Juni 1962 die schon erwähnte Währungsreform, durch die das in den privaten Haushalten gesparte Geld in Industriekapitel umgewandelt werden sollte, bekanntgegeben hatte, erfragte Park Lees Meinung dazu. Lee überzeugte Park, daß dieses Vorhaben ein großer Fehler der neuen Regierung sei, der bei der Bevölkerung nur Ratlosigkeit über den Kurs der Regierung erzeuge, und erreichte von Park die Zusage, künftig wichtige wirtschaftliche Entscheidungen erst nach der Konsultierung des Unternehmerverbandes zu treffen. ${ }^{81}$

Es verwundert daher nicht, daß Lee als Vorsitzender des Unternehmerverbandes von Park auch beauftragt wurde, zu entscheiden, welcher Unternehmer welches im Rahmen des ersten Fünfjahresplanes zu vergebene Projekt bekommen sollte. Lee konnte sich deshalb sein eigenes Wunschprojekt selbst auszusuchen. Er entschied sich für die von ihm schon vor dem Putsch noch mit Unterstützung von Präsident Rhee relativ weit vorangetriebene Gründung einer chemischen Düngemittelfabrik, deren Größe und Produktionsumfang allerdings wesentlich größer als ursprünglich geplant war und die deshalb als Gemeinschaftsprojekt mit anderen Unternehmern realisiert werden sollte. ${ }^{82}$

Für Lee war die staatliche Billigung seiner Beteiligung an der Gründung der Düngemittelfirma insofern ein wichtiger unternehmerischer Erfolg, als er damit über einen sehr großen Absatzmarkt in Korea verfügt hätte. Denn - wie im vorigen Kapitel schon erwähnt - litt die koreanische Landwirtschaft im Süden seit dem Ende der japanischen Kolonialzeit und der Abtrennung von Nordkorea unter einem Mangel an Düngemitteln. Doch Lee scheiterte an den Einwänden des amerikanischen Hilfsfonds, da kurz vor dem Militärputsch bereits ein amerikanisches Düngemittelunternehmens - zu für Korea allerdings sehr ungünstigen Vertragsbedin-

\footnotetext{
${ }^{80}$ Maeng-Hee Lee, Mudedun Yiyagi (Die unbekannte Geschichte), Seoul 1993, S. 126.

${ }^{81}$ Byong-Chul Lee, Hoam Chacheon (Hoams Autobiographie), Seoul 1985, S. 129.
} 
gungen - gegründet worden war. Die Amerikaner befürchteten, daß ein neues Düngemittelunternehmen zu einer Überproduktion und damit zur Beendigung ihres bisherigen Monopols führen würde. ${ }^{83}$ Lee mußte deshalb seinen Plan aufgeben und zahlte 1963 das verlangte Strafgeld.

Dennoch gelang es Lee zwischen 1961 und 1963 weiter zu expandieren. Er übernahm nicht nur verschiedene Versicherungsgesellschaften, sondern wurde auch Gründer des ersten privaten Rundfunks in Korea. Diese beiden Branchen werden traditionell staatlich kontrolliert, doch aufgrund seiner Vertrauensstellung zu Park war Lee von dieser Kontrolle weitgehend ausgenommen. ${ }^{84}$

1964 entschloß sich Lee dann, einen neuen Versuch zur Durchsetzung der Gründung eines Düngemittelunternehmens zu unternehmen. Er traf mit Präsident Park eine geheime Abmachung, die vorsah, daß Park dem Unternehmen mit all seiner politischen Macht behilflich sein sollte. Damit meinte Lee nicht nur die Übernahme der staatlichen Bürgschaft bei ausländischen Krediten, sondern vor allem den Verzicht auf politische Spendengelder, die Park bei den Unternehmen einzutreiben pflegte. Gleichzeitig forderte Lee, daß der Staat inm bei der Auswahl der ausländischen Kreditgeber freie Hand lassen sollte. Damals benötigte Park das neue Düngemittelunternehmen für seinen nächsten Wahlkampf, deshalb ging er auf Lees Forderungen ein. Won-Chul Oh, ein ehemaliger Mitarbeiter des Handels- und Industrieministeriums, weist in seinen Erinnerungen darauf hin, daß Lee darüber hinaus auch seine Beziehung zum neu gewählten Minister im Planungsministerium, Ki-Young Chang, geschickt für seine Pläne genutzt habe. ${ }^{85}$

Diesmal bekam Lee das benötigte Kapital für die Gründung seines neuen Unternehmens problemlos von den Japanern. Denn für die Wiederaufnahme der diplomatischen Beziehungen zwischen Korea und Japan hatte die Regierung Park von der japanischen Regierung günstige Kredite für die industrielle Entwicklung in

\footnotetext{
${ }^{82}$ Myo-Min Lim, 5.16 ihu eui Chaegae Kapeon (Die unternehmerische Entwicklung nach dem 16. Mai), in: Sintonga, Heft Mai (1968), S. 221. Vgl. auch oben Abschnitt IV.5 (S. $149 \mathrm{f}$.).

${ }^{83}$ Won-Chul Oh, Hangukheong Keongje Keonsul (Das koreanische Entwicklungsmodell), Seoul 1995, Bd. 1, S. 169.

${ }^{84}$ Sang-Hun Choe, Der Stellenwert der Mischkonzere (Chaebol) im koreanischen Industrailiserungsprozeß, Hamburg 1994, S. 100, S. 110.

${ }^{85}$ Won-Chul Oh, Hangukheong Keongje Keonsul (Das koreanische Entwicklungsmodell), Seoul 1995, Bd. 1, S. 190 f.
} 
Korea verlangt. Weil Präsident Park und der Minister im Planungsbüro Chang bei allen Regierungsstellen zügige Unterstützung von Lees Plänen angeordnet hatten, wurde Lees Vorhaben so behandelt, als ob es sich hier nicht um ein privates Unternehmen, sondern um eine staatliche Angelegenheit handelte. ${ }^{86}$

Die Beziehung zwischen Lee auf der einen und Park und Chang auf der anderen Seite schien durch Nichts zu trüben zu sein. Immer, wenn er staatliche Hilfe benötigte, wandte sich Lee an Chang und Park, so auch bei dem Problem des Geldtransfers: Als das japanische Unternehmen Mitsui, das von Lee den Auftrag zur Lieferung der gesamten technischen Anlagen einschließlich des dazugehörigen Know-hows bekommen hatte, als Gegenleistung für den geschlossenen Vertrag einen Teil der benötigten Kreditsumme zur Verfügung stellen wollte, konnte Lee dieses Geld ohne staatliche Hilfe nicht ins Land bringen. Als Park von der Sache erfuhr, schlug der öffentlich als unerbittlicher Kämpfer gegen den Schmuggel auftretende Präsident vor, dieses Geld in Schmuggelwaren zu verwandeln und auf diese Weise durch den Verkauf dieser Waren auf dem Schwarzmarkt in Korea dreifache Gewinne zu erzielen. Ein Drittel dieses Geldes sollte Park von Lee als politische Spende erhalten, ein anderes Drittel für die noch fehlenden Baukosten und das letzte Drittel für Betriebskosten verwendet werden. ${ }^{87}$

Doch durch eine politische Intrige wurde die Schmuggeltätigkeit Lees im Sommer 1966 öffentlich bekannt. Für die Öffentlichkeit war dieses Ereignis ein unwiderlegbarer Beweis für den typischen Charakter der koreanischen ChaebolUnternehmer, die sich als "illegale Akkumulatoren" ausschließlich für die Ansammlung von Geld interessierten. Obwohl die Regierung diesen Vorfall mit dem Zugeständnis, Lee ein Strafgeld aufzuerlegen, herunterzuspielen versuchte, entwickelte sich die öffentliche Meinung (vor allem durch die Zeitungen) in immer negativere Richtung. Lee selbst war der Eigentümer einer Zeitung und einer Rundfunkanstalt, aber auch inm gelang es nicht, die Wut in der Bevölkerung zu besänftigen. Er versuchte es sogar mit der Behauptung, daß die Waren, die sich als Schmuggelwaren entpuppt hatten, in Wirklichkeit chemische Rohstoffe für Düngemittel seien. Dabei glaubte er fest daran, daß Park als Teilhaber und Initiator die-

\footnotetext{
${ }^{86}$ Ebenda.

${ }^{87}$ Maeng-Hee Lee, Mudedun Yiyagi (Die unbekannte Geschichte), Seoul 1993, S. 137.
} 
ses Schmuggelplans inn nicht fallen lassen würde. Doch Park war nur noch der Präsident, der sein Amt auf keinen Fall verlieren wollte, und so ordnete er eine schonungslose Untersuchung dieses Vorfalls an. Auf diese Weise verwandelte sich von einem bevorzugten Schützling in einen untergeordneten Abhängigen, der die erniedrigenden Forderungen des Präsidenten-Patrons (vor allem die nach politischen Spendengeldern) nur noch gehorsam erfüllen konnte. Um die Öffentlichkeit zu befrieden, bot Lee als eine Art der Wiedergutmachung sogar von sich aus an, sein eigenes Aktienpaket an diesem neuen Unternehmen dem Staat zu übergeben. Aber der Staat bzw. Park beanspruchten das ganze Unternehmen als staatliches Eigentum. ${ }^{88}$ Damit war endgültig klar, daß der Staat nicht mehr bereit war, Lee zu schützen: Die wechselseitige Beziehung zwischen Patron und Klient löste sich auf.

Nach dieser Niederlage entschloß sich Lee, sein Amt als Präsident seines gesamten Unternehmens aufzugeben. Sein Nachfolger wurde sein ältester Sohn, der mit Parks engerer militärischer Gefolgschaft wegen ihrer gemeinsamen regionalen und schulischen Herkunft ein neues Patron-Klient-Verhältnis aufbauen konnte. $\mathrm{Da}$ diese Strategie erfolgreich war, zeigte sich darin, daß der Staat 1969 trotz der Widerstände schon bestehender Unternehmen aus der Elektrobranche (vor allem Lucky-Goldstar) die Beteiligung von Samsung an der Elektroindustrie genehmigte, obwohl das Unternehmen keinerlei Erfahrung in diesem Bereich hatte. ${ }^{89}$

Obwohl Lee seit seinem Rücktritt als Leiter seiner Unternehmen offiziell nichts mehr mit Park zu tun hatte, versuchte er weiter, die patronalistische Rolle des Staates zugunsten seiner unternehmerischen Interessen auszunutzen. Weil er keinen unmittelbaren Zugang mehr zum Präsidenten hatte, richtete er in seinem Unternehmen ein "Sekretariat" (Biseosil) ein, dessen Hauptaufgabe darin bestand, Informationen über das Regierungslager zu sammeln. ${ }^{90}$ Ohne diese Informationen über die neuen wirtschaftspolitischen Richtlinien wäre es kaum möglich gewesen, sich als Unternehmer für ein neues Unternehmensfeld zu entscheiden. Obwohl so-

\footnotetext{
${ }^{88}$ Heong-Sun Mun, Hanbi Heonaphu uei Samsung-Chaebol (Das Samsung-Chaebol nach der Übergabe des Düngemittelunternehmens), in: Sintonga, Heft Dezember (1967), S. 97.

${ }^{89}$ Keong-Nam Lee, Kumsung dae Samsung (Kumsung[=Lucky-Goldstar] vs. Samsung), in: Sintonga, Heft Oktober (1969), S. 252.

${ }^{90}$ Maeng-Hee Lee, Mudedun Yiyagi (Die unbekannte Geschichte), Seoul 1993, S. 159. 
wohl in Lees Autobiographie als auch in der seines ältesten Sohnes versucht wird, den Eindruck zu erwecken, als ob ihr plötzlicher Einstieg in die Elektroindustrie aus rein ökonomischer Überlegungen erfolgt sei, halte ich es nicht für einen Zufall, daß Lees Entscheidung für diese Investition erst nach der Bekanntgabe der staatlichen Förderung der Elektroindustrie erfolgte. ${ }^{91}$

Die Art und Weise, in der Lee seine Patron-Klienten-Beziehung zum Staat aufbaute und pflegte, läßt inn als Typus des "widerwilligen Anpassers" erkennen. Weil er die untergeordnete Rolle des Klienten gegenüber dem ehemaligen General Park nicht akzeptieren konnte, glaubte er, den Staat als seinen verlängerten Arm für seine unternehmerischen Zwecke nutzen zu können. Dabei scheute er sich auch nicht, das Risiko eines öffentlichen Skandals einzugehen. Als sein Vorgehen seinem staatlichen Patron gefährlich wurde, fügte er sich in die Rolle des "normalen" Klienten, indem er nicht länger den Anspruch erhob, gleichberechtigter Partner des Patrons zu sein. Damit hatte Lee, der diese Strategie auch nach dem Tode Parks im Jahre 1979 weiter verfolgte, letztendlich Erfolg, so daß er trotz seiner gestörten persönlichen Beziehung zu Park die patronalistische Rolle des Staates zugunsten seines Unternehmens weiter nutzen konnte.

Joo-Young Cheong: Als die Putschisten die Liste der "illegalen Akkumulatoren" veröffentlichten, fand Joo-Young Cheong seinen Namen nicht darauf, ${ }^{92}$ was Cheong in seiner Autobiographie später damit erklärte, daß seine Beziehung zu den vorherigen beiden Regierungen nicht so eng gewesen sei wie die der anderen Gründerväter der Chaebol. Als Beleg dafür führt er an, daß sein Antrag auf Gründung eines Zementunternehmens immer abgelehnt worden sei. ${ }^{93}$ Als der interne Machtkampf der Putschisten mit dem Sieg der aus dem Süden stammenden Offiziere endete, geriet Cheong mit seinen Mitarbeitern in eine schwierige Situation, weil er aus dem Norden stammte. Man verdächtigte inn der "Unterstützung der antirevolutionären Kräfte". Selbst kein Absolvent einer Eliteuniversität, fehlte ihm

\footnotetext{
${ }^{91}$ Keong-Nam Lee, Kumsung dae Samsung (Kumsumg [= Lucky-Goldstar] vs. Samsung), in: Sintonga, Heft Oktober (1969), S. 246 ff.

${ }^{92}$ Auf der Liste standen nur die Namen der Unternehmer, die sofort verhaftet werden sollten.

${ }^{93}$ Joo-Young Cheong, I Tange Taenaseo (Geboren in diesem Lande), Seoul 1998, S. 95.
} 
die Möglichkeit einen persönlichen Zugang zu den Mitarbeitern des Ministeriums aufzubauen. Kurz gesagt: Für Cheong gab es zunächst keinen Weg, mit den neuen militärischen Führungskräften in ein Patron-Klienten-Verhältnis einzutreten.

Die Jahre von 1961 bis 1967 verbrachte Cheong daher als "normaler" Bauunternehmer, der nicht in einem besonderen Schutzverhältnis zum Staat stand. Als charakteristisches Merkmal eines solches nicht-protektionierten Unternehmerdaseins nannte Cheong später in seiner Biographie die ungerechte Behandlung durch die zuständigen Technokraten der Regierung, die inm nicht die Möglichkeit gaben, seine eigenen unternehmerischen Vorstellungen in die staatlichen Pläne einzubringen. ${ }^{94}$

Da sein neu gegründetes Zementwerk trotz der großen Nachfrage auf dem einheimischen Markt ohne enge Beziehung zu den neuen militärischen Führungskräften keinen unternehmerischen Erfolg in Korea erzielen konnte, entschloß Cheong sich schließlich, für den ausländischen Markt zu produzieren. ${ }^{95}$ Dies war eine Entscheidung, die nicht aus wirtschaftlichen Überlegungen heraus, sondern aus Rücksicht auf die koreaspezifische Beziehungslogik zwischen Staat und Unternehmen getroffen wurde. 1965 bekam Cheong seinen ersten ausländischen Auftrag. Es ging um ein Autobahnprojekt in Thailand. Obwohl dieses Projekt ein Verlustgeschäft war, führte es dazu, daß Cheong zwei Jahre später der einzige Bauunternehmer in Korea war, der Erfahrung mit dem Bau von Autobahnen hatte, weshalb er 1967 mit der Durchführung des bisher größten und von Präsident Park zu dessen Lebenswerk erklärtem Autobahnprojekt in Korea beauftragt wurde. ${ }^{96}$ Für Cheong war dies eine einmalige Gelegenheit, den Präsidenten persönlich kennenzulernen und eine stabile Patron-Klienten-Beziehung zu ihm aufzubauen.

Als Park nach seiner Deutschlandreise im Jahre 1964 bekannt gab, eine Autobahn zwischen Seoul und Pusan errichten zu wollen, stieß dieser Entschluß wegen der zu erwartenden hohen Kosten auf heftige Kritik in der Öffentlichkeit. ${ }^{97}$ Deswegen war es für Park sehr wichtig, dieses Projekt möglichst ohne großen Kostenaufwand und schnell durchzuführen. Von den Kostenvoranschlägen, die Park von

\footnotetext{
${ }^{94}$ Ebenda, S. 107.

${ }^{95}$ Joo-Young Cheong, Sireon eun issedo Silpaenun Eopda (Es gibt Schwierigkeiten, aber keinen Mißerfolg), Seoul 1991, S. 99.

${ }^{96}$ Ebenda, S. 108.
} 
verschiedenen Unternehmen hatte erstellen lassen, war der von Cheongs Unternehmen, der Hyundai-Bauindustrie, der preiswerteste. Als Cheong vom Staat deshalb den Auftrag zugesprochen bekam, war inm klar, daß das Projekt wegen der (zu) niedrig angesetzten Kosten für inn äußerst risikoreich war. Aber er rechnete ein, welche politische Bedeutung die erfolgreiche Beendigung dieses Projekts für sein künftiges unternehmerisches Leben haben würde.

Obwohl er vom Staat Unterstützung (z. B. durch den Einsatz von Soldaten als Bauarbeiter) bekam, war es für inn keine leichte Aufgabe, dieses Projekt nicht wie schon bei seinem ersten Brückenbau für die Regierung Rhee ${ }^{98}$ - als riesiges Verlustgeschäft zu beenden. Um die Baukosten zu reduzieren, benutzte er nicht nur die modernsten Geräte, sondern ließ vor allem die Arbeiter ohne Unterbrechung arbeiten. Dabei übernahm er selbst die Aufgabe des Kontrolleurs, indem er den Druck auf die Arbeiter durch seine Präsenz auf den Baustellen erhöhte. Auch Park, der ebenfalls oft diese Baustelle besuchte, trug zu diesem Druck bei. ${ }^{99}$ Auf diese Weise bekam Cheong die Gelegenheit, Park seine loyale Gefolgschaft überzeugend zu demonstrieren. Als das Autobahnprojekt im Juli 1970 beendet war, gehörte Cheong längst zu den engsten Schützlingen von Park.

Abgesehen von dem Autobahnprojekt begann Cheong 1967 auch Interesse an der Gründung eines koreanischen Automobilunternehmens zu zeigen, und zwar genau zu dem Zeitpunkt, an dem sich der amerikanische Autohersteller Ford für den Einstieg in den koreanischen Markt interessierte. Obwohl der amerikanische Autohersteller bei der Auswahl seines koreanischen Partners das Unternehmen von Cheong, das ja zur Baubranche gehörte, zunächst überhaupt nicht im Blick gehabt hatte, gelang es Cheong schließlich doch, Ford für ein Automobil-JointVenture-Unternehmen zu gewinnen. ${ }^{100}$ Weil die Militärregierung wegen des kleinen Binnenmarktes die Konkurrenz mehrerer Automobilunternehmen in ökonomischer Hinsicht nicht für sinnvoll hielt, hatte sie bisher der Firma "Shinjin" eine Mo-

\footnotetext{
${ }^{97}$ Ebenda, S. 116.

${ }^{98}$ Auch damals hatte sich Cheongs Gewinn erst sekundär als Zuwachs an technischem Know-how und in einer guten Beziehung zur Regierung materialisiert. Dies war offenbar die Erfahrung, die Cheong bewog, ein derartiges Risiko noch einmal einzugehen. Vgl. dazu Abschnitt IV.5 (S. 152 f.)

${ }^{99}$ Joo-Young Cheong, Sireon eun issedo Silpaenun Eopda (Es gibt Schwierigkeiten, aber keinen Mißerfolg), Seoul 1991, S. 118.
} 
nopolstellung verschafft. Shinjin war das erste koreanische Joint-VentureUnternehmen (mit dem japanischen Autohersteller Toyota) in Korea gewesen. Obwohl der Staat mit der Gründung dieses Unternehmens eigentlich hatte Fortschritte in der einheimischen Automobilindustrie erzielen wollen, begnügte sich Schinjin damit, das aus importierten Teilen montierte japanische Modell auf dem einheimischen Markt teurer als in Japan zu verkaufen. ${ }^{101}$ Dies aber hatte zu immer stärkerer öffentlicher Kritik an Shinjin geführt. Der Staat entschloß sich daher zur Aufhebung dieses Monopolgesetzes. ${ }^{102}$ Als Folge davon wurde im Dezember 1967 Cheongs Plan, mit Ford ein Joint-Venture-Unternehmen zu gründen, vom Staat genehmigt.

Als sich Cheong 1973 entschloß, den Joint-Venture-Vertrag aufzulösen und sich auf die Entwicklung eines eigenen Automodells einzulassen, bat er den Präsidenten, der, um den teure Devisen kostenden Import von Autoteilen aus dem Ausland einzuschränken, die inländische Herstellung von Autoteilen ausdrücklich verlangt hatte, ${ }^{103}$ um eine entsprechende Rückversicherung. Cheong bekam daraufhin von Park ein "Memorandum", in dem dieser inm die staatliche Unterstützung der einheimischen Automobilindustrie ausdrücklich bestätigte. ${ }^{104}$

Im großen und ganzen läßt die Strategie von Cheong, Park als starken Patron für sich zu gewinnen, als den Typus des "loyalen Gefolgsmannes", der anpassungswillig bis zur Selbstaufgabe war, erkennen. Cheong, dessen nichtuniversitäre Bildung sich Zeit seines Lebens in einem Mangel an einflußreichen (Studien-)Freunden niederschlug und der anders als Ku und Lee, noch nicht einmal über den Vorteil einer gleichen regionalen Herkunft mit Park verfügte, konnte die patronalistische Fürsorge von Park nur durch blinde Anpassung an die staatli-

\footnotetext{
${ }^{100}$ Ebenda, S. 132.

${ }^{101}$ Won-Chul Oh, Hangukheong Keongje Keonsul (Das koreanische Entwicklungsmodell), Seoul 1995, Bd. 4, S. 116, wirft Shinjin vor, daß das Unternehmen keinerlei Interesse daran hatte, wie viele Devisen für den Import der Autoteile ausgegeben werden mußten.

${ }^{102}$ Redaktion Sintonga (nicht gezeichneter Artikel), Keolye Korona Kamssanun Upsa wa Gyotongbu (Der Unternehmer und das Verkehrsministerium, die das Fehlprodukt Korona [= japanisches Automodell] protegieren), in: Sintonga, Heft August (1969), S. 71.

${ }^{103}$ Won-Chul Oh, Hangukheong Keongje Keonsul (Das koreanische Entwicklungsmodell), Seoul 1995, Bd. 4, S. 132.

${ }^{104}$ Joo-Young Cheong, I Tange Taenaseo (Geboren in diesem Lande), Seoul 1998, S. 164.
} 
che Wirtschaftspolitik unter Beweis stellen. Diese für inn überlebenswichtige Strategie ließ inm kaum freien unternehmerischen Entscheidungsspielraum und erlaubte ihm nicht, seine unternehmerischen Tätigkeitsfelder nach eigenen Interessen auszuwählen. Wie er selbst in seiner zweiten Autobiographie schrieb, war es für Cheong bezeichnend, daß er niemals eine Forderung von Park ablehnte. ${ }^{105}$

\section{V.4 "Oligarchisierung" der Wirtschaft in den 70er Jahren}

Mit Beginn der 70er Jahre änderte sich weltweit das politische Klima. Der Kalte Krieg zwischen den kapitalistischen und den kommunistischen Ländern war durch die neue amerikanische Chinapolitik mehr oder weniger gegenstandslos geworden, und Park, der seine dritte Präsidentenwahl im Jahr 1971, wenn auch nur mit knappem Abstand vor dem oppositionellen Kandidaten Dae-Jung Kim, gewonnen hatte, nutzte dies für die Restrukturierung des politischen Systems in Korea. Angesichts des Ausschlusses von Taiwan aus der UNO war er sich nicht sicher, ob Korea als geteiltes Land weiterhin durch die militärische Hilfe der USA ausreichend geschützt werden könne. Daraus leitete er ab, daß Korea sich von nun an mit der Entwicklung einer eigenen Waffenindustrie gegen einen potentiellen Angriff aus dem kommunistischen Norden wappnen müsse. Wegen dieser militärischen Bedrohung durch den Norden forderte er von der koreanischen Bevölkerung wieder einmal Zurückhaltung bei ihren Forderungen nach Demokratie. Denn - so Park - während das kommunistische Regime im Norden seine ganze Kraft für die Entwicklung der Waffenindustrie einsetzen könne, müsse sich die südkoreanische Regierung ständig auf aufwendige und zeitraubende politischen Diskussionen einlassen und könne sich deshalb nicht voll auf die wirtschaftliche Entwicklung in Korea konzentrieren. ${ }^{106}$

Die oben schon erwähnte Yushin-Verfassung vom Oktober 1972, durch die Macht von Präsident und Regierung vor allem gegenüber Justiz und Parlament noch einmal erheblich gestärkt worden war (das Parlament verlor beispielsweise

${ }^{105}$ Ebenda. 
sein Recht, die staatlichen Haushaltsausgaben zu überprüfen), erweiterte auch den wirtschaftspolitischen Handlungsspielraum der Regierung ganz erheblich. Park, der - wie oben schon gesagt - der Bevölkerung die neue Verfassung vor allem durch das Versprechen eines schnelleren ökonomischen Aufschwung schmackhaft gemacht hatte, nutzte nun seine neue Machtvollkommenheit vor allem dafür, um ungehindert von lästigen Parlamentsdebatten das Niveau der koreanischen Waffenindustrie möglichst schnell dem des kommunistischen Nordkorea anzugleichen. Auch Warnungen vor den Gefahren einer einseitigen Entwicklung der Waffenindustrie ignorierte er, zumal er ein inm ergebenen Wirtschaftsberater hatte, der vorschlug, zunächst die Grundlagenindustrie für die Waffenproduktion zu fördern. Weil Waffen aus verschiedenen mechanischen Teilen bestehen, könne sich der Staat zunächst mit der Förderung jener Industriebranchen beschäftigen, deren Produkte auch für die Herstellung von modernen Waffen verwendet werden könnten. ${ }^{107}$ Zu diesen Grundlagensektoren gehörten vor allem der Stahl-, Maschinen- und der Schiffsbau, die Energie-, Elektro- und die chemische Industrie. Die Parole der neuen Industriepolitik lautete daher: Staatliche Förderung der bisher vernachlässigten Schwerindustrie.

Der koreanischen Bevölkerung gegenüber vermittelte die Regierung den Eindruck, daß die staatliche Förderung der Schwerindustrie zur Verbesserung der Lage des koreanischen Arbeiters beitragen könne. Mit dem Slogan "Konzentrieren wir die Kraft unseres 30 Millionen-Volkes, dann erreichen wir einen Export von 30 Billionen Won" forderte der Staat die Bevölkerung auf, die Exportpolitik des Staates zu unterstützen. Gemeint war damit, daß die Koreaner trotz niedriger Löhne und langer Arbeitszeiten und im Gegensatz zu dem, was innen Park bei der Einführung der neuen Verfassung versprochen hatte, ihren Anspruch auf wirtschaftliche Verbesserung ihrer Lage noch einmal zurückstellen sollten. Die Koreaner, so die offizielle staatliche Propaganda, hätten erst als Bürger eines industrialisierten Staates ein Recht auf die sozial-gerechte Verteilung des ökonomischen Wachstums. Dieser Ideologie entsprechend bezeichnete die Regierung die Ar-

\footnotetext{
${ }^{106}$ Cheong-Reom Kim, Hanguk Keongje Cheong-Chaek 30 Yeonsa (Dreißig Jahre koreanische Wirtschaftspolitik), Seoul 1995, S. 324.

${ }^{107}$ Ebenda, S. 322 f.
} 
beiter der Schwerindustriebranche als "Industriesoldaten", die durch den Export ihrer Produkte das Land retteten. ${ }^{108}$

Obwohl die Ölkrise des Jahres 1973 der koreanischen Wirtschaft, die über keine Rohstoffe für die Entwicklung einer Schwerindustrie verfügte, ihre Grenzen zeigte, bekundeten die führenden Chaebol wie Samsung, Hyundai und LuckyGoldstar großes Interesse am Aufbau einer Schwerindustrie. Wenn man bedenkt, daß diese Unternehmen (vor allem Hyundai) wegen der hohen finanziellen Belastungen kurz zuvor um das staatliche Einfrieren der privaten Kredite sowie um Zinssenkungen gebeten hatten, dann muß man fragen, woher ihre plötzliche Bereitschaft für Investitionen in die Schwerindustrie rührte, zumal sie in diesem Bereich über keine Erfahrung verfügten. ${ }^{109}$

Zwar hatte der Staat zugesagt, die Unternehmen bei der Kreditvergabe zu bevorzugen, die sich für ein Engagement in der Schwerindustrie oder für den Import von Rohstoffen und technischen Produktionsanlagen entschieden, doch halte ich es für unwahrscheinlich, daß dieser staatliche Anreiz der entscheidende Grund für die Bereitschaft der führenden koreanischen Unternehmen zur Beteiligung an einem völlig unbekannten Industriesektor war. Ich vermute vielmehr, daß dabei die Rivalität zwischen alten und neuen staatlichen Unternehmer-Klienten eine entscheidende Rolle gespielt hat. Konkret: Die Sorge der alten unternehmerischen Klienten, zu denen Samsung, Lucky-Goldstar und Hyundai zählten, von ihrem staatlichen Patron durch eine neue, im Bereich der Schwerindustrie tätige Klientel ersetzt zu werden. Um dies zu verhindern, blieb innen keine andere Wahl, als sich selbst an der Gründung der neuen Schwerindustrie aktiv zu beteiligen. So konnten sie den Aufstieg einer neuen potentiellen Klientel im Keim ersticken. Damit war die Konzentration der koreanischen Ökonomie auf einige wenige koreanische Chaebol, die Oligarchisierung der koreanischen Wirtschaft vorprogrammiert.

Ein Beleg für meine These ist die Tatsache, daß sich alle Chaebol ungeachtet ihrer unterschiedlichen Unternehmensgeschichte plötzlich für die Schwerindustrie interessierten. Nach der Bekanntgabe der Beteiligung Hyundais an der Schiffsbauindustrie 1972 erklärte im darauffolgenden Jahr Samsung seine Bereitschaft

${ }^{108}$ Ebenda, S. 337. 
zur Gründung eines Schiffsbau- und Maschinenbauunternehmens. ${ }^{110}$ Die Folge war, daß die koreanische Schwerindustrie plötzlich durch Mehrfachgründungen auf dem gleichen Industriesektor nicht nur unter den hohen ausländischen Krediten, sondern auch unter Überkapazitäten zu leiden hatte. Selbst wenn der Staat die mehrfache Genehmigung gleicher Industriezweige im Zusammenhang mit der Entwicklung der Waffenindustrie zu rechtfertigen versuchte, ist unverkennbar, daß sich dahinter ein harter Rivalitätskampf mehrerer koreanischer Unternehmer verbarg. Angesichts der zunehmenden Zahl der Unternehmen, die sich um Protektion des Präsidenten bemühten, nahm auch die Zahl der Korruptionsfälle auf der Ebene der führenden Regierungsbürokraten zu, so daß die bisherige Kontrolle über die Leistung der Unternehmen nicht mehr funktionierte. Natürlich nutzten die Unternehmer-Klienten diese geschwächte Position des Staates aus, um, ungeachtet ihrer schlechten Finanzlage aufgrund der hohen Kapitalinvestitionen für die Schwerindustrie, die Zahl ihrer Unternehmen zu vergrößern. ${ }^{111}$ Dabei glaubten sie fest, daß der Staat als Patron der Chaebol, die inzwischen nicht nur neue Unternehmen gegründet, sondern auch unter finanziellen Engpässen leidende Klein- und mittlere Unternehmen aufgekauft hatten, ${ }^{112}$ sie niemals im Stich las-

\footnotetext{
${ }^{109}$ Cheong-Jae Lee, Chaebol Yireokseo (Die Entwicklungsgeschichte der Chaebol), Seoul 1993, S. 259.

${ }^{110}$ Ebenda.

${ }^{111}$ Ebenda, S. 262.

${ }^{112}$ Jae-Jin Suh, Hanguk Chabonga Kaegup (Die koreanische Kapitalistenklasse), Seoul 1991, S. 98 f.
} 
sen würde. Durch diese ungehinderte Expansion der Chaebol geriet der Staat nun umgekehrt immer mehr in Abhängigkeit von den Unternehmen, weil der Bankrott der Chaebol nicht nur große finanzielle Verluste, sondern auch eine Explosion der Arbeitslosenzahlen bedeutet hätte.

Verstärkt wurde diese wilde Expansion der koreanischen Chaebol und damit die Oligarchisierung der koreanischen Wirtschaft noch durch die staatlichen Exportmaßnahmen, die im Jahr 1975 bekannt gegeben wurden. Weil die Exportbranche infolge des ersten Ölpreisschocks am Beginn der 70er Jahre stagnierte, erließ das Ministerium für Handel- und Industrie eine gesetzliche Regelung, in der Handelsunternehmen, deren Anteil am Gesamtexport Südkoreas mindestes zwei Prozent betrugen, als General Trading Company (GTS) bezeichnet werden konnten. ${ }^{113}$ Dabei sollte eine GTS mindestens fünf Produkte mit im Gesamtwert von jeweils über einer Million US-Dollar exportieren. Ursprünglich stammte diese Förderstrategie für den Export aus Japan. Um die unternehmerische Motivation für die Erlangung des Titel "General Trading Company" zu verstärken, bot der Staat verschiedene finanzielle und bürokratische Privilegien. Dabei bestand der größte Anreiz in günstigen Bankkrediten. Wenn diese Unternehmen Exportverträge abschlossen, stellten die Banken die für die Produktion der Exportgüter benötigten Gelder zur Verfügung. Insofern benötigten die GTS's nur ein sehr schmales Eigenkapital; sie mußten nur imstande sein, Exportverträge mit ausländischen Unternehmen abzuschließen. Als erstes Unternehmen wurde Samsung zu einer GTS, aber es dauerte nicht lange, bis auch die anderen beiden Chaebol Lucky-Goldstar und Hyundai diesen Titel bekamen. Zwar beabsichtigte der Staat mit den höheren Anforderungen an die GTS (z. B. dem verlangten hohen Anteil an der Exportquote), daß die GTS's als eine Art Handelsagentur für kleine und mittlere Betriebe, die aufgrund ihrer fehlenden Kenntnis auf dem Weltmarkt nicht so leicht Exportpartner finden konnten, fungieren sollten. Faktisch aber nutzten die Chaebol ihre GTSPosition dazu, die exportfähigen kleinen und mittleren Unternehmen aufzukaufen. ${ }^{114}$ Schon Ende der 70er Jahre sprach man deshalb in Korea spöttisch von ei-

\footnotetext{
${ }^{113}$ Jae-Yeul Lee, Entwicklung und Führung südkoreanischer Unternehmen, Göttingen 1993, S. 77.

${ }^{114}$ Cheong-Jae Lee, Chaebol Yireokseo (Die Entwicklungsgeschichte der Chaebol), Seoul 1993, S. 281.
} 
ner "Chaebol-Republik", weil es kaum noch Produkte zu kaufen gab, die nicht den Namen der führenden Chaebol trugen.

Je mehr die staatlichen Förderungsmaßnahmen für die Schwerindustrie und die Exportunternehmen griffen, desto schneller wuchsen die Chaebol. Weil der Staat $70 \%$ seines Etats für die Ankurbelung der Schwerindustrie ausgab, lagen Ende der 70er Jahre schon über $40 \%$ der Maschinenbauunternehmen in den Händen von fünf Chaebol in Korea: Samsung, Lucky-Goldstar, Hyundai, Daewoo und Sunkeong. ${ }^{115}$ Ähnliches galt für andere Sektoren der Schwerindustrie sowie für die Exportunternehmen. Von 1970 bis 1979 betrug die durchschnittliche Wachstumsrate der koreanischen Unternehmen 130\%, während die der Chaebol $340 \%$ betrug. ${ }^{116}$

Demnach unterschied sich die Expansionsstrategie der Chaebol deutlich von der westlicher Großunternehmen. Während die westlichen Großunternehmen eine Wachstumsstrategie entweder durch vertikale oder horizontale Integration ihrer Produktionspalette verfolgten, die auf eine effiziente Kostensenkung oder auf Risikoverteilung durch Spezialisierung abzielte, zeichnete sich die Expansionsstrategie der koreanischen Chaebol dadurch aus, daß sie unmittelbar einen schnellen und harten Konzentrations- oder Oligarchisierungsprozeß verfolgten, um das Entstehen einer neuen staatlichen Klientel zu verhindern. Insofern war es konsequent, daß sie mit allen Mitteln das Wachstum der kleinen und mittleren Unternehmen in Korea einzudämmen versuchten, indem sie diese aufkauften oder sie zumindest als Zulieferunternehmen nutzten. Sie übernahmen damit die Rolle des unternehmerischen Patrons für diese kleinen und mittleren Unternehmen, so daß diesen keine selbständige unternehmerische Entwicklung mehr möglich war.

Als es in der Schwerindustrie zu immer mehr Überkapazitäten kam, nahm in der Bevölkerung (vor allem unter Studenten und Intellektuellen) die Kritik an Parks Wirtschaftspolitik zu. ${ }^{117}$ Aber erst die neue militärische Führung, die nach der Er-

\footnotetext{
${ }^{115}$ In-Hak Yu, Hanguk Chaebol eui Haebu (Analyse der koreanischen Chaebol), Seoul 1991, S. 93.

${ }^{116}$ Ebenda, S. 103.

${ }^{117}$ Dabei richtete sich die Kritik des Studenten vor allem gegen die Unterdrückung der Gewerkschaftsbewegung unter Präsident Park. Vgl. dazu Cheong-Jae Lee, Chaebol Yreokseo (Die Entwicklungsgeschichte der Chaebol), Seoul 1993, S. 293.
} 
mordung von Park im Jahr 1979 wiederum durch einen Militärputsch an die Macht kam, wirkte der Oligarchisierung im Bereich der Schwerindustrie entgegen.

\section{V.5 Resümee}

Es ist in Korea allgemein bekannt, daß Cheong-Hee Park, der vom Tag des Militärputsches am 16. Mai 1961 bis zu seiner Ermordung am 26. Oktober 1979 Staatsoberhaupt war, keinen Hehl daraus machte, daß er kein Sympathisant der Chaebol war. ${ }^{118}$ Aber dies ändert nichts an der Tatsache, daß er durch sein fehlgeleitetes Verständnis von der Rolle des Staates in der Wirtschaft die Verfestigung der wenigen Chaebol (vor allem Samsung, Lucky-Goldstar und Hyundai) als oligarchische Kräfte in der koreanischen Gesellschaft überhaupt erst ermöglichte.

Die bisherigen wirtschaftswissenschaftlichen Erklärungsansätze für die der Rolle des Staates in Korea neigen dazu, die Errichtung des Superministeriums für wirtschaftliche Planung sowie die Durchsetzung des Fünfjahresplans als Indikator für einen starken wirtschaftspolitisch rational handelnden Staat anzusehen. So behaupten manche Anhänger des institutionalistischen Ansatzes, daß die schnelle Expansion der koreanischen Chaebol zwischen 1961 und 1979 allein aufgrund der richtigen Wahl der wirtschaftspolitischen Maßnahmen (z. B. rationale RessourcenAllokation) durch den Staat erfolgt sei. ${ }^{119}$

Ich halte diese Auffassung nicht nur für unvollständig, sondern sogar für unzutreffend, weil sie die gesellschaftlich-kulturelle Gebundenheit der jeweiligen ökonomischen Akteure und ihre gegenseitige Interessenabhängigkeit vernachlässigt. Die obigen Ausführungen haben gezeigt, daß sich die Rolle des Staates bzw. des Präsidenten Park innerhalb des Industrialisierungsprozesses in Korea in den 60er und 70er Jahren adäquat nur durch die Handlungslogik eines Patrons erklären läßt, während die Rolle der Unternehmer bzw. der Chaebol dementsprechend als die eines Klienten oder Schützlings definiert werden kann. Die Tatsache, daß sich sowohl der Staat (vor allem in der Person von Park) als auch die Unternehmer fast

${ }^{118}$ Cheong-Reom Kim, Hanguk Keongje Cheong-Chaek 30 Yeonsa (Dreißig Jahre koreanische Wirtschaftspolitik), Seoul 1995, S. 437. 
um jeden Preis um die Aufrechterhaltung ihrer Patron-Klienten-Beziehung bemühten, zeigt, wie stark dieses Patronageverhältnis ihr Verständnis von der Funktion des Staates und der Rolle des Unternehmens in diesem Staat prägte.

Seine Basis hatte dieses Patronageverhältnis zwischen Staat und Unternehmen in einer koreaspezifischen Beziehungslogik: So wurzelte die enge Beziehung zwischen Park (einschließlich seiner militärischen Gefolgschaft) und den beiden Unternehmern Byung-Chul Lee und In-Hoe $\mathrm{Ku}$ in der gemeinsamen regionalen Herkunft und wurde durch gemeinsame Studienerfahrungen zusätzlich verstärkt, während der "ungebildete" Unternehmer Cheong, der aus einer Region im Norden Koreas stammte, seine Loyalität gegenüber den neuen politischen Führungskräften erst unter Beweis stellen mußte.

Es scheint so, als seien die Chaebol in Korea besonders risikofreudig gewesen, weil sie sich ohne Erfahrung und ohne Kapital immer wieder auf neue Unternehmensfelder einließen, ${ }^{120}$ doch erklärt sich auch dieser Expansionismus, wie oben gezeigt, meiner Meinung nach allein durch die spezifische koreanische zwischen Staat und Unternehmern herrschende Patron-Klienten-Beziehung.

Das von mir in der hier vorliegenden Arbeit erstmals auf Korea angewandte Begriffspaar "Patron-Klient" zur Charakterisierung des wechselseitigen Abhängigkeitsverhältnisses zwischen Staat und Unternehmern hat sich daher als äußerst tragfähig erwiesen.

Auch diese Patronageverhältnis ist im übrigen ein Grund, warum ich die Bezeichnung der Chaebol als "Familienunternehmen" für irreführend halte (auch dann, wenn man die im vorigen Kapitel dargestellten erweiterten koreanischen Familienbegriff zugrundelegt). Denn obwohl sich die koreanischen Chaebol in der Unternehmensstruktur auf den ersten Blick nicht von einem westlichen Familienunternehmen unterscheiden, zeichnen sie sich durch eine so große Abhängigkeit vom Staat aus, daß dieses Merkmal mindestens genauso bedeutend, wenn nicht sogar wichtiger ist als die interne, auf "Familienbeziehungen" gegründete Unternehmenstruktur: Diese sich als wechselseitige Abhängigkeit materialisierende

\footnotetext{
${ }^{119}$ Siehe z. B. Alice Amsden, Asia's Next Giant, New York/Oxford 1989, S. 80 f.

${ }^{120}$ Richard Steers u. a., The Chaebol: Korea's New Industrial Might, New York 1989, S. 68 relativiert die Behauptung der koreanischen Unternehmer, daß sie besonders risiko-
} 
Staatsbindung ist daher als entscheidend für die Charakterisierung der Chaebol anzusehen. ${ }^{121}$

freudig gewesen seien, durch die Bemerkung, daß sie außerdem auch noch "Glück" gehabt hätten.

${ }^{121}$ Ein kürzlich in der FAZ erschiener Artikel von Barabara Odrich über "Familienbande in Asien" konkretisiert die Auswirkungen dieser wechselseitigen Abhängigkeit von Chaebol und Staat am Beispiel des völlig überschuldeten Chaebol Daewoo: "Besonders auffällig ist dieser Machtmissbrauch (die Ausnutzung des Staates durch Großuntenehme bzw. Chaebol) in Südkorea, einem Land, in dem wenige Großfamilien ungleich mehr wirtschaftliche Macht verkörpern, als das für jedes andere ostasiatisches Land zutrifft. Das gerade jüngst wieder offensichtlich gewordene Gerangel um den finanziell angeschlagenen großen Mischkonzern Daewoo macht das eindrücklich deutlich: Die Daewoo-Gruppe allein verkörpert rund fünf Prozent des koreanischen Bruttoinlandsprodukts. Damit war über Jahrzehnte lang der Fortbestand des Konzerns für die Großaktionärfamilie, die auch den Konzern tatsächlich führt, gesichert. Keine Regierung hätte es sich leisten können, im Ernstfalle Daewoo Finanzhilfe zu verwehren, weil ein Zusammenbruch dieses - und in der Folge mehrerer anderer so genannter ChaebolKonzerne - das Land viel zu hart getroffen hätte. Damit könnte die Daewoo-Familie in gewohnter Weise immer weiter in schnellem Tempo expandieren, ohne befürchten zu müssen, von einer inzwischen beträchtlichen Fremdkapitalbelastung erdrückt zu werden." (Frankfurter Allgemeine Zeitung 13.8.1999, Nr. 186, S. 13) 


\section{Das Management in den Chaebol - die Führungsstruktur der koreanischen Massenproduktionsunternehmen}

\section{VI.1. Das koreanische Verständnis von Management}

In diesem Kapitel über das koreanische Management geht es nicht um die Organisation, Kontrolle und Koordinierung des Arbeitsprozesses, nicht um die Art und Weise, wie der Betriebsfrieden gesichert oder die Arbeiter in das Unternehmen integriert und zu guter Arbeit motiviert werden, auch nicht um die vertikale oder horizontale Zusammenarbeit der verschiedenen Unternehmensebenen, um nur einige der Aufgabenbereiche zu nennen, die nach allgemeiner Auffassung zu den Aufgaben des betrieblichen Managements gehören. ${ }^{1}$ Es geht überhaupt nicht um die konkrete Tätigkeit von Managern, sondern vielmehr um das Prinzip, das der koreanischen Praxis der Rekrutierung sowie der Kontrolle und der Karrieren von Managern zugrundeliegt, anders gesagt: um die Beschreibung und Analyse einer spezifischen koreanischen Managementkultur, die ich nicht nur als ein kulturelles Phänomen, sondern auch als eine "verdeckte Herrschaftsstrategie" kritisch beleuchten will.

Mit der im letzten Kapitel geschilderten forcierten staatlichen Förderung der Export- und hier insbesondere der Schwerindustrie in den 70er Jahren waren die Chaebol gezwungen, sich an den großen Massenmärkten in den westlichen Ländern zu orientieren und ihre Produktionsstrategie entsprechend zu verändern. Sie näherten sich daher, sowohl was den Produktionsausstoß als auch was die ständig steigende Zahl von Beschäftigten anging, mehr und mehr den westlichen Großunternehmen der Massenproduktionsbranchen an. Nun gilt gemeinhin die Existenz eines eigenständigen, um der besseren Rentabilität des Kapitals eingesetzten Managements als konstitutives Charakteristikum eines (westlichen) Großunternehmens, das sich gerade dadurch von einem Familienunternehmen unterscheidet. In Korea bestand jedoch auch in den neuen Massenproduktionsunternehmen der Eigentümer bzw. Gründervater des Unternehmens trotz des massiven Zuwachses an Kapitaleinsatz weiterhin auf seiner füh-

\footnotetext{
1Vgl. dazu Gerd Schienstock, Management als sozialer Prozeß. Theoretische Ansätze zur Instiutionalisierung, in: Hans-Dieter Ganter/ Gerd Schienstock (Hrsg.), Management aus soziologischer Sicht, Wiesbaden 1993, S. 8. 
renden Rolle als Leiter des gesamten Unternehmens. Dies änderte sich auch dann nicht, wenn der Gründervater des Unternehmens aus Altersgründen von seinem Posten zurücktrat. Denn dann übernahm der älteste Sohn oder ein enges anderes Familienmitglied des Gründervaters dessen Rolle als führender Unternehmer.

Zwar gibt es eine Bezeichnung in Korea, die den spezifischen Charakter des Managements in den Chaebol zum Ausdruck bringen will: Man spricht in diesem Zusammenhang von „Owner-Management", was häufig als Vorstufe des "employed, salaried Management" gekennzeichnet wird. ${ }^{2}$ Aber wie plausibel diese Bezeichnung auf den ersten Blick auch erscheinen mag, möchte ich doch einwenden, daß das Wort "Management" im Rahmen eines traditionellen Familienunternehmens eigentlich keine Bedeutung hat. Es mag sein, daß der Egentümer des Familienunternehmens bestimmte Funktionen des Managements (wie Kontrolle und Koordination) übernimmt, aber das bedeutet nicht, daß er wirklich eine Tätigkeit als Manager ausübt, wie dies die entsprechend ausgebildeten Manager mit ihren definierten und klar abgegrenzten Aufgabenbereichen in einem westlichen Großunternehmen bzw. Massenproduktionsunternehmen tun. Kurz gesagt: Ich bin der Meinung, daß sich die Eigentümlichkeit des koreanischen Managements durch die Bezeichnung „Owner-Management" nicht genügend erklären läßt.

Meiner Auffassung nach läßt sich das Management in Korea als eine eigenartige Mischung von in Familienunternehmen und von in Großunternehmen vorzufindenden Strukturen charakterisieren. Denn die Gründerväter der koreanischen Chaebol waren trotz ihrer fehlenden Kenntnisse von einem modernen Management auf irgendeine (zu analysierende) Weise offensichtlich imstande, die organisatorischen Herausforderungen der Massenproduktion (obwohl sie anfänglich noch nicht einmal genau wußten, was darunter eigentlich zu verstehen sei) erstaunlich schnell erfolgreich zu bewältigen: Bereits Mitte der 80er Jahre erwirtschafteten die koreanischen Chaebol durch den Export höherwertiger Massenprodukionsgüter wie Autos und Haushaltselektronik den ersten koreanischen Handelsüberschuß.

${ }^{2}$ Yu-Kun Shin, Hanguk eui Keong-Yeong (Das Management in Korea), Seoul 1993, S. 91. 
Ich gehe daher von der folgenden Annahme aus: Zwar sind die Chaebols nicht der gleichen Lösungsstrategie wie die westlichen Großunternehmen (z. B. dem tayloristischen Arbeitsorganisationsprinzip) gefolgt, aber dennoch haben sie aus einer anderen Perspektive, einer koreanischen Sicht heraus, eine besondere Managementkultur entwickelt. Wichtige Prämisse meiner Analyse dieser koreanischen Managementkultur ist dabei die Annahme, daß Manager nicht nur das ökonomische Ziel ihres Unternehmens vor Augen haben, sondern sich als handelnde Subjekte auch bei der Lösung unternehmerischer Probleme nicht von koreanischen kulturellen Denkmustern lösen können. Aufgrund dieser Überlegung gehe ich davon aus, daß sich hinter dem koreanischen Verständnis von Management ein kulturbedingtes Führungs- bzw. Organisationsprinzip verbirgt. Um das zu verdeutlichen, werde ich die folgenden Fragen beantworten:

- Wie entstand das Management in Korea?

- Wie sind die Qualifikationsanforderungen im koreanischen Management?

- Wie läßt sich die spezifisch koreanische Managementkultur charakterisieren?

\section{VI.2 Entstehungsbedingungen des Managements in Korea}

Während die bisherige koreanische Forschung dazu neigt, unter den verschiedenen konkurrieren Erklärungsvariablen jeweils nur einen einzigen Faktor als Ursache für die Herausbildung einer spezifischen koreanischen Managementkultur anzunehmen (z. B. die Rolle des Staates oder die Rolle der konfuzianischen Kultur), ${ }^{3}$ bin ich der Auffassung, daß es sich hier um ein gesellschaftliches Phänomen handelt, dessen Entstehung nicht monokausal zu erklären ist. So gehe ich davon aus, daß die folgenden institutionellen und kulturellen Faktoren für die Entstehung eines koreaspezifischen Verständnisses von Management eine Rolle gespielt haben: Zum einen das koreanische Bankensystem, dann die schwache Position der koreanischen Gewerkschaften, außerdem das koreanische Verständnis von "Arbeit" und die Bildungsmentalität der koreanischen Bevölkerung.

3Siehe beispielsweise Alice Amsden, Asia's Next Giant: South Korea and Late Industrialization, New York/Oxford 1989, S. 80; Chang-Won Lee, Hanguk eui Kiup Elite (Die Elite des koreanischen Unternehmens), Seoul 1995, S. 139. 
Das koreanische Bankensystem: Vor 1962 war das koreanische Bankensystem dem amerikanischen Zentralbanksystem nachgebildet, in dem die Zentralbank ihre Geldpolitik formal unabhängig von der Regierung betreiben konnte. ${ }^{4}$ Gleichzeitig war es von Bedeutung, daß die Bankaktien privaten Eigentümern gehörten. 1962 geriet das koreanische Bankensystem unter die strikte Kontrolle der neuen Militärregierung, die den Banken - wie oben geschildert sogar das Entscheidungsrecht über die Kreditvergabe beschnitt. ${ }^{5}$

Obwohl die Banken in Korea die größten Kreditgeber der koreanischen Unternehmen waren, durften sie nach koreanischer Aktiengesetzgebung nie mehr als $10 \%$ der Unternehmensaktien besitzen. ${ }^{6}$ Damit wollte die Regierung verhindern, daß die Stabilität der Unternehmen durch Kauf und Verkauf der Aktien durch die Banken gefährdet werden könne. Die Konsequenz war, daß sich die Banken nach anderen Sicherheiten für ihre Kredite umsehen mußten. Statt sich um die ökonomische Rentabilität des vorgelegten unternehmerischen Projekts zu kümmern, waren die Banken daher nur an einer Absicherung durch eine Hypothek auf das Unternehmensgrundstück und/oder durch eine Bürgschaft von anderen Unternehmen, die zu dem gleichen Mutterunternehmen gehörten, interessiert. 7

Für die Unternehmer war dies insofern vorteilhaft als die verlangte Bürgschaft ja von einem Unternehmen stammte, das innen ebenfalls gehörte, so daß sie praktisch für sich selbst bürgten und daher natürlich kein Problem hatten, diese Bürgschaft zu bekommen. Häufig war es sogar so, daß das neue Unternehmen, das mit der Bürgschaft z. B. des Mutterunternehmens gegründet worden war, später selbst eine Bürgschaft für ein weiteres neues Unternehmen übernahm. Dabei interessierten sich die Banken in Korea nicht dafür, daß diese

\footnotetext{
${ }^{4}$ In Wirklichkeit hat die Unabhängigkeit des Zentralbankensytems in Korea allerdings nie richtig funktioniert. Es gab regelmäßige Versuche des Finanzministeriums, ein Gesetz zu erlassen, das die Unterordnung der Zentralbank unter das Finanzministerium festschrieb. Vgl. dazu: Cheong-Reom Kim, Hanguk Keongje Cheong-Chaek 30 Yeonsa (Dreißig Jahre koreanische Wirtschaftspolitik), Seoul 1995, S. 73.

5 Kwon-Hee Hong, Chaemubu wa Haneun: 30nyon Dang Batki Ssaum (Finanzministerium und Zentralbank: Dreißig Jahre Kampf ums Territorium), in: Sintonga, Heft April (1991), S. 442.

6Jeong-Pyo Choi, Sunjinhwa rul wihan Chaebol eui Seontak (Die Modernisierungsstrategie der koreanischen Chaebol), Seoul 1996, S. 209.

7 Yu-Kun Shin, Hanguk eui Keong-Yeong (Das Management in Korea), Seoul 1993, S. 288.
} 
in Korea treffend als "oktopusartig" bezeichnete Expansionsstrategie der Unternehmen eine finanzielle Kettenreaktion auslösen könnte, in der ein angeschlagenes Unternehmen das bürgende gesunde Unternehmen mit in den Bankrott zog. ${ }^{8}$ Die Unternehmer selbst vertrauten darauf, daß sie bei einem drohenden Bankrott ihres Kernunternehmens, den sie im übrigen für äußerst unwahrscheinlich hielten, wegen der Folgen, die ein solcher Bankrott für die gesamte koreanische Wirtschaft hätte, in bewährter Weise Unterstützung durch den Staat erhalten würden.

Wegen dieser günstigen Bankkredite sahen die koreanischen Unternehmen auch keinen Anlaß, die Expansion ihres Unternehmens etwa durch den Verkauf der von ihnen gehaltenen Firmenaktien zu ermöglichen. Denn damit hätten sie möglicherweise ihre uneingeschränkte Führungsmacht im Unternehmen einbüBen können. Um ihre persönliche Macht zu erhalten, scheuten sie sich nicht, immer mehr Kredite aufzunehmen, so daß ihr eigener Kapitalanteil häufig nicht einmal 1/4 der gesamten Kreditsumme abdeckte. ${ }^{9}$

Die schwache Position der koreanischen Gewerkschaften: Obwohl die hdustrialisierung in Korea erst in den 1960er Jahren einsetzte, wurden die ersten Gesetze zur gewerkschaftlichen Betätigung schon 1953 unter Präsident Rhee erlassen. ${ }^{10}$ Sie waren angelehnt an die amerikanische Gesetzgebung und zielten auf die Freiheit der Gewerkschaften, um den Eindruck zu erwecken, daß das Verfassungssystem der neuen Republik in Südkorea auf dem Prinzip der modernen westlichen Demokratie beruhte. In Wirklichkeit dienten die wenigen organisierten Gewerkschaften lediglich als Plattform für die politische Karriere ihrer Vertreter. Die koreanischen Arbeiter dagegen, von denen es allerdings

\footnotetext{
${ }^{8}$ Erst nach der Finanzkrise im Herst 1987 begannen die koreanischen Banken zu merken, wie wichtig es ist, bei der Vergabe von Krediten die Rentablität des Unternehmens genau unter die Lupe zu nehmen. Im Moment gehört die Einführung einer solchen obligatorischen Rentabilitätsprüfung zu den wichtigsten Reformmaßnahmen der gegenwärtigen koreanischen Regierung.

9Jeong-Pyo Choi, Sunjinhwa rul wihan Chaebol eui Seontak (Die Modernisierungsstrategie der koreanischen Chaebol), Seoul 1996, S. 57.

10 Yu-Kun Shin, Hanguk eui Keong-Yeong (Das Management in Korea), Seoul 1993, S. $634 \mathrm{f}$.
} 
wegen der ökonomischen Unterentwicklung Koreas zu diesem Zeitpunkt erst sehr wenige gab, profitierten von diesen Gesetzen kaum oder gar nicht. ${ }^{11}$

Die Militärputschisten übernahmen dann 1961 das westdeutsche Modell der gewerkschaftlichen Organisation. ${ }^{12}$ Zunächst wurden einzelne Gewerkschaften getrennt nach industriellen Sektoren gegründet und daraus dann eine gewerkschaftliche Dachorganisation gebildet. Obwohl die Zahl der Arbeiter im Laufe des Industrialisierungsprozesses gestiegen war, verstanden sich auch diese neuen Gewerkschaften jedoch nicht als deren Interessenvertretung, sondern konzentrierten sich auf die enge Zusammenarbeit mit Arbeitergebern und Regierung. ${ }^{13}$ Gewerkschaftliches Handeln im eigentlichen Sinne dagegen wurde als prokommunistisch bzw. als Verrat am Staat diffamiert. Während bei Samsung und Hyundai von Anfang an die Bildung einer Gewerkschaft untersagt war, ließ In-Hoe Ku in seinem Unternehmen Lucky-Goldstar seit 1962 eine gewerkschaftliche Organisation zu. Doch war dies eine Scheingewerkschaft, in der die von der Unternehmensleitung bestochenen Gewerkschaftsführer ausschließlich im Interesse der Unternehmensführung handelten. ${ }^{14}$

Die ablehnende Haltung der Unternehmensleiter, die eine Interessenvertretung der Arbeiter als Verrat an der Gemeinschaft aller Unternehmensangehörigen und insbesondere an ihnen selbst als den "Vätern" dieser Gemeinschaft empfanden und entsprechend ahndeten, läßt sich beispielhaft an Byong-Chul Lee, dem Gründervater von Samsung, zeigen. Lee reagierte 1961 auf einen Streik in seinem Textilunternehmen nicht etwa mit Verhandlung, sondern mit sofortiger Aussperrung. ${ }^{15}$ Für inn waren die Arbeiter keine Verhandlungspartner, sondern armselige Menschen, denen er mit der von ihm geschaffenen Arbeitsstelle ein einträgliches Auskommen verschaffte und die ihm deshalb zu Dank verpflichtet sein mußten. Warum - so seine Meinung - brauchten die Arbeiter(innen) eine Gewerkschaft, wenn sie doch in seiner Fabrik besser als zu

\footnotetext{
${ }^{11}$ Sun-Dong Kim, Samsung eui Nocho rul Pilyoro Hachi Annun Keong-Young (Samsungs Manangement, das keine Gewerkschaften braucht), Seoul 1995, S. 20.

12Yun-Hwan Kim, Hanguk Nodong Undong eui Sengkek (Der Charakter der koreanischen Arbeiterbewegung), in: Shin, II-Chul (Hrsg.), Hangukineui Sasang (Das Denken in Korea), Seoul 1984, S. 248.

${ }^{13}$ Ebenda, S. 245.

${ }^{14}$ In-Hak Yu, Hanguk Chaebol eui Haebu (Analyse der koreanischen Chaebol), Seoul 1991, S. 242.

15Samsung Keongje Yeonguso (Verfassergruppe), Hoameui Keongyeong Chulhak (Managementsphilosophie von Hoam), Seoul 1988, S. 208.
} 
Hause essen und wohnen konnten? ${ }^{16}$ Er sah "seine" Arbeiter nicht als selbständige Menschen, sondern als ganz und gar von ihm abhängig, ${ }^{17}$ und rechnete sich seine patriarchalische "Fürsorge" auch noch als hohen moralischen Verdienst an. Obwohl diese Auffassung Lees immer häufiger von koreanischen Sozialwissenschaftlern kritisiert wurde, ${ }^{18}$ änderte er sie niemals. Nach seinem Tod übernahm auch sein Sohn und Nachfolger Kun-Hee Lee diese Ansicht. ${ }^{19}$

Seit Mitte der 60er Jahre stieg die Zahl der koreanischen Arbeiter kontinuierlich, hauptsächlich in der Textilbranche, in der die Mehrheit der aus den ländlichen Gebieten stammenden Frauen beschäftigt war. Männer fanden zumeist in der expandierenden Baubranche Arbeit. Aber weder die Arbeiterinnen in der Textilbranche noch die Bauarbeiter interessierten sich für gewerkschaftliche Aktivitäten. Innen war die Sicherheit ihrer Arbeitsplätze wichtiger als die Arbeitsbedingungen oder ihre soziale Stellung innerhalb des Unternehmens. Nur wenn ihre Löhne nicht gezahlt wurden, scheuten sie sich nicht, ihre Wut gegen die Unternehmensführung teilweise auch gewaltsam auszudrücken. ${ }^{20}$ In der Regel dauerten solche Konflikte jedoch nicht lange, weil die Arbeitgeberseite

\footnotetext{
${ }^{16}$ Ebenda, S. 48.

${ }^{17}$ Sogar seinen Freund Sun-Kun Lee, der in der japanischen Kolonialzeit sein Geschäft geführt hatte, bezeichnete Lee in seiner Autobiographie durchgehend als "Chibain", was eine Art höhergestellter Hausdiener ist, der im Namen des Herrn den gesamten Haushalt verwaltet.

18Yu-Kun Shin, Hanguk eui Keong-Yeong (Das Management in Korea), Seoul 1993, S. 650.

19Hyo-Jin Oh, Samsung New Leader Lee Kun-Hee Hoejang (Der neue Unternehmensleiter von Samsung, Kun-Hee Lee), in: Wolgan-Chosun, Heft 12 (1989), S. 357. Kun-Hee war Byong-Chul Lees dritter Sohn. Eigentlich hätten der älteste Sohn MaengHee und nach diesem zunächst der zweite Sohn Chang-Hee Nachfolger ihres Vaters werden müssen. Doch hatte Lee zu diesen beiden Söhnen kein Vertrauen: Maeng-Hee hatte von 1967 bis 1973 bereits die Unternehmen seines Vaters geleitet, der wegen eines aufgeflogenen Schmuggelgeschäfts hatte zurücktreten müssen. Nachdem der Vorfall vergessen war, übernahm der Vater jedoch wieder die Firmenleitung, hielt aber Maeng-Hee seitdem nicht mehr für einen kompetenten Unternehmer. Chang-Hee, der als Manager bei Samsung arbeitete, hatte Anfang der 70er Jahre - wahrscheinlich um Maeng-Hee zu unterstützen und die Rückkehr des Vaters zu verhindern - seinen Vater wegen Steuerhinterziehung angezeigt. Obwohl Chang-Hee, der Mitte der 70er Jahre ein eigenes Unternehmen gründete, und sein Vater sich später wieder versöhnten, entschied sich Lee, seinem Lieblingssohn Kun-Hee sein Firmenimperium zu übergeben. Vgl. dazu Maeng-Hee Lee, Mudedun Yiyaki (Die unbekannte Geschichte), Seoul 1985, S. 285.

${ }^{20}$ Yun-Hwan Kim, Sanuphwa Dangae eui Nodong Munje wa Nodong Undong (Probleme der koreanischen Arbeiterbewegung), in: Cho, Hee-Yeon (Hrsg.), Hanguk Sahoe eui Chae Insik (Neue Erkenntnisse über die koreanische Gesellschaft), Seoul 1985, S. 370.
} 
durch frühzeitige Entlassung der Gewerkschafter einen organisierten längerandauernden Kampf zu verhindern wußte. Gleichzeitig lernten die Unternehmer aber auch, daß unternehmerischer Erfolg ohne Betriebsfrieden nicht zu erreichen sei. Die Erfahrung, daß sich die Arbeiterschaft vor allem dann gegen die Unternehmensführung wandte, wenn sie das Gefühl hatte, von den (zumeist sehr jungen) Angestellten der mittleren Führungsebene nicht "menschlich" behandelt zu werden, veranlaßte die Unternehmensleitung, den persönlichen Kontakt zu den Arbeitern zu suchen und ihre Angestellten darauf hinzuweisen, daß auch die Arbeiter "normale Menschen" seien, die durch die Mißachtung beleidigt werden könnten. 21

Als sich die wirtschaftliche Lage der Arbeitnehmer auch in Folge des zune hmenden Industrialisierungsprozesses langfristig nicht verbesserte, engagierten sich Anfang der 70er Jahre zunehmend gesellschaftskritisch gesinnte Studenten in der "Arbeiterfrage". In Abendschulen versuchten sie die Arbeiter von der Notwendigkeit gewerkschaftlicher Organisation zu überzeugen. Aufgerüttelt hatte die Studenten die Selbstverbrennung eines jungen Textilarbeiters, der auf diese Weise für bessere Arbeitsbedingungen und vor allem für die Umsetzung der Gewerkschaftsgesetze demonstrieren wollte. ${ }^{22}$ Ebenfalls aufgerüttelt durch dieses Ereignis wurde die Regierung Park, allerdings in der entgegengesetzten Richtung: Sie fürchtete um ihre exportorientierte Industrialisierungsstrategie, deren wichtigste Grundlage die niedrigen Löhne der Arbeiter waren, und schaffte deshalb die bisherige gesetzliche Grundlage für freie Gewerkschaften ab. Schon im Dezember 1969 waren Arbeitskämpfe in ausländischen Unternehmen untersagt worden, und im Dezember 1971 erließ die Regierung nun ein "Sondergesetz für die Sicherheit des Landes", das praktisch jeden Streik und darüber hinaus auch jede kollektive Verhandlung von Arbeitern verbot. Mit der Einführung der sog. Yushin-Verfassung 1972 war dann jede freie gewerkschaftliche Organisation streng untersagt. Statt dessen setzte sich die Regierung dafür ein, daß die vorhandenen schwachen koreanischen Gewerkschaften nach

21Joo-Young Cheong, Sireon eun issedo Silpaenun Eopda (Es gibt Schwierigkeiten, aber keinen Mißerfolg), Seoul 1991, S. 161.

${ }^{22}$ Chun Tae-II Kineom Kwan Saup Chujin Wiwonhoi (Das Komittee für Chun Tae-II), Eonu Cheongeneon Nodoncha eui Samkwa Chugeum (Das Leben und der Tod eines jungen Arbeiters), Seoul 1983, S. 237-248. 
dem japanischen Modell in Betriebsgewerkschaften umgewandelt wurden. ${ }^{23}$ Die Studenten, die sich in der Arbeiterbewegung engagierten, wurden vom koreanischen Geheimdienst beobachtet und so die Gewerkschaftsbewegung endgültig erstickt. ${ }^{24}$ Seitdem mußten sich die koreanischen Unternehmer, insbesondere in den Chaebol, trotz der rapide zunehmenden Zahl ihrer Arbeiter keine Gedanken mehr darüber machen, mit welchem Managementkonzept der betriebliche Frieden gesichert werden könnte. Dieser Zustand dauerte bis zum Sommer 1987.25

Das koreanische Verständnis von "Arbeit": In der Yi-Dynastie verstand man unter Arbeit vor allem körperliche Arbeit. Arbeit leisteten nach diesem Verständnis überhaupt nur Bauern und Handwerker. Charakteristisch war dabei, daß diese Arbeit in der Regel als Gemeinschaftsarbeit ausgeführt wurde. Jedes Dorf bildete eine Art "Arbeitsgemeinschaft", die man vielleicht am besten als Arbeitskollektiv bezeichnen könnte, ${ }^{26}$ und jeder junge männliche Dorfbewohner mußte sich diesem Kollektiv anschließen. (Die Yangban-Familien schickten anstelle ihrer Kinder die jungen männlichen Sklaven.) Vor Beginn der Arbeit machte man gemeinsam einen Arbeitsplan, in dem festgelegt wurde, in welcher Reihenfolge die (Feld-)Arbeit durchgeführt werden sollte. ${ }^{27}$ Insofern tauschte

23Sun-Dong Kim, Samsung eui Nocho rul Pilyoro Hachi Annun Keong-Young (Samsungs Manangement, das keine Gewerkschaften braucht), Seoul 1995, S. 53.

${ }^{24}$ Mu-Ki Bae, 6.29 Seonun Yihu eui Nodong Undong 3 Yeon (Drei Jahre nach der Ankündigung politischer Reformen vom 29. Juni 1987), in: Kaegan Sasang, Heft Herbst (1990), S. 340.

25Nach der Ermordung von Park im Jahre 1979 durch den koreanischen Geheimdienst fand zum ersten Mal wieder ein landesweiter Arbeitskampf in Koea statt. Aber dieser wurde durch den darauffolgenden Militärputsch von Doo-Hwan Cheon im Jahr 1980 erneut unterdrückt. Zwischen 1980 und 1987 engagierten sich einige Studenten trotz der verschärften staatlichen Überwachung wieder für die koreanische Arbeiterbewegung. Sie verließen die Universität und wurden Arbeiter(innen), um Basisarbeit für die Bildung von Gewerkschaften zu leisten. Wenn entdeckt wurde, daß sie Studenten waren, wurden sie nicht nur sofort entlassen, sondern auch verhaftet. Sun-Taek Kwon, Yeodaesaeng Konghwal kwa Nodongundong (Die Fabrikarbeit der Studentinnen und ihre Wirkung auf die Arbeiterbewegung), in: Sintonga, Heft September (1986), S. 404

${ }^{26}$ Dabei muß man sich allerdings den aus sozialistischen Staaten bekannten Kontext für diesen Begriff wegdenken.

27Dieses "Arbeitskollektiv" heißt auf koreanisch "Dure". Was die Bedeutung von Dure anbelangt, existieren verschiedene Interpretationen. So gibt es z. B. die Auffassung, daß "Dure" die Reihenfolge bedeutete, nach der die kollektive Arbeit ausgeführt wurde. Der koreanische Soziologe, Yong-Ha Shin, ist allerdings der Meinung, daß "Dure" einfach "Gemeinschaft" bedeutet: Yong-Ha Shin, Dure Kondongche wa Nongak eui Sahoesa (Dure-Gemeinschaft und die Sozialgeschichte der koreanischen ländlichen Arbeitsmusik), in: Hanguk Sahoe Yeongu, Vol 2 (1984), S. 13. 
man seine Arbeit gegen die Arbeit anderer Dorfbewohner. Wenn eine Familie keine männlichen Arbeitskräfte zur Verfügung stellen konnte, wurde die Arbeit von den anderen für diese Familie mitübernommen. Die gemeinschaftliche Arbeit, die in der Regel von dem ältesten Dorfbewohner geplant und kontrolliert wurde, diente also in erster Linie dazu, die Belastung durch geschickte Arbeitsteilung für jeden einzelnen erträglich zu machen und auf diese Weise auch Notleidende bzw. Nicht-Arbeitsfähige zu unterstützen. Während der kollektiven Arbeit wurde von der jeweiligen Familie, deren Land gerade bearbeitet wurde, ein gemeinsames Essen und Trinken angeboten. Außerdem sammelte das Arbeitskollektiv Reis bei den einzelnen Familien, der dann als Gemeinschaftsgut des Dorfes für gemeinsame Angelegenheiten (z. B. für Dorffeste und als Hilfe für notleidende Dorfbewohner) zur Verfügung stand. Insofern bekamen die einzelnen Mitglieder der Dorfgemeinschaft niemals eine individuelle Belohnung für ihre Arbeit. 28

In Korea fand ein Tausch von Arbeit gegen Geld erstmals mit Beginn der japanischen Kolonialzeit statt, nachdem die japanischen Fabriken im Lande die Koreaner als billige Arbeitskräfte entdeckt hatten. ${ }^{29}$ Obwohl viele dieser Koreaner nur als Tagelöhner arbeiteten, waren sie die ersten koreanischen Lohnarbeiter, die ihre Arbeitskraft als Ware verkauften. Gleichzeitig entstanden in Korea auch Berufe, deren Vertreter als "Spezialisten" bezeichnet wurden, worunter beispielsweise Ärzte, Richter und Anwälte fielen. Allerdings gab es während der japanischen Kolonialzeit nur eine Handvoll Koreaner, die in diesem Sinne "Spezialisten" waren (die meisten Ärzte, Richter, Anwälte usw. waren Japaner). Das Verständnis der Koreaner von Arbeit war also bis zum Ende der japanischen Kolonialzeit mehrheitlich - wenn überhaupt - durch ihre Erfahrung als billige unqualifizierte Arbeiter bestimmt. Aufgrund der niedrigen Löhne und schlechten Arbeitsbedingungen bedeutete der Wechsel von der bäuerlichen oder handwerklichen Arbeit auf dem Dorfe zur Lohnarbeit in einer Fabrik für die meisten Koreaner keine Verbesserung ihres Lebensstandards. ${ }^{30}$ In gewissen

\footnotetext{
28Ebenda, S. $21 \mathrm{f}$.

29Dae-Keong Seong, 3.1 Undong Siki eui Hanguk Nodongja eui Hwaldonge Kwanhayeo (Über die Aktivitäten der koreanischen Arbeiter während der Zeit der Bewegung vom 1. März), in: Reoksa Hakbo, Vol 41 (1969), S. 62.

30Yong-Ha Shin, Hanguk Kundae Sahoes Yeongu (Die Sozialgeschichte der Neuzeit in Korea), Seoul 1987, S. 351. 
Sinne verschlechterten sich ihre Lebensbedingungen sogar: Denn obwohl sie als Bauern vom gesellschaftlichen Status her dem Grundbesitzer bzw. der herrschenden Schicht untergeordnet gewesen waren, waren sie im Hinblick auf den Arbeitsinhalt, Arbeitsmethoden und Arbeitsrhythmus weitgehend frei gewesen. Diesen Handlungsspielraum verloren sie als unqualifizierte Arbeitskräfte in einer Fabrik.

Die Frage ist, ob sich das durch die Erfahrung eines unqualifizierten Arbeiters, der seine Arbeit ohne besondere innere Motivation verrichtet, geprägte Verständnis von Arbeit in Korea mit dem Ende der japanischen Kolonialzeit geändert hat. Zwar wurden nach 1945 früher von Japanern besetzte Stellen (hauptsächlich im Verwaltungsbereich) nun von Koreanern übernommen, aber an der allgemeinen Verachtung für körperliche Arbeit änderte sich zunächst jedenfalls erst einmal nichts. Nach wie vor gehörten zu den angesehenen Berufen nur der des Arztes, des Richters, des Anwalts und des Lehrer, da für diese eine durch eine lange Ausbildungszeit erworbene, hochspezialisierte Qualifikation nötig war. ${ }^{31}$ Da sich bis 1960 in Korea aufgrund des nur zögernd voranschreitenden Industrialisierungsprozesses keine neue Schicht von Industriearbeitern gebildet hatte, gab es keinen gesellschaftlich strukturellen Anlaß, der das traditionelle nur über das gesellschaftliche Ansehen definierte Verständnis von Arbeit in Frage gestellt hätte. Das erklärt auch die zu verzeichnende Zunahme der höheren Schulabsolventen in Korea, was allgemein auf die "Abscheu vor Arbeit" zurückgeführt wurde. 32 Den meisten westlichen Lesern wird diese Deutung eigenartig oder sogar unverständlich erscheinen, weil ihr Verständnis von Arbeit weniger vom gesellschaftlichen Ansehen als vielmehr von einem „Berufsethos" geprägt ist, wie Max Weber das in seinen berühmten Studien über die protestantische Ethik gezeigt hat. Ein solches Berufsethos ist für Koreaner ein Fremdwort.

Erst mit dem von Präsident Park in Gang gesetzten rasanten Industrialisierungsprozeß stieß das bisherige koreanische Verständnis von Arbeit an seine Grenzen. Weil Industrialisierung ohne Mobilisierung der Industriearbeiter nicht denkbar ist, war Park der erste koreanische Politiker, der die traditionelle Ab-

${ }^{31}$ Keong-Dong Kim, Hanuk in eui Gachikwan kwa Sahoe Euisik (Koreanische Wertvorstellungen und Gesellschaftsbewußtsein), Seoul 1993, S. 354.

32Ebenda, S. 162. 
scheu vor der körperlichen Arbeit öffentlich kritisierte und ein positives Verständnis von Arbeit forderte. Nach Auffassung des koreanischen Soziologen Keong-Dong Kim war die Propaganda der Militärputschisten "Auch wir, Koreaner, können besser leben, wenn wir bereit sind, uns selbst zu helfen" (was bedeute, daß man hart arbeiten müsse) der erste koreanische Versuch, die negative Einstellung zur Arbeit durch einen staatlichen Appell in eine positive Richtung zu wenden. ${ }^{33}$ Weil die Militärputschisten die Abschaffung der Armut zu ihrem höchsten politischen Ziel erklärt hatten, richtete sich ihre Forderung nach mehr Bereitschaft zur Arbeit vor allem an die armen Bevölkerungsgruppen. Mit diesem Propagandafeldzug wollte Park daher offenbar einen gesellschaftlichen Anerkennungsprozeß für Arbeit bei den niederen gesellschaftlichen Gruppen in Korea in Gang setzen. Aber dieser staatliche Appell nach "Mehr Arbeit" betonte nicht nur für Korea ganz neu die gesellschaftliche Nützlichkeit von Arbeit und wertete diese dadurch auf, sondern enthielt zugleich auch einen starken Verpflichtungscharakter für jeden einzelnen Koreaner und zielte damit auf das herkömmliche Verständnis von Arbeit, nach dem Arbeit nicht als konkrete, individuell zu erbringende Leistung gesehen, sondern als eine abstrakte oder besser moralische Pflicht eines Untergeordneten/Untergebenen gegenüber seinem Herrn aufgefaßt wurde. 34

Vor diesem Hintergrund wird verständlich, daß sich die koreanischen Arbeiter und Büroangestellten nicht durch ihre Qualifikation oder persönliche Leistung, sondern vielmehr durch ihre Bereitschaft zu hohem Arbeitseinsatz auszeichneten. Arbeit wurde eben als notwendige Pflichterfüllung eines Untergebenen verstanden und nicht als individuelle Anstrengung oder gar als Quelle persönlicher Befriedigung. ${ }^{35}$ Für die koreanischen Chaebolunternehmer, die sich immer wieder mit unbekannten Industriesektoren beschäftigen mußten, war eine solche Haltung insofern sehr nützlich, als sich ihre Mitarbeiter als Untergeordnete in der betrieblichen Hierarchie den verschiedenen neuen unternehmerischen Anforderungen immer wieder mit großem moralischen Pflichtbewußtsein stellten.

${ }^{33}$ Ebenda, S. 545; Cheong-Hee Park, Ein Weg für unser Volk, Seoul 1964, S. 50.

${ }^{34}$ Darauf verweist auch der ständige Appell an die Opferbereitschaft der Bevölkerung. Vgl. dazu Korean Overseas Information Service (Hrsg.), New Year Press Conference by President Park Chung-Hee: January 15. 1976, Seoul 1976, S. 22. 
Während es in den westlichen Ländern kaum denkbar ist, ein Unternehmen ohne eine klare Arbeitsteilung zu führen, findet man diese in den koreanischen Betrieben nicht oder kaum, sondern statt dessen eine strenge, sehr differenzierte Hierarchie zwischen Vorgesetzten und Untergebenem, die es ermöglicht, Arbeit (auch eine Versetzung an einen anderen Arbeitsplatz) einfach anzuordnen und dabei mit widerspruchsfreier, pflichtgetreuer Ausführung rechnen zu können. ${ }^{36}$

Die Bildungsmentalität der koreanischen Bevölkerung: Obwohl Korea lange Zeit ökonomisch so unterentwickelt war, gab es zu jeder Zeit in allen Schichten ein niemals nachlassendes virulentes Interesse an Bildung. Sogar während der japanischen Kolonialherrschaft gelang es nicht, dieses Bedürfnis nach höherer Bildung in der Bevölkerung vollständig zu unterdrücken, 37 was sich ja auch in der Massendemonstration vom 1. März 1919 zeigte, die sich - wie oben erwähnt - u. a. auch an dem fehlenden Zugang von koreanischen Kindern zu höheren Schulen und Universitäten entzündet hatte. In der konfuzianischen YiDynastie hatte Bildung die wichtigste gesellschaftliche Aufstiegsmöglichkeit dargestellt, und diese Bedeutung von Bildung hatte sich im Bewußtsein der Koreaner nicht verändert, obwohl das Bildungssystem mit Beginn der japanischen Kolonialherrschaft nach westlichem Vorbild weitgehend umgestaltet worden war. 38

Ein wirklicher Bildungsboom wurde allerdings erst nach dem Ende der japanischen Kolonialzeit möglich. Unter Präsident Rhee galt die Bildungsfreiheit aller Bevölkerungsschichten als wichtiger Indikator für ein demokratisches Verfassungssystem und wurde entsprechend gefördert oder zumindest propagiert. Auch das amerikanische "Reeducation-Programm" spielte eine wichtige Rolle. ${ }^{39}$ Das nach 1945 sich verbreitende allgemeine "Bildungsfieber" erfaßte - der oben

35Dieses Pflichtbewußtsein ist meines Erachtens auch ein Grund für das oben beschriebene mangelnde Interesse der koreanischen Arbeiter an gewerkschaftlicher Organisation.

${ }^{36}$ Yu-Kun Shin, Hanguk eui Keong-Yeong (Das Management in Korea), Seoul 1993, S. 480.

${ }^{37}$ Eberhard Schoenfeldt, Der Edle ist kein Instrument: Bildung und Ausbildung in Korea (Republik), Kassel 1996, S. 131.

${ }^{38}$ Ebenda, S. 144.

39Noel F. McGinn u.a., Education and Development in Korea: Studies in the Modernization of the Republic of Korea: 1945-1975, Cambridge u. a. 1980, S. 12. 
beschriebenen allgemeinen Verachtung für körperliche Arbeit entsprechend auch die arme ländliche Bevölkerung, so daß sich viele Eltern nicht scheuten, allein wegen der besseren Bildungsmöglichkeiten für ihre Kinder in die Stadt abzuwandern. ${ }^{40}$ In anderen Fällen wurden die Kinder allerdings auch einfach zu in der Stadt wohnenden Verwandten geschickt.

Obwohl die koreanische Gesellschaft bis Anfang der 60er Jahre außer den staatlichen Beamtenposten keine Berufe für Akademiker bot, wurde die Zahl der Universitätsabsolventen immer größer. ${ }^{41}$ So erinnerte sich der ehemalige Regierungsmitarbeiter Won-Chul Oh, daß in dem ersten, 1961 errichteten toreanischen staatlichen Düngemittelunternehmen "Chungnam" auch die Stellen, die eigentlich für die Absolventen der technischen Highschools bzw. für Produktionsarbeiter gedacht waren, von Universitätsabsolventen besetzt wurden. ${ }^{42}$ Dies zeigt, daß sich das "Bildungsfieber" in Korea nicht als Folge der Nachfrage des Arbeitsmarktes, sondern im Gegenteil gegen den Markt entwickelte.

Mit der als Maßnahme zur Bekämpfung der landesweiten Armut propagierten Förderung der verarbeitenden Industrien durch das Regime Park erhöhte sich auch der Anteil des staatlichen Bildungsetats. Da sich die staatliche Förderung im wesentlichen auf die Berufsschulen beschränkte, wurden als Folge davon allgemeinbildende Schulen, die in erster Linie auf die Aufnahmeprüfung für die Universitäten vorbereiteten, immer häufiger von privaten Trägern übernommen. 43

Die Militärregierung beabsichtigte mit der Konzentration auf das Berufsschulwesen vor allem die zunehmende industrielle Nachfrage nach technisch ausgebildeten Fachleuten abzudecken, doch scheiterte sie mit diesem Vorhaben weitgehend. Wie nach dem oben Dargestellten kaum anders zu erwarten, wählten die meisten der neuen Bildungswilligen nämlich nicht den neuen zweiten Bildungsweg über die Berufsschule, sondern trotz der erheblichen Kosten

40Soweit ich weiß, wurde die wichtige Rolle, die dieses "Bildungsfiebers" für die rapide Urbanisierung in Korea spielte, in bisherigen Koreastudien kaum beachtet.

${ }^{41}$ Edward S. Mason u.a., The Economic and Social Modernization of the Republic of Korea: Studies in the Modernization of the Republic of Korea: 1945-1975, Cambridge u. a. 1980, S. 354.

42Won-Chul Oh, Hangukheong Keongje Keonsul (Das koreanische Entwicklungssmodell), Bd. 1. Seoul 1995, S. 143.

${ }^{43}$ Eberhard Schoenfeldt, Der Edle ist kein Instrument: Bildung und Ausbildung in Korea (Republik), Kassel 1996, S. 206. 
das Universitätsstudium und konzentrierten sich dort auch noch hauptsächlich auf die geisteswissenschaftlichen Disziplinen. Hier zeigt sich noch einmal eindrücklich die langlebige Wirkung der traditionellen konfuzianischen Kultur der Yi-Dynastie, in der jede Form von nicht-geistiger Arbeit verachtet wurde und Bildung eo ipso schon einen höheren sozialen Status bedeutete. ${ }^{44}$

Diese weitverbreitete Hochschätzung von allgemein-wissenschaftlicher Bildung schlug sich auch in der weiter unten genauer zu schildernden Rekrutierungspraxis für die (mittleren und höheren) Führungskräfte in den Chaebol nieder, in denen unabhängig von ihrer fachlichen Qualifikation bevorzugt Absolventen der Eliteuniversitäten eingestellt wurden. ${ }^{45}$ Dies wiederum hatte zur Folge, daß das Ansehen der Absolventen der Eliteuniversitäten weiter stieg (wie umgekehrt übrigens auch die Chaebol von dem Ansehen der Eliteuniversitäten profitierten), so daß der Ansturm auf diese Universitäten noch mehr zunahm, was einen unglaublich harten, bis weit in die Schulen zurückreichenden Konkurrenzkampf um die Aufnahme auf diesen Universitäten zur Folge hatte. Die Kosten dieses "Bildungswahns" trugen (und tragen bis heute) im engeren Sinne die ehrgeizigen koreanischen Eltern, die die hohen Studiengebühren nicht nur für die privaten Schulen und Eliteuniversitäten aufbringen müssen, sondern auch für den privaten Zusatzunterricht, den sie ihren Kindern zur Verbesserung ihrer Startchancen zukommen lassen, und im weiteren Sinne tragen diese Kosten auch deren Kinder, die den größten Teil ihrer Jugend mit der Vorbereitung auf die schwierigen universitären Aufnahmeprüfungen zubringen.

\section{VI.3. Rekrutierung und innerbetrieblicher Aufstieg der Manager}

Wie oben schon gesagt, bevorzugten die Chaebolunternehmer bei der Rekrutierung ihrer Manager, soll heißen der für eine höhere und mittlere Führungsebene vorgesehenen Angestellten, unabhängig von deren Qualifikation die Absolventen der Eliteuniversitäten, ${ }^{46}$ denen sie von sich aus jedes Jahr ihre

\footnotetext{
${ }^{44}$ Ebenda, S. 242.

${ }^{45}$ Chang-Won Lee, Hanguk eui Kiup Elite (Die Elite der koreanischen Unternehmen), Seoul 1995, S. 21.

${ }^{46}$ Das waren die Seoul National University, die Yeonse University und die Korea University, die sich alle in Seoul befanden. Man könnte auch noch die Frauenuniversität I-
} 
Einstellungsangebote unterbreiteten. In der Regel begründeten die Unternehmer diese Bevorzugung von Absolventen der Eliteuniversitäten damit, daß diese schon in der Schulzeit ein sehr diszipliniertes Leben hätten führen müssen, um die schwierige Zulassungsprüfung für diese angesehenen Universitäten bestehen zu können. Diese disziplinierte Haltung sei vor allem deswegen wichtig, weil die Mitarbeiter angesichts der ständigen Expansion der Chaebol sehr häufig mit unbekannten unternehmerischen Anforderungen konfrontiert werden und diesen neuen Aufgaben nur mit einer großen Lernbereitschaft und einem hohen Arbeitseifers gewachsen sein würden. 47

Aber es gab noch einen anderen Grund, der sich nur im Kontext der im vorigen Kapitel geschilderten engen Verflechtung zwischen Staat und Unternehmen in Korea verstehen läßt: Die Absolventen der Eliteuniversitäten wurden auch wegen ihres sozialen Beziehungskapitals bevorzugt eingestellt. 48 Denn, da die Eliteuniversitäten in Korea schon seit der japanischen Kolonialzeit existierten, war es keine Seltenheit, daß sich unter den ehemaligen Absolventen höhere Regierungsmitglieder befanden. ${ }^{49}$ In diesem Fall konnten die Chaebol durch den geschickten Einsatz der jüngeren Absolventen der Eliteuniversitäten erfolgreich mit der Regierung verhandeln, weil zwischen den beiden Verhandlungspartnern durch die Zugehörigkeit zu derselben Universität von vornherein eine Vertrauensbeziehung bestand. .50

Die Hochschätzung der Chaebolunternehmer für die Absolventen der Eliteuniversitäten, die sich bis Mitte der 60er Jahre kaum für einen Posten in der

Hwa dazu zählen. Aber die Absolventinnen dieser Universität hatten keine Chance auf eine Anstellung als Manager in einem koreanischen Unternehmen. Sie konnten höchstens als deren Sekretärinnen arbeiten.

47Yu-Kun Shin, Hanguk eui Keong-Yeong (Das Management in Korea), Seoul 1993, S. 483. Myong-Han Kang, ein ehemaliger Manager in der Hyundai-Automobilindustrie, erinnert sich in seinem Buch, Pony rul Mandun Byeolnan Hangukindul (Die sonderbaren Koreaner, die das Auto Pony gebaut haben), Seoul 1986, S. 57, daran, daß das Büro seiner Abteilung wie ein Seminarraum aussah, weil die Mitarbeiter jeden Tag das für die Produktion benötigte neue Wissen lernten.

${ }^{48}$ Chang-Won Lee, Hanguk eui Kiup Elite (Die Elite der koreanischen Unternehmen), Seoul 1995, S. 111.

49In Korea ist es üblich, daß man für einen höheren Beamten- bzw. Regierungsposten ein Staatsexamen ablegen muß. In der Regel bestanden diese Prüfung mehrheitlich wieder die Absolventen der Eliteuniversitäten.

50Dabei scheuten sich die Unternehmen auch nicht, hohe Regierungsbeamte als Manager in ihr Unternehmen abzuwerben. Leroy P. Jones/ll Sakong, Government, Business, and Entrepreneurship in Economic Development: The Korean Case, Cambridge u. a. 1980, S. 70. 
Privatindustrie interessiert hatten, 51 wirkte insofern zurück, als mit deren Expansion in den 70er Jahren die Chaebol zu einem der beliebtesten Arbeitsplätze für die Eliteuniversitätsabsolventen wurden. Dies wiederum führte umgekehrt dazu, daß die Mitarbeiter der Chaebol in der Öffentlichkeit ausnahmslos und alle für Absolventen der Eliteuniversitäten gehalten wurden, was den Chaebol nicht nur Vorteile etwa bei der Vergabe von Bankkrediten, 52 sondern auch bei der Allokation menschlicher Ressourcen gegenüber Klein- und mittleren Unternehmen verschaffte. So entstand ein dichtes Netz von Beziehungen zwischen den Chaebol, den Eliteuniversitäten, staatlichen Regierungsstellen und den Banken, das sich immer wieder selbst generierte.

Obwohl die Abschlußprüfungen an den Universitäten in der Regel im Frühjahr abgelegt wurden, war es üblich, daß das Einstellungsverfahren für neue Mitarbeiter der koreanischen Chaebol schon im Herbst des vorhergehenden Abschlußjahres stattfand. ${ }^{53}$ Das Einstellungsverfahren wurde dabei immer für das gesamte Unternehmen organisiert. ${ }^{54}$ Die Bewerber konnten sich also nicht für ein bestimmtes Tochterunternehmen der Chaebol entscheiden, sondern ihre Bewerbung galt für das gesamte Chaebol. Wenn das Einstellungsverfahren beendet war, entschied die Firmenleitung, wer in welchem Tochterunternehmen arbeiten sollte. Wer diese Anordnung nicht akzeptierte, wurde trotz erfolgreich durchlaufenen Bewerbungsverfahrens nicht eingestellt. Entsprechend der von den Mitarbeitern geforderten Flexibilität bei der Übernahme neuer Aufgaben, mußten die Angestellten außerdem damit rechnen, später je nach Bedarf auch wieder in anderen Tochterunternehmen eingesetzt zu werden.

Die Auswahl neuer Angestellter erfolgte unabhängig von den Branchen, in denen die Chaebol tätig waren, nach einem immer gleichen Verfahren: Zunächst gab die Personalabteilung des Mutterunternehmens durch eine Zeitungsanzeige die Bewerbungsvoraussetzungen (wie z. B. die Altersgrenze, den

51Zu den beliebtesten Arbeitsplätzen gehörten damals die Banken, staatliche Unternehmen und Zeitungsfirmen. Vgl. Redaktion Sintonga, Urinun Irun Sawon eul Posubmida (Wie wählt man neue Mitarbeiter aus?), in: Sintonga, Heft Dezember (1966), S. 318.

52Won-Chul Oh, Hangukheong Keonje Keonsul (Das koreanische Entwicklungsmodell), Bd. 2, Seoul 1995, S. 28.

${ }^{53}$ Chang-Won Lee, Hanguk eui Kiup Elite (Die Elite des koreanischen Unternehmens), Seoul 1995, S. 87.

54 Yu-Kun Shin, Hanguk eui Keong-Yeong (Das Management in Korea), Seoul 1993, S. 491. 
notwendigen Schulabschluß und die gewünschten Studienfächer) bekannt und forderte die Bewerbungsunterlagen an (dazu gehörten in Korea nicht nur ein Lebenslauf, das Schulabschlußzeugnis und Gutachten von Professoren, sondern auch Angaben über die familiären und freundschaftlichen Beziehungen). Aufgrund dieser Unterlagen sortierte die Personalabteilung aus, wer sich für die nächste Stufe des Bewerbungsverfahrens qualifiziert hatte. Schon dabei wurden hauptsächlich Absolventen der Eliteuniversitäten ausgewählt. Bei den Fächern gab es dagegen kaum Präferenzen der Unternehmen. Es wurden sowohl geisteswissenschaftliche als auch naturwissenschaftliche Studenten genommen. ${ }^{55}$ Wer dieses erste Auswahlverfahren bestanden hatte, konnte an den schriftlichen und mündlichen Prüfungen teilnehmen.56 In der schriftlichen Prüfung wurde in der Regel das Allgemeinwissen, die Englischkenntnisse und das Ausdrucksvermögen im Aufsatz geprüft. Obwohl die Firmenleitung der koreanischen Chaebol durchaus der Auffassung war, daß beispielsweise gute Englischkenntnisse für Auslandsgeschäfte sehr nützlich seien, wurde auf die schriftliche Prüfung weniger Wert gelegt als auf die anschließende mündliche Prüfung, die dazu diente, die "Persönlichkeit" des Bewerbers kennenzulernen. ${ }^{57}$ Bei Samsung wurde die mündliche Prüfung für so wichtig gehalten, daß der Chaebolgründervater selbst regelmäßig an diesem Ritual teilnahm. 58

Bei der mündlichen Prüfung, die eher einem Interview (Bewerbungsgespräch) glich, interessierte man sich vor allem für die folgenden Persönlichkeitsmerkmale des Bewerbers: Aussehen, Sprachfähigkeit, Manieren, Charakter, politische Einstellung (besonders den Verdacht, links zu sein, durfte der Bewerber nicht erwecken) und bisheriger Lebenslauf. Für die Beurteilung dieser persönlichen Merkmale gibt es zwar kein quantitativ meßbares Kriterium, durch das man die "Objektivität" des Prüfungsverfahrens hätte sichern können. Doch hielt die Leitung der koreanischen Chaebol daran fest, daß beispielsweise ein

\footnotetext{
${ }^{55}$ Für den Produktionsbereich wurden häufig gezielt Naturwissenschaftler gesucht, doch mußten auch diese im weiteren Prüfungsverfahren ihr allgemeines Wissen und ihre Englischkenntnisse unter Beweis stellen.

56Sun-Dong Kim, Samsung eui Noch rul Pilyoro Hachi Annun Keong-Young (Samsungs Management, das keine Gewerkschaften braucht), Seoul 1995, S. 120.

${ }^{57}$ Redaktion Sintonga, Urinun Irun Sawon eul Posubmida (Wie wählt man neue Mitarbeiter aus?), in: Sintonga, Heft Dezember (1966), S. 326.

58 Samsung Keongje Yeonguso (Verfassergruppe), Hoameui Keongyeong Chulhak (Hoams Managementphilosophie), Seoul 1988, S. 67.
} 
Bewerber, der besser aussieht und bessere Manieren hat, für die Bewältigung der verschiedenen unternehmerischen Anforderungen besser gerüstet und vor allem für das Chaebol vorteilhafter sei, als ein Bewerber, bei dem dies nicht der Fall war. Insbesondere ging man davon aus, daß sich anhand der genannten Merkmale die "potentielle Lernfähigkeit" des Bewerbers feststellen läßt, womit nicht etwa die Fähigkeit, sich an die verändernden unternehmerischen Anforderungen anzupassen, gemeint war, sondern die Fähigkeit, gute zwischenmenschliche Beziehungen zu schaffen und zu pflegen. ${ }^{59}$ Weil in Korea der Einfluß persönlicher Beziehungen insbesondere auf den Informationsfluß sehr hoch ist, war die Fähigkeit, fremde Menschen als Freunde zu gewinnen, und damit für einen reibungslosen Informationsfluß innerhalb und außerhalb des Unternehmens zu sorgen, zentral wichtig für die Unternehmen. ${ }^{60}$ Das war der Grund, warum sich die Aufmerksamkeit der Unternehmen bei der Beurteilung des Bewerbers nicht auf dessen fachliche Qualifikation, sondern auf seine allgemeine Sympathie hervorrufenden persönlichen Merkmale, wie z. B. Aufrichtigkeit, Fleiß, Bescheidenheit und vor allem soziale Kompetenz, konzentrierte.

Dieses Rekrutierungsverfahren hieß "Kong-Chae" (Rekrutierung durch Ausschreibung) - im Gegensatz zu "Teuk-Chae" (Rekrutierung durch persönliche Beziehungen). 61

Wenn die Bewerber das Prüfungsverfahren erfolgreich durchlaufen hatten, begannen sie als einfache Mitarbeiter ("Peongsanwon") in der untersten Position der koreanischen Managementhierarchie. Dabei absolvierten sie zunächst ein vierwöchiges Trainingsprogramm, durch das das Zugehörigkeitsgefühl des

59Yu-Kun Shin, Hanguk eui Keong-Yeong (Das Management in Korea), Seoul 1993, S. S. 480.

60 So wurde der Bewerber beispielsweise gefragt, ob er aus Rücksicht anderen gegenüber bereit sei, ein Go-Spiel zu verlieren. Denn einem Bewerber, der immer gewinnen will, unterstellte man, ein egoistischer Mensch zu sein, der sich nicht für die Ziele des Unternehmens interessierte, während man von dem, der durch sein Verlieren das Gesicht des anderen zu wahren versucht, erwartete, bei anderen Menschen großen Sympathien zu erwecken. Dies wiederum werde sich dann in gegenseitiger Hilfsbereitschaft und in aktivem Informationsaustausch niederschlagen. Man ging also davon aus, daß sich der "Ich-kann-auch-verlieren-Typ" leichter an die sozialen Anforderungen im Unternehmen anpassen könne als der "Ich-will-immer-gewinnen-Typ" und sprach in diesem Sinne davon, daß ersterer über mehr "potentielle Lernfähigkeit" verfüge als der zweite Typ. Siehe Yu-Kun Shin, Hanguk eui Keong-Yong (Das Management in Korea), Seoul 1993, S. 509. 
neuen Mitarbeiters zum Unternehmen geweckt und zielorientierte Teamarbeit auf der Grundlage dieser Basissolidarität zum Unternehmen eingeübt werden sollte. Außerdem wurden die Mitarbeiter mit Aufgaben konfrontiert, die Risikobereitschaft und Ausdauer trainieren sollten. Deshalb gehörten auch Abente uerprogramme wie Hochgebirgsklettern oder Überlebenstraining ohne Lebensmittel und Geld zum Training. 62 Erst nach diesem Trainingsprogramm wurde der neue Mitarbeiter einem bestimmten Unternehmen und einer bestimmten Abteilung zugewiesen.

Von nun an stand jeder Mitarbeiter unter starkem Konkurrenzdruck, weil er sich bemühen mußte, schneller als seine Mitbewerber eine möglichst hohe Position innerhalb der unternehmerischen Hierarchie zu erreichen. Unabhängig von der Unternehmensgröße lassen sich in einem koreanischen Unternehmen zwei Hierarchieebenen unterscheiden: Die erste Ebene begann mit oben genannten einfachen Mitarbeiter und reichte bis zum höheren Abteilungsleiter ("Bujang"), entsprach also einer mittleren Managementebene. Die darüberliegende höhere Managementebene umfaßte die Mitglieder des Aufsichtsrates ("Isa") und die Geschäftsführer der Tochterunternehmen ("Sajang"). Darüber gab es dann nur noch den Unternehmensleiter. 63 In der Regel sprach man von einer erfolgreichen Karriere eines Managers, wenn dieser den Sprung vom mittleren ins höhere Management geschafft hatte.

Trotz der strukturellen Ähnlichkeit dieser Hierarchieebenen mit denen amerikanischer oder westlicher Großunternehmen ist meine These, daß die koreanische Unternehmenshierarchie insofern einen völlig anderen Charakter hat, weil nicht nur - wie oben schon beschrieben - die Einstellung von Mitarbeitern, sondern auch die Karrieren innerhalb der Unternehmen nach anderen Kriterien und Gesichtspunkten abliefen als in westlichen Unternehmen und damit anderen Wirkungsmechanismen unterlagen. Die Funktionsweise der Hierarchien ist in einem koreanischen Chaebol eine völlig andere als in amerikanisch-westlichen Unternehmen, in denen der Aufstieg von Mitarbeitern zu allererst (zumindest

${ }^{61}$ Bei Teuk-Chae fällt das schriftliche Prüfungsverfahren weg. Insbesondere ehemalige höhere Beamten oder Personen, die aus dem engen Kreis der Unternehmensleitung direkt empfohlen wurden, wurden über Teuk-Chae rekrutiert. Ebenda, S. 139.

62Jae-Yeul Lee, Entwicklung und Führung südkoreanischer Unternehmen: Insbesondere die Struktur, Organisation und Strategie südkoreanischer Unternehmensgruppen Chaebol, Dissertation Göttingen 1993, S. 92 
weitgehend) dem Prinzip von Arbeitsteilung, Spezialisierung und fachlicher Qualifikation folgt. ${ }^{64}$ In Korea dagegen ist die Position innerhalb einer Hierarchie nicht in erster Linie mit der Verantwortung für einen bestimmten Aufgabenbereich verbunden, sondern dient dazu, dem Mitarbeiter über die mit der Position verbundene soziale Statuszuweisung bessere Entfaltungsmöglichkeiten für seine Persönlichkeit zu verschaffen. Nicht der Mensch, so das dahinterstehende Verständnis von Hierarchie, fült eine entsprechende Position aus, sondern die Position macht (überspitzt gesagt) den Menschen. 65 Sobald man einen Posten übernahm, repräsentierte man die mit diesem verbundene Autorität und mußte diese nur noch der eigenen Persönlichkeit, der eigenen Phantasie und dem eigenen Durchsetzungsvermögen entsprechend mit Leben füllen - dies aber ratürlich im Interesse des Unterne hmens. 66

Dieser Auffassung von Hierarchie entsprechend ist es für die koreanischen Chaebol bezeichnend, daß ein mittlerer Manager in der Regel in das höhere Management eines neu entstandenen bzw. übernommenen Tochterunternehmen aufstieg, unabhängig davon, ob er bisher in der gleichen Branche tätig gewesen war oder nicht. Am konkreten Beispiel gesagt: Ein Topmanager von Samsung begann seine Karriere als mittlerer Manager in einem Textilunternehmen, wechselte dann in die Unternehmensleitung eines Kaufhauses und wurde schließlich Geschäftsführer wieder eines anderen Unternehmens. ${ }^{67}$ Ähnliche Karrieren finden sich auch bei Lucky-Goldstar oder Hyundai. Ebenso wie

${ }^{63}$ Ebenda, S. $94 \mathrm{f}$.

${ }^{64}$ Der japanische Sozialwissenschaftler Masahiko Aoki, Information, Incentives, and Bargaining in the Japanese Economy, New York u. a. 1988, hat auf die unterschiedliche Bedeutung der Hierarchie in amerikanischen und japanischen Unternehmen aufmerksam macht: "The view I habe presented in this book, however, ist that the Japanese organization has developed a nonhierarchical information structure (in the vertical sense), but that the nonhierarchical nature of this information structure makes it necessary to centralize the admnistration of the ranking hierarchy (horizontal in our sense) in order to ensure that employees will comply with, and cooperate for the purpose of achieving, organizational goals." (Ebenda, S. 303).

65Dies spiegelt auch die übliche Anrede: Als Abteilungsleiterin würde ich nicht mit Frau Rhee, sondern als Rhee-Bujang angesprochen.

${ }^{66}$ Vgl. dazu Samsung Keongje Yeonguso (Verfassergruppe), Hoameui Keongyeong Chulhak (Hoams Managementphilosophie), Seoul 1988, S. 218.

67Leider wird in der Quelle nicht angeben, welches Unternehmen der genannte Manager zuletzt übernahm, nur, daß es sich wieder um eine andere Branche handelte. Vgl. Samsung Keongje Yeonguso (Verfassergruppe), Hoameui Keongyeong Chulhak (Managementsphilosophie von Hoam), Seoul 1988, S. 216 f. Entsprechend wurde es übri- 
bei der Einstellung von Mitarbeitern spielte also spezialisiertes Fachwissen in Korea auch beim innerbetrieblichen Aufstieg keine Rolle.

Obwohl dies nahezuliegen scheint, halte ich es für unzutreffend, diese innerbetriebliche Rekrutierungspraxis von Führungskräften als "generalistischen Ausbildungsprozeß", den der Manager zu durchlaufen hat, zu kennzeichnen, wie dies in Anlehnung an Japan und England beispielsweise Yu-Ku Shin getan hat. 68 Denn diese Bezeichnung erweckt den Eindruck, als ob es innerhalb der koreanischen Chaebol ein systematisches Ausbildungsprogramm, an dem sich jeder Manager und Mitarbeiter orientieren konnte, gegeben hätte. Das war aber nicht der Fall: Dieser scheinbar "generalistische Ausbildungsprozeß" war im wesentlichen von der Willkür des Chaebolgründers abhängig, der sich in keiner Weise für das fachliche Wissen seiner Manager interessierte, sei es nun ein generelles oder ein spezielles Fachwissen. Den koreanischen Unternehmensleitern ging es einzig und allein um eine Eigenschaft, die als Führungsqualität oder besser Führungsverantwortlichkeit bezeichnet werden kann. Gemeint war, die Fähigkeit und Bereitschaft des jeweiligen Managers, die Autorität seiner Position für das unternehmerische Interesse des Chaebolgründers einzusetzen (und das schloß auch ein, die Arbeitskraft der Mitarbeiter in vollem Umfang für das Unternehmen zu mobilisieren). Fraglose Loyalität und persönliche Opferbereitschaft waren daher die wichtigste Voraussetzung für einen Aufstieg in höhere Führungspositionen. Erst danach kam als weitere erwünschte Fähigkeit das Geschick im Umgang mit dieser Position für die Ziele des Unterne hmens. 69

Dahinter verbarg sich die Befürchtung der Chaebolgründer, daß ihre Manager in hohen Positionen angesichts der fehlenden klaren Aufgabenzuweisung, die Autorität ihrer Position zur Erreichung eigennütziger persönlicher Ziele nutzen könnten. ${ }^{70}$ Deshalb war es den Unternehmensleitern sehr wichtig, den Mitarbeitern immer den Eindruck zu vermitteln, daß ihre Beförderung zum höheren

gens nicht akzeptiert, wenn ein Mitarbeiter, der sich für einen neuen Posten nicht für genügend qualifiziert hielt, eine Beförderung ablehnte. Vgl. dazu ebenda, S. 217.

68 Yu-Kun Shin, Hanguk eui Keong-Yeong (Das Management in Korea), Seoul 1993, S. 489.

69Vgl. dazu Byong-Chul Lee, Hoam Chacheon (Hoam Autobiographie), Seoul 1985, S. 246; Lucky Goldstar (Hrsg.), Hanbeon Midemyeon Modu Matkeora (Wenn du anfängst, jemandem einmal zu glauben, dann sollst du bereit sein, ihm alles anvertrauen zu können), Seoul 1979/1993, S. 368.

70 Yu-Kun Shin, Hanguk eui Keong-Yeong (Das Management in Korea), Seoul 1993, S. 168. 
Manager nicht mit ihren fachlichen Fähigkeiten zu tun hatte, sondern einzig und allein eine Belohnung für ihre Loyalität und ihre Einsatz- oder Opferbereitschaft war. Aufgrund dieses Beförderungsmechanismus konnte man dann von den Mitarbeitern immer noch mehr Loyalität bzw. eine noch größere Identifikation mit dem Ziel des Unternehmens verlangen, was auch die Bereitschaft einschloß, sich jederzeit für neue unternehmerische Anforderungen weiter ausbilden zu lassen (womit dann gleichzeitig auch das Problem der fachlichen Qualifikation gelöst war)..$^{71}$

Es war für die koreanischen Chaebolleiter keine leichte Aufgabe, herauszufinden, welcher Mitarbeiter für ihre Zwecke besonders geeignet war. Ihr großes Dilemma bestand darin, daß die Hierarchie als solche keine Garantie dafür war, daß die Manager über die geforderte Loyalität und Führungsverantwortlichkeit verfügten. Zwar konnten sie davon ausgehen, daß Beförderungen die Motivation des Mitarbeiters steigerten und damit auch seine Loyalität, aber das reichte nicht aus. In den Chaebol gab es daher ein ausdifferenziertes Benotungssystem ("Insagokwache"), durch das das Verhalten eines Mitarbeiters durch seinen Vorgesetzten im einzelnen bewertet wurde und das die Grundlage für dessen weiteren Aufstieg bildete. ${ }^{72}$ Wer bei der Benotung durch den Vorgesetzen kein gutes Ergebnis erzielte, hatte keine Chance befördert zu werden.

Wenn ein neuer Mitarbeiter auf der untersten Position der unternehmerischen Hierarchie mit seiner beruflichen Laufbahn begann, dann war seine erfolgreiche Karriere als Manager von nun an davon abhängig, wie er seinem Vorgesetzen gefallen würde. ${ }^{73}$ Seine "potentielle Lernfähigkeit", die schon im Einstellungsverfahren eine zentrale Rolle gespielt hatte, wurde nun anhand seiner konkreten Tätigkeiten und vor allem seiner sozialer Beziehungen zu Vorgesetzten und Kollegen laufend überprüft. Die Aufgabe des neuen Mitarbeiters bestand daher vor allem darin, sich - getreu konfuzianischer Tradition - der Autorität seines Vorgesetzten unterzuordnen und seinem Vorbild nachzueifern. ${ }^{74}$

71Vgl. Samsung Keongje Yeonguso (Verfassergruppe), Hoameui Keongyeong Chulhak (Hoams Managementphilosophie), Seoul 1988, S. 213.

72 Yu-Kun Shin, Hanguk eui Keong-Yeong (Das Management in Korea), Seoul 1993, S. 481.

${ }^{73}$ Chang-Won Lee, Hanguk eui Kiup Elite (Die Elite des koreanischen Unternehmens), Seoul 1995, S. 94.

74Die Autorität, die sich im menschlich vorbildhaften Charakter des Vorgesetzen bzw. des älteren Menschen ausdrücken sollte, war ein wichtiges Merkmal der konfuziani- 
Auch das notwendige Fachwissen eignete sich ein neuer Mitarbeiter in der Regel nicht etwa durch ein schriftlich fixiertes Arbeitsmanual, sondern durch Anleitung und direkte Unterweisung durch seinen Vorgesetzten an. ${ }^{75}$ Weil aber schon dessen Beförderung nicht wegen seines fachlichen Wissens, sondern wegen seiner Loyalität erfolgt war, war nicht gewährleistet, daß der Vorgesetzte über das notwendige fachliche Wissen überhaupt verfügte. Deshalb neigten die Vorgesetzten in der Regel zu guten Benotungen ihrer Untergebenen, weil sie selbst keinen negativen Eindruck bei ihren eigenen Vorgesetzten erwecken wollten und sich aber auch gegenüber ihren Untergebenen keine Blöße geben wollten. ${ }^{76}$ Dieses scheinbar so objektive Benotungssystem war daher faktisch sowohl für die Unternehmensleiter als auch für die Untergebenen höchst unbefriedigend und garantierte - auch wenn man nur die Kriterien Loyalität und Führungsverantwortlichkeit zugrundegelegt - keineswegs die Auswahl des jeweils besten Mitarbeiters. ${ }^{77}$

Zwischen Vorgesetzen und ihren Mitarbeitern bestand eine wechselseitige Abhängigkeit: Der Mitarbeiter mußte sich um eine möglichst gute persönliche Beziehung zu seinem Vorgesetzten bemühen und insbesondere jederzeit einsatz- und arbeitsbereit sein, wenn der Vorgesetzte dies verlangte. (Er konnte deshalb beispielsweise nie vor seinem Vorgesetzten Feierabend machen). Für die Vorgesetzten wiederum war es eine große Schande, wenn ihre Mitarbeiter innen keinen Respekt erwiesen und nicht genug oder gut genug arbeiteten. So viel Autorität und Respekt bei seinen Mitarbeitern zu haben, daß diese besonders gut und besonders viel arbeiteten - genau das machte die Führungsqualität des Vorgesetzten aus (und entschied nebenbei über seine eigene weitere Beförderung). Um das zu erreichen, war aber eine rein sachliche, auf die gemeinsame Arbeit beschränkte Beziehung nicht ausreichend. Daher war es ïblich, daß der Vorgesetzte zu seinen Mitarbeitern Beziehungen auch außerhalb der Arbeitszeit pflegte, indem er beispielsweise mit innen gemeinsam Essen

schen Gelehrten, die sich lebenslang darum bemühen sollten, für andere Menschen ein Vorbild abzugeben.

75Dieser konnte inm aber natürlich schriftliche Unterlagen oder Fachbücher zur Verfügung stellen. Vgl. oben Anm. 47.

${ }^{76}$ Chang-Won Lee, Hanguk eui Kiup Elite (Die Elite des koreanischen Unternehmens), Seoul 1995, S. 95.

77In Korea gibt es zur Zeit eine Tendenz, auch die Vorgesetzten durch die Untergebenen benoten zu lassen. 
und Trinken ging. Auf diese Weise entstand rasch eine sehr persönliche Beziehung zwischen dem Vorgesetzten und seinem Mitarbeiter, der sich nun auf eine persönliche Förderung verlassen konnte. Auch innerhalb der Unternehmen war also das bereits im vorigen Kapitel geschilderten Patronagesystem wirksam. Der Vorgesetzte fungierte dabei als Patron, der sich für das Weiterkommen eines von ihm aus welchen Gründen auch immer geschätzten Mitarbeiters einsetzte, was häufig einfach so aussah, daß er bei seiner eigenen Beförderung seinen Mitarbeiter in seine neue Wirkungsstätte mitnahm, der dadurch automatisch ebenfalls aufstieg.78

Weil neue Mitarbeiter, die keine Beförderungschance sehen, dazu neigen, ohne großes Engagement zu arbeiten, war es in den Chaebol üblich, daß jeder neue Mitarbeiter nach einer gewissen Dienstzeit automatisch ins mittlere Management befördert wurde. Obwohl es im Topmanagement nur sehr wenige Ste Ilen gab und ein weiterer Aufstieg daher nur wenigen offenstand, arbeiteten die meisten mittleren Manager mit der durch ihre erste Beförderung genährten Hoffnung, eines Tages auch ins Topmanagement aufsteigen zu können.79 Um diese Hoffnung möglichst lange zu erhalten, war die Unternehmensleitung daran interessiert, ihre Beförderungsstrategie möglichst im Dunkeln zu lassen, da für die Mitarbeiter auf der unteren Ebene nicht vorhersehbar war, wer einen Sprung auf die zweiten Ebene der Hierarchie schaffen würde und wer nicht. 80

Eine wichtige Gegenstrategie der aufstiegswilligen Mitarbeiter war daher, ihre verwandtschaftlichen, schulischen und regionalen Netzwerke ins Spiel zu bringen. Einen höheren Vorgesetzten oder ein Mitglied des Topmanagements, das zu diesem persönlichen Netzwerk gehörte, konnten sie als inoffiziellen Patron nutzen. Da das Topmanagement der Chaebol in der Regel aus den Absolven-

${ }^{78}$ Chang-Won Lee, Hanguk eui Kiup Elite (Die Elite des koreanischen Unternehmens), Seoul 1995, S. 116.

79Die Angestellten der mittleren Führungsebene, die den Aufstieg ins Topmanagement nicht schafften, blieben in der Regel im Unternehmen und wurden nicht entlassen. Dieses lebenslängliche Anstellungsprinzip, daß die Unternehmen ursprünglich ihren neuen Mitarbeitern fest zusicherten, wird erst in letzter Zeit vermehrt durchbrochen. Seit Mitte der 90er Jahre folgen die Chaebol verstärkt dem amerikanisch-westlichen Vorbild und kündigen ihre Mitarbeiter abhängig von der ökonomischen Situation des Unternehmens. Vgl. dazu z. B. den Artikel in der Tageszeitung Chosun-llbo vom 6.2.1998: Cheongri Haegoche Doipdoemeon... (Wenn die neuen Entlassungsgesetze eingeführt werden,...).

80Sun-Dong Kim, Samsung eui Nocho rul Pilyoro Hachi Annun Keong-Young (Samsungs Manangement, das keine Gewerkschaft braucht.), Seoul 1995, S. 63. 
ten der Eliteuniversitäten bestand, verfügte ein jüngerer Absolvent einer Elite universität über gute Chancen, eine solche inoffizielle Beziehung zu höheren Vorgesetzen aufbauen zu können. Die Unternehmensleitung sah die Bildung solche informellen Gruppen allerdings aus verschiedenen Gründen sehr ungern81: Zum einen erschwerten diese Strukturen die von ihnen angestrebte Geheimhaltung der innerbetrieblichen Beförderungsstrategie, zum zweiten befürchtete sie, daß die Mitarbeiter, die nicht über solche Netzwerke verfügten, demotiviert werden könnten, und zum dritten und wichtigsten bestand die Gefahr, daß sich die Mitarbeiter in verschiedene Fraktionen zersplitterten und so der funktional notwendige Informationsfluß innerhalb des Unternehmens blokkiert werden könnte. Völlig unterbinden ließen sich diese inoffiziellen Gruppierungen allerdings nicht, dafür basierte das gesamte Rekrutierungs- und Aufstiegssystem in koreanischen Betrieben zu stark genau auf diesen informellen Strukturen.

\section{VI.4 Die Doppelbödigkeit der koreanischen Managementkultur}

Erst seit Beginn der 80er Jahre mit der nicht mehr zu übersehenden Präsenz von japanischen Auto- und Elektrounternehmen auf dem Weltmarkt begannen sich Soziologen und Betriebswirte für den Begriff der "Managementkultur" zu interessieren. 82 Die Tatsache, daß japanische Unternehmen trotz gleicher ökonomischer Zielsetzung andere Verhaltensmuster produzierten, evozierte ein verstärktes Interesse an länderspezifischen kulturellen Prägungen, die auf die Unternehmensstruktur einwirkten, und führte dazu, daß die Kultur bzw. das kulturelle Orientierungsmuster eines Managers seitdem als wichtige unabhängige Variable für die Organisationsstruktur gelten. 83

\footnotetext{
${ }^{81}$ Vgl. dazu Samsung Keongje Yeonguso (Verfassergruppe), Hoameui Keongyeong Chulhak (Hoams Managementphilosophie), Seoul 1988, S. 167 f.

82Lediglich Anthropologen wie James C. Abegglen, The Japanese Factory, Glencoe/lllinoi 1958, und Chie Nakane, Die Struktur der japanischen Gesellschaft, Frankfurt am Main 1985, hatten schon früher auf die kulturbedingten Unterschiede in den Organisationsstrukturen japanischer Unternehmen aufmerksam gemacht.

${ }^{83}$ So hat beispielsweise Geert Hofstede, Culture's Consequences: International Differences in Work-Related Values, Beverly Hills/London 1980, empirisch untersucht, wie stark das Managementhandeln von der länderspezifischen Kultur bzw. von "kollektiver Programmierung" geprägt ist. Und Friedrich Fürstenberg, Managementkultur, in: Hans-
} 
Im Zusammenhang mit Korea wird das charakteristische Merkmal der Managementkultur in dem Phänomen gesehen, daß die Gründerväter der Chaebol trotz der rapiden Expansion ihrer Unternehmen ihre Führungsrolle nicht aufgaben, so, wie ein Familienvater bis zu seinem Tod niemals die Rolle des familiären Oberhauptes aufgibt. Ein beliebter Ausdruck zur Charakterisierung der koreanischen Managementkultur ist „Kabujanjeok-Munhwa" (patriarchalische Kultur), was häufig als Synonym für „Clan-Kultur" verwendet wird. 84

Doch weist die bisherige Herangehensweise an die Managementkultur meines Erachtens Defizite auf. Meiner Meinung nach fehlen vor allem Überlegungen dazu, daß die Managementkultur letztendlich auch in Korea oder anderen asiatischen Ländern ein Mittel unternehmerischen Handelns ist, um ökonomische Ziele besser durchsetzen zu können. Ich bin daher der Auffassung, daß man die Managementkultur im Zusammenhang dieser unternehmensgenuinen ökonomischen Interessenslogik sehen muß und sie nicht allein aus der länderspezifischen kulturellen Eigentümlichkeit erklären kann. Warum sollte der Gründervater eines koreanischen Chaebol, der wie jeder Unternehmer in den westlichen Ländern auch ein klares ökonomisches Ziel vor Augen hat, sein ökonomisches Interesse hinter seinen kulturellen Verpflichtungen zurückstellen und nur an die Anpassung an die traditionelle Kultur denken?

Um den Charakter der Managementkultur der koreanischen Chaebol zu verdeutlichen, werde ich im folgenden die Managementkultur aus der Perspektive des koreanischen Chaebolgründer betrachten. Dies bedeutet jedoch nicht, daß ich mich mit den häufig an traditionelle koreanische Familientugenden anknüpfenden Firmenslogans der Chaebol beschäftige, wie sie in Begriffen wie "Förderung des begabten Menschen", "harmonische Beziehung zwischen oben und

Dieter Ganter/ Gerd Schienstock (Hrsg.), Management aus soziologischer Sicht, Wiesbaden 1993, S. 133-145, verdeutlicht das Verhältnis von Kultur und Organisationsstruktur folgendermaßen: „Ein von individualisierender Arbeitsethik geprägtes Management wird die Schaffung von Einzelarbeitsplätzen in der Organisationskultur fördern, an denen eine personenbezogene Zurechnung von Leistung und Verantwortung möglich wird. Ein von koopertativem Arbeitsethos geprägtes Management wird hingegen stärkeres Gewicht auf Gemeinschaftsleistungen legen und diese auch organisatorisch ermöglichen, so daß die Grenzen individueller Verantwortungsbereiche weniger *kzentuiert werden. Dies ist z. B. ein Erklärungsgrund für den unterschiedlichen Aufbau von Wirtschaftsorganisationen in Japan und Westeurpa." (Ebenda, S. 133 f.)

84 Yu-Kun Shin, Hanguk eui Keong-Yeong (Das Management in Korea), Seoul 1993, S. 455. 
unten", "Fleiß, Bescheidenheit und Freundlichkeit" etc. zum Ausdruck kommen. ${ }^{85}$ Es ist selbstverständlich, daß solche Slogans Ausdruck von kulturellen Wertvorstellungen sind, die von der gesamten koreanischen Bevölkerung als erstrebenswerte Handlungsmuster anerkannt werden. Trotzdem halte ich es für unwahrscheinlich, daß das ökonomische Handeln in einem Unternehmen durch solche moralische Handlungsziele bestimmt wird, sondern gehe davon aus, daß andere Interessen vorherrschend sind.

Meines Erachtens kann man nicht alle traditionelle Wertvorstellungen als Kultur bezeichnen. Wenn man unter Kultur vor allem jene Handlungs- bzw. Orientierungsmuster versteht, die für die Definition der Handlungssituation unentbehrlich ist, dann ist es nicht schwer, zu erkennen, daß Kultur ohne eine konkrete Handlungssituation nicht denkbar ist. Es mag durchaus richtig sein, daß traditionelle Verhaltensmuster oder Denkweisen ein allgemein erstrebenswertes Prinzip oder eine Wertvorstellung beinhalten, aber es ist eine andere Frage, ob solche traditionellen Elemente vom handelnden Subjekt als tatsächliches kulturelles Muster wahrgenommen und praktiziert werden. Um feststellen zu können, welches Element der traditionellen Wertvorstellung und Handlungsweise als Kultur zu bezeichnen ist, reicht es nicht aus, daß man hierbei ohne genauere Berücksichtigung der jeweiligen Handlungssituation auf eine allgemeine Vorliebe für die Tradition hinweist. Deswegen meine ich, daß eine soziologische Kulturanalyse immer in Rückkoppelung auf die konkrete Handlungssituation erfolgen muß. Das gilt auch für die Analyse der koreanischen Managementkultur.

Vor diesem Hintergrund soll nun die koreanische Managementkultur anhand der betriebsinternen Machtstruktur der koreanischen Chaebol analysiert werden. Dabei richtet sich meine Aufmerksamkeit auf die Beziehung zwischen dem Eigentümer-Unternehmer und seinen Topmanagern. Ein wichtiges Element dieser Beziehung ist der verborgene Wirkungszusammenhang zwischen dem Planungsbüro der Chaebol und dem Topmanagement. Ich meine, daß die "HerrDiener-Beziehung" im Management, die ich im Gegensatz zu der vorherrschenden Charakterisierung dieser Beziehung als familiär bzw. patriarchalisch für zu-

${ }^{85}$ Byong-Mu Kwon, Hyundai wa Samsung Group Keongyeong Cheonrak Bigyo (Ein Vergleich der Managementstrategie von Samsung und Hyundai), in: Wolgan-Chosun, Heft 9 (1980), S. 302. 
treffender halte, 86 ohne genauere Analyse der Funktion dieses Planungsbüros nicht zu erklären ist. Das Planungsbüro ist die wichtigste organisatorische hstanz in einem Chaebol und schränkt den unternehmerischen Handlungsspielraum des koreanischen Topmanagers wesentlich ein. 87

Es ist noch nicht lange her, daß in koreanischen Unternehmen fremde, nicht zur Familie gehörende Personen zu Topmanagern ernannt werden. Bis Mitte der 60er Jahre konnten alle unternehmerischen Aufgaben von den Chaebolgründern selbst oder mit Hilfe ihres engsten Familienkreises bewältigen werden. ${ }^{88}$ Die Chaebolgründer bezeichneten zwar sich selbst und ihre engen Familienmitglieder als Manager, dies war aber nicht im westlichen Sinne zu verstehen. Denn außer dem Gründervater selbst waren diese Familienmitglieder keine autonomen Manager, die unabhängig Verantwortung trugen und über einen entsprechenden Handlungsspielraum verfügten. Ihre Rolle im Unternehmen entsprach der eines jüngeren Mitgliedes innerhalb der Familie. Insofern war es kaum denkbar, daß diese als "Manager" tätigen Familienmitglieder unabhängig von ihrer familiären Beziehung eine neue, eigenständige Berufskultur entwikkelten.

Die Gründerväter der koreanischen Chaebol fühlten sich angesichts der Ernennung von fremden Angestellten als Topmanager völlig verunsichert. Sie fürchteten, daß ihr gesamtes unternehmerisches Imperium durch falsche Entscheidungen (z. B. eine falsche Produktions- und Marktstrategie) der Topmanager beeinträchtigt bzw. existentiell bedroht werden könnte. $89 \mathrm{lhr}$ Dilemma bestand darin, daß sie aufgrund der Größe, die ihre Unternehmen inzwischen hatten, den Überblick über alle unternehmerischen Angelegenheiten nur mit Hilfe der Topmanager und ihrer regelmäßigen Berichte, zu denen diese verpflichtet waren, behalten konnten. So befürchtete beispielsweise Byong-Chul

${ }^{86} \mathrm{Vgl}$. dazu oben Abschnitt VI.2 (S. 217).

87Jae-Yeul Lee, Entwicklung und Führung südkoreanischer Unternehmen: Insbesondere die Struktur, Organisation und Strategie südkoreanischer Unternehmensgruppen Chaebol, Dissertation Göttingen 1993, S. 90.

${ }^{88}$ Es war 1957, als Samsung als erstes Unternehmen in Korea durch eine öffentliche Ausschreibung Mitarbeiter für das Management rekrutierte. Doch erst seit Ende der 70er Jahre konnten diese auch ins Topmangement aufsteigen. Vgl. Yong-Cheong Park, Yise wa Inmak dul (Zweite Generation und personelle Verflechtung), in: WolganChosun, Heft 9 (1980), S. 272 ff.

89Samsung Keongje Yeonguso (Verfassergruppe), Hoameui Keongyeong Chulhak (Managementsphilosophie von Hoam), Seoul 1988, S. 187. 
Lee insbesondere, daß ihm seine Topmanager nur beschönigende Information mitteilten und er selbst deshalb keinen realitätsadäquaten Überblick über sein Unternehmen gewinnen könnte. Außerdem traute er seinen Topmanagern, die alle viel jünger als er waren, nicht zu, die unternehmerischen Angelegenheiten als Ganzes im Auge zu behalten und nicht nur aus der Perspektive des von innen jeweils vertretenen Tochterunternehmen zu betrachten. Er befürchtete, daß der Informationsfluß zwischen seinen Tochterunternehmen wegen der Konkurrenz unter den Topmanagern nicht reibungslos funktionieren würde. ${ }^{90}$ Deshalb entschloß er sich, die Struktur seines Managements so zu gestalten, daß die ernannten Topmanager trotz ihrer hohen Position in einem seiner Tochterunternehmen nicht über einen freien unternehmerischen Handlungsspielraum verfügten, sondern von einer zentralen Leitungsstelle überwacht wurden. Deshalb schuf er ein zusätzliches Planungs- und Koordinationsbüro, das auf koreanisch "Biseosil" (Sekretariat) oder "Kihoek-Chochungsil" (Planung- und Koordinationsbüro) heißt. 91

Ursprünglich war die Grundidee dieses 1957 eingerichteten Büros, daß seine Mitarbeiter verschiedene unternehmensrelevante Informationen über den Staat, den Markt etc. sammeln und analysieren sollten, und Lee nutzte es zunächst als "Think-Tank" für seine unternehmerischen Entscheidungen. So war z. B. die Rekrutierungsstrategie durch Ausschreibung ein Vorschlag, der von diesem Büro entwickelt wurde. ${ }^{92}$ Anfänglich arbeitete das Büro, in dem Lee die besten Mitarbeiter seines Unternehmens versammelte, unter Lees Kontrolle, ohne direkt Aufgaben im Management zu übernehmen. Obwohl es nicht selten war, daß Mitarbeiter dieses Büros später wegen der besonderen Nähe zum Gründervater in der günstigen Situation waren, ihre Beförderung zu beschleunigen, hatte es daher zunächst keinen großen Einfluß auf die Managementkultur.

Als aber das Topmanagement eines seiner Tochterunternehmen durch einen unternehmerischen Fehler große finanzielle Verluste verursacht hatte, ent-

\footnotetext{
90Ebenda, S. 185.

${ }^{91 E b e n d a, ~ S . ~ 180 . ~ B e i ~ S a m s u n g ~ h e i ß t ~ d i e s e s ~ B u ̈ r o ~ n o c h ~ i m m e r ~ ' B i s e o s i l ", ~ w a ̈ h r e n d ~}$ Lucky-Goldstar und Hyundai später die Bezeichnung "Kehoek-Chochungsil" verwendeten.

92Byong-Mu Kwon, Hyundai wa Samsung Group Keongyeong Cheonrak Bigyo (Ein Vergleich der Managementstrategie von Samsung und Hyundai), in:Wolgan-Chosun, Heft 9 (1980), S. 304.
} 
schloß Lee sich nicht nur, das Sekretariat zu erweitern, sondern ernannte die Mitarbeiter dieses Büro auch zu seinen Stellvertretern, 93 die die Topmanager überwachen und kontrollieren sollten. Weil die Aufgabe dieses Büros darin bestand, die Fehler der Topmanager aufzudecken und sie gegebenenfalls auch durch öffentliche Abmahnung und Versetzung auf einen aussichtslosen Posten zu bestrafen, 94 arbeiteten dessen Mitarbeiter wie "Geheimagenten" des Gründervaters. 95 Obwohl die Mitarbeiter des Sekretariats in der offiziellen Unternehmenshierarchie unter den Topmanagern standen, übten sie als Stellvertreter des Gründervaters große Macht aus. Aber ihre Macht war nicht öffentlich, da es ein strenges Geheimnis war, wer welchen Topmanager überwachte und seine Leistung auswertete. In der Regel wurde der Bericht dieses Mitarbeiters zunächst durch den Leiter des Sekretariats an Lee weitergeleitet. Danach entschied dieser, wer weiter Zugang dazu erhielt.

Diese verworrene Managementstruktur von Samsung trug dazu bei, daß Lee als Gründervater des Unternehmens nach wie vor über die meisten Informationen verfügte und den Überblick über das gesamte Unternehmen hatte. 96 Auf der Grundlage dieses seines exklusiven Wissens traf Lee weiterhin selbst alle wichtigen Entscheidungen. Insofern gründete sich seine Überlegenheit und Autorität als Chaebolgründer gegenüber den einzelnen Topmanagern nicht allein auf seine Kapitalmacht, sondern vor allem auf das bei ihm konzentrierte Wissen. Die genuinen Aufgaben der Topmanager bei Samsung wurden angesichts ihres eingeschränkten Wissensstandes logischerweise immer weniger. ${ }^{97}$

93Lee betonte, daß wer im "Biseosil" arbeite, auch wie Lee selbst denken, fühlen und handeln sollte. Sun-Dong Kim, Samsung eui Nocho rul Pilyoro Hachi Annun KeongYoung (Samsungs Manangement, das keine Gewerkschaft braucht.), Seoul 1995, S. 85.

${ }^{94} \mathrm{Oft}$ baten die so abgestrafen Manager danach selbst um ihre Entlassung. In extremen Fällen (z. B bei Bruch der Loyalität) ging das Unternehmen danach so weit, dem ehemaligen Mitarbeiter alle weiteren Geschäftsaktivitäten unmöglich zu machen, indem es potentielle Geschäftspartner bedrohte oder erpresste, falls sie mit diesem Mitarbeiter Geschäfte machten. Vgl. Maeng-Hee Lee, Mudedun Yiyaki (Die unbekannte Geschichte), Seoul 1993, S. 171.

95Sun-Dong Kim, Samsung eui Nocho rul Pilyoro Hachi Annun Keong-Young (Samsungs Manangement, das keine Gewerkschaft braucht.), Seoul 1995, S. 91.

96Ebenda, S. 87.

97Vgl. dazu Jeong-Pyo Choi, Sunjinhwa rul wihan Chaebol eui Seontak (Die Modernisierungsstrategie der koreanischen Chaebol), Seoul 1996, S. 61; Jae-Yeul Lee, Entwicklung und Führung südkoreanischer Unternehmen: Insbesondere die Struktur, Organisation und Strategie südkoreanischer Unternehmensgruppen Chaebol, Dissertation Göttingen 1993, S. 17. 
Denn so die Entscheidungen nicht von Lee persönlich getroffen wurden, war sein Sekretariat für alle relevanten Entscheidungen (wie etwa den Einsatz des Firmenkapitals, die Produktions- und Marktstrategie und die Ernennung bzw. Rekrutierung neuer Mitarbeiter) zuständig. Insofern könnte man sagen, daß sich im Management von Samsung zwei verschiedene Typen von Managern finden lassen: Der eine war der offiziell ernannte Manager, der keine eigenständige unternehmerische Entscheidung treffen konnte, und der andere war ein Mitarbeiter des sog. Sekretariats, der ohne offizielle entsprechende Position als geheimer Stellvertreter des Eigentümer-Unternehmers fungierte. Weil beide nur durch die verborgene Regie des Gründervaters funktionierten, entwickelte sich zwischen innen eine starke Konkurrenzbeziehung und ein großes gegenseitiges Mißtrauen. Lee wiederum versuchte diese Konkurrenz auch in sein Büro hineinzutragen, indem er dort einmal die Position des obersten Managers und dann wieder die eines Mitarbeiters im Büro einnahm. Er persönlich hielt dies für seine wichtigste Managementstrategie, die den Ehrgeiz seiner Mitarbeiter anstachelte und sie so zum besseren Arbeiten brachte. ${ }^{98}$

Mitte der 60er Jahre folgten Lucky-Goldstar und Hyundai dem Vorbild von Samsung und richteten ebenfalls Planungs- und Koordinationsbüros in ihren Unternehmen ein, die sie als "Stab" ihres Unternehmens bezeichneten. Wie bei Samsung gab es diese Planungsbüros nur im Mutterunternehmen, in dem der Gründervater selbst Topmanager war. Nachdem Präsident Park die staatliche Förderung der Schwerindustrie bekannt gegeben hatte, konzentrierte sich die Aufgabe der Planungsbüros darauf, durch geschickte Verhandlungen mit der Regierung das Betätigungsfeld der Unternehmen zu erweitern. Obwohl die Mitarbeiter dieses Büros, die aus dem mittleren Management ausgewählt wurden, über keine unmittelbare unternehmerische Erfahrung verfügten, scheuten sie sich nicht, durch Lektüre ausländischer Fachliteratur beispielsweise eine richtungweisende Produktions- und Marktstrategie für die jeweiligen Tochterunternehmen zu entwickeln. Als sich etwa Hyundai für die Massenproduktion von

98Dabei begründete Lee die Nützlichkeit dieser Strategie mit dem folgenden Beispiel: Wenn man versucht, in einem Aquarium sowohl einen großen, fischfressenden Fisch als auch einen kleinen Fisch zu züchten, dann muß der kleine Fisch so schnell wie möglich vor diesem fressenden Fisch flüchten, was seine Muskeln und Schwimmflossen stärkt. Vgl. Hyo-Jin Oh, Samsung New Leader Lee Kun-Hee Hoejang (Der neue 
Automobilen entschied, bestimmten die Mitarbeiter dieses Büros nicht nur die Produktionszahl, sondern entschieden auch über die Art und Weise des Techniktransfers. ${ }^{99}$ Gleichzeitig gehörte es zur wichtigen Aufgabe dieses Büro, den Kapitaltransfer von den verschiedenen Tochterunternehmen zu verwalten. Ob die Tochterunternehmen bei Übernahme oder Errichtung eines neuen Unternehmens bürgen oder Kapital investieren sollten, wurde nicht vom Topmanager des jeweiligen Tochterunternehmens, sondern vom Planungsbüro bestimmt. So war es keine Seltenheit, daß der Topmanager über einen sein Unternehmen betreffenden Investitionsplan erst während einer Sitzung aller Topmanager unterrichtet wurde, die unter Vorsitz des Gründervater selbst oder seines familiären Nachfolger regelmäßig stattfand. ${ }^{100}$ Manchmal gab man auch hier die Entlassung von Topmanagern bekannt.

Die Folge einer solchen Unternehmensstrategie war natürlich, daß sich die Manager wie Marionetten des Planungsbüros verhielten. Sie verloren damit ihre Beziehung zu den genuinen Aufgaben eines Topmanagers. Viele interessierten sich nicht mehr für die aktuelle Marktlage ihres Produktes, denn dies war die Aufgabe des Planungsbüro. Welche unternehmerische Erfahrung und Qualifikation diese einzelnen Topmanager hatten, war daher völlig bedeutungslos. Ihre Entfremdung innerhalb des Unternehmens glorifizierte gleichzeitig die Fähigkeiten des Gründervaters als Topmanager. Am stärksten zeigte sich diese Tendenz bei Hyundai: Für Joo-Young Cheong war es bezeichnend, daß er sich neben seinem Planungsbüro noch selbst um die Sammlung der wichtigen unternehmerischen Informationen kümmerte. Dabei verfügte er über den großen Vorteil, seine hauptsächlich durch Bestechungsgelder ermöglichten engen und langen Beziehungen zu wichtigen Politikern und Regierungsbeamten als Quelle für neue Informationen nutzen zu können. 101

Die Macht des Planungsbüros war der Herausbildung einer eigenständigen koreanischen Managementkultur selbstverständlich abträglich. Die koreanischen Topmanager konnten keine selbständige Berufskultur entwickeln. Um

Unternehmensleiter von Samsung, Kun-Hee Lee), in: Wolgan-Chosun, Heft 12 (1989), S. 351.

99Meong-Han Kang, Pony rul Mandun Byeolnan Hangukindul (Die sonderbaren Koreaner, die das Auto Pony gebaut haben.), Seoul 1986, S. 24.

100 Seoul Keongje Sinmun Sanupbu (Verfassergruppe), Chaebol, Seoul 1995, S. 173.

${ }^{101}$ Ebenda, S. 167. 
Kritik und Bestrafung durch das Planungsbüro zu vermeiden, begnügten sie sich zumeist mit der Rolle des gehorsamen Untergebenen und orientierten ihr Verhalten nur ausschließlich daran, was dem Gründervater und dem Planungsbüro gefallen würde. Natürlich ist ein solches passives und unterwürfiges Verhalten vom Idealbild eines westlichen Topmanagers weit entfernt und führte im übrigen dazu, daß sich die koreanischen Topmanager entgegen der offiziell von den Gründervätern propagierten Firmenpolitik keineswegs stark mit den Zielen des Unternehmens identifizierten. ${ }^{102}$ Gleiches galt - wie der Abschnitt über Rekrutierung und innerbetrieblichen Aufstieg oben gezeigt hat - im übrigen auch für die Manager auf einer mittleren Führungsebene. Hier übernahm die Funktion des Planungsbüros der Vorgesetzte, der ebenfalls nur Anpassung und Unterwerfung unter seine Vorgaben verlangte, während Eigeninitiative und Kreativität verpönt waren. Dieses Verhalten wirkte außerdem (im negativen Sinne) vorbildhaft auf viele junge Büroangestellte, die sich daher ebensowenig mit "ihrem" Unternehmen identifizierten wie die Topmanager.

Das bedeutet, daß in den Chaebol - entgegen weitverbreiteten Vorstellungen - keineswegs auf Vertrauen oder gar, wie es in den Firmenslogans hieß, auf Harmonie gegründete familiäre Strukturen herrschten, mit dem Gründervater als Patriarchen an der Spitze. Statt dessen gab es ein vom Chaebolgründer zur Durchsetzung seiner ökonomischen und auf die Sicherung der eigenen Macht gerichteten Interessen geschaffenes und von ihm ständig verfeinertes Kontrollsystem, dessen Funktionsweise den Mitarbeitern verborgen blieb und das deshalb hauptsächlich auf der Grundlage von Angst funktionierte. Das heißt, daß die koreanische Managementkultur sozusagen einen doppelten Boden hatte: Unter der offiziell sichtbaren Managementstruktur lag eine zweite Ebene, auf der die wirklichen Entscheidungen getroffen wurden. Dabei muß noch einmal betont werden, daß sich auch in den Planungsbüros keine eigenständige Managementkultur entwickeln konnte. Dafür hatte der Chaebolgründer durch die untergeordnete Position der Mitarbeiter dieses Büros innerhalb der Unternehmenshierarchie und seine eigene häufige Präsenz in diesem "Planungsstab" gesorgt.

${ }^{102}$ Chang-Won Lee, Hanguk eui Kiup Elite (Die Elite des koreanischen Unternehmens), Seoul 1995, S. 94. 
Diese Doppelbödigkeit der koreanischen Managementkultur beweist, daß der Vergleich mit der "Clan-Kultur" einer koreanischen Großfamilie deren Charakter nicht gerecht wird. Die dort ablaufenden Mechanismen scheinen mir dagegen durch die ebenfalls in einer langen koreanischen Tradition wurzelnde Charakterisierung als "Herr-Diener-Beziehung" zutreffend beschrieben.

\section{VI.5 Resümee}

Für die Führungsstruktur der koreanischen Chaebol ist es bezeichnend, daß sie trotz ihrer Entscheidung für die Massenproduktionsstrategie keine Trennung von Eigentümer und Manager kannte. ${ }^{103}$ Doch war dies kein naturwüchsiges Phänomen, sondern eine Folge einer im koreanischen Kontext verankerten, subjektiven Haltung der Gründerväter der Chaebol, die in den westlichen Großunternehmen nicht ihr organisatorisches Vorbild sehen wollten. Obwohl die koreanischen Chaebol durchaus bereit waren, vom Fortschritt des westlichen $\mathrm{Ma}$ nagements zu profitieren, entstand daher in Korea ein eigenständiges Verständnis von Management, das im wesentlichen durch die Sichtweise der Chaebolleiter geprägt war. Deren starke Rolle in Staat und Gesellschaft wäre natürlich nicht denkbar gewesen wären, wenn das Bankensystem und die Gewerkschaften in Korea in der Lage gewesen wären, Kontrolle über die Unternehmer auszuüben, so wie dies in den westlichen Ländern der Fall war. Eine solche Kontrolle hätte sicher auch die Managementkultur in Korea insofern beeinflußt, als dadurch sowohl die unangefochtene Stellung des Chaebolgründers als auch das nicht an fachlicher (speziell betriebswirtschaftlicher) Qualifikation orientierte Rekrutierungssystem für Manager in Frage gestellt worden wären.

Die Gründerväter der Chaebol bevorzugten als Manager Absolventen der Eliteuniversitäten und zwar deshalb, weil sie hofften, auf diese Weise sowohl

\footnotetext{
${ }^{103}$ Auch als die Chaeboleigentümer Ende der 60er Jahre aufgrund zunehmenden staatlichen Drucks gezwungen wurden, ihre Unternehmen in eine Aktiengesellschaft umzuwandeln, umgingen sie die Gefahr einer Kontrolle ihrer Unternehmen durch fremde Aktieninhaber, indem sie weiter die Mehrheitsaktien hielten. Sie interessierten sich aus Furcht, ihre Profite mit anderen Aktieninhabern teilen zu müssen, auch nicht für den Aktienmarkt als Ressource zur Kapitalgewinnung. Vgl. dazu Cheong-Reom Kim, Hanguk Keongje Cheong-Chaek 30 Yeonsa (Dreißig Jahre koreanische Wirtschaftspolitik), Seoul 1995, S. 281.
} 
das Ansehen des Unternehmens steigern als auch von dem Beziehungskapital derjenigen profitieren zu können, die gemeinsam mit einflußreichen Regierungsbeamten auf der gleichen Universität studiert hatten. Natürlich hängt diese Rekrutierungsstrategie eng mit dem koreaspezifischen Kontext unternehmerischen Handelns zusammen, in dem Planung und Umsetzung der unternehmerischen Ziele nur durch geschicktes Verhandeln mit Regierungsmitarbeitern möglich war. Aufgrund der konfuzianischen Tradition, die Hilfsbereitschaft gegenüber einem Freund (wobei Freundschaft sich schon durch gemeinsames Studium oder gleiche regionale Herkunft konstituierte) zur höchsten Tugend erklärte, war der Regierungsbeamte moralisch verpflichtet, den "befreundeten" Verhandlungspartner auf Unternehmensseite zu unterstützen, wofür sich das Unternehmen seinerseits durch Geschenke erkenntlich zeigte. In Korea galten solche Geschenke eher als Tugend denn als Unmoral, weil sie dazu dienten, die Hilfsbereitschaft unter Freunden zu fördern. ${ }^{104}$ Obwohl es auch in Korea gesetzlich vorgeschrieben war, Person und Amt strikt zu trennen, waren die traditionellen konfuzianischen Werte noch so wirksam, daß es für "asozial" gehalten werden wäre, wenn jemand wirklich eine solche Trennung vorgenommen hätte. Als "sozial-korrekt" galt es dagegen, sein Amt unter Berücksichtigung dieses persönlichen Beziehungsgefüges für andere zu nutzen. ${ }^{105}$ Aufgrund der im vorigen Kapitel geschilderten engen Verflechtung von Staat und Chaebol gehörten die Chaebol zu den größten Nutznießern dieser traditionellen koreanischen Kultur.

Auch bezogen auf den innerbetrieblichen Aufstieg ihrer Manager interessierten sich die Chaebolgründer nicht für deren fachliche Qualifikation, sondern ausschließlich für deren Loyalität gegenüber der Unternehmensleitung und für deren sog. Führungsverantwortlichkeit, was bedeutete, daß sie ihre und die

${ }^{104}$ Als die Öffentlichkeit nach der Demokratisierung des Landes erfuhr, welches Ausmaß und welche Höhe diese (Geld-)Geschenke annehmen konnten, änderte sich die allgemeine Haltung zu solchen Geschenken radikal und den Beamten wurde Bestechlichkeit vorgeworfen. Doch wenn es wegen dieser Bestechungsgeschenke zu einer Anklage kommt, entscheidet das koreanische Gericht häufig, daß die Entgegennahme solcher Geschenke auf alltäglichen koreanischen Konventionen beruht und daher nicht strafbar ist. Vgl. z. B. den Artikel in der Tageszeitung Chosun-llbo vom 30.7.1999: Yu Sung-Su Keomsawa eui Daedam (Ein Gespräch mit dem Staatanwalt über das Urteil in der Spendenangelegenheit).

105Vgl. dazu Young-Bok Ko, Hanguk Sahoe Kujo eui Bunsek (Analyse der koreanischen Gesellschaftsstruktur), in: Sintonga, Heft Februar (1965), S. 67. 
Kräfte ihrer Mitarbeiter in vollem Umfang für das Unternehmen einsetzten. Trotz des hohen gesellschaftlichen Ansehens, das mit dem Posten eines Managers verbunden war, entwickelte sich daher in Korea kein eigenständiges Berufsbild für Manager, so daß auch ein koreanischer Topmanager nicht als ein professioneller Manager im westlichen Sinne angesehen werden kann. ${ }^{106}$

Um den Anforderungen der Unternehmensleitung zu genügen, mußten die Manager der koreanischen Chaebol nicht nur bereit sein, ohne Anspruch auf ein eigenes spezielles Tätigkeitsfeld nur im Interesse des Unternehmens zu arbeiten, sondern brauchten vor allem eine Strategie, um ihre Beförderungschancen durch geschicktes Einfädeln informeller Beziehungen sowohl zu Untergebenen als auch zu Vorgesetzten zu verbessern. Natürlich führte dies dazu, daß das Management der koreanischen Chaebol die Form einer geschlossenen Gesellschaft annahm, aus der viele Mitarbeiter, die nicht zu den einflußreichen, durch gemeinsame schulische und regionale Herkunft gebildeten, informellen Gruppen gehörten, herausfielen. Rekrutierungs-, Aufstiegs- und Entscheidungsprozesse innerhalb des koreanischen Managements erinnern daher stark an "Cliquenwirtschaft", was im übrigen dazu führte, daß die Chaebol als Verstärker von "Regionalismuswahn" und "Bildungsfieber" in letzter Zeit massiv in die Kritik gerieten. ${ }^{107}$

Ein wichtiges Charakteristikum der koreanischen Manager zumindest bis 1987 war es, daß sie sich niemals für Arbeitnehmerinteressen einsetzten, da ihre Ziele sich ja nur an den Interessen des Arbeitgebers bzw. des Gründervaters orientierten und nicht an der gesamten Belegschaft des Unternehmens. Diese einseitige Interessenlage der koreanischen Manager ist insofern nicht erstaunlich, als eine Position im Topmanagement in Korea in der Regel mit einem Sitz im Aufsichtsrat gekoppelt war, ${ }^{108}$ dessen Aufsichtsfunktion dadurch natürlich weitgehend obsolet wurden.

\footnotetext{
${ }^{106}$ Vgl. dazu auch Yu-Kun Shin, Hanguk eui Keong-Yeong (Das Management in Korea), Seoul 1993, S. 92.

107Vgl. z. B. den Artikel in der Tageszeitung Chosun-llbo vom 31.10.1996: Jikjang Anin Jikupeul Korza (Wichtig ist nicht, daß man in einem Großunternehmen arbeitet, sondern, daß man Wert auf seine berufliche Tätigkeit legt.)

${ }_{108}$ Vgl. dazu Jae-Yeul Lee, Entwicklung und Führung südkoreanischer Unternehmen: Insbesondere die Struktur, Organisation und Strategie südkoreanischer Unternehmensgruppen Chaebol, Dissertation Göttingen 1993, S. 12.
} 
Trotz dieser formalen Machtfülle war der Einfluß der koreanischen Topmanager auf unternehmerische Entscheidungen extrem gering. Statt der formalen offiziellen Hierarchie wurden - ebenso wie die Karrieren der Manager - auch unternehmerische Entscheidungsprozesse durch informelle Strukturen bestimmt, in diesem Fall durch eine verdeckte Herrschaftsstrategie des Unternehmensgründers: Um seine Machtfülle zu sichern und seine ökonomischen Ziele durchzusetzen, schuf dieser ein firmeninternes Überwachungsorgan für seine Manager, das als sein "verlängerter Arm" fungierte und einerseits völlig von ihm abhängig war und andererseits gegenüber den Managern enorme Macht besaß. Die Planungs- und Koordinationsbüros in den koreanischen Chaebol kontrollierten die Manager nicht nur, sondern bestraften sie auch, wenn diese nicht die von der Unternehmensleitung erwartete ökonomische Leistung erbrachten. Die Topmanager waren dem Planungsbüro gegenüber weisungsgebunden und agierten, da innen wesentliche Informationen vorenthalten wurden, zwangsläufig mehr und mehr als dessen Marionetten. Innerhalb des Unternehmens war die Position der koreanischen Manager zwar mit der Stellung der jüngeren Familienmitglieder, denen vor der Expansion der Chaebol ja bevorzugt Managementaufgaben übertragen worden waren, vergleichbar, doch erinnerte ihre Rolle - insbesondere aufgrund der starken Stellung der Planungsbüros 109 - stärker an die eines "gehorsamen Dieners", der die Anordnungen seines Unternehmerherrn unhinterfragt ausführt.

Die Gründerväter der Chaebol, die, wie ihre Biographien zeigen, durchaus frühzeitig die Notwendigkeit eines modernen Managements erkannten und daher auch bereit waren, Planungs-, Koordinations- und Kontrollaufgaben abzugeben, hatten mit dem von innen abhängigen Planungsbüro eine Institution geschaffen, an das sie diese Aufgaben delegieren konnten, ohne die direkte Kontrolle darüber zu verlieren oder gar Machtbefugnisse abzugeben. Es gelang ihnen daher auf eine (korea-)eigentümliche Weise Organisationsstrukturen eines traditionellen Familienunternehmens mit denen eines Großunternehmens vermischen. Bewußt oder unbewußt nutzten sie dabei alte konfuzianische, nach wie vor in Korea äußerst lebendige Kulturmuster (wie beispielsweise, daß Arbeit

${ }^{109}$ Gerade weil diese Manager nicht zur Familie gehörten und man ihnen daher nicht in gleicher Weise trauen konnte, hatten sich ja die Chaebolgründer bemüßigt gefühlt, die Planungsbüros einzurichten. 
nicht als Beruf aufgefaßt wurde und es kein eigentliches Berufsethos gab, was sicher wesentlich dazu beitrug, daß sich kein professionelles Managertum in Korea entwickelte, oder, daß man sich einem Vorgesetzten ("Herrn") unterzuordnen und ihm loyal ergeben zu sein hatte, was dafür verantwortlich war, daß sich kein Widerstand gegen die Marginalisierung der Manager in koreanischen Unternehmen regte). Auf diese Weise spiegelte die "Doppelbödigkeit" der toreanischen Managementkultur die "Doppelbödigkeit" der sich sowohl an kulturellen Traditionen als auch an rein ökonomischen, unternehmensgenuinen Zielen orientierenden Motive der koreanischen Chaebolgründer.

Solange die Gründerväter der koreanischen Chaebol mit Hilfe des Planungsbüros die zentralen Angelegenheiten des Unternehmens selbst in die Hand nehmen konnten, war eine derartige Managementstruktur kein Problem. Doch mit den immer komplexer werdenden Anforderungen des Marktes seit dem Ende der 80er Jahre, die ein immer schnelleres Reagieren verlangten, verwandelte sich diese Managementkultur der koreanischen Chaebol in ein großes Hindernis, das die Anpassung an diese durch die Öffnung des einheimischen Marktes und die Erstarkung der Gewerkschaftsbewegung gegebenen neuen unternehmerischen Herausforderungen zunehmend erschwerte. Die koreanischen Chaebolleiter versuchen daher seit Beginn der 90er Jahre ihren Managern nicht nur mehr Entscheidungsspielraum zuzugestehen und mehr Eigenverantwortung zu übertragen, sondern auch die starren Hierarchien aufzuweichen und insbesondere die Gleichsetzung von Position und sozialem Status aufzuheben, um auf diese Weise auch in koreanischen Unternehmen zu mehr Teamwork zu gelangen. ${ }^{110}$

110Vgl. dazu Cha-Keong Ku, O jik Yi Kil Bake Eopda (Es gibt keinen anderen Weg), Seoul 1992, S. 40. 


\section{Schlußfolgerung}

\section{VII.1 Zusammenfassung der Ergebnisse}

Trotz ihrer relativ kurzen Unternehmensgeschichte erreichten die koreanischen Chaebol innerhalb von drei Jahrzehnten einen unternehmerischen Status, der dem von Großunternehmen, Konzernen oder Konglomerat in den westlichen Ländern vergleichbar ist, und entwickelten sich zu auf dem Weltmarkt konkurrenzfähigen Massenproduktionsunternehmen für Automobil- oder Schiffsbau, Elektronik oder Halbleitertechnik. Dies ist um so erstaunlicher als die Koreaner erst nach der von Japan erzwungene Öffnung des Landes 1876 nicht nur zum ersten Mal in ihrer Geschichte von der Existenz einer nichtkonfuzianischen Gesellschaftsordnung erfuhren, sondern vor allem völlig abrupt an ein Welthandelssystem mit einer ausdifferenzierten Geldwirtschaft angeschlossen wurden. So mußten die Koreaner nicht nur innerhalb kürzester Zeit die im Konfuzianismus verankerte Verachtung für jedes auf Gewinn ausgerichtete ökonomische Handeln überwinden, sondern auch die zu diesem Zeitpunkt in Korea noch immer vorherrschende Naturalwirtschaft. Diese enge Verbindung zwischen (konfuzianischer) Ideologie und gesellschaftlich-ökonomischer Wirklichkeit macht einsichtig, warum die Entstehung der Chaebol und inre spezifische Eigentümlichkeit nur durch eine soziologische Analyse der Wechselwirkung zwischen diesem gesellschaftlichen Transformationsprozeß und dem entsprechenden Normenwandlungsprozeß, durch eine Untersuchung der Interdependenzen zwischen Gesellschaft und Individuum (bzw. der subjektiven Wahrnehmung der gesellschaftlichen Wirklichkeit durch den handelnden Akteur) erklärbar ist. Dies geschah in der hier vorliegenden Arbeit durch eine Analyse des spezifischen koreanischen Verständnis des ökonomischen Handelns der Chaebolunternehmer, hier exemplifiziert an den Gründervätern von Lucky-Goldstar (In-Hoe Ku), Samsung (Byong-Chul Lee) und Hyundai (Joo-Young Cheong).

Bis 1876 gab es in Korea kein Anzeichen für die Entwicklung eines unternehmerischen Denkens, das mit dem in den westlichen Ländern vergleichbar gewesen wäre, und auch nach der erzwungenen Öffnung des Landes vollzog sich der gesellschaftlich-ökonomische Wandlungsprozeß nur langsam. Obwohl es erste koreanische Unternehmensgründungen schon vor 1910 gab, war die- 
sen Anfängen, die im wesentlichen national als Zurückdrängen vom fremden, ausländischen Einfluß, nicht aber unternehmerisch oder technologisch motiviert waren, zumeist keine lange Lebensdauer beschieden.

Ernstzunehmende koreanische unternehmerische Aktivitäten entstanden daher erst nach Beginn der japanischen Kolonialzeit und verstärkt dann vor allem nach den durch die Massendemonstration vom März 1919 erzwungenen politischen Veränderungen. Denn die japanische Kolonialregierung, die das Land von 1910 bis 1945 beherrschte, schaffte nicht nur die alte ständisch und konfuzianisch geprägte institutionelle Ordnung der Yi-Dynastie ab, sondern brachte dem Land mit der Errichtung moderner Schulen sowie der gesetzlichen Verankerung des privaten Eigentumsrechts moderne, westlich geprägte gesellschaftliche Institutionen. Auf dieser Grundlage entwickelten sich in Korea zwei Unternehmertypen: zum einen gab es den nationalistisch gesinnten erfolgreichen Unternehmer aus der ehemaligen Yangban-Schicht, der aufgrund seiner guten Beziehungen zur Kolonialregierung zum Besitzer von Banken, Kaufhäusern und Fabriken geworden war. Seine Karriere endete jedoch wegen seiner Verstrikkung in die japanische Kriegswirtschaft mit dem Ende der Kolonialregierung 1945. Zum anderen gab es den Typus des Kleinunternehmers, der aus bäuerlichem Milieu (oft aus einer verarmten Yangban-Familie) kam und sich aus beruflicher Perspektivlosigkeit heraus für die Gründung eines kleinen, regional ausgerichteten Betriebes in einer von den Japanern nicht besetzten Marktnischen entschieden hatte. Dieser letzte Typ des genuin koreanischen Kleinunternehmers und nicht die von den Japanern geförderten Großunternehmer bildete die Basis für die Entwicklung eines eigenständigen koreanischen Unternehmertums in der Nachkriegszeit, womit der Nachahmungsthese insbesondere in der Form, nach der die Chaebol eine Nachahmung der japanischen Zaibatsu sein sollen, eine ihrer wesentlichen historischen Grundlagen entzogen wäre.

Dieses Ergebnis stellt auch die nachträgliche Rechtfertigung für die intensive Beschäftigung mit der historischen Genese des ökonomischen Handelns in Korea dar, das sich eben nicht mit dem Hinweis auf die schon von Max Weber konstatierte Ablehnung jeden ökonomischen Handelns durch den Konfuzianismus angemessen erfassen läßt. Die historischen Fakten lassen ein differenzierteres Bild entstehen als der ideologische Hintergrund dies erwarten lassen 
würde. Obwohl die Parallelentwicklung zwischen der Auflösung der traditionellen Gesellschaftsstruktur und der Herausbildung der ersten Generation von koreanischen Unternehmern den Eindruck erwecken mag, daß nicht zuletzt der strukturelle Bruch mit der traditionellen Ordnung die Entstehung des koreanischen Unternehmertums ermöglicht hat, zeigt sich auf der Ebene des subjektiv handelnden (und wahrnehmenden) Akteurs dieser gesellschaftlich-strukturellen Wandlungsprozeß vielschichtig und widersprüchlich und keineswegs so linear oder evolutionistisch, wie dies von manchen modernisierungstheoretisch angelegten soziologischen Erklärungsansätzen unterstellt wird. Das heißt: Der strukturelle Wandlungsprozeß führte nicht dazu, daß sich der subjektiv handelnde Akteur aus Anpassungsdruck an die veränderten institutionellen Rahmenbedingungen von den traditionellen kulturellen Denkmuster radikal verabschiedete und sich die von außen eingeführten neuen Denkweisen bzw. die westlichen Wertvorstellungen aneignete.

Diese These wird durch das Ergebnis meiner biographischen Analyse über die Kindheit und den unternehmerischen Werdegang der drei von mir untersuchten Chaebolgründer zwischen 1945 und 1960 bestätigt. Die ihnen gemeinsame subjektive Anlehnung an die traditionelle konfuzianische Kultur, die zwar nicht mehr wie in der Yi-Dynastie als konkreter Verhaltenskodex, aber als allgemeine Lehre für harmonische zwischenmenschliche Beziehungen weiter existierte, gaben sie im Laufe ihres unternehmerischen Lebens keineswegs auf. Dies zeigt sich insbesondere an ihrem Verhältnis zu ihren Eltern, die nicht mehr auf der konfuzianischen Ausbildung ihrer Kinder bestanden hatten und damit diesen gegenüber ihre berufszuweisende Funktion verloren hatten. Aber die Kinder, die späteren Gründerväter der koreanischen Chaebol, nahmen diesen mit der Auflösung der familiären Hierarchiestruktur verbundenen Wandlungsprozeß der traditionellen koreanischen Familie nicht als eine Selbstverständlichkeit, wie dies häufig von struktur-funktionalistischen Soziologen unterstellt wird, sondern mit einem starken Gefühl der Dankbarkeit und Respekt für diese schwach gewordenen Eltern, die in diesem Zusammenhang als Symbol für die alte konfuzianische Tradition aufgefaßt werden können. Auf der Grundlage ihrer weiterbestehenden starken familiären Bindung erschlossen sich die koreanischen Unternehmer eine neue Verbindung zur konfuzianischen Kultur und es gelang innen darüber hinaus, in ihren Unternehmen eine eigene konfuzianisch 
geprägte Unternehmenskultur zu schaffen, die die Basis ihres späteren Erfolges bildete.

Besonders nützlich erwies sich diese Verknüpfung des unternehmerischen Handelns mit der konfuzianisch geprägten Familienvorstellung nicht nur in der Anfangsphase ihres unternehmerischen Handelns während der japanischen Kolonialzeit, sondern auch in der Nachkriegszeit zwischen 1945 und 1960. In dieser Zeit verfügten die koreanischen Unternehmer über die historisch einmalige Gelegenheit, sowohl das zurückgelassene ehemalige japanische Eigentum als auch die großzügige amerikanische Entwicklungshilfe für ihren unternehmerischen Aufstieg nutzen zu können. Um ihre fehlende schulische, technologische und fachliche Qualifikation auszugleichen, stützten sich die späteren Gründerväter der koreanischen Chaebol vorwiegend auf in der Familienhierarchie untergeordnete jüngere, innen zu Dank verpflichtete Familienmitglieder und Freunde aus der gleichen Schule oder der gleichen Heimatregion als Mitarbeiter, die unter zum Teil sehr hohem persönlichen Einsatz den unternehmerischen Handlungsspielraum des Unternehmenseigners erweiterten. War die familiäre Unterstützung für die koreanischen Unternehmer während der japanischen Kolonialzeit noch vornehmlich finanzieller Art gewesen, so überwog jetzt in der Nachkriegszeit die funktionelle Unterstützung durch die Familie durch das Zurverfügungstellen von Arbeitskraft, Wissen und Fähigkeiten. Man kann daher sagen, daß der besondere Expansionswille der Gründerväter der koreanischen Chaebol ohne dieses spezifisch koreanische Verständnis von unternehmerischem Handeln, das Dankbarkeit und Verpflichtung zur Basis des erfolgreichen ökonomischen Handelns machte, nicht im vollen Maße zu verstehen ist. Die besondere unternehmerische Fähigkeit der drei Chaebolgründer läßt sich dementsprechend daran messen, wie geschickt sie jeweils das Wissen und die Fähigkeiten ihrer Familienmitglieder und Freunde in ihr unternehmerisches Handeln einbezogen.

Wie naheliegend dies auch erscheinen mag, erscheint mir jedoch trotz aller äußerlichen Ähnlichkeiten eine direkte Gleichsetzung dieser familienorientierten koreanischen Unternehmen mit westlichen Familienunternehmen verfehlt. Meiner Meinung nach haben die Gründerväter der koreanischen Chaebol die Bedeutung der Familie im Zusammenhang mit ihrem expandierenden unternehmerischen Interesse sozusagen neu entdeckt und in einer spezifisch koreani- 
schen Weise neu definiert, indem sie durch und in ihren Unternehmen eine "fiktive Familie" schufen: Aufgrund der familienartig organisierten Unternehmensstruktur herrschte in der Frühphase der koreanischen Chaebol ein so starkes auch die im engeren Sinne nicht-familiären Mitarbeiter einschließendes Gemeinschaftsgefühl (oder genauer, es wurde ein solches Gemeinschaftsgefühl gefordert), daß die offizielle Unternehmensideologie nicht die Profitmaximierung, sondern das Wohl der großen Unternehmens-Gemeinschaft zum Ziel des Unternehmens e rklären konnte.

Wenn man die Schumpetersche Auffassung vom innovativem unternehmerischen Handeln für diese Frühphase der koreanischen Chaebol prüft, dann trifft diese natürlich dann nicht zu, wenn man, wie Schumpeter, die unternehmerischen Innovationen auf die Mobilisierung von Produktionsmitteln, die neue Kombination von Produktions- und Vertriebsprozessen beschränkt. Wenn man allerdings die Fähigkeiten der Chaebolgründer zur kreativen Nutzung der traditionellen Kultur und hier insbesondere des sozialen "Kapitals Familie" in den Blick nimmt, dann kann man den koreanischen Unternehmern nur bescheinigen, äußerst i nnovativ die vorhandenen Ressourcen neu genutzt zu haben.

Zwei politisch-ökonomische Faktoren sollten allerdings sozusagen als materiale Basis bei der Herausbildung der beschriebenen koreanischen "Unternehmensfamilien" nicht vernachlässigt werden: nämlich zum einen die schlechte Arbeitsmarktsituation während und nach der japanischen Kolonialzeit in Korea, aufgrund derer den Familienmitgliedern und Freunden der Chaebolgründer kaum andere Erwerbsmöglichkeiten offenstanden als im Unternehmen des Bruders/Freundes; zum anderen die Tatsache, daß Präsident Rhee unter der Flagge der freien Marktwirtschaft, die seiner Auffassung nach keinerlei staatliche Einflußnahme dulde, den Unternehmern fast unbeschränkten Zugang zu Bankkrediten sowie zu der reichlich fließenden amerikanischen Entwicklungshilfe verschaffte. Obwohl das amerikanische Geld explizit für den Wiederaufbau der durch den Koreakrieg zerstörten Industrieanlagen gedacht war, kamen weder Rhee noch andere Regierungsmitglieder je auf die Idee, eine staatliche Kontrollinstanz bei der Vergabe dieser Gelder einzuführen. In den Augen der koreanischen Unternehmer waren sowohl das ehemalige japanische Eigentum als auch die amerikanische Entwicklungshilfe "herrenloses" Geld, das innen daher uneingeschränkt zur Mehrung von Kapital und Besitz zur Verfügung 
stand. Sie reagierten daher mit völligem Unverständnis bzw. Ratlosigkeit, als sie nach den Studentendemonstrationen vom April 1960 und als "illegale Akkumulatoren" vor Gericht gestellt wurden und einen Teil ihres Vermögens als Strafgeld an den Staat abgeben mußten.

Als am 16. Mai 1961 der Militärputsch unter der Führung von General Park erfolgte, ahnte keiner der drei Gründerväter der koreanischen Chaebol, wie radikal sich angesichts der veränderten gesellschaftlichen und vor allem politischen Lage ihr bisheriges Verständnis des unternehmerischen Handelns ändern mußte. Für sie ergab sich eine ganz neue Situation nicht nur dadurch, daß der neue Machtinhaber Park, ganz anders als der zurückgetretene Präsident Rhee, die Unternehmer weniger als Träger der demokratischen kapitalistischen Ordnung als vielmehr als ökonomische "Kriminelle" behandelte, sondern auch dadurch, daß Park selbst unter einem starken politischen Legitimationsdruck stand, den sie für sich nutzen konnten. Weil Park die Legitimität seines Putsches durch ökonomischen Aufschwung absichern wollte, konnte er sich überhaupt kein feindliches Verhältnis zu den Unternehmern leisten.

Anfänglich verhielten sich Park und seine Offizieren eher wie Sympathisanten eines sozialistischen Wirtschaftssystems, in dem der Staat die Wirtschaft kontrolliert. So scheuten sie sich auch nicht, das private Eigentum der Gründerväter der Chaebol zumindest teilweise zu verstaatlichen und den Zweck ihres unternehmerischen Handelns ihrem politischen Interesse unterzuordnen. Die Regierung Park und die drei Gründerväter der koreanischen Chaebol waren sich aber sehr schnell in ihrer gegenseitigen Interessenabhängigkeit einig, was nicht zuletzt dazu führte, daß die Rolle des Staates bzw. von Präsident Park innerhalb des Industrialisierungspozesses in Korea in den 60er und 70er Jahren zunehmend durch die Handlungslogik eines Patrons bestimmt wurde, während die Rolle der Unternehmer bzw. der Chaebol dementsprechend als die eines Klienten oder Schützlings definiert werden kann. Dabei ist wichtig festzuhalten, daß sich dieses Patron-Klienten-Verhältnis zwischen Staat und Unternehmer niemals auf einer öffentlichen Ebene, sondern auf einer persönlichen Beziehungsebene abspielte. Das heißt: Offiziell sollte zwar der gesamte Industrialisierungsprozeß vom Ministerium für Wirtschaftsplanung auf der Grundlage des Fünfjahresplans bestimmt werden, aber bei der konkreten Umsetzung dieses Wirtschaftsplans handelten weder die Regierungsbürokraten (einschließlich des 
Präsidenten) noch die Unternehmer nach dieser öffentlichen Richtlinie. Was ihre Zusammenarbeit in Wirklichkeit förderte und bestimmte, war nicht nur ihre gegenseitige Interessenabhängigkeit bei der Beschleunigung des Industrialisierungsprozesses im Lande, sondern auch die bereits aus den familiaren Anfängen der Chaebol hinreichend bekannte, konfuzianisch geprägte zwischenmenschliche Beziehungslogik, deren Hautmerkmal darin bestand, Menschen aus dem Familien- und Freundeskreises immer behilflich zu sein.

Als die Konkurrenz unter den Unternehmern bezüglich der jeweils besten Beziehung zum Staat (vor allem zu den mächtigen Regierungsmitgliedern) immer härter wurde, entwickelte sich eine enge oligarchische Verflechtung zwischen dem Staat und einer bestimmten Gruppe von Unternehmen, was zur Folge hatte, daß der Erfolg eines Unternehmers ausschließlich davon abhängig war, inwieweit es inm gelang, den Staat als Patron für sein Unternehmen anzuwerben. Für die drei Gründerväter der koreanischen Chaebol ist bezeichnend, daß sie jeweils auf unterschiedliche Weise eine sehr erfolgreiche und stabile Patron-Klienten-Beziehung zum Staat aufbauen konnten: Bei Lee beruhte diese nicht nur darauf, daß er aus der gleichen Region stammte wie Präsident Park, sondern vor allem auf seiner geschickten (Informations-)Politik als Vorsitzender des Unternehmerverbandes. Kus Beziehung zum Staat basierte wie bei Lee auf dem Regionalismus und wurde zusätzlich durch seinen Bruder verstärkt, der als Abgeordneter der regierenden Partei und Mitarbeiter im Unternehmen seines Bruders dessen unternehmerische Interessen besser als jeder andere vertreten konnte. Cheong mußte dagegen die ihm aufgrund von niedriger Abstammung, "falscher" regionaler Herkunft und unvollständiger Schulbildung fehlenden Beziehungen durch blinde Loyalität dem Staatsoberhaupt gegenüber ersetzen und sich die notwendige Patron-Klienten-Beziehung durch erhöhte Risikobereitschaft im wörtlichen Sinne erst "verdienen", was beinahe seinen unternehmerischen Ruin bedeutet hätte.

Die oligarchische Verflechtung zwischen Staat und Unternehmern hatte zur Folge, daß sich das unternehmerische Handeln in Korea weniger an der Logik des Marktes als vielmehr an der Logik der verschiedenen menschlichen Beziehungsformen orientierte. So war es keine Seltenheit, daß neue unternehmerische Betätigungsfelder nicht von ökonomischen Überlegungen des Unternehmers, sondern vom Interesse des führenden Politikers bestimmt wurden. Daher 
betraten $\mathrm{Ku}$, Lee und Cheong wahllos unternehmerische Felder ausschließlich deshalb, weil sie kurzfristig gesehen den nationalen ökonomischen Aufschwung dienten, was den Politikern und insbesondere Präsident Park für ihre eigene Legitimation, vor allem im Wahlkampf, nützte. Zu nennen wären hier ihr unternehmerischer Einstieg in die Produktion höherwertiger Massenproduktionsgüter wie Automobil- und Schiffbau, Elektronik etc. Entgegen der Annahme, daß dies als erfolgreich staatlich gesteuertes unternehmerisches Handeln zu beurteilen ist, bin ich der Auffassung, daß sich dahinter ein ganz einfaches Handlungsmodell verbirgt, in dem der Unternehmer seine Hauptaufgabe vor allem darin sah, durch geschickte Anpassung an die staatlichen Anforderungen seine vorhandene Klientenbeziehung zum Staat als Patron nicht zu gefährden.

Sowohl der "Familiarismus" in der Frühphase der koreanischen Chaebol als auch deren besondere Abhängigkeit vom Staat in ihrer Expansionsphase bestätigen also die insbesondere von Granovetter herausgestellte Bedeutung sozialer Netzwerke für das unternehmerische Handeln. Doch ebenso wie die $\mathrm{Ha}-$ miltonsche Annahme von der Rolle des starken Staates diese meiner Meinung nach einseitig verkürzt auf eine Reproduktion der konfuzianischen Auffassung vom Staat als unhinterfragter, absoluter Herrschaftsinstanz zurückführt, berücksichtigt auch Granovetter nicht ausreichend, daß die koreanischen Unternehmer nicht einfach nur eine vorgegebene soziale Struktur reproduzierten, sondern diese - abhängig jeweils von den situativ gegebenen (politischen) Bedingungen - gemeinsam mit den involvierten Politikern gestalteten und ihr so eine bestimmte, situationsabhängige Form gaben, die ich hier erstmals als PatronKlienten-Beziehung gekennzeichnet habe. In diesem Zusammenhang möchte ich hervorheben, daß meine Charakterisierung des koreanischen Verhältnisses zwischen Staat und Chaebol als Patron-Klienten-Verhältnis keineswegs darauf abzielt, die koreanische Entwicklung des Unternehmens analog zur mittelalterlichen westlichen Gesellschaftsordnung zu erklären. Der Sinn meines Gebrauchs dieser Begrifflichkeit liegt vielmehr darin, die durch gegenseitige Interessenabhängigkeit bedingte situative Handlungslogik in dem koreanischen Verhältnis zwischen Staat und Chaebol durch einen anschaulich-konkreten Begriff zu erfassen.

Informelle Netzwerke prägten auch die koreanische Managementkultur, die sich erst in den 80er Jahren voll ausbildete und sich durch eine eigentümliche 
Mischung von Organisationsstrukturen eines traditionellen Familienunternehmens mit denen eines Großunternehmens auszeichnete: Einerseits erkannte der Unternehmereigentümer sehr wohl, daß Kontrolle, Koordination und Planung des immer komplexer werdenden Produktionsprozesses in seinem sich immer stärker auf unbekannte und kapitalintensive Industriesektoren ausweitenden Unternehmen nicht mehr allein von ihm selbst oder von seinen "Familienmitgliedern" (im weiteren Sinne) geleistet werden konnten, andererseits aber verzichtete er dennoch auf die Installation eines auf betriebswirtschaftliches Fachwissen gegründeten professionellen Managements und rekrutierte statt dessen Personen, die inm aufgrund ihrer Beziehungen (vor allem zur Regierung) nützlich für sein Unternehmen sein konnten. Da deshalb die Qualifikation der neuen Mitarbeiter erst innerhalb des Unternehmens erfolgte, konnte der Chaebolleiter ein zentral auf Vertrauen und wieder persönliche Beziehungen zwischen Vorgesetztem und Mitarbeitern gegründetes betriebsinternes Karrieresteuerungsinstrumentarium schaffen, das Eigeninitiative und damit Widerspruch unterband und durch Anpassung und Loyalität ersetzte und somit seine persönliche dominierende Stellung nicht gefährdete. Diese auf diese Weise institutionalisierte Beziehung zwischen Unternehmensleitern und Managern habe ich als Herr-Diener-Beziehung charakterisiert. Der trotz der sorgfältigen Auswahl von Topmanagern nach dem Kriterium der Loyalität dennoch nicht versiegenden Angst vor zuviel Autonomie ihrer Unternehmensleiter begegneten die Chaebolleiter durch die Einrichtung eines Sekretariats oder Planungsbüros, das - direkt dem Unternehmenseigner unterstellt - die Manager zunächst überwachte, sie aber schließlich zu bloßen Weisungen ausführenden Marionetten degradierte und damit die Herr-Diener-Beziehung zwischen Unternehmenseigner und seinen Manager noch verstärkte.

Dem deutschen Soziologen Johannes Berger, dem es gelungen ist, die neoinstitutionalistische Betrachtung des unternehmerischen Handelns mit neodurkheimschen soziologischen Ansätzen zu verbinden, und seiner daraus resultierenden Einsicht von dem freien Handlungsspielraum des Unternehmens, über den dieser insbesondere im Bereich des Managements verfügt, verdankt die vorliegende Arbeit die Aufmerksamkeit für das Geschick, mit dem die Gründerväter der koreanischen Chaebol durch die Errichtung ihres internen Überwachungssystems in Form der Planungsbüros ihre Mitarbeiter in ihr Unternehmen 
integrierten. Darüber hinaus ging es mir aber auch darum zu zeigen, daß die koreanische Managementkultur insofern undurchschaubar oder "doppelbödig" war, als sie nicht nur auf der Ausbeutung ihrer Mitarbeiter im Interesse des Unternehmens bzw. des Unternehmenseigners beruhte, sondern im Widerspruch zum hohen gesellschaftlichen Ansehen, das die Chaebolmanager genossen (und genießen), ihre wahre betriebsinterne Rolle verdeckte. Dies ist auch der Grund, warum ich mich gegen die von dem koreanischen Betriebswirt Yu-Kun Shin benutzte Charakterisierung der koreanischen Managementpraxis als "patriarchalisch" entschieden habe und statt dessen mit Blick auf ihre ideologieaufdeckende Wirkung die ein wenig provokative Bezeichnung "Herr-DienerBeziehung" verwende. "Patriarchalisch" verweist dagegen lediglich auf die traditionellen (autoritären) Familienstrukturen in Korea, die meines Erachtens gerade nicht das Modell für die koreanische Unternehmensorganisation abgeben haben. Denn der autoritäre Führungsstil der Chaebolleiter entwickelte sich ja aus dem Mißtrauen gegenüber den nicht zur Familie gehörenden Mitarbeitern, so daß die von innen geschaffene Managementstruktur nicht das Resultat der traditionellen koreanischen Familienkultur, sondern vielmehr einer unternehmerisch durchdachten Personalpolitik war, die sich zwar auch auf kulturelle Traditionen, aber außerfamiliärer - wie der des Gehorsams eines Dieners gegenüber seinem Herrn - stützte.

Die Entstehung der koreanischen Chaebols und ihre spezifische Eigentümlichkeit, wie sie in der hier vorliegenden Arbeit durch Rückgriff auf das spezifische Verständnis des ökonomischen Handelns der koreanischen Unternehmer analysiert wurde, ist also - und das verdient abschließend noch einmal festgehalten zu werden - ohne ideologie- und kulturkritische Ansätze nicht realitätsadäquat zu beschreiben.

\section{VII.2 Diskussion über den Veränderungsbedarf bei den koreanischen Chaebol}

Abschließend möchte ich kurz diskutieren, inwiefern mein soziologischer Versuch, die Geschichte der koreanischen Chaebol auf der Ebene des unternehmerischen Handelns zu rekonstruieren, auch bei der Diagnose der ökono- 
mischen Tragfähigkeit dieser Unternehmen sinnvoll sein könnte. Da ich hier weder die Marktstrategie noch die Produktionsstrategie der Chaebol berücksichtige, ist es nicht angebracht, über die Zukunft der koreanischen Chaebol auf der Grundlage von alternativen Markt- oder Produktionsstrategien zu spekulieren, ich beschäftige mich daher ausschließlich mit inrer Organisationsstruktur.

Um die ökonomischen Stärke und Schwäche der koreanischen Chaebol auszuloten, möchte ich hier kurz auf die Finanz- bzw. Währungskrise der koreanischen Wirtschaft vom Herbst 1997 eingehen: Die Krise begann mit der abrupten Flucht der ausländischen Kapitalinvestoren aus dem koreanischen Aktienmarkt. ${ }^{1}$ Dadurch wurde das koreanische Dollarreservoir knapp, außerdem rückte der Rückzahlungstermin für ausländische Kredite näher. Die meisten dieser Kredite stammten von koreanischen Privatbanken, die wegen des verglichen mit langfristigen Krediten niedrigeren Zinssatzes vor allem kurzfristige ausländische Kredite aufgenommen hatten. ${ }^{2}$ Weil der Zinsrate in Korea viel höher lag, verdienten die privaten Banken dadurch, daß sie das kurzfristig ausgeliehene ausländische Geld mit hohen Zinsen an die einheimischen Unternehmen weiterverliehen. Obwohl solche kurzfristigen Kredite immer mit dem Risiko verbunden sind, daß der Investor den Kredit ganz plötzlich zurückzieht, interessierten sich die kleinen koreanischen Privatbanken aufgrund ihrer hohen Gewinnspanne bis zum Crash 1997 kaum für diese Gefahr. Gleichzeitig brachte der Bankrott der Kia-Automobilindustrie und die Krise der Hanbo-Stahlindustrie nicht nur die Effizienz der koreanischen Chaebol sowie des Bankensystems ins Zwielicht, sondern ließ bei die ausländischen Investoren auch Zweifel daran aufkommen, ob der Staat, der nicht wie in den 30 Jahren zuvor üblich sofort eingegriffen und die Krise abgewendet hatte, noch immer eine wirtschaftlich be-

\footnotetext{
${ }^{1}$ Gyun, Kim, Chaebol Kaeheok kwa Hanguk Chabonjueui Hyangbang (Die Reform der koreanischen Chaebol und die Zukunft des koreanischen Kapitalismus), in: Donghyang kwa Cheonmang, Vol. 37 (1998), S. 168.

${ }^{2}$ Nachdem Young-Sam Kim im Jahr 1992 zum Präsident gewählt worden war, erließ er ein Gesetz, das die Gründung von kleinen privaten Banken zuließ, die dazu dienen sollten, die zunehmende Nachfrage nach Kaptial seitens der koreanischen Unternehmen (vor allem der Chaebol) zu befriedigen. Doch da die Zahl dieser Banken rapideanstieg, verlor der Staat bald den Überblick über die aufgenommenen ausländischen Kredite.
} 
stimmende starke Rolle in Korea spielte. ${ }^{3}$ Dadurch beschleunigte sich der Fluchtprozeß des ausländischen Kapitals immer mehr.

Die koreanischen Wirtschaftsexperten kamen sehr schnell zu dem Schluß, daß sich hinter dieser Krise ein strukturelles Problem der koreanischen Chaebol verbarg. ${ }^{4}$ Vor allem der Ökonom Gyun Kim machte auf die "Ineffizienz des koreanischen Chaebol-Systems" aufmerksam, die schon vor der Krise absehbar gewesen sei. ${ }^{5}$ Da der Binnenmarkt in Korea seit Mitte der 90er Jahre stagnierte, waren schon in den Jahren vorher einige Chaebol Bankrott gegangen, was ein völlig neues gesellschaftlich neues Phänomen in Korea war, da in den Jahrzehnten zuvor niemals ein Chaebol zur Schließung gezwungen worden war. Doch während der letzten zehn Jahre hatten sich die Produktionsbedingungen für die koreanischen Chaebol rapide geändert. Die Konkurrenz auf dem Weltmarkt war härter geworden, während die Chaebol in Korea zugleich den Verlust ihres wichtigsten ökonomischen Vorteils, nämlich der niedrige Arbeitslöhne, hatten hinnehmen müssen. Die Folge war ein geringerer Exportanteil. Zu Recht verweist Kim jedoch darauf, daß sowohl die Regierung als auch die Chaebol dazu neigen, die Ursache der abnehmenden Wettbewerbsfähigkeit der koreanischen Produkte nur in den höheren Arbeitslöhne zu sehen und nicht die strukturbedingten Ursachen bei den koreanischen Chaebol im Blick zu haben. ${ }^{6}$

Obwohl die gegenwärtige, von Präsident Kim in Angriff genommene Reform der Chaebol sehr darum bemüht zu sein scheint, strukturelle Maßnahmen zur Förderung der Transparenz der koreanischen Chaebol zu ergreifen, ist mein Eindruck, daß diese Maßnahmen zu stark an dem Vorbild westlicher Großunternehmen orientiert sind und damit indirekt der Nachahmungsthese folgen.

\footnotetext{
${ }^{3}$ Kia und galten als die wichtigsten Chaebol in Korea neben Samsung, Lucky-Goldstar und Hyundai. Beide hatten gehofft, durch ihre gute Beziehung zu den führenden Politikern (vor allem zum Sohn des Präsidenten) wie in den Jahren zuvor günstige Bankkredite in Anspruch nehmen zu können. Aber die Regierung war nicht mehr bereit, zahlungsunfähige Unternehmen weiter durch die Steuern des Volkes zu finanzieren. Zwar unternahm die Regierung einen Versuch, Käufer für diese Unternehmen zu finden, scheiterte aber am Einspruch der oppositionellen Partei sowie der Gewerkschaften.

${ }^{4}$ Sang-Jo Kim, IMF Kuje Kumyung kwa Hanguk Keongje (Die Finanzhilfe des IWF und die koreanische Ökonomie), in: Keongje wa Sahoe, Heft April (1998), S. 119; Je-Uk Kong, IMF ha Hanguk Chabonjueui eui Kujo Kaepeon (Die Restrukturierung der koreanischen Chaebol unter dem Einfluß von IWF) - Manuskript 1998, S. 119.

${ }^{5}$ Gyun, Kim, Chaebol Kaeheok kwa Hanguk Chabonjueui Hyangbang (Die Reform der koreanischen Chaebol und die Zukunft des koreanischen Kapitalismus), in: Donghyang kwa Cheonmang, Vol. 37 (1998), S. 171.
} 
Konkreter gesagt: Das Bemühen um eine Reform der koreanischen Chaebol zeigt sich vor allem darin, daß der Staat nur noch unter der Bedingung die Vergabe von Bankkrediten billigen will, daß sich die Organisationsstruktur der Chaebol an die der westlichen Großunternehmen annähert. Das wichtigste Kriterium dieser Annäherung ist dabei die "Spezialisierung" des Unternehmens sowie die "Dezentralisierung" der zwischenbetrieblichen Beziehungen. Vielleicht ist es voreilig, wenn ich hier ein Scheitern dieser staatlich angeleiteten Reformpolitik voraussage. Dennoch besteht mein größtes Unbehagen an den gegenwärtigen Reformversuchen darin, daß weder der Staat noch die Chaebol begriffen zu haben scheinen hatte, daß der größte Schwäche der koreanischen Chaebol in einem "gefährlichen Opportunismus" liegt, der das koreanische Verständnis des unternehmerischen Handelns bestimmt.

Ursprünglich stammt der Begriff "Opportunismus" in wirtschaftlichen Zusammenhängen von dem amerikanischen Ökonomen Oliver Williamson, der diesen wie folgt definiert hat:

"Self-interest seeking with guile, to include calculated efforts to mislead, deceive, obfuscate, and othewise confuse. Opportunism ist to be distinguished from simple self-interest seeking, according to which individuals play a game with fixed rules that they reliably obey." (Williamson, 1994, S. 102)

Während Williamson den Opportunismus als allgemein menschliche Neigung betrachtet und dessen Bändigung zur wichtigsten Aufgabe der Wirtschaft erklärt, bin ich der Auffassung, daß in Korea unternehmerisches Handeln, was sich besonders deutlich an der Entwicklung der Chaebol zeigen läßt, nicht von Bändigung, sondern vielmehr von der bewußten und beabsichtigen Umsetzung von Opportunismus gekennzeichnet ist. Ich halte diese koreanische Variante des Opportunismus vor allem deswegen für gefährlich, weil das unternehmerische Handeln der koreanischen Chaebol anders als in den westlichen Ländern von einer - wie ich es bezeichnen würde - "nach außen orientierten Organisationskultur" geprägt ist und dieser Charakter der koreanischen Organisationskultur den Opportunismus des Unternehmers noch verstärkt hat. Den begrifflichen Gegensatz zu der "nach außen orientierten Organisationskultur" der koreanischen Unternehmen bildet der Typus des unternehmerischen Handelns in

${ }^{6}$ Ebenda, S. 173. 
den westlichen Unternehmen, das dementsprechend auf einer "nach innen gerichteten Organisationskultur" beruht.

Die von mir gewählte Begrifflichkeit bedarf der Erläuterung: Ich spreche den westlichen Unternehmen deswegen eine "nach innen orientierte Organisationskultur" zu, weil das dort praktizierte Verständnis des unternehmerischen Handelns weniger auf potentiellen menschlichen Ressourcen als viel mehr auf organisatorische Regeln beruht, die nicht zuletzt auch die Funktion und Rolle eines Mitarbeiters vorgeben. Daher interessiert sich das Unternehmen bei der Rekrutierung von Mitarbeitern hauptsächlich für die Frage, ob die Person X die für die Aufrechterhaltung der Organisation benötigte Qualifikation mitbringt oder nicht. Insofern beschränkt sich das Nutzungspotential der menschlichen Arbeitskräfte auf den Bedarf der Organisation. So hängt der Erfolg oder Mißerfolg des Unternehmens davon ab, wie neben den technologischen Anlagen die Arbeitskräfte am effizientesten in die Struktur der Organisation eingepaßt werden können. Meines Erachtens findet sich der Höhepunkt dieser Denkweise in der Entwicklung der tayloristischen Arbeitsorganisationsform im Produktionsbereich und in der bürokratische Herrschaftsstruktur im Managementbereich. ${ }^{7}$ Kurz gesagt: In westlichen Ländern herrscht ein Bild des Unternehmens als einer Oganisation vor, in der die Menschen nur Funktionsträger sind, deren Handlungsspielraum strikt nach der internen Logik der Organisation definiert und kontrolliert wird. Logische Konsequenz ist, daß die Anforderungen an die Mitarbeiter immer spezialisierter werden, wobei ihre Leistung nicht willkürlich, sondern an dem jeweiligen Qualifikationsanspruchs gemessen und kontrolliert wird.

Dementgegen möchte ich das koreanische Unternehmen (vor allem die Chaebol) deswegen als einen Prototyp der "nach außen orientierten Organisationskultur" bezeichnen, weil dessen Organisation nicht wie in westlichen Uhternehmen den Charakter eines geschlossenen Systems aufweist. Zwar sind wie oben beschrieben - auch koreanische Unternehmen hierarchisch strukturiert, aber der Wirkungsmechanismus der Organisation ist weniger durch die eigenständige Logik der Organisation als vielmehr durch die Logik zwischenmenschlicher Beziehungen bestimmt, die sich in der Regel nicht der internen Logik der Organisation unterwerfen lassen. Ein wichtiges Ergebnis der hier vor- 
gelegten Arbeit war ja, daß in Korea nicht die bessere Produktionstechnologie oder die geschicktere Kapitalmobilisierung über den unternehmerischen Erfolg entschied, sondern die Fähigkeit, anderen Menschen zugunsten des eigenen unternehmerischen Interesses handeln zu lassen. Dabei betrachteten die koreanischen Unternehmer ihre Mitarbeiter nicht als Funktionsträger mit bestimmter Qualifikation, sondern vielmehr als "potentielle Allround-Problemlöser", weil sie fest davon überzeugt waren, daß nicht die Organisation, sondern der Mensch die Funktion oder den Wirkungsmechanismus der Organisation bestimmt. Das war der Grund, warum sie nicht den Mitarbeiter mit bestimmten spezieller Qualifikation, sondern jenen Mitarbeitertyp bevorzugten, der über die Fähigkeit verfügte, die außerhalb der Organisation existierenden verschiedenen ökonomischen Ressourcen für den Zweck des Unternehmens zu mobilisieren. Das heißt: Die koreanischen Unternehmer interessierten sich nicht oder kaum für die Verbesserung der internen Organisationsstruktur, sondern fast ausschließlich für die "Außenwirkung" ihrer Mitarbeiter. Während in den westlichen Länder ein Mitarbeiter, der keine Trennung zwischen der von inm vertretenen Organisation und seinem persönliche Beziehungsgefüge vornimmt, als jemand gelten würde, der überhaupt nicht begriffen hat, wie sich ein Mensch in einer Organisation verhalten soll, werden in Korea die außerhalb der Organisation bestehende Beziehungen als wichtige interne unternehmerische Ressourcen betrachtet. Der wichtigste Beleg dafür ist die selbstverständliche Integration staatlicher Aktivitäten in das genuin unternehmerischen Handeln, das in der letzten 40 Jahren den gesellschaftlichen Wirkungsmechanismus der koreanischen Wirtschaftsentwicklung beherrscht hat.

Meiner Auffassung nach sind diese "nach außen orientierte Organisationskultur" und das fehlende Bewußtsein von deren Gefahren die größte Schwäche der koreanischen Chaebol. Worauf es meiner Meinung nach ankäme, wäre diese Organisationskultur und den mit dieser verbundenen unternehmerischen Opportunismus genau zu analysieren und auf diese Weise zur Definition einer vernünftigen Grenze des bisher unbeschränkten, wildwüchsigen Expansionismus der koreanischen Chaebol zu gelangen. Weil die Chaebol bis jetzt nie ein

${ }^{7}$ Näheres dazu bei: Alfred Kieser (Hrsg.), Organisationstheorien, Stuttgart/Berlin 1993, S. 37-94. 
Problem mit ihrer extensiven Expansion hatten, das sie nicht mit Hilfe des Staates oder/und Vermittlung ihrer immer einsatzbereiten Mitarbeiter hätten bsen können, haben sie eine solche Grenze bisher noch nicht einmal ansatzweise diskutiert. Worauf ich aufmerksam machen möchte, ist vor allem die Gefahr des blinden Vertrauen in die Effizienz der "nach außen orientierten Organisationskultur", in der sich keiner der Beteiligten, sei es auf staatlicher oder unternehmerischer Seite, aufgrund der auch für alle undurchschaubaren gegenseitigen Verflechtungen und Verpflichtungen darüber klar ist, wer eigentlich wofür verantwortlich ist. Man braucht keine besonderen organisationssoziologischen Kenntnisse, um zu verstehen, daß das durch verschiedene persönliche Beziehungsgeflechte bestimmte unternehmerische Handeln in Korea von seiner Grundlogik her keine Abgrenzung genauerer Verantwortungsbereiche kennt. Wo Dankbarkeit und Verantwortung für andere als oberste Maxime des menschlichen Handelns fungieren, greifen Vorschriften oder bürokratische Regeln zu kurz. Mit Hilfe dieses inneren Wirkungsmechanismus der "nach außen orientierten Organisationskultur" läßt sich auch erklären, warum sich die koreanischen Banken trotz aller allgemein bekannten Gefahren auf die kurzfristigen ausländischen Kredite eingelassen haben. Sie verlagerten einfach die Verantwortung auf den Staat, der für sie selbstverständlich weiter dafür zuständig war, den Unternehmen aus jeder (auch aus einer selbstverschuldeten) Krise zu helfen.

Um dieses grundlegende Problem der koreanischen Organisationskultur bzw. des bisherigen koreanischen Verständnisses des ökonomischen Handelns zu lösen, ist es wichtig, daß sich die Chaebol bemühen, ihren eigenen "gefährlichen Opportunismus", dessen Ursprung in der "nach außen organisierten Organisationskultur" zu finden ist, zu bändigen und dadurch ihren unternehmerischen Handlungsspielraum "neu" zu definieren. Unter "gefährlichem Opportunismus" verstehe ich dabei vor allem die Haltung, ungeachtet der veränderten gesellschaftlichen Situation weiterhin nur auf dem eigenen, engbegrenzten ökonomischen Interesse zu beharren. Trotz staatlicher Forderung nach Veränderung reagieren die koreanischen Unternehmer daher nur mit einer "Scheinanpassung". Denn obwohl sie einerseits in der Öffentlichkeit den Eindruck zu erwecken versuchen, daß die gegenwärtige staatliche Intervention in das unmittelbare unternehmerische Handeln das Prinzip der freien Marktwirtschaft 
verletzt, sind sie andererseits bemüht, möglichst schnell die formellen Anforderungen des Staates zu erfüllen, um den durch ihre Abhängigkeit vom Staat gegebenen ökonomischen Vorteil nicht zu verlieren. In Wirklichkeit engen jedoch nicht die jetzt getroffenen staatlichen Maßnahmen, sondern ihre fehlende Bereitschaft, ihre Abhängigkeit vom Staat zu lösen, den genuin unternehmerischen Handlungsspielraum der koreanischen Chaebol ein.

Insofern halte ich es für erforderlich, daß die Chaebol sich nicht darauf beschränken, die von Staat als neue Förderrichtlinien ausgegebenen Regeln des demokratischen Marktes zu beschwören, sondern sich von sich aus um die Schaffung eines neuen Typus des unternehmerischen Handelns bemühen, um das allgemeine Mißtrauen in die koreanischen Chaebol als "die am meisten ökonomisch Privilegierten" des staatlich geleiten Industrialisierungsprozesses zu beseitigen. Dazu gehört nicht nur der Versuch, sich mit dem Problem der "nach außen orientieren Organisationskultur" offen und kulturkritisch auseinanderzusetzen, sondern vor allem das echte Bemühen, jenseits des bisherigen Expansionismus eine neue Unternehmensform finden, die die oligarchischen Verflechtung mit dem Staat aufbricht, die daraus erwachsene staatliche Kontrolle zurückdrängt und im übrigen auch die unsoziale Ausbeutung der koreanischen Arbeitnehmer verringert. Um das zu ermöglichen, ist es nicht nötig, daß die Chaebol in Korea die formale Organisationsstruktur des westlichen Großunternehmens eins zu eins nachahmen. Aber es ist erforderlich, die Schwäche der eigenen Organisationskultur im Spiegel der westlichen Organisationskultur, deren Vorteil meines Erachtens vor allem in den unternehmensinternen Transparenz, durch die allen Beteiligten eine klare Funktion zugewiesen wird, neu zu reflektieren und unter Berücksichtigung der länderspezifischen Charakteristika daraus eine innovative Organisationskultur zu entwickeln. Ich habe daher die Hoffnung, daß die Entwicklung von spezifisch koreanischen Unternehmen nicht mit den Chaebol endet, sondern daß auf der Grundlage der aus inrer Geschichte gewonnenen Erfahrungen ein neuer Typus unternehmerischen Handelns entstehen wird. 


\section{Literaturverzeichnis}

\section{Biographisches Material und andere Quellen (Übersetzung der korea- nischen Titel in Klammern)}

Cheong, Joo-Young [verfaßt von Su-Heon Kim], I Tange Taenaseo (Geboren in diesem Lande), Seoul 1998 [(Auto-)Biographie].

Ders. [verfaßt von Su-Heon Kim], Sireonun Issedo Silpae nun Eopda (Es gibt zwar Schwierigkeiten, aber keinen Mißerfolg), Seoul 1991 [(AutoBiographie].

Kang, Meong-Han, Pony rul Mandun Byeolnan Hangukindul (Die sonderbaren Koreaner, die das Auto Pony gebaut haben.), Seoul 1986 [Erinnerungen eines ehemaligen Managers in der Hyundai-Automobilindustrie].

Kim, Cheong-Reom, Hanguk Keongje Cheong-Chaek 30 Yeonsa (Dreißig Jahre koreanische Wirtschaftspolitik), Seoul 1995 [Autobiographie eines ehemaligen Mitarbeiters der koreanischen Zentralbank und des Finanzministeriums].

Kim, Jeong-Ki, Gregory Henderson eui Hoigo (Erinnerungen von Gregory Henderson), in: Sintonga, Heft Mai (1987), S. 221-235 [das ist ein Bericht über ein Interview mit dem ehemaligen amerikanischen Kulturattaché Gregory Henderson].

Kim, Jin-Heon, Kiupineui Sahoejeok Chaekim Nopyeoya (Die Unternehmen sollten ein größeres gesellschaftliches Verantwortungsbewußtsein entwikkeln), in: Sintonga, Heft März (1987), S. 314-337 [Interview mit Cha-Keong $\mathrm{Ku}$, dem ältesten Sohn von In-Hoe Ku, aus Anlaß von von dessen Wahl zum Präsidenten des koreanischen Unternehmerverbandes].

Lee, Byong-Chul, Hoam Chacheon (Hoams Autobiographie), Seoul 1985 [Autobiographie].

Lee, Maeng-Hee, Mudedun Yiyagi (Die unbekannte Geschichte), Seoul 1993 [Autobiographie].

Lucky-Goldstar (Hrsg.), Hanbeon Midemyeon Modu Matkeora (Wenn du anfängst, jemandem einmal zu glauben, dann sollst du bereit sein, inm alles anvertrauen zu können), Seoul 1979/1993 [Biographie des Gründervaters von Lucky-Goldstar, In-Hoe Ku].

Oh, Hyo-Jin, Samsung New Leader Lee Kun-Hee Hoejang (Der neue Unternehmensleiter von Samsung, Kun-Hee Lee), in: Wolgan-Chosun, Heft 12 (1989), S. 334-359 [ein auf einem Interview beruhender Artikel über das Leben von Kun-Hee Lee]. 
Oh, Won-Chul, Hangukheong Keongje Keonsul (Das koreanische Entwicklungsmodell), Bd. 1-4, Seoul 1995 [Autobiographie eines ehemaligen Mitarbeiters des Handels- und Industrieministeriums].

Park, Cheong-Hee, Ein Weg für unser Volk, Seoul 1964 [eine auf Deutsch in Korea erschienene Propagandaschrift des koreanischen Präsidenten Park (1964-1979), der diese Schrift in mehrere Sprachen übersetzen und ins Ausland verschicken ließ]

Samsung Keongje Yeonguso (Verfassergruppe), Hoameui Keongyeong Chulhak (Hoams Managementphilosophie), Seoul 1988 [eine von Mitarbeitern der Firma Samsung verfaßte Darstellung der Managementphilosophie von Byong-Chul Lee, illustriert durch Anekdoten aus dessen unternehmerischem Leben].

Sintonga, Redaktion (Interview mit den Managern des koreanischen Unternehmens), Urinun Irun Sawon eul Posubmida (Wie wählt man neue Mitarbeiter aus?), in Sintonga, Heft Dezember (1966), S. 318-329 [das sind Interviews mit Managern verschiedener Unternehmen (einer Bank, eines staatlichen Düngemittelunternehmen, einer Zeitungsfirma und einer Pharmafir$\mathrm{ma})]$.

Sintonga, Redaktion, Park Hung-Sik ssi Bangmunki (Ein Besuch bei HungSik Park), in: Sintonga, Heft Januar (1935), S. 193-196 [das ist ein Interview mit dem Kaufhausbesitzer Hung-Sik Park].

\section{Literarische Texte (koreanischsprachig)}

Chae, Man-Sik, Chogmanhan Kiupga (Der kleine Unternehmer), in: Sintonga, Heft Dezember (1931), S. 106-108.

Lee, Kwang-Soo, Heulg (Erde), Seoul 1933.

Park, Chi-Won, Yangbancheon (Biographie eines Yangban), o. O., o. J. (der Verfasser lebte von 1738 bis 1805) 


\section{Koreanischsprachige Literatur (in Klammern die Übersetzung des Titels ins Deutsche)}

Ahn, Byong-Jik, Ilche eui Chosun Chibae wa Sutalkujo (Die koloniale Ausbeutung Koreas durch Japan), in: Kim, Yun-Hwan u. a., Hanguk Keongje eui Cheongae Kujo (Der Entwicklungsprozeß der koreanischen Ökonomie), Seoul 1981, S. 17-34.

Bae, Mu-Ki, 6. 29 Seonun Yihu eui Nodong Undong 3 Yeon (Drei Jahre nach der Ankündigung politischer Reformen vom 29. Juni 1987), in: Kaegan Sasang, Heft Herbst (1990), S. 337-375.

Byon, Heung-Yun, Hanguk Keongje Kaebal Gaeheok eui Banghyang (Die ökonomische Entwicklung in Korea), in: Shin, Il-Chul (Hrsg.), Hangukineui Sasang (Das Denken in Korea), Seoul 1984, S. 179-193.

Cha, Ki-Beok, Hanguk eui Cheongchi Balcheon kwa Cheontong (Die Entwicklung von Politik und Tradition in Korea), in: II-Chul Shin (Hrsg.), Hangukineui Sasang (Das Denken in Korea), Seoul 1984, S. 135-166.

Chang, Duk-Jin, Busil Kiup Cheongri eui Silmal (Die Säuberung von unrentablen Unternehmens), in: Sintanga, Heft Oktober (1969), S. 99-108.

Cheong, Chang-Soo, Hanguk Sahoeron (Studie über die koreanische Gesellschaft), Seoul 1995.

Cheong, Yun-Heong, Keongje Seongjang kwa Dokcheom Chabon (Das ökonomische Wachstum und das Monopol-Kapital), in: Kim, Yun-Hwan u. a., Hanguk Keongje eui Cheongae Kujo (Die Entwicklung der koreanischen Ökonomie), Seoul 1981, S. 131-164.

Cho, Dong-Sung, Hanguk Chaebol (Die Organisation der Chaebol), Seoul 1991 (zweite veränderte Auflage 1997).

Cho, Ki-Jun, Hanguk Chabonjueui Balcheonsa (Die Geschichte des koreanischen Kapitalismus), Seoul 1991.

Ders., Hanguk Chabonjueui Seonripsaron (Die koreanische Entwicklung des Kapitalismus), Seoul 1973.

Cho, Ki-Jun, Hanguk Minjok Kiup Keonsol eui Sasngjeok Baegyong (Der intellektuelle Hintergrund des nationalen Unternehmens in Korea), in: Oki Kwon (Hrsg.), Inchon Kim Sung-Su eui Aejok Sasang kwa ku Silcheon (Der Patriotismus von Sung-Su Kim in Denken und Praxis), Seoul 1982, S. 85155.

Cho, Yong-Chung, Kukga Chaegon Choigo Hoeeui (Das Komitee für den Wiederaufbau des Staates), in: Sintonga, Heft Mai (1983), S. 115-179.

Choi, Jeong-Pyo, Sunjinhwa rul wihan Chaebol eui Seontak (Die Modernisierungsstrategie der koreanischen Chaebol), Seoul 1996. 
Chosun-llbo (Tageszeitung von Chosun), Redaktion, Jikjang Anin Jikupeul Korza (Wichtig ist nicht, daß man in einem Großunternehmen arbeitet, sondern, daß man Wert auf seine berufliche Tätigkeit legt.), 31.10.1996.

Dies., Hyundi seo Hanra Insu Pogi (Hyundai will Hanra nicht übernehmen), 19.1.1998.

Dies., Cheongri Haegoche Doipdoemeon... (Wenn die neuen Entlassungsgesetze eingeführt werden,...), 6.2.1998.

Dies., Yu Sung-Su Keomsawa eui Daedam (Ein Gespräch mit dem Staatanwalt über das Urteil in der Spendenangelegenheit), 30.7.1999.

Chun Tae-II Kineom Kwan Saup Chujin Wiwonhoi (Das Komittee für Chun Tae-II), Eonu Cheongeneon Nodoncha eui Samkwa Chugeum (Das Leben und der Tod eines jungen Arbeiters), Seoul 1983.

Han U-Kun, Hanguk Kaehangki eui Sangup Yeongu (Studie über den Handel während der Öffnungszeit in Korea), Seoul 1970.

Han, Ki-Chun, Hanguk Keongje eui Onul eul Chindan (Diagnose der gegenwärtigen koreanischen Ökonomie), in: Sintonga, Heft Juli (1970), S. 114125.

Han, Ki-Un, Sahak eui Balcheon kwa 3.1. Undong (Die Entwicklung privater Schulen und die Bewegung des 1. März), in: The Journal of Asiatic Studies, Vol XII (1969), S. 89-116.

Hanguk Chongsin Munhwa Yonguwon, Hanguk Minjok Munhwa Taepaekwa Sajon (Enzyklopädie der koreanischen Kultur), 27 Bde, Seoul 1991.

Hanguk Sahoesa Yeonguhoe (Arbeitskreis für koreanische Sozialgeschichte, Hrsg.), Hanguk Chabonjueui wa Chaebol (Der koreanische Kapitalismus und die Chaebol), Seoul 1992.

Hanguk Sanup Chojik Hakhoe (Arbeitskreis für koreanische industrielle $O$ ganisation, Hrsg.), Hanguk Keongjeeui Jinrowa Daekop-Gibdan (Die Zukunft der koreanischen Ökonomie und die Gruppe der Großunternehmen), Seoul 1996.

Heon, Sang-Yun, Chosun Yuhaksa (Die Geschichte des koreanischen Konfuzianismus), Seoul 1949.

Hong, Duk-Yul, Hanguk eui Dae Chabonga Chojik Yeongu (Studie über den Verband der koreanischen Großunternehmer), in: Hanguk Sahoesa Yeonguhoe, Hanguk Chabonjueui wa Chaebol (Der koreanische Kapitalismus und die Chaebol), Seoul 1992, S.56-98.

Ders., Hanguk Daechabonga eui Chojikhwa wa Kaegup Silcheone daehan Yeongu (Eine Abhandlung über die Organisation der koreanischen Großkapitalisten und ihr Klassenverhalten), Seoul 1993. 
Ders., Hanguk Chabonjueui wa Chaebol (Der koreanische Kapitalismus und die Chaebol), in: Reoksa wa Bipeong, (Sommer 1998), S. 91-108.

Hong, Kwon-Hee, Chaemubu wa Haneun: 30nyon Dang Batki Ssaum (Finanzministerium und Zentralbank: Dreißig Jahre Kampf ums Territorium), in: Sintonga, Heft April (1991), S. 438-448.

Kang, In-Seop, Yuksa 8ki-Saeng (Der achte Jahrgang der Militärakademie), in: Sitonga, Heft Oktober (1964), S.170-198.

Kang, Man-Kil, Chosun Hugi Sangup Chabonjueui Baldal (Entwicklung des Handelskapitalismus in der späteren Yi-Dynastie), Seoul 1974.

Ders., Hanguk Sangup eui Yeoksa (Die Geschichte des koreanischen Handels), Seoul 1975.

Kang, Tong-Jin, Ilch Chibaeha eui Nodong Yahak (Die Abendschule für Arbeiter in der japanischen Kolonialzeit), in: Reoksa Hakbo, Vol. 43 (1970), S. 1-39.

Kim, Byong-Tae, Nongchi Kaeheokeui Peongka wa Banseong (Auswertung und Reflexion über die Bodenreform), in: Kim, Yun-Hwan u. a., Hanguk Keongje eui Cheongae Kujo (Die Entwicklung der koreanischen Ökonomie), Seoul 1981, S. 35-65.

Kim, Gyun, Chaebol Kaeheok kwa Hanguk Chabonjueui Hyangbang (Die Reform der koreanischen Chaebol und die Zukunft des koreanischen Kapitalismus), in: Donghyang kwa Cheonmang, Vol. 37 (1998), S. 168-182.

Kim, Jeong-Tae, Hanguk eui Keonjesang (Die Gegenwart der koreanischen Ökonomie), in: Sintonga, Heft März (1966), S. 62-81.

Kim, Jin-Heon, Bucheong Chukchae Cheori Simalseo (Bericht über die Behandlung der illegalen Akkumulatoren), in: Sintonga, Heft November (1964), S. 158-177.

Ders./Chi, Dong-Uk, Hanguk Changi Kaebal Kaehoek eui Naimak (Der Hintergrund des langfristigen Entwicklungsplans in Korea), Sintonga, Heft September (1966), S. 100-120.

Kim, Keong-Dong, Haunguk in eui Gachikwn kwa Sahoe Euisik (Koreanische Wertvorstellungen und Gesellschaftsbewußtsein), Seoul 1993 (erstmals 1967).

Kim, Sang-Cho, IMF Kuje Kumyung kwa Hanguk Keongje (Finanzhilfe vom IWF und die koreanische Ökonomie), in: Keonje wa Sahoe, (Frühling 1998), S. 118-142.

Kim, Sang-Jo, IMF Kuje Kumyung kwa Hanguk Keongje (Die Finanzhilfe des IWF und die koreanische Ökonomie), in: Keongje wa Sahoe, Heft April (1998), S. 118-142. 
Kim, Sun-Dong, Samsung eui Nocho rul Pilyoro Hachi Annun Keong-Young (Samsungs Manangement, das keine Gewerkschaften braucht), Seoul 1995.

Kim, Sung-Du, Gudulyi Hanguk Keongje rul Chajiuju hago issunga (Die Chaebol, die die koreanische Wirtschaft beherrschen), in: Wolgan-Chosun, Heft 9 (1980), S. 224-234.

Kim, Yong-Duk, Ilche uei Keongjecheok Sutal kwa Minu:1910-1918 (Die ökonomische Ausbeutung durch Japan und das Elend des koreanischen Volkes), in: Reoksa Hakbo, Vol. 41/42 (1969), S. 1-19; S. 78-96.

Kim, Yong-Seop, Hanguk Kunheondae Nongupsa Yeongu (Studie über die neuzeitliche Agrargeschichte in Korea), Seoul 1993.

Kim, Young-Mo, Hanguk Kwonreok Chibaechung eui Sahoejeok Kiwon (Die soziale Herkunft der koreanischen herrschenden Schicht), in: Shin, II-Chul (Hrsg.), Hangukineui Sasang (Das Denken in Korea), Seoul 1984, S. 297315.

Kim, Yun-Hwan u. a., Hanguk Keongje eui Cheongae Kujo (Der Entwicklungsprozeß der koreanischen Ökonomie), Seoul 1981.

Ders., Hanguk Nodong Undong eui Reoksajeik Kwaje wa Banghyang (Die historische Aufgabe der koreanischen Arbeiterbewegung und die Zukunft), in: Kim, Byong-Tae u. a., Hanguk Keongje eui Cheongaekwajeong (Der Entwicklungsprozeß der koreanischen Ökonomie), Seoul 1981.

Ders., Hanguk Nodong Undong eui Sengkek (Der Charakter der koreanischen Arbeiterbewegung), in: Shin, II-Chul (Hrsg.), Hangukineui Sasang (Das Denken in Korea), Seoul 1984, S. 241-257.

Ders., Sanuphwa Dangae eui Nodong Munje wa Nodong Undong (Probleme der koreanischen Arbeiterbewegung), in: Cho, Hee-Yeon (Hrsg.), Hanguk Sahoe eui Chae Insik (Neue Erkenntnisse über die koreanische Gesellschaft), Seoul 1985, S. 355-388.

Ko, Young-Bok, Hanguk Sahoe Kujo eui Bunsek (Analyse der koreanischen Gesellschaftsstruktur), in: Sintonga, Heft Februar (1965), S. 58-89.

Kong, Je-Uk, 1950neondae Gukka eui Chaejeong-Kumyung Cheongchaek kwa Daekiup eui Seongjang (Die staatliche Finanz- und Bankenpolitik in den 50er Jahren und die Entwicklung des Großunternehmens), in: Hanguk Sahoesa Yeonguhoe (Arbeitskreis für koreanische Sozialgeschichte) (Hrsg.), Hanguk Chabonjueuiwa Chaebol (Der koreanische Kapitalismus und die Chaebol), Seoul 1992, S. 11-55.

Ders., Haguk Chabonga Kaegup eui Seongjang kwa Gukga (Die Herausbildung der koreanischen Kapitalistenklasse und der Staat), Seoul 1994.

Ders., IMF ha Hanguk Chabonjueui eui Chaebol Kujo Kaepeon (Der koreanische Kapitalismus unter der Führung des IWF und die Restrukturierung 
der Chaebol), Vortragsmanuskript für den koreanischen Soziologentag im Frühling 1998.

$\mathrm{Ku}$, Cha-Keong, O jik Yi Kil Bake Eopda (Es gibt keinen anderen Weg), Seoul 1992.

Kwon, Byong-Mu, Hyundai wa Samsung Group Keongyeong Cheonrak Bigyo (Ein Vergleich der Managementstrategie von Samsung und Hyundai), in: Wolgan-Chosun, Heft 9 (1980), S. 298-307.

Kwon, Sun-Taek, Yeodaesaeng Konghwal kwa Nodongundong (Die Fabrikarbeit der Studentinnen und ihre Wirkung auf die Arbeiterbewegung), in: Sintonga, Heft September (1986), S. 399-409.

Lee, Chae-Joo, Busil Kiup Cheongri rul Bipanhanda (Kritik an der Säuberung von unrentablen Unternehmen), in: Sintonga, Heft Oktober (1969), S. 109-121.

Lee, Chang-Won, Hanguk eui Kiup Elite (Die Elite der koreanischen Unternehmen), Seoul 1995.

Lee, Cheong-Jae, Chaebol Yireokseo (Die Entwicklungsgeschichte der Chaebol), Seoul 1993.

Lee, Dae-Kun/Cheong, Un-Young (Hersg.), Hanguk Chabonjueuiron (Studie über den koreanischen Kapitalismus), Seoul 1987.

Lee, Dong-In, Yugyo wa Kundaehwa (Konfuzianismus und Modernisierung), in: Hanguk Sahoehak Yeongu, Vol. 8 (1985), S. 8-28.

Lee, Gab-Seop, Hwansang euro guchil Sobi-Heokmeong (Massenkonsum als Illusion), in: Sintonga, Heft 1 (1967), S. 104-113.

Lee, Keong-Nam, Kumsung dae Samsung (Kumsumg [= Lucky-Goldstar] vs. Samsung), in: Sintonga, Heft Oktober (1969), S. 244-255.

Lee, Ki-Baik, Hanguksa Sinron (Die neuere koreanische Geschichte), Seoul 1976.

Lee, Kwang-Rin, Hanguk Kaehwasa Youngu (Studie über die koreanische Kaehwa-Geschichte), Seoul 1981.

Ders., Kaehwadang Yeongu (Studie über Kaehwadang), Seoul 1981.

Lee, Man-Gyu, Saeyangban Yirago Bulechuka? (Sollten sie neue Yangban genannt werden?), in: Sintonga, Heft Oktober (1935), S. 120.

Lee, Sang-Eun, Hanguke isseosseui Yukyoeui Kongbiron (Vorteile und Nachteile des Konfuzianismus in Korea), in: Shin, Il-Chul (Hrsg.), Hangukineui Sasang (Das Denken in Korea), Seoul 1984, S. 319-348. 
Lee, Suk-Ryun, Urinara Hwape Kumyungsa (Die Geschichte der koreanischen Währung und Banken), Seoul 1994.

Lee, Taek-Hwi, Chosuncho Cheongchi Jedo wa Cheongchi Heongtae (Politische Institution und Handeln in der Chosun-Epoche), in: Cheong, ChangSoo, Hanguk Sahoeron (Studie über die koreanische Gesellschaft), Seoul 1995, S. 35-86.

Lim, Chong-Chul, Chakwan Uddeke Ssyeochigo Issnunga? (Wie werden ausländische Kredite verwendet?), in: Sintonga, Heft Mai (1967), S. 78-91.

Ders., Konguphwa wa Bulpeondung Simhwa (Industrialisierung und Verschärfung der ökonomischen Ungleichheit), in: Sintonga, Heft Juli (1970), S. 126-145.

Lim, Myo-Min, 5.16 ihu eui Chaegae Kapeon (Die unternehmerische Entwicklung nach dem 16. Mai), in: Sintonga, Heft Mai (1968), S. 216-235.

Mun, Heong-Sun, Hanbi Heonaphu uei Samsung-Chaebol (Das SamsungChaebol nach der Übergabe des Düngemittelunternehmens), in: Sintonga, Heft Dezember (1967), S. 91-99.

Mun, II-Peong u. a., Chosunin eui Chibangyeol Keomto (Überlegungen über den koreanischen Regionalismuswahn), in: Sintonga, Heft Januar (1934), S. 71-75.

Paik, Sun-Jae, Ilche Sidae eui Gundaehwa Undong (Die Modernisierungsbewegung in der japanischen Kolonialzeit), in: Sintonga, Heft Februar (1966), S. 331-343.

Park, Byong-Yun, Tansaeng kwa Molrak eui Naimak (Die Entstehungsgeschichte der koreanischen Chaebol), in: Wolgan-Chosun, Heft 9 (1980), S. 258-269.

Park, Chang-Rae, Ulsan Kongup Center (Ulsan Industrie Center), in: Sintonga, November (1967), S. 170-197.

Park, Chan-II, Migukeui Keongje Weonjo eur Seonggeok kwa Gu Keongjejeok Guikeol (Der Charakter der amerikanischen Wirtschaftshilfe und deren ökonomischen Folgen), in: Kim, Yun-Hwan u. a., Hanguk Keongje eui Cheongae Kujo (Die Entwicklung der koreanischen Ökonomie), Seoul 1981, S. 67-95.

Park, Heon-Chae, Hanguk Keongje Kuchoron (Lehre von der koreanischen ökonomischen Struktur), Seoul 1986.

Park, Yong-Cheong, Yise wa Inmak dul (Zweite Generation und personelle Verflechtung der koreanischen Chaebol), in: Wolgan-Chosun, Heft 9 (1980), S. 270-286.

Ryu, Young-lk, Hanguk Kunheondaron, (Die Geschichte der koreanischen Neuzeit), Seoul 1992. 
Sakong, II, Keongje Seongjang kwa Chaebol (Ökonomisches Wachstum und die Chaebol), in: Wolgan-Chosun, Heft 9 (1980), S. 245-257.

Seong, Dae-Keong, 3.1 Undong Siki eui Hanguk Nodongja eui Hwaldonge Kwanhayeo (Über die Aktivitäten der koreanischen Arbeiter während der Zeit der Bewegung vom 1. März), in: Reoksa Hakbo, Vol 41 (1969), S. 5283.

Seoul Keongje Sinmun Sanupbu (Verfassergruppe), Chaebol, Seoul 1995.

Shin, Yong-Ha, Dure Kondongche wa Nongak eui Sahoesa (Dure-Gemeinschaft und die Sozialgeschichte der koreanischen ländlichen Arbeitsmusik), in: Hanguk Sahoe Yeongu, Vol 2 (1984), S. 11-53.

Ders., Hanguk Kundae Sahoesa Yeongu (Die Sozialgeschichte der Neuzeit in Korea), Seoul 1987.

Ders., Hanguk Kundae Sahoe Sasangsa Yeongu (Die Ideengeschichte der Neuzeit in Korea), Seoul 1987.

Shin, Yu-Kun, Hanguk eui Keong-Yeong (Das Management in Korea), Seoul 1993.

Sintonga, Redaktion, Keolye Korona Kamssanun Upsa wa Gyotongbu (Der Unternehmer und das Verkehrsministerium, die das Fehlprodukt Korona [= ein japanisches Automodell] protegieren), in: Sintonga, Heft August (1969), S. $70 \mathrm{ff}$.

Suh, Jae-Jin, Hanguk Chabonga Kaegup (Die koreanische Kapitalistenklasse), Seoul 1991.

Yu, In-Hak, Hanguk Chaebol eui Haebu (Analyse der koreanischen Chaebol), Seoul 1991. 


\section{Deutsprachige und englischsprachige Literatur}

Abegglen, James C., The Japanese Factory, Gle ncoe/lllinoi 1958.

Amsden, Alice, Asia's Next Giant: South Korea and Late Industrialization, New York/Oxford 1989 (Koreanische Übersetzung: Seoul 1989).

Aoki, Masahiko, Information, Incentives, and Bargaining in the Japanese Economy, New York u. a. 1988.

Bahrdt, Hans Paul, Schlüsselbegriffe der Soziologie: eine Einführung mit Lehrbeispielen, München 1997.

Bellah, Robert N., Analogien zur protestantische Ethik in Asien? in: Seyfarth, Constans/Sprondel, Walter M. (Hrsg.), Seminar: Religion und gesellschaftliche Entwicklung, Frankfurt am Main 1973, S. 179-189.

Berger, Johannes, Warum arbeiten die Arbeiter? Neomarxistische und neodurkheimsche Erklärungen, in: Zeitschrift für Soziologie, Jg. 4. Heft 6 (1995), S. 407-421.

Burke, Peter, Soziologie und Geschichte, Hamburg 1989.

Chandler, Alfred D., The Visible Hand: The Managerial Revolution in American Business, Cambridge 1977.

Choe, Sang-Hun, Der Stellenwert der Mischkonzerne (Chaebol) im koreanischen Industrialisierungsprozeß: Dargestellt am Beispiel des Werdegangs und der Strukturmerkmale Samsungs, Hamburg 1994.

Coase, R. H., The Nature of the Firm, in: Economica, Vol. IV, No. 16 (1937), S. 386-405.

D'Iribarne, Phillipe, Nationale Formen gesellschaftlicher Bindung und unternehmerische Funktionsprinzipien, in: Heidenreich, Martin/Schmidt Gert (Hrsg.), International vergleichende Organisationsforschung, Opladen 1991, S. 106-116.

Deuchler, Martina, The Confucian Transforamation of Korea: A Study of Society and Ideology, Cambridge u. a. 1992.

Deutschmann, Christoph, Der Betriebsclan: Der japanische Organisationstyp als Herausforderung an die soziologische Modernisierungstheorie, in: Soziale Welt, Heft 2 (1987), S. 133-147.

Eckert, Carter J. u. a., Korea Old and New - A History, Cambridge u. a. 1990.

Ders., Offspring of Empire: The Kochang Kims and the Colonial Origins of Korean Capitalism 1876-1945, Seattle/London 1991. 
Friedrich Fürstenberg, Managementkultur, in: Hans-Dieter Ganter/ Gerd Schienstock (Hrsg.), Management aus soziologischer Sicht, Wiesbaden 1993, S. 133-145.

Ganter, Hans-Dieter/Schienstock, Gerd (Hrsg.), Management aus soziologischer Sicht, Wiesbaden 1993.

Giddens, Anthony, Central Problems in Social Theory: Action, Structure and Contradiction in Social Analysis, London u. a. 1979.

Granovetter, Mark, Economic Action and Social Structure - The Problem of Embeddedness, in: American Journal of Sociology, Nr. 2 (1985), S. 481510.

Ders., Entrepreneurship, Development and the Emergence of Firms. Discussion Paper FS I 90-2, Wissenschaftszentrum Berlin für Sozialforschung 1990.

Gransow, Bettina, Chinesische Modernisierung und kultureller Eigensinn, in: Zeitschrift für Soziologie, Heft 3 (1995), S. 183-195.

Guttandin, Friedhelm, Einführung in die "Protestantische Ethik" Max Webers, Opladen u. a. 1998.

Hamilton, Gary G. (Ed.), Asian Business Networks, Berlin/New York 1993.

Ders./Biggart, Nicole Woolsey, Market, Culture and Authoriy: A Comparative Analysis of Management and Organisation in the Far East, in: American Journal of Sociology, Vol. 94 (Supplement 1988), S. 52-94.

Hirschmeier, Johanne, The Origins of Entrepreneurship in Meiji Japan, Cambridge u. a. 1964.

Hofstede, Geert, Culture's Consequences: International Differences in Work-Related Values, Beverly Hills/London 1980.

Hong, Soon-Ho, Social Groups and Their Dynamics, in: Park, Sung-Jo u. a. Economic Development and Social Change in Korea, Frankfurt 1980, S. 337-352.

Jones, Leroy P./Sakong, II, Government, Business, and Entrepreneurship in Economic Development: The Korean Case, Cambridge u. a. 1980.

Kern, Horst, Empirische Sozialforschung: Ursprünge, Ansätze, Entwicklungslinien, München 1982.

Ders., Über die Gefahr, das Allgemeine im Besonderen zu sehr zu verallgemeinern, in: Soziale Welt, Heft 1/2 (1989) S. 259-268.

Kieser, Alfred (Hrsg.), Organissationstheorien, Stuttgart/Berlin 1993. 
Kim, Eun-Mee, The Industrial Organisation and Growth of the Korean Chaebol. Integrating Development and Organizational Theories, in: Gary G. Hamiliton (Ed.), Asian Business Networks, Berlin/New York 1996, S. 231-251.

Kocka, Jürgen, Unternehmer in der deutschen Industrialisierung, Göttingen 1975.

Koh, Sung-Jae, Charakteristics of the Industrial Entrepreneurship, in: Park, Sung-Jo u. a. Economic Development and Social Change in Korea, Frankfurt 1980, S. 370-379.

Korean Overseas Information Service (Hrsg.), New Year Press Conference by President Park Chung-Hee: January 15. 1976, Seoul 1976.

Lamnek, Siegfried, Qualitative Sozialforschung, Bd. 2: Methoden und Techniken, München 1989.

Lee, Hae-Young, Traditional Family and its Transformation, in: Park, SungJo u. a., Economic Development and Social Change in Korea, Frankfurt 1980, S. 301-309.

Lee, Jae-Yeul, Entwicklung und Führung südkoreanischer Unternehmen: Insbesondere die Struktur, Organisation und Strategie südkoreanischer Uhternehmensgruppen Chaebol, Dissertation Göttingen 1993.

Lee, Man-Gap, Social Aspects of Economic Development, in: Park, Sung-Jo u. a., Economic Development and Social Change in Korea, Frankfurt 1980, S. 273-287.

Machetzki, Rüdiger/Pohl, Manfred (Hrsg.), Korea, Stuttgart/Wien 1988.

Pohl, Manfred, Die Entstehung zweier Staaten, in: Machetzki, Rüdiger/Ders. (Hrsg.), Korea, Stuttgart-Wien 1988, S. 76-79

Mason, Edward S. u. a., The Economic and Social Modernization of the Republic of Korea: Studies in the Modernization of the Republic of Korea: 1945-1975, Cambridge u. a. 1980.

Matthes, Joachim, Zwischen den Kulturen?: Die Sozialwissenschaften vor dem Problem des Kulturvergleichs, Sonderband 8 (Soziale Welt), Göttingen 1992.

McGinn, Noel F. u. a., Education and Development in Korea: Studies in the Modernization of the Republic of Korea: 1945-1975, Cambridge u. a. 1980.

McNamara, Dennis L., The Colonial Origins of Korean Enterprise 19101945, New York 1990.

Myers, Ramon H./Peattie, Mark R .(Ed.), Colonialism and Development: Korea, Taiwan, and Kwangtung, Pinceton/New York 1984. 
Odrich, Barbara, Familienbande in Asien, in: Frankfurter Allgemeine Zeitung 13.8.1999, Nr. 186, S. 13.

Park, Sung-Jo u. a., Economic Development and Social Change in Korea, Frankfurt 1980.

Piore, Michael/Sabel, Charles F., Das Ende der Massenproduktion: Studie über die Requalifizierung der Arbeit und die Rückkehr der Ökonomie in die Gesellschaft, Berlin 1985.

Reinhard, Wolfgang, Oligarchische Verflechtung und Konfession in oberdeutschen Städten, in: Maczak, Antoni (Hrsg.), Klientelsysteme im Europa der Frühen Neuzeit, Oldenburg 1988, S. 47-62.

Schienstock, Gerd, Management als sozialer Prozes. Theoretische Ansätze zur Instiutionalisierung, in: Ganter, Hans-Dieter/Schienstock, Gerd (Hrsg.), Management aus soziologischer Sicht, Wiesbaden 199Nakane, Chie, Die Struktur der japanischen Gesellschaft, Frankfurt am Main 1985.

Schoenfeldt, Eberhard, Der Edle ist kein Instrument: Bildung und Ausbildung in Korea (Republik), Kassel 1996.

Schumpeter Joseph, Theorie der wirtschaftlichen Entwicklung, München/ Leipzig 1926 (2. Auflage).

Senghass, Dieter, Von Europa lernen: Entwicklungsgeschichtliche Betrachtungen, Frankfurt am Main 1982.

Senghass, Dieter, Zivilisierung wider Willen, Frankfurt am Main 1998.

Seyfarth, Constans/Sprondel, Walter M., Seminar: Religion und gesellschaftliche Entwicklung, Frankfurt am Main 1973.

Smelser, Neil J./Swedberg, R. (Ed.), The Handbook of Economic Sociology, Princeton/New York 1994.

Ders., The Sociological Perspective on the Economy, in: Dies. (Ed.), The Handbook of Economic Sociology, Princeton/New York 1994, S. 3-26

Spickard, James V., Ethnocentrism, Social Theory and Non-Western Sociologies of Religion: Toward a Confucian Alternative, in: International Sociology, Vol. 13 (1998), S. 173-194.

Steers, Richard M./Shin, Yoo-Keun/Ungson, Gerardo R., The Chaebol: Korea's New Industrial Might, New York 1989 (koreanische Übersetzung: Seoul 1990).

Suh, Sang-Chul, Growth and Structrual Changes in the Korean Economy 1910-1940, Cambridge u. a. 1978.

Swedberg, Richard, Schumpeter: A Biography, Princeton/New York 1991. 
Tönnies, Ferdinand, Gemeinschaft und Gesellschaft, Leipzig 1935.

Trauzettel, Rolf (Hrsg.), Konfuzianismus und die Modernisierung Chinas, Mainz 1990.

Tsurumi, E. Patricia, Colonial Education in Korea and Taiwan, in: Myers, Ramon H./Peattie, Mark R. (Ed.), Colonialism and Development: Korea, Taiwan, and Kwangtung, Princeton/New York 1984, S. 275-311.

Tu, Wei-Ming (Ed.), Confucian Traditions in East Asian Modernity: Moral Education and Economic Culture in Japan und the Four Mini-Dragons, Cambridge u. a. 1996.

Wade, Robert, Governing the Market: Economic Theory and The Role of Government in East Asian Industrialization, Princeton/New Jersey 1990.

Weber, Max, Die protestantische Ethik und der "Geist" des Kapitalismus, in: Archiv für Sozialwissenschaft und Sozialpolitik, Bd. 20, Tübingen 1905.

Weber, Max, Gesammelte Aufsätze zur Religionssoziologie, 3 Bde, Tübingen 1920/21.

Westney, D. Eleanor, Imitation and Innovation: The Transfer of Western Organzational Pattern to Meiji Japan, Cambridge u. a. 1987.

Williamson, Oliver E., The Modern Corporation: Origins, Evolution, Attributes, in: Journal of Economic Literature, Vol. XIX (December 1981). S. 15371568.

Ders., Transaction Cost Economic and Organization Theory, in: Smelser, Neil J./Swedeberg, R. (Ed.), The Handbook of Economic Sociology, Princeton/New York 1994, S. 77-107.

\section{Zur Zitierweise:}

Um dem nicht-koreanischen Leser die Orientierung zu erleichtern, wurde die Literatur in den Fußnoten nicht in Kurzform, sondern immer mit dem vollständigen Titel (einschließlich der deutschen Übersetzung) zitiert. Aus systematischen Gründen wurde diese ausführliche Zitierweise auch für die deutsche und englische Literatur übernommen. 